Keywords: High level waste glass, structure, durability

Retention: Permanent

\title{
Summary of 2010 DOE EM International Program Studies of Waste Glass Structure and Properties
}

K. M. Fox

A. S. Choi

J. C. Marra

A. L. Billings

S. V. Stefanovsky

December 2010

Savannah River National Laboratory Savannah River Nuclear Solutions, LLC Aiken, SC 29808

Prepared for the U.S. Department of Energy under contract number DE-AC09-08SR22470.

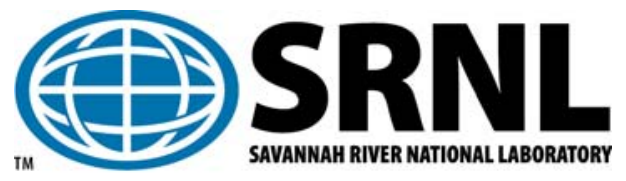


SRNL-STI-2010-00805

Revision 0

\section{DISCLAIMER}

This work was prepared under an agreement with and funded by the U.S. Government. Neither the U.S. Government or its employees, nor any of its contractors, subcontractors or their employees, makes any express or implied:

1. warranty or assumes any legal liability for the accuracy, completeness, or for the use or results of such use of any information, product, or process disclosed; or

2. representation that such use or results of such use would not infringe privately owned rights; or

3. endorsement or recommendation of any specifically identified commercial product, process, or service.

Any views and opinions of authors expressed in this work do not necessarily state or reflect those of the United States Government, or its contractors, or subcontractors.

\section{Printed in the United States of America \\ Prepared for \\ U.S. Department of Energy}




\section{REVIEWS AND APPROVALS}

AUTHORS:

K. M. Fox, Process Technology Programs Date

A. S. Choi, Engineering Process Development

Date

J. C. Marra, DOE-EM Office of Technology Innovation and Development

Date

A. L. Billings, Process Technology Programs

Date

TECHNICAL REVIEW:

D. K. Peeler, Process Technology Programs

Date

APPROVAL:

C. C. Herman, Manager

Date

Process Technology Programs

A. B. Barnes, Manager

Date

Engineering Process Development

S. L. Marra, Manager

Date

Environmental \& Chemical Process Technology Research Programs 


\section{ACKNOWLEDGEMENTS}

The authors would like to thank Dr. Fabienne Johnson for assistance with glass composition selection and data interpretation, Irene Reamer, Phyllis Workman, David Best, Patricia Simmons, Whitney Riley, and David Missimer for assistance with fabricating and characterizing the study glasses, and Dr. Tanya Albert for skilled translations. The twelve glass samples used for Task 3 were prepared by Don Miller, and his efforts are greatly appreciated. The authors also acknowledge the International Program and the EM-31 Technology Development \& Deployment (TDD) Program at the U.S. Department of Energy Office of Environmental Management for financial support of this work. 


\section{EXECUTIVE SUMMARY}

Collaborative work between the Savannah River National Laboratory (SRNL) and SIA Radon in Russia was divided among three tasks for calendar year 2010. The first task focused on the study of simplified high level waste glass compositions with the objective of identifying the compositional drivers that lead to crystallization and poor chemical durability. The second task focused on detailed characterization of more complex waste glass compositions with unexpectedly poor chemical durabilities. The third task focused on determining the structure of select high level waste glasses made with varying frit compositions in order to improve models under development for predicting the melt rate of the Defense Waste Processing Facility (DWPF) glasses.

The majority of these tasks were carried out at SIA Radon. Selection and fabrication of the glass compositions, along with chemical composition measurements and evaluations of durability were carried out at SRNL and are described in this report. SIA Radon provided three summary reports based on the outcome of the three tasks. These reports are included as appendices to this document.

Briefly, the result of characterization of the Task 1 glasses may indicate that glass compositions where iron is predominantly tetrahedrally coordinated have more of a tendency to crystallize nepheline or nepheline-like phases. For the Task 2 glasses, the results suggested that the relatively low fraction of tetrahedrally coordinated boron and the relatively low concentrations of $\mathrm{Al}_{2} \mathrm{O}_{3}$ available to form $\left[\mathrm{BO}_{4 / 2}\right]^{-} \mathrm{Me}^{+}$and $\left[\mathrm{AlO}_{4 / 2}\right]^{-} \mathrm{Me}^{+}$tetrahedral units are not sufficient to consume all of the alkali ions, and thus these alkali ions are easily leached from the glasses.

All of the twelve Task 3 glass compositions were determined to be mainly amorphous, with some minor spinel phases. Several key structural units such as metasilicate chains and rings were identified, which confirms the current modeling approach for the silicate phase. The coordination of aluminum and iron was found to be mainly tetrahedral, with some octahedral iron ions. In all samples, trigonally-coordinated boron was determined to dominate over tetrahedrally-coordinated boron. The results further suggested that $\mathrm{BO}_{4}$ tetrahedra and $\mathrm{BO}_{3}$ triangles form complex borate units and may be present as separate constituents. However, no quantification of tetrahedral-totrigonal boron ratio was made. 


\section{TABLE OF CONTENTS}

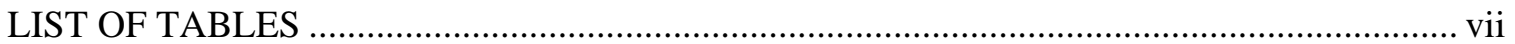

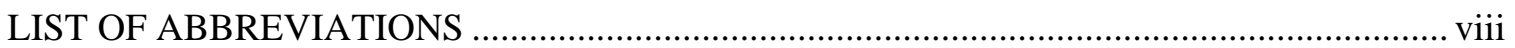

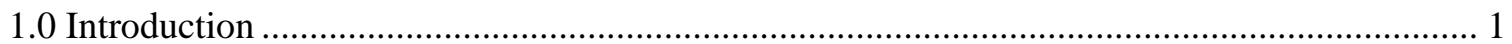

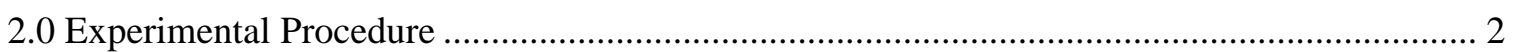

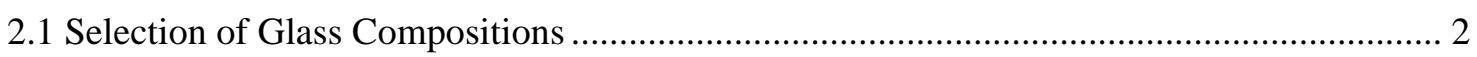

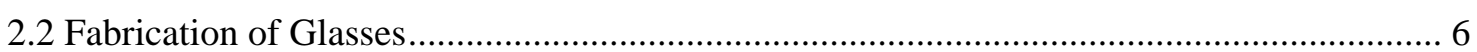

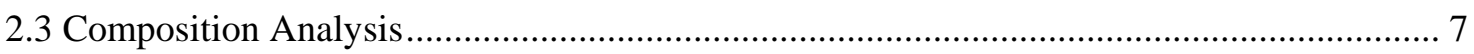

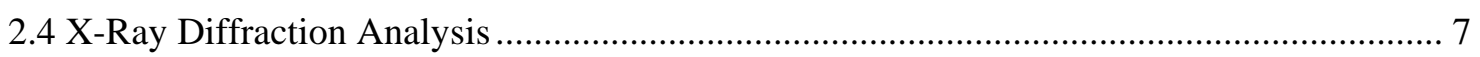

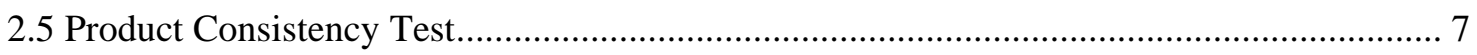

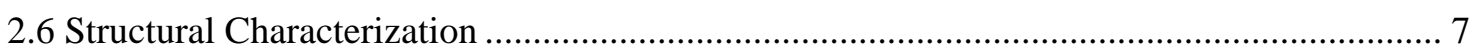

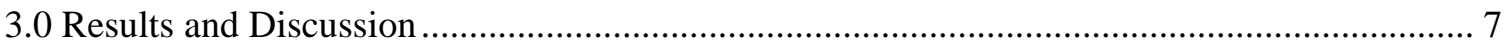

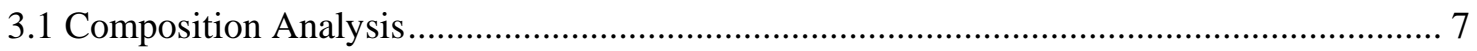

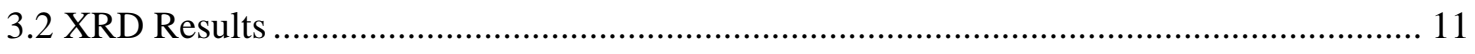

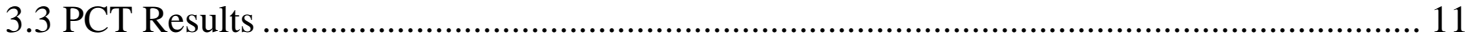

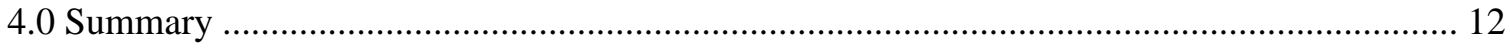

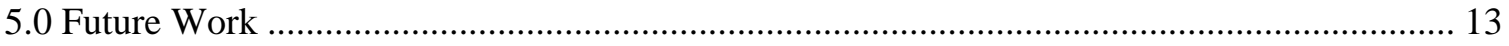

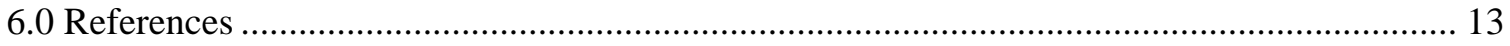




\section{LIST OF TABLES}

Table 2-1. Target Compositions for the Task 1 Glasses................................................................. 3

Table 2-2. Target Compositions for the Task 2 Glasses (wt \%)................................................... 3

Table 2-3. Composition of DWPF SB6 Simulant used in Task 3.............................................. 4

Table 2-4. Composition of Frits Used in Task 3 (wt\%)............................................................. 5

Table 2-5. Melt and Annealing Temperatures for the Task 1 and 2 Glass Compositions.............. 6

Table 3-1. Target and Measured Compositions of the Task 1 Glasses (wt \%).............................. 9

Table 3-2. Target and Measured Compositions of the Task 2 Glasses (wt \%)............................. 10

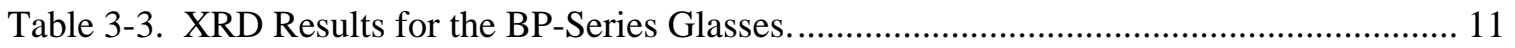

Table 3-4. PCT Results for the Task 1 and Task 2 Glasses....................................................... 12 


\section{LIST OF ABBREVIATIONS}

$\begin{array}{ll}\text { AD } & \text { Analytical Development } \\ \text { ARM } & \text { Approved Reference Material } \\ \text { CCC } & \text { Canister Centerline Cooling } \\ \text { CT } & \text { Computed Tomography } \\ \text { DSC } & \text { Differential Scanning Calorimeter } \\ \text { DWPF } & \text { Defense Waste Processing Facility } \\ \text { EA } & \text { Environmental Assessment } \\ \text { EDS } & \text { Energy Dispersive Spectroscopy } \\ \text { EPR } & \text { Electron Paramagnetic Resonance } \\ \text { EXAFS } & \text { Extended X-ray Absorption Fine Structure } \\ \text { HLW } & \text { High Level Waste } \\ \text { ICP-AES } & \text { Inductively Coupled Plasma - Atomic Emission Spectroscopy } \\ \text { IR } & \text { Infrared } \\ \text { LM } & \text { Lithium Metaborate } \\ \text { NL } & \text { Normalized Leachate } \\ \text { NMR } & \text { Nuclear Magnetic Resonance } \\ \text { PCT } & \text { Product Consistency Test } \\ \text { PF } & \text { Peroxide Fusion } \\ \text { PSAL } & \text { Process Science Analytical Laboratory } \\ \text { SB6 } & \text { Sludge Batch 6 } \\ \text { SEM } & \text { Scanning Electron Microscopy } \\ \text { SRNL } & \text { Savannah River National Laboratory } \\ \text { SRS } & \text { Savannah River Site } \\ \text { XANES } & \text { X-ray Absorption Near Edge Spectroscopy } \\ \text { XPS } & \text { X-ray Photoelectron Spectroscopy } \\ \text { XRD } & \text { X-ray Diffraction } \\ & \end{array}$




\subsection{Introduction}

The Savannah River National Laboratory (SRNL) performs extensive development work on immobilization of high level waste (HLW) in glass. The applied nature of this work dictates that the glass compositions are very complex, and therefore characterization of the glass structure becomes difficult. A study of simplified glass compositions would be useful in providing insight into the performance of the more complex glasses while making characterization data easier to interpret. For example, the formation of nepheline crystals in complex glass compositions, which reduces the chemical durability of the glass waste form, may be easier to understand by characterizing a simplified composition.

The structure of $\mathrm{Al}_{2} \mathrm{O}_{3}-\mathrm{B}_{2} \mathrm{O}_{3}-\mathrm{Na}_{2} \mathrm{O}-\mathrm{SiO}_{2}$ glasses has been reported in the literature using Nuclear Magnetic Resonance (NMR) and optical characterization techniques (see Pierce et al. for a brief review $^{1}$ ). The published work has been successful in identifying compositionally driven coordination changes in aluminum and boron, changes in the fraction of non-bridging oxygens, and the tendency for sodium to preferentially associate with aluminum. However, the addition of iron - a major component of high level waste glass at the Savannah River Site (SRS) - makes NMR studies difficult. Therefore, the first task of this international, collaborative study was developed to characterize the chemistry and structure of $\mathrm{Al}_{2} \mathrm{O}_{3}-\mathrm{B}_{2} \mathrm{O}_{3}-\mathrm{Na}_{2} \mathrm{O}-\mathrm{SiO}_{2}$ glasses with the addition of $\mathrm{Fe}_{2} \mathrm{O}_{3}$ using a unique suite of characterization tools at SIA Radon in Russia. These tools include Scanning Electron Microscopy with Energy Dispersive Spectroscopy (SEM/EDS), Infrared (IR) and Raman Spectroscopy, X-ray Absorption Near Edge Structure (XANES), and Extended X-ray Absorption Fine Structure (EXAFS). As described later in this report, simplified versions of several glass compositions based on SRS HLW glasses are selected and characterized, and the results are used to help identify compositional factors influencing crystallization and chemical durability.

A second task of this collaborative study is to investigate more complex glass compositions that have exhibited unexpected performance. SRNL has identified a small number of simulated, multi-component waste glass compositions that, while amorphous via XRD, have unusually poor chemical durability. The cause of the reduction in durability is not known, but is suspected to be amorphous phase separation. The objective of this task is to recreate three of the previously identified glass compositions and characterize them using SEM in an attempt to screen for amorphous phase separation. If phase separation can be identified using SEM, EDS will be used to approximate the compositions of each phase. IR and Raman Spectroscopy will also be used in order to identify any changes in the chemistry and structure of these anomalous glasses and possibly each phase.

The third task in this collaborative study is to provide glass structural data for full DWPF glass compositions to support the development of predictive models for the melting behavior of glass. SRNL has developed several models of the processes occurring as a glass batch is converted to a melt, ${ }^{2}$ although additional glass structural data are needed to improve these models. This portion of the study will apply the insight gained from the first task in studying the impact of varying levels of boron, alkali, and some additives such as $\mathrm{Ca}$ and $\mathrm{Mn}$ on the coordination chemistry of simulated HLW glass systems using X-ray Photoelectron Spectroscopy (XPS), XANES, EXAFS, Electron Paramagnetic Resonance (EPR), and IR and Raman spectroscopy. The sample glass compositions for this task have been made using simulated Defense Waste Processing Facility (DWPF) Sludge Batch 6 (SB6) simulant (high in both $\mathrm{Al}$ and Fe concentrations) with 12 different frit compositions at a constant waste loading of $36 \mathrm{wt} \%$. The baseline frit composition is Frit 418 and the remaining frit compositions contain 8-16 wt $\% \mathrm{~B}_{2} \mathrm{O}_{3}, 4-8 \mathrm{wt} \% \mathrm{Na}_{2} \mathrm{O}, 0-4$ wt $\% \mathrm{MnO}$ and 
$0-2 \mathrm{wt} \% \mathrm{CaO}$. The rate of melting of these various sludge and frit combinations has been measured at SRNL using visual as well as X-ray imaging and Computed Tomography (CT) techniques. The structural information determined at SIA Radon will be used to link the melt rate performance with the composition and structure of these glasses.

\subsection{Experimental Procedure}

\subsection{Selection of Glass Compositions}

Glasses for Task 1 were selected based on a range of compositions of interest for SRS HLW. SB6 was being prepared for processing at the DWPF when this study was initiated, and therefore was selected as the first composition. SB19, which was projected to be the last sludge batch processed at the DWPF, and which also has a significantly different composition than SB6, was selected as the next composition of interest. Previous work on a glass composition identified as 121506-07 showed that while this composition was predicted to form nepheline crystals with a subsequent reduction in chemical durability, it was in fact free of nepheline with good durability. ${ }^{3}$ This composition is therefore of interest since a better understanding of its structure may aid future efforts in preventing nepheline crystallization. An additional SB19 composition was also selected, and combined with a frit composition where all of the $\mathrm{Na}_{2} \mathrm{O}$ has been removed and replaced with $\mathrm{B}_{2} \mathrm{O}_{3}$. The compositions of each of these four glasses were simplified by eliminating all of the components except for $\mathrm{Al}_{2} \mathrm{O}_{3}, \mathrm{~B}_{2} \mathrm{O}_{3}, \mathrm{Fe}_{2} \mathrm{O}_{3}, \mathrm{Na}_{2} \mathrm{O}$, and $\mathrm{SiO}_{2}$, and then normalizing the concentrations of these remaining components to $100 \mathrm{wt} \%$. A second version of each of these glasses was developed by removing the $\mathrm{Fe}_{2} \mathrm{O}_{3}$ component, and again normalizing the concentrations of the remaining components to $100 \mathrm{wt} \%$. This will provide for the opportunity to specifically study the impact of $\mathrm{Fe}_{2} \mathrm{O}_{3}$. The target compositions for these glasses are given in Table $2-1$.

Glasses for Task 2 were selected from a previous study of glasses for enhanced melter throughput. ${ }^{4}$ These glasses were found to be free of any crystallization detected by X-ray Diffraction (XRD), but had unexpectedly poor durabilities. The target compositions of these glasses are given in Table 2-2.

The glass compositions selected for Task 3 were prepared as part of the EM-31 melt rate program. The composition of the SB6 simulant used is the same as that used for the DWPF melter bubbler demonstration tests (Table 2-3); ${ }^{5}$ it contained neither $\mathrm{Hg}$ nor noble metals. The twelve frit compositions tested in conjunction with the SB6 simulant are given in Table 2-4. The theoretical compositions of the resulting glasses are included in the report from SIA Radon in Appendix C. 
Table 2-1. Target Compositions for the Task 1 Glasses.

\begin{tabular}{|c|c|c|c|c|c|c|}
\hline Glass ID & Composition & $\begin{array}{l}\mathrm{Al}_{2} \mathrm{O}_{3} \\
\text { (wt \%) }\end{array}$ & $\begin{array}{l}\mathrm{B}_{2} \mathrm{O}_{3} \\
(\text { wt \%) }\end{array}$ & $\begin{array}{l}\mathrm{Fe}_{2} \mathrm{O}_{3} \\
(\mathrm{wt} \%)\end{array}$ & $\begin{array}{l}\mathrm{Na}_{2} \mathrm{O} \\
(\mathrm{wt} \%)\end{array}$ & $\begin{array}{c}\mathrm{SiO}_{2} \\
(\mathrm{wt} \%)\end{array}$ \\
\hline A1 & Simplified SB6 Glass & 12.46 & 5.00 & 11.48 & 22.27 & 48.79 \\
\hline A2 & $\begin{array}{c}\text { Simplified SB6 Glass, } \\
\text { without Iron }\end{array}$ & 14.14 & 5.90 & 0.00 & 25.32 & 54.64 \\
\hline $\mathrm{B} 1$ & Simplified SB19 Glass & 21.07 & 4.03 & 11.66 & 25.18 & 38.07 \\
\hline B2 & $\begin{array}{c}\text { Simplified SB19 Glass, } \\
\text { without Iron }\end{array}$ & 24.06 & 4.62 & 0.00 & 28.34 & 42.98 \\
\hline C1 & $\begin{array}{l}\text { Simplified 121506-07 } \\
\text { Glass }\end{array}$ & 34.62 & 23.28 & 8.21 & 6.38 & 27.51 \\
\hline $\mathrm{C} 2$ & $\begin{array}{c}\text { Simplified 121506-07 } \\
\text { Glass, without Iron }\end{array}$ & 37.72 & 25.29 & 0.00 & 7.09 & 29.91 \\
\hline D1 & $\begin{array}{c}\text { Simplified SB19 Glass } \\
\text { with High } \mathrm{B}_{2} \mathrm{O}_{3} \text { Frit }\end{array}$ & 20.91 & 8.09 & 12.01 & 21.19 & 37.79 \\
\hline D2 & $\begin{array}{l}\text { Simplified SB19 Glass } \\
\text { with High } \mathrm{B}_{2} \mathrm{O}_{3} \text { Frit, } \\
\text { without Iron }\end{array}$ & 23.94 & 9.19 & 0.00 & 24.10 & 42.76 \\
\hline
\end{tabular}

Table 2-2. Target Compositions for the Task 2 Glasses (wt \%).

\begin{tabular}{|c|c|c|c||}
\hline Oxide & FY09EM21-02 & FY09EM21-07 & FY09EM21-21 \\
\hline $\mathrm{Al}_{2} \mathrm{O}_{3}$ & 4.01 & 4.87 & 4.86 \\
\hline $\mathrm{B}_{2} \mathrm{O}_{3}$ & 5.07 & 13.92 & 9.01 \\
\hline $\mathrm{BaO}$ & 0.08 & 0 & 0.08 \\
\hline $\mathrm{CaO}$ & 0 & 3.92 & 0 \\
\hline $\mathrm{CdO}$ & 0.3 & 0 & 0.3 \\
\hline $\mathrm{Ce}_{2} \mathrm{O}_{3}$ & 0.36 & 0 & 0.36 \\
\hline $\mathrm{Cr}_{2} \mathrm{O}_{3}$ & 0 & 0 & 0.2 \\
\hline $\mathrm{CuO}$ & 0.13 & 0 & 0.13 \\
\hline $\mathrm{Fe}_{2} \mathrm{O}_{3}$ & 20.63 & 17.98 & 19.95 \\
\hline $\mathrm{La}_{2} \mathrm{O}_{3}$ & 0.1 & 0 & 0.1 \\
\hline $\mathrm{Li}_{2} \mathrm{O}$ & 4 & 4 & 7 \\
\hline $\mathrm{MgO}_{\mathrm{MnO}}$ & 1.5 & 1.5 & 0 \\
\hline $\mathrm{Na}_{2} \mathrm{O}$ & 0.3 & 5.5 & 1 \\
\hline $\mathrm{NiO}_{\mathrm{PbO}}$ & 2.5 & 12.71 & 14.67 \\
\hline $\mathrm{SO}_{4}$ & 0.22 & 0 & 0 \\
\hline $\mathrm{SiO}_{2}$ & 40.48 & 0 & 0.22 \\
\hline $\mathrm{TiO}_{2}$ & 2 & 0 & 0.48 \\
\hline $\mathrm{ZnO}_{\mathrm{ZrO}}$ & 0.13 & 33.6 & 39.31 \\
\hline $\mathrm{ZrO}_{2}$ & 0.21 & 2 & 2.01 \\
\hline
\end{tabular}


Table 2-3. Composition of DWPF SB6 Simulant used in Task 3.

\begin{tabular}{|c|c|c|c|}
\hline Elements & wt \% & Oxides & wt \% \\
\hline $\mathrm{Fe}$ & 18.9 & $\mathrm{Fe}_{2} \mathrm{O}_{3}$ & 27.0218 \\
\hline $\mathrm{Al}$ & 15.9 & $\mathrm{Al}_{2} \mathrm{O}_{3}$ & 29.9505 \\
\hline Mn & 5.92 & $\mathrm{MnO}$ & 7.6441 \\
\hline $\mathrm{Ca}$ & 0.949 & $\mathrm{CaO}$ & 1.3271 \\
\hline $\mathrm{Mg}$ & 0.454 & $\mathrm{MgO}$ & 0.7526 \\
\hline $\mathrm{P}$ & $<0.100$ & $\mathrm{P}_{2} \mathrm{O}_{5}$ & 0.0000 \\
\hline $\mathrm{Ni}$ & 2.54 & $\mathrm{NiO}$ & 3.2318 \\
\hline $\mathrm{Cr}$ & - & $\mathrm{Cr}_{2} \mathrm{O}_{3}$ & - \\
\hline $\mathrm{Cu}$ & 0.181 & $\mathrm{CuO}$ & 0.2266 \\
\hline $\mathrm{Ti}$ & 0.014 & $\mathrm{TiO}_{2}$ & 0.0234 \\
\hline Si & 0.141 & $\mathrm{SiO}_{2}$ & 0.3006 \\
\hline $\mathrm{Na}$ & 15.4 & $\mathrm{Na}_{2} \mathrm{O}$ & 20.7589 \\
\hline $\mathrm{Zn}$ & 0.00 & $\mathrm{ZnO}$ & 0.0000 \\
\hline $\mathrm{K}$ & 0.07 & $\mathrm{~K}_{2} \mathrm{O}$ & 0.0843 \\
\hline $\mathrm{Ce}$ & $<0.010$ & $\mathrm{Ce}_{2} \mathrm{O}_{3}$ & - \\
\hline $\mathrm{Sr}$ & 0.049 & $\mathrm{SrO}$ & 0.0579 \\
\hline $\mathrm{Ba}$ & $<0.010$ & $\mathrm{BaO}$ & - \\
\hline $\mathrm{Pb}$ & $<0.010$ & $\mathrm{PbO}$ & - \\
\hline $\mathrm{La}$ & $<0.010$ & $\mathrm{La}_{2} \mathrm{O}_{3}$ & - \\
\hline $\mathrm{Zr}$ & 0.217 & $\mathrm{ZrO}_{2}$ & 0.2924 \\
\hline$S$ & 0.37 & $\mathrm{SO}_{3}$ & 0.9240 \\
\hline Total & 61.054 & Total & 92.5959 \\
\hline
\end{tabular}


Table 2-4. Composition of Frits Used in Task 3 (wt\%).

\begin{tabular}{||c|c|c|c|c|c|c|c|c|c|c|c|c||}
\hline \hline Frit & $\mathbf{4 1 8}$ & $\mathbf{5 1 0}$ & CEF1 & CEF2 & CEF3 & CEF4 & CEF5 & CEF6 & CEF7 & CEF8 & CEF9 & CEF10 \\
\hline $\mathrm{B}_{2} \mathrm{O}_{3}$ & 8 & 14 & 11 & 11 & 11 & 8 & 8 & 8 & 8 & 8 & 8 & 16 \\
\hline $\mathrm{CaO}$ & 0 & 0 & 0 & 0 & 0 & 0 & 0 & 0 & 2 & 2 & 2 & 0 \\
\hline $\mathrm{Li}_{2} \mathrm{O}$ & 8 & 8 & 8 & 8 & 9 & 8 & 8 & 8 & 8 & 8 & 8 & 8 \\
\hline $\mathrm{MnO}$ & 0 & 0 & 0 & 2 & 4 & 1 & 2 & 4 & 1 & 2 & 4 & 0 \\
\hline $\mathrm{Na}_{2} \mathrm{O}$ & 8 & 8 & 8 & 6 & 5 & 8 & 7 & 6 & 7 & 6 & 6 & 4 \\
\hline $\mathrm{SiO}_{2}$ & 76 & 70 & 73 & 73 & 71 & 75 & 75 & 74 & 74 & 74 & 72 & 72 \\
\hline $\mathrm{Total}$ & 100 & 100 & 100 & 100 & 100 & 100 & 100 & 100 & 100 & 100 & 100 & 100 \\
\hline $\begin{array}{c}\mathrm{MRF} \text { Run \# } \\
(10-\mathrm{xxx})\end{array}$ & 35 & 36 & 37 & 38 & 39 & 40 & 41 & 42 & 43 & $44 \mathrm{~A}$ & 45 & 46 \\
\hline
\end{tabular}




\subsection{Fabrication of Glasses}

Each of the glasses for Tasks 1 and 2 were prepared from the proper proportions of reagent-grade metal oxides, carbonates, and boric acid in $150 \mathrm{~g}$ batches. The raw materials were thoroughly mixed and placed into platinum/gold, $250 \mathrm{ml}$ crucibles. The batch was placed into a hightemperature furnace at the melt temperatures shown in Table 2-5. The crucible was removed from the furnace after an isothermal hold for 60 minutes. The glasses were poured onto clean, stainless steel plates and allowed to air cool (quench). Glasses D1 and D2 were melted for only 30 minutes to reduce volatilization at the high melting temperature. Glasses C1 and C2 would not melt at the maximum furnace temperature of $1550{ }^{\circ} \mathrm{C}$, and therefore were eliminated from the rest of the study.

Approximately $25 \mathrm{~g}$ of each glass was heat-treated to simulate cooling along the centerline of a DWPF-type canister ${ }^{6}$ to gauge the effects of thermal history on the product performance. This cooling schedule is referred to as the CCC heat treatment.

Portions of each glass were annealed in order to produce stress-free samples for the structural characterization at SIA Radon. The annealing temperatures for each composition were determined by using a Differential Scanning Calorimeter (DSC) to determine the glass transition temperature for each composition, and then subtracting approximately $5{ }^{\circ} \mathrm{C}$ from this value. The glasses were annealed at these temperatures, given in Table $2-5$, for approximately 4 hours and then slowly cooled.

Table 2-5. Melt and Annealing Temperatures for the Task 1 and 2 Glass Compositions.

\begin{tabular}{|c|c|c|c||}
\hline Glass ID & Composition & $\begin{array}{c}\text { Melt } \\
\text { Temperature }\left({ }^{\circ} \mathbf{C}\right)\end{array}$ & $\begin{array}{c}\text { Annealing } \\
\text { Temperature }\left({ }^{\circ} \mathbf{C}\right)\end{array}$ \\
\hline A1 & Simplified SB6 Glass & 1350 & 520 \\
\hline A2 & Simplified SB6 Glass, without Iron & 1350 & 520 \\
\hline B1 & Simplified SB19 Glass & 1450 & 505 \\
\hline B2 & $\begin{array}{c}\text { Simplified SB19 Glass, without } \\
\text { Iron }\end{array}$ & 1500 & 505 \\
\hline C1 & Simplified 121506-07 Glass & $-*$ & - \\
\hline C2 & $\begin{array}{c}\text { Simplified 121506-07 Glass, } \\
\text { without Iron }\end{array}$ & $-*$ & - \\
\hline D1 & $\begin{array}{c}\text { Simplified SB19 Glass with High } \\
\text { B }_{2} \text { Frit }\end{array}$ & 1500 & 525 \\
\hline D2 & $\begin{array}{c}\text { Simplified SB19 Glass with High } \\
\text { B }_{3} \text { Frit, without Iron }\end{array}$ & 1500 & 525 \\
\hline FY09EM21-02 & From FY09 EM Study & 1150 & 425 \\
\hline FY09EM21-07 & From FY09 EM Study & 1150 & 425 \\
\hline FY09EM21-21 & From FY09 EM Study & 1150 & 425 \\
\hline
\end{tabular}

*Glasses C1 and C2 would not melt at $1550{ }^{\circ} \mathrm{C}$.

The glass samples for Task 3 were prepared by fusing the blend of dried SB6 simulant and the frit in the Melt Rate Furnace (MRF). When the MRF reached the target temperature of $1,150{ }^{\circ} \mathrm{C}$, a stainless steel beaker containing enough sludge and frit to make 50-60 g of glass at a target waste loading of $36 \mathrm{wt} \%$ was lowered into the MRF and heated from the bottom for 20 min. After the beaker was removed from the furnace, any loose material not yet fully melted was poured out, and the remaining 30-40 g of glass and froth materials were collected for shipment to SIA Radon. 


\subsection{Composition Analysis}

To confirm that the as-fabricated glasses met the target compositions, a representative sample from each quenched glass was submitted to the SRNL Process Science Analytical Laboratory (PSAL) for chemical analysis. Two dissolution techniques, sodium peroxide fusion (PF) and lithium-metaborate (LM), were used to prepare the glass samples for analysis. Each of the samples was analyzed, twice for each element of interest, by Inductively Coupled Plasma Atomic Emission Spectroscopy (ICP-AES).

\subsection{X-Ray Diffraction Analysis}

Representative samples of each of the Task 2 quenched and CCC glasses were submitted to SRNL Analytical Development (AD) for XRD analysis. Samples were run under conditions providing a detection limit of approximately $0.5 \mathrm{vol} \%$. That is, if crystals (or unincorporated batch material) were present at $0.5 \mathrm{vol} \%$ or greater, the diffractometer would not only be capable of detecting the crystals but would also allow a qualitative determination of the type of crystal(s) present. Otherwise, a characteristically high background signal (amorphous hump) devoid of crystalline peaks indicates that the glass is free of crystallization, suggesting either a completely amorphous product or that the degree of crystallization is below the detection limit.

\subsection{Product Consistency Test}

The Product Consistency Test (PCT) Method- $\mathrm{A}^{7}$ was performed in triplicate on each quenched and CCC glass to assess chemical durability. Also included in the experimental test matrix was the Environmental Assessment (EA) benchmark glass, ${ }^{8}$ the Approved Reference Material (ARM) glass, ${ }^{9}$ and blanks from the sample cleaning batch. Samples were ground, washed, and prepared according to the standard procedure. ${ }^{7}$ Fifteen milliliters of Type-I ASTM water were added to $1.5 \mathrm{~g}$ of glass in stainless steel vessels. The vessels were closed, sealed, and placed in an oven at $90 \pm 2{ }^{\circ} \mathrm{C}$ where the samples were maintained at temperature for 7 days. Once cooled, the resulting solutions were sampled (filtered and acidified), then labeled and analyzed by PSAL using ICP-AES. Normalized leachate (NL) values were calculated based on the targeted compositions using the average of the common logarithms of the leachate concentrations.

\subsection{Structural Characterization}

Detailed characterization of the structure of the glasses was carried out at SIA Radon. These results and their interpretation are provided in the reports included as appendices in this document. Appendix A describes the results for the Task 1 glasses, Appendix B describes the results for the Task 2 glasses, and Appendix $\mathrm{C}$ describes the results for the Task 3 glasses.

\subsection{Results and Discussion}

\subsection{Composition Analysis}

The results of the chemical composition measurements for the Task 1 glass compositions are shown in Table 3-1. The measured values are the mean of two measurements from the ICP-AES instrument. The targeted concentrations and the percent difference between the targeted and measured values are also given in the table. The $\mathrm{B}_{2} \mathrm{O}_{3}$ and the $\mathrm{Na}_{2} \mathrm{O}$ concentrations are slightly low for each of the glasses, which is likely due to volatility during melting. The $\mathrm{Fe}_{2} \mathrm{O}_{3}$ concentration is low for glass A1. These issues are not expected to impact the outcome of the study.

The results of the chemical composition measurements for the Task 2 glasses are shown in Table 3-2. It appears that $\mathrm{NiO}$ was omitted from the batch for glass FY09EM21-02. The MnO 
concentration is low for glass FY09EM21-07. The $\mathrm{Fe}_{2} \mathrm{O}_{3}$ concentration is high for glass FY09EM21-21. Again, these issues are not expected to impact the outcome of the study. 
Table 3-1. Target and Measured Compositions of the Task 1 Glasses (wt \%).

\begin{tabular}{|c|c|c|c|c|c|c|c|c|c|c|c|c|c|c|c|}
\hline \multirow{2}{*}{$\begin{array}{c}\text { Glass } \\
\text { ID }\end{array}$} & \multicolumn{3}{|c|}{$\overline{\mathrm{Al}_{2} \mathrm{O}_{3}(\mathrm{wt} \%)}$} & \multicolumn{3}{|c|}{$\mathrm{B}_{2} \mathrm{O}_{3}$ (wt \%) } & \multicolumn{3}{|c|}{$\overline{\mathrm{Fe}_{2} \mathrm{O}_{3} \text { (wt \%) }}$} & \multicolumn{3}{|c|}{$\mathrm{N}_{\mathrm{Na}} \mathrm{O}$ (wt \%) } & \multicolumn{3}{|c|}{$\mathrm{CSiO}_{2}$ (wt \%) } \\
\hline & Target & Meas. & Diff. & Target & Meas. & Diff. & Target & Meas. & Diff. & Target & Meas. & \% Diff. & Target & Meas. & Diff. \\
\hline A1 & 12.46 & 12.50 & $0.3 \%$ & 5.00 & 4.88 & $-2.5 \%$ & 11.48 & 10.35 & $-9.8 \%$ & 22.27 & 21.42 & $-3.8 \%$ & 48.79 & 48.31 & $-1.0 \%$ \\
\hline $\mathrm{A} 2$ & 14.14 & 14.31 & $1.2 \%$ & 5.90 & 5.57 & $-5.5 \%$ & 0.00 & - & - & 25.32 & 23.80 & $-6.0 \%$ & 54.64 & 54.33 & $-0.6 \%$ \\
\hline B1 & 21.07 & 21.00 & $-0.3 \%$ & 4.03 & 3.79 & $-5.9 \%$ & 11.66 & 11.08 & $-5.0 \%$ & 25.18 & 24.04 & $-4.5 \%$ & 38.07 & 38.03 & $-0.1 \%$ \\
\hline B2 & 24.06 & 24.05 & $0.0 \%$ & 4.62 & 4.35 & $-5.9 \%$ & 0.00 & - & - & 28.34 & 26.79 & $-5.5 \%$ & 42.98 & 43.32 & $0.8 \%$ \\
\hline D1 & 20.91 & 20.63 & $-1.3 \%$ & 8.09 & 7.73 & $-4.4 \%$ & 12.01 & 12.55 & $4.5 \%$ & 21.19 & 20.24 & $-4.5 \%$ & 37.79 & 37.36 & $-1.1 \%$ \\
\hline D2 & 23.94 & 23.51 & $-1.8 \%$ & 9.19 & 8.98 & $-2.3 \%$ & 0.00 & - & - & 24.10 & 22.96 & $-4.7 \%$ & 42.76 & 42.34 & $-1.0 \%$ \\
\hline
\end{tabular}


Table 3-2. Target and Measured Compositions of the Task 2 Glasses (wt \%).

\begin{tabular}{|c|c|c|c|c|c|c|c|c|c|}
\hline \multirow{2}{*}{ Oxide } & \multicolumn{3}{|c|}{ FY09EM21-02 } & \multicolumn{3}{|c|}{ FY09EM21-07 } & \multicolumn{3}{|c|}{ FY09EM21-21 } \\
\hline & Target & Meas. & \% Diff. & Target & Meas. & \% Diff. & Target & Meas. & \% Diff. \\
\hline $\mathrm{Al}_{2} \mathrm{O}_{3}$ & 4.01 & 4.31 & $7 \%$ & 4.87 & 5.07 & $4 \%$ & 4.86 & 4.75 & $-2 \%$ \\
\hline $\mathrm{B}_{2} \mathrm{O}_{3}$ & 5.07 & 5.29 & $4 \%$ & 13.92 & 13.75 & $-1 \%$ & 9.01 & 8.77 & $-3 \%$ \\
\hline $\mathrm{BaO}$ & 0.08 & 0.08 & $-2 \%$ & 0.00 & - & - & 0.08 & 0.07 & $-12 \%$ \\
\hline $\mathrm{CaO}$ & 0.00 & - & - & 3.92 & 3.88 & $-1 \%$ & 0.00 & - & - \\
\hline $\mathrm{CdO}$ & 0.30 & 0.28 & $-8 \%$ & 0.00 & - & - & 0.30 & 0.27 & $-11 \%$ \\
\hline $\mathrm{Ce}_{2} \mathrm{O}_{3}$ & 0.34 & 0.34 & $0 \%$ & 0.00 & - & - & 0.32 & 0.32 & $0 \%$ \\
\hline $\mathrm{Cr}_{2} \mathrm{O}_{3}$ & 0.00 & - & - & 0.00 & - & - & 0.20 & 0.20 & $2 \%$ \\
\hline $\mathrm{CuO}$ & 0.13 & 0.14 & $6 \%$ & 0.00 & - & - & 0.13 & 0.13 & $-4 \%$ \\
\hline $\mathrm{Fe}_{2} \mathrm{O}_{3}$ & 20.63 & 22.24 & $8 \%$ & 17.98 & 17.88 & $-1 \%$ & 19.95 & 23.40 & $17 \%$ \\
\hline $\mathrm{La}_{2} \mathrm{O}_{3}$ & 0.10 & 0.09 & $-12 \%$ & 0.00 & - & - & 0.10 & 0.08 & $-17 \%$ \\
\hline $\mathrm{Li}_{2} \mathrm{O}$ & 4.00 & 3.98 & $0 \%$ & 4.00 & 3.88 & $-3 \%$ & 7.00 & 6.63 & $-5 \%$ \\
\hline $\mathrm{MgO}$ & 1.50 & 1.51 & $1 \%$ & 1.50 & 1.47 & $-2 \%$ & 0.00 & - & - \\
\hline $\mathrm{MnO}$ & 0.30 & 0.33 & $11 \%$ & 5.50 & 4.36 & $-21 \%$ & 1.00 & 1.01 & $1 \%$ \\
\hline $\mathrm{Na}_{2} \mathrm{O}$ & 17.98 & 18.00 & $0 \%$ & 12.71 & 12.49 & $-2 \%$ & 14.67 & 13.68 & $-7 \%$ \\
\hline $\mathrm{NiO}$ & 2.50 & 0.00 & $-100 \%$ & 0.00 & - & - & 0.00 & - & - \\
\hline $\mathrm{PbO}$ & 0.22 & 0.21 & $-2 \%$ & 0.00 & - & - & 0.22 & 0.21 & $-6 \%$ \\
\hline $\mathrm{SO}_{4}$ & 0.48 & 0.55 & $14 \%$ & 0.00 & - & - & 0.48 & 0.53 & $9 \%$ \\
\hline $\mathrm{SiO}_{2}$ & 40.02 & 38.73 & $-3 \%$ & 33.60 & 32.21 & $-4 \%$ & 39.31 & 36.17 & $-8 \%$ \\
\hline $\mathrm{TiO}_{2}$ & 2.00 & 1.97 & $-2 \%$ & 2.00 & 1.90 & $-5 \%$ & 2.01 & 1.84 & $-8 \%$ \\
\hline $\mathrm{ZnO}$ & 0.13 & 0.13 & $3 \%$ & 0.00 & - & - & 0.13 & 0.12 & $-8 \%$ \\
\hline $\mathrm{ZrO}_{2}$ & 0.21 & 0.20 & $-4 \%$ & 0.00 & - & - & 0.21 & 0.19 & $-9 \%$ \\
\hline
\end{tabular}




\subsection{XRD Results}

The XRD results for the quenched and CCC versions of the Task 2 glasses are shown in Table 3-3. All of the quenched glasses were XRD amorphous. Magnetite was identified in the CCC version of glass FY09EM21-07. Lithium silicate was identified in glass FY09EM21-21. Based on previous experience, magnetite will not likely impact the durability of the glass while lithium silicate is more likely to be detrimental.

Table 3-3. XRD Results for the BP-Series Glasses.

\begin{tabular}{|c|c|c|}
\hline Glass ID & Heat Treatment & XRD Results \\
\hline \multirow{2}{*}{ FY09EM21-02 } & Quenched & Amorphous \\
\cline { 2 - 3 } & CCC & Amorphous \\
\hline \multirow{2}{*}{ FY09EM21-07 } & Quenched & Amorphous \\
\cline { 2 - 3 } & CCC & Magnetite $\left(\mathrm{Fe}_{3} \mathrm{O}_{4}\right)$ \\
\hline \multirow{2}{*}{ FY09EM21-21 } & Quenched & Amorphous \\
\cline { 2 - 3 } & CCC & Lithium Silicate $\left(\mathrm{Li}_{2} \mathrm{SiO}_{3}\right)$ \\
\hline
\end{tabular}

\subsection{PCT Results}

The PCT results for the Task 1 and Task 2 glasses are listed in Table 3-4. A review of the data showed no issues with the blank vessels, no issues with the ARM reference glass, no water loss issues, and no issues with the surface to volume ratios of the study glasses. The PCT values are normalized based on the targeted glass compositions. Composition B1 has the highest normalized leachate concentration for boron (NL [B]) among the Task 1 glasses, with a value of $1.10 \mathrm{~g} / \mathrm{L}$. This may be due to the carnegieite phase identified in this composition at SIA Radon (see Appendix A). Overall, the durabilities of the Task 1 glass compositions are considerably better than that of the EA reference glass.

As reported in the original study from which the Task 2 glasses were selected, ${ }^{4}$ the durabilities of these glasses are relatively poor. In particular, composition FY09EM21-21 has a durability that is worse than that of the EA reference glass. The identification of lithium silicate in the CCC version of this glass by XRD (see Section 3.2) may indicate the cause of poor durability for this composition. Lithium silicate removes silicon, a glass network former, from the residual amorphous phase. The XRD results do not explain the durability results of the other two Task 2 glasses. Composition FY09EM21-02 was found to be XRD amorphous. Composition FY09EM21-07 contained magnetite after slow cooling, which is not expected to impact durability. The intent of the study at SIA Radon was to further investigate the potential causes of these poor durability values (see Appendix B). 
Table 3-4. PCT Results for the Task 1 and Task 2 Glasses.

\begin{tabular}{|c|c|c|c|c|c|}
\hline \multirow{2}{*}{ Glass ID } & $\begin{array}{c}\text { Heat } \\
\text { Treatment }\end{array}$ & NL [B] (g/L) & NL [Li] (g/L) & NL [Na] (g/L) & NL [Si] (g/L) \\
\hline EA & n/a & 15.08 & 8.58 & 11.82 & 3.73 \\
\hline A1 & Quenched & 0.83 & - & 0.81 & 0.42 \\
\hline A2 & Quenched & 0.78 & - & 1.29 & 0.46 \\
\hline B1 & Quenched & 1.10 & - & 1.19 & 0.58 \\
\hline B2 & Quenched & 0.65 & - & 1.29 & 0.49 \\
\hline D1 & Quenched & 0.54 & - & 0.62 & 0.40 \\
\hline D2 & Quenched & 0.48 & - & 0.55 & 0.32 \\
\hline \multirow{2}{*}{ FY09EM21-02 } & Quenched & 3.36 & 2.30 & 2.75 & 2.63 \\
\cline { 2 - 6 } & CCC & 5.75 & 3.32 & 4.32 & 1.69 \\
\hline \multirow{2}{*}{ FY09EM21-07 } & Quenched & 12.57 & 9.74 & 9.16 & 1.06 \\
\cline { 2 - 6 } & CCC & 3.18 & 2.62 & 2.41 & 0.78 \\
\hline \multirow{2}{*}{ FY09EM21-21 } & Quenched & 19.16 & 11.38 & 12.17 & 3.17 \\
\cline { 2 - 6 } & CCC & 27.47 & 13.07 & 18.22 & 3.55 \\
\hline
\end{tabular}

\subsection{Summary}

The complete Task 1 report from SIA Radon is included as Appendix A. Briefly, microscopy work showed that the glasses were amorphous except for composition B1, which contained carnegieite. No amorphous phase separation was identified. Iron, which is present mainly as $\mathrm{Fe}^{3+}$, was found to reduce the glass network connectivity and increase the number of non-bridging oxygens. Iron ions are well distributed throughout the glasses. The coordination of the iron ions varied as a function of composition. In composition $\mathrm{A} 1,75 \%$ of the iron ions were octahedrally coordinated and $25 \%$ were tetrahedrally coordinated. In composition B1, $70 \%$ of the iron ions were tetrahedrally coordinated and 30\% were octahedrally coordinated. In composition D1, all of the iron ions were octahedrally coordinated. These results may indicate that glass compositions where iron is predominantly tetrahedrally coordinated have more of a tendency to crystallize nepheline or nepheline-like phases.

The complete Task 2 report from SIA Radon is included as Appendix B. Briefly, the glasses were homogeneous and free of both crystalline phases and liquid-liquid phase separation. Composition FY09EM21-02 has the highest degree of glass network connectivity, followed by composition FY09EM21-21 and then by composition FY09EM21-07. Aluminum is tetrahedrally coordinated in all of the glasses. Boron is present in both trigonal and tetrahedral coordinations. The fraction of tetrahedrally coordinated boron is highest for composition FY09EM21-02, and lowest for composition FY09EM21-07. Iron was homogeneously distributed throughout the glasses, and was predominantly trivalent and tetrahedrally coordinated. The report also offers a potential reason for the low chemical durability of these glasses: the relatively low fraction of tetrahedrally coordinated boron and the relatively low concentrations of $\mathrm{Al}_{2} \mathrm{O}_{3}$ available to form $\left[\mathrm{BO}_{4 / 2}\right]^{-} \mathrm{Me}^{+}$and $\left[\mathrm{AlO}_{4 / 2}\right]^{-} \mathrm{Me}^{+}$tetrahedral units are not sufficient to consume all of the alkali ions, and thus these alkali ions are easily leached from the glasses.

The complete Task 3 report from SIA Radon is included as Appendix C. Additional glasses were produced using the same experimental procedures as used for those sent to SIA Radon and characterized at SRNL using X-ray imaging and CT techniques for melt rate evaluation. A report summarizing the CT results of these and other glass samples produced during FY10 under the EM-31 melt rate program is currently being drafted. Briefly, the report in Appendix C showed that all of the Task 3 glass compositions were mainly amorphous, with some minor spinel phases. 
Some aggregation of the crystals was identified. The coordination of aluminum and iron was found to be mainly tetrahedral, with some octahedral iron ions $\left(\mathrm{FeO}_{6}\right)$. Iron was mainly present as $\mathrm{Fe}^{3+}$. Boron was present mainly in trigonal coordination, along with some tetrahedrally coordinated boron forming complex borate units. SRNL researchers will further evaluate the results of the Task 3 glass studies to determine their impact on melt rate modeling efforts.

\subsection{Future Work}

Future studies should focus on the role of tetrahedrally coordinated iron in influencing crystallization behavior in glass. It would be useful to determine whether iron is present in a similar local environment in more complex HLW glasses, and to determine whether compositional changes can shift iron into octahedral coordination. In terms of factors influencing durability, further study is needed to better determine the impacts of boron coordination along with aluminum and alkali concentrations on leaching of components from the glass network. It is recommended that a method to quantify the fraction of tetrahedrally-coordinated boron in high-Fe glasses be sought after with a focus on its impact on NBO distribution.

\subsection{References}

1. Pierce, E. M., L. R. Reed, W. J. Shaw, B. P. McGrail, J. P. Icenhower, C. F. Windisch, E. A. Cordova and J. Broady, "Experimental Determination of the Effect of the Ratio of B/Al on Glass Dissolution Along the Nepheline (NaAlSiO4)-Malinkoite(NaBSiO4) Join," Geochimica et Cosmochimica Acta, 74 2634-2654 (2010).

2. Choi, A. S., "Thermodynamic Modeling of Comparitive Melt Rates: FY08 Summary," U.S. Department of Energy Report SRNL-PSE-2008-00178, Savannah River National Laboratory, Aiken, SC (2008).

3. Fox, K. M. and D. K. Peeler, "Demonstration of Very High Aluminum Retention in Simulated HLW Glass,” U.S. Department of Energy Report SRNL-PSE-2007-00231, Washington Savannah River Company, Aiken, SC (2007).

4. Johnson, F. C. and T. B. Edwards, "Results of the FY09 Enhanced DOE High-Level Waste Melter Throughput Studies at SRNL,” U.S. Department of Energy Report SRNL-STI-2009-00778, Revision 0, Savannah River National Laboratory, Aiken, SC (2010).

5. Choi, A. S., "DWPF Melter Off-Gas Flammability Assessment,” U.S. Department of Energy Memorandum X-CLC-S-00164, Revision 4, Savannah River National Laboratory, Aiken, SC (2009).

6. Marra, S. L. and C. M. Jantzen, "Characterization of Projected DWPF Glass Heat Treated to Simulate Canister Centerline Cooling,” U.S. Department of Energy Report WSRC-TR-92-142, Revision 1, Westinghouse Savannah River Company, Aiken, SC (1993).

7. ASTM, "Standard Test Methods for Determining Chemical Durability of Nuclear Waste Glasses: The Product Consistency Test (PCT),” ASTM C-1285, (2002).

8. Jantzen, C. M., N. E. Bibler, D. C. Beam, C. L. Crawford and M. A. Pickett, "Characterization of the Defense Waste Processing Facility (DWPF) Environmental Assessment (EA) Glass Standard Reference Material," U.S. Department of Energy Report WSRC-TR-92-346, Revision 1, Westinghouse Savannah River Company, Aiken, SC (1993). 
9. Jantzen, C. M., J. B. Picket, K. G. Brown, T. B. Edwards and D. C. Beam, "Process/Product Models for the Defense Waste Processing Facility (DWPF): Part I. Predicting Glass Durability from Composition Using a Thermodynamic Hydration Energy Reaction Model (THERMO)," U.S. Department of Energy Report WSRC-TR-93-672, Revision 1, Westinghouse Savannah River Company, Aiken, SC (1995). 
SRNL-STI-2010-00805

Revision 0

Appendix A. Final Report from SIA Radon on Task 1:

Chemistry and Structure of $\mathrm{Al}_{2} \mathrm{O}_{3}-\mathrm{B}_{2} \mathrm{O}_{3}-\mathrm{Fe}_{2} \mathrm{O}_{3}-\mathrm{Na}_{2} \mathrm{O}-\mathrm{SiO}_{2}$ Glasses 
SRNL-STI-2010-00805

Revision 0

FINAL REPORT

Subcontract Number AC69549N

Task 1: Chemistry and Structure of $\mathrm{Al}_{2} \mathrm{O}_{3}-\mathrm{B}_{2} \mathrm{O}_{3}-\mathrm{Fe}_{2} \mathrm{O}_{3}-\mathrm{Na}_{2} \mathrm{O}-\mathrm{SiO}_{2}$ Glasses

Glass Structural Characterization and Analysis

\section{INTRODUCTION}

SRNL performs extensive development work on immobilization of high level waste in glass. The applied nature of this work dictates that the glass compositions are very complex [1-3], and therefore structural characterization becomes difficult. A study of simplified glass compositions would be useful in providing insight into the performance of the more complex glasses while making characterization data easier to interpret. For example, the formation of nepheline crystals in complex glass compositions, which reduces the chemical durability of the glass waste form [1,2], may be easier to understand by characterizing a simplified composition.

The structure of $\mathrm{Al}_{2} \mathrm{O}_{3}-\mathrm{B}_{2} \mathrm{O}_{3}-\mathrm{Na}_{2} \mathrm{O}-\mathrm{SiO}_{2}$ glasses has been reported in the literature using NMR and optical characterization techniques [4-6]. The published work has been successful in identifying compositionally driven coordination changes in aluminum and boron, changes in the fraction of non-bridging oxygens, and the tendency for sodium to preferentially associate with aluminum. However, the addition of iron (a major component of HLW glass) makes NMR studies difficult. The objective of this task would be to characterize the chemistry and structure of $\mathrm{Al}_{2} \mathrm{O}_{3}-\mathrm{B}_{2} \mathrm{O}_{3}-\mathrm{Na}_{2} \mathrm{O}-\mathrm{SiO}_{2}$ glasses with the addition of $\mathrm{Fe}_{2} \mathrm{O}_{3}$ using XPS, XANES, EXAFS, IR and Raman Spectroscopy. Comparisons would be made with the literature data, with any additional influences of $\mathrm{Fe}_{2} \mathrm{O}_{3}$ being identified and described. 


\section{EXPERIMENTAL}

Samples of glasses were delivered by customer (SRNL). Their target and actual chemical compositions are given in Table I.

Actual chemical compositions of the glasses were determined at SRNL using a Perkin-Elmer 403 ICPAAS spectrometer. Samples were examined by X-ray diffraction (XRD) using a Rigaku D / Max 2200 diffractometer ( $\mathrm{Cu} \mathrm{K \alpha}$ radiation, $40 \mathrm{keV}$ voltage, $20 \mathrm{~mA}$ current, stepwise 0.02 degrees 20), scanning electron microscopy with energy dispersive spectrometry using a JSM-5610LV+JED-2300 analytical unit, Fourier-transform infrared spectroscopy (FTIR) using a Perkin-Elmer 2000 Fourier spectrophotometer (compaction of glass powders in pellets with $\mathrm{KBr}$ at recording within the range of $4000-350 \mathrm{~cm}^{-1}$, and placement of micron-sized powder between two glass plates at recording within the range of $600-30 \mathrm{~cm}^{-1}$ ), and Raman spectroscopy using a Jobin Yvon U1000 spectrophotometer operated at an excitation wavelength of $532 \mathrm{~nm}$.

X-ray absorption (XAS) spectra were recorded at the Structural Materials Science (STM) Beamline of the synchrotron source at RRC "Kurchatov Institute". The glass samples were measured at room temperature either as dispersed powder or as pellets pressed from powder mixed with sucrose in the transmission mode using a $\mathrm{Si}(220)$ channel-cut monochromator and two air-filled ionization chambers. Fluorescence spectra were also acquired. Powders of chemically pure Fe oxides $\mathrm{Fe}_{2} \mathrm{O}_{3}$ and $\mathrm{FeO}$ were used as standards and measured under identical conditions. Experimental XAFS spectra were fitted in R-space using an IFEFFIT package [7] and crystal structures of corresponding oxides and silicates. In the fitting, $a b$ initio photoelectron backscattering amplitudes and phases calculated self-consistently using FEFF8 [8] were used.

Wavelet transform (WT) is commonly applied to evaluation of complex time-frequency signals. As shown in refs [9,10], WT is easily adapted to EXAFS analysis, and the expression of the WT of the $\mathrm{k}^{\mathrm{n}}$ weighted EXAFS data takes the form:

$$
W_{\chi}^{\psi}(k, r)=(2 r)^{1 / 2} \int_{-\infty}^{\infty} \chi\left(k^{\prime}\right) k^{\prime n} \psi^{*}\left[2 r\left(k^{\prime}-k\right)\right] d k^{\prime},
$$

where $\chi(\mathrm{k})$ is the EXAFS signal and $\psi^{*}\left[2 r\left(k^{\prime}-k\right)\right]$ is the complex wavelet function.

The WT is able to resolve the k dependence of the absorption signal, which potentially allows separation of contributing backscattering atoms even situated at the same distances from the core. One of the advantages of the wavelet analysis is the visualization of the WT modulus in a k-R plot, which provides an easy way to interpret the results. Our analysis of EXAFS data for Pu and Hf were performed using the FORTRAN program HAMA employing Morlet wavelet algorithm [11]. The Morlet wavelet is well-suited for EXAFS signal since it consists of a slowly varying amplitude term and a fast oscillating phase term. Its mathematical description is broadly analogous to the Fourier transform. The Morlet wavelet is obtained by taking a complex sine wave with frequency $\eta$ (as in FT) and by confining it with a Gaussian envelope with the half width $\sigma$,

$$
\psi(k)=\frac{1}{(2 \pi)^{1 / 2} \sigma} \exp (i \eta k) \exp \left(-k^{2} / 2 \sigma^{2}\right)
$$

The choice of the $\eta$ and $\sigma$ parameters is important for data analysis since, besides other issues, it determines resolution in $\mathrm{k}-\mathrm{R}$ space. Various combinations of these parameters were used in an attempt to resolve contributions from atoms at close distances from the central atom. As shown in ref.[8] use of higher k-weighting decreases resolution in the k-space, since backscattering amplitudes become flattened 
and shifted to higher values. Nevertheless, WT modulus plots for different $\mathrm{k}$ weights are shown to emphasize contributions of light and heavy backscatterers. Note, that in all plots of the WT modulus the interatomic distances are given without phase shift correction. 
Table I. Chemical Compositions of SRNL Borosilicate Glasses.

\begin{tabular}{|c|c|c|c|c|c|c|c|c|c|c|c|c|c|c|c|c|c|c|}
\hline \multirow{3}{*}{ Oxides } & \multicolumn{3}{|c|}{$\begin{array}{c}\text { A1 } \\
\text { (SB6) }\end{array}$} & \multicolumn{3}{|c|}{$\begin{array}{c}\text { A2 } \\
\text { (SB6 w/o Fe) }\end{array}$} & \multicolumn{3}{|c|}{$\begin{array}{c}\text { B1 } \\
\text { (SB19) }\end{array}$} & \multicolumn{3}{|c|}{$\begin{array}{c}\mathrm{B} 2 \\
(\mathrm{SB} 19 \mathrm{w} / \mathrm{o} \mathrm{Fe})\end{array}$} & \multicolumn{3}{|c|}{$\begin{array}{c}\mathrm{D} 1 \\
\text { (high } \mathrm{B}_{2} \mathrm{O}_{3} \text { frit) }\end{array}$} & \multicolumn{3}{|c|}{$\begin{array}{c}\text { D2 (high } \mathrm{B}_{2} \mathrm{O}_{3} \text { frit w/o } \\
\mathrm{Fe} \text { ) }\end{array}$} \\
\hline & \multicolumn{2}{|c|}{ target } & \multirow{2}{*}{\begin{tabular}{|c|} 
actual \\
wt.\% \\
\end{tabular}} & \multicolumn{2}{|c|}{ target } & \multirow{2}{*}{\begin{tabular}{|l} 
actual \\
wt. $\%$
\end{tabular}} & \multicolumn{2}{|c|}{ target } & \multirow{2}{*}{\begin{tabular}{|l|} 
actual \\
wt. $\%$ \\
\end{tabular}} & \multicolumn{2}{|c|}{ target } & \multirow{2}{*}{\begin{tabular}{|c|} 
actual \\
wt. $\%$ \\
\end{tabular}} & \multicolumn{2}{|c|}{ target } & \multirow{2}{*}{\begin{tabular}{|l|} 
actual \\
wt.\% \\
\end{tabular}} & \multicolumn{2}{|c|}{ target } & \multirow{2}{*}{$\frac{\text { actual }}{\text { wt. } \%}$} \\
\hline & mol\% & wt.\% & & mol\% & wt.\% & & $\mathrm{mol} \%$ & wt.\% & & $\mathrm{mol} \%$ & wt.\% & & mol\% & wt.\% & & mol\% & wt.\% & \\
\hline $\mathrm{Al}_{2} \mathrm{O}_{3}$ & 8.5 & 12.46 & 12.50 & 9.0 & 14.14 & 14.30 & 15.0 & 21.06 & 21.00 & 16.0 & 24.06 & \begin{tabular}{|l|}
24.05 \\
\end{tabular} & 15.0 & 20.91 & 20.60 & 16.0 & 23.94 & 23.50 \\
\hline $\mathrm{B}_{2} \mathrm{O}_{3}$ & 5.0 & 5.00 & 4.88 & 5.5 & 5.90 & 5.58 & 4.2 & 4.03 & 3.80 & 4.5 & 4.62 & 4.35 & 8.5 & 8.09 & 7.73 & 9.0 & 9.19 & 8.98 \\
\hline $\mathrm{Fe}_{2} \mathrm{O}_{3}$ & 5.0 & 11.48 & 10.35 & - & - & 0.08 & 5.3 & 11.66 & 11.05 & - & - & 0.12 & 5.5 & 12.01 & 12.55 & - & - & 0.05 \\
\hline $\mathrm{Na}_{2} \mathrm{O}$ & 25.0 & 22.27 & 21.45 & 26.5 & 25.31 & 23.80 & 29.5 & 25.18 & 24.05 & 31.0 & 28.34 & 26.80 & 25.0 & 21.19 & 20.25 & 26.5 & 24.10 & 22.95 \\
\hline $\mathrm{SiO}_{2}$ & 56.5 & 48.80 & 48.30 & 59.0 & 54.64 & 54.30 & 46.0 & 38.07 & 38.00 & 48.5 & 42.98 & 43.30 & 46.0 & 37.80 & 37.35 & 48.5 & 42.77 & 42.35 \\
\hline Total & 100.0 & 100 & 97.48 & 100.0 & 100 & 98.06 & 100.0 & 100 & 98.90 & 100.0 & 100 & \begin{tabular}{|l|}
98.62 \\
\end{tabular} & 100.0 & 100.00 & 98.58 & 100.0 & 100.00 & 97.83 \\
\hline$\psi_{\mathrm{B}}$ & 3.3 & & & 3.2 & & & 3.5 & & & 3.3 & & & 1.2 & & & 1.2 & & \\
\hline$\psi_{\mathrm{B}}(\mathrm{Fe})$ & 3.0 & & & & & & 3.1 & & & & & & 1.0 & & & & & \\
\hline
\end{tabular}




\section{THEORETICAL REMARKS}

There are several structural parameters characterizing some features of the structure of glasses. The most important among them are degree of connectedness of the silica-oxygen network $\left(f_{\mathrm{si}}\right)$ for silicate-based and relative fraction of four-coordinated boron $\left(\psi_{\mathrm{B}}\right)$ for borate and borosilicate glasses [12]:

$$
\psi_{\mathrm{B}}=\left\{\left(\mathrm{Na}_{2} \mathrm{O}+\mathrm{K}_{2} \mathrm{O}+\mathrm{BaO}\right)+\left[0.7(\mathrm{CaO}+\mathrm{SrO})+[0.3(\mathrm{MgO}+\mathrm{ZnO}+\mathrm{PbO})]-\mathrm{Al}_{2} \mathrm{O}_{3}\right\} / \mathrm{B}_{2} \mathrm{O}_{3}\right.
$$

Formally, boron is three-coordinated if $0 \leq \psi_{\mathrm{B}} \leq 1 / 3$ and forms boron-oxygen triangles. At $1 / 3<\psi_{\mathrm{B}}<1$ both three- and four-coordinated boron atoms co-exist and are present in complex borate groups. At $\psi_{\mathrm{B}} \geq$ 1 all the boron is four-coordinated and forms boron-oxygen tetrahedra associated with alkali and, in less extent, alkali earth cations as, for example, $\mathrm{Me}^{+}\left[\mathrm{BO}_{4 / 2}\right]$ units. Actually, significant excess of alkali or/and alkali earth oxides as oxygen donors to form $\mathrm{BO}_{4}$ tetrahedra and convert all the boron into fourcoordinated state is needed. This process depends also on silica content in glass. At relatively high silica content (60-80 wt.\%) the $\psi_{\mathrm{B}}$ value is estimated to be 1.5-2. At lower silica contents (44-60 wt.\%) this value should be much higher. We have demonstrated using IR and electron paramagnetic resonance (EPR) spectroscopy that in borosilicate glasses for high-sodium intermediate level waste immobilization containing $40-50$ wt. $\% \mathrm{SiO}_{2}$ minor fraction of trigonally coordinated boron is present even at $\psi_{\mathrm{B}} \cong 4 \div 5$ [13].

Because $\mathrm{Al}_{2} \mathrm{O}_{3}$ is stronger acceptor of oxygen than $\mathrm{B}_{2} \mathrm{O}_{3}$, oxygen introduced with alkali and alkali earth oxides is in the first instance spent for transformation of Al into four-coordinated state. Scheme of coordination transformations for aluminoborosilicate glasses is shown in Table II [6].

Table II. Coordination of boron and aluminum in glasses at various $\psi_{\mathrm{B}}$ values [12].

\begin{tabular}{|c|c|c|c|c|}
\hline$\varphi_{\mathrm{B}}$ & \multicolumn{4}{|c|}{ Coordination } \\
\hline$\psi_{\mathrm{B}}>1$ & {$\left[\mathrm{AlO}_{4}\right]$} & {$\left[\mathrm{BO}_{4}\right]$} & - & - \\
\hline $1 / 3<\psi_{\mathrm{B}}<1$ & {$\left[\mathrm{AlO}_{4}\right]$} & {$\left[\mathrm{BO}_{4}\right]$} & {$\left[\mathrm{BO}_{3}\right]$} & - \\
\hline $0<\psi_{\mathrm{B}}<1 / 3$ & {$\left[\mathrm{AlO}_{4}\right]$} & - & {$\left[\mathrm{BO}_{3}\right]$} & {$\left[\mathrm{AlO}_{6}\right]$} \\
\hline$\psi_{\mathrm{B}}<0$ & {$\left[\mathrm{AlO}_{4}\right]$} & - & {$\left[\mathrm{BO}_{3}\right]$} & \\
\hline
\end{tabular}

As seen from Table III, aluminum offers negative effect on transformation of trigonally coordinated boron into tetragonally coordinated one. Stability of coordination state depends on a value of cationic to anionic radii ratio $\left(r_{\mathrm{c}} / r_{\mathrm{a}}\right)$. For tetrahedral oxygen coordination this ratio ranges between 0.22 and 0.41 [14] (radius of $\mathrm{O}^{2-}$ anion is assumed to be $1.36 \AA$ ). Deviation from average value of the $r_{\mathrm{c}} / r_{\mathrm{O}}{ }^{2-}$ ratio expressed as $|\Delta|=\left[r_{\mathrm{c}} / r_{\mathrm{O}}{ }^{2-}\right]_{\mathrm{av}}-\left[r_{\mathrm{c}} / r_{\mathrm{O}}{ }^{2-}\right]_{\text {calc }}$ may be considered as a measure of stability of tetrahedral coordination for the given cation. The values calculated from

two different reference data are given in Table III. Due to higher stability of $\left[\mathrm{AlO}_{4}\right]$ tetrahedra as compared to $\left[\mathrm{BO}_{4}\right]$ tetrahedra oxygen delivered by alkali oxides is firstly spent for formation of $\mathrm{AlO}_{4}$ tetrahedra and at relatively high $\mathrm{Al}_{2} \mathrm{O}_{3}$ concentrations major boron remains three-coordinated. Nevertheless this does not offer negative effect on chemical durability of glasses, because aluminosilicate glass network built from $\mathrm{SiO}_{4}$ and $\mathrm{AlO}_{4}$ tetrahedra with associated alkali ions is leach resistant [16,17].

Table III. Cationic radii, cationic to oxygen anion radii ratios and their deviations from average value $(0.315 \AA)$ for tetrahedrally coordinated ions.

\begin{tabular}{|c|c|c|c|c|c|c|c|c|}
\hline Cation & \multicolumn{2}{|c|}{$\mathrm{B}^{3+}$} & \multicolumn{2}{c|}{$\mathrm{Si}^{4+}$} & \multicolumn{3}{c|}{$\mathrm{Al}^{3+}$} & \multicolumn{2}{c|}{$\mathrm{Fe}^{3+}$} \\
\hline Refs & {$[14]$} & {$[15]$} & {$[14]$} & {$[15]$} & {$[14]$} & {$[15]$} & {$[14]$} & {$[15]$} \\
\hline$r_{\mathrm{c}} \AA$ & 0.20 & 0.11 & 0.39 & 0.26 & 0.57 & 0.39 & 0.67 & 0.49 \\
\hline$r_{\mathrm{c}} / r_{\mathrm{O}}{ }^{2-}$ & 0.15 & 0.08 & 0.29 & 0.19 & 0.42 & 0.29 & 0.49 & 0.36 \\
\hline
\end{tabular}




\begin{tabular}{|l|l|l|l|l|l|l|l|l|}
$|\Delta|$ & 0.165 & 0.235 & 0.025 & 0.125 & 0.105 & 0.025 & 0.175 & 0.045 \\
\hline
\end{tabular}

Effect of iron oxides on boron coordination in borosilicate glasses is more complicated. $\mathrm{Fe}^{3+}$ ions being network-formers act similarly to $\mathrm{Al}^{3+}$ ions forming $\mathrm{FeO}_{4}$ tetrahedra and suppressing $\mathrm{B}^{\mathrm{III}} \rightarrow \mathrm{B}^{\mathrm{IV}}$ transformation. However, since stability of $\left[\mathrm{Fe}^{3+} \mathrm{O}_{4}\right]$ tetrahedron is lower then that of $\left[\mathrm{AlO}_{4}\right]$, the effect of $\mathrm{Fe}_{2} \mathrm{O}_{3}$ on $\mathrm{B}^{\mathrm{III}} \rightarrow \mathrm{B}^{\mathrm{IV}}$ transformation is weaker. Molar concentration of $\mathrm{Fe}_{2} \mathrm{O}_{3}$ should be subtracted like $\mathrm{Al}_{2} \mathrm{O}_{3}$ in eq. (2) but with a coefficient less than 1. Taking into account that energy of $\mathrm{Fe}^{3+}-\mathrm{O}$ bond is lower than that of $\mathrm{Al}-\mathrm{O}$ bond by $\sim 3$ times, this coefficient may be suggested to be $\sim 3$ as well. Therefore, in the numerator of the eq. (2) we have to subtract additionally $\sim 0.3 \times\left[\mathrm{Fe}_{2} \mathrm{O}_{3}\right]$. Thus in the presence of $\mathrm{Fe}_{2} \mathrm{O}_{3}$ the $\psi_{\mathrm{B}}$ values for the glasses studied are somewhat lower (Table I). At high concentrations in glasses $\mathrm{Fe}^{3+}$ ions may become network-modifiers with higher coordination number $(\mathrm{CN}=6)$ or form separate crystalline phase - hematite $\left(\mathrm{Fe}_{2} \mathrm{O}_{3}\right)$ or spinel, especially in the presence of $\mathrm{Fe}^{2+}$ ions or different transition metal ions $\left(\mathrm{Mn}^{2+}, \mathrm{Ni}^{2+}, \mathrm{Co}^{2+}, \mathrm{Cu}^{2+}, \mathrm{Zn}^{2+}\right.$ ) as well as $\mathrm{Mg}^{2+}$ and $\mathrm{Al}^{3+}$ ions. $\mathrm{Fe}^{2+}$ ions, if present, are network-modifiers, but often form spinel type phase. 
SRNL-STI-2010-00805

Revision 0

\section{RESULTS AND DISCUSSION}

\section{Chemical Composition and XRD Patterns}

Target and actual chemical compositions of glasses are similar (Table I). Trace of $\mathrm{Fe}_{2} \mathrm{O}_{3}$ is present in glasses which should not contain it due to impurity in chemicals.

All the glasses except glass B1 are X-ray amorphous (Figure 1). XRD pattern of glass B1 contains reflections due to carnegieite. Positions of reflections are a little different from tabular values due to isomorphic substitutions with various ions in its crystal lattice.

Glass B1 has complex texture and contains crystalline phase carnegieite (Figures 1, 3-5). Carnegieite is a high temperature variety of nepheline. Features of chemical composition of this phase will be discussed later.

\section{Optical and SEM/EDS Data}

Glasses A1 and A2 have uniform texture and does not contain any imhomogeneities (Figure 2, 1-3 and Figure 3,1-3). Tables IV and V demonstrate homogeneous distribution of major elements over the bulk of the glass. Optical microscopy study shows that thin section of the glass A1 is predominantly composed of transparent glass. Minor brown-colored glass also occurs. Local aggregations of fine gas bubbles are observed (Figure 2, 4). Glass A2 is nearly optically uniform but is characterized by cracking (Figure 3, 4).

As follows from optical and SEM data areas of devitrified glass B1 have symmetric zoned structure (Figures 4 and 5). The rim is uniform and composed of carnegieite structure crystalline phase. Optical microscopy data in transparent cross-section at single Nichol shows that unlike the glass having lightbrown color carnegieite is colorless and has double reflection in the crossed Nichols. It has also contraction cracks being characteristic of devitrification of glass. This zone with a thickness of 50-70 $\mu \mathrm{m}$ is darker than the glass in backscattered electrons (Figure 5).

Chemical composition of carnegieite is similar to that of glass but does not contain boron (Tables VI and VII). It is calculated well to formula with four oxygen ions (Table VII).

The next symmetric zone (Figures 3-5) has a thickness of about $25 \mu \mathrm{m}$ and clear borders and brown color at single Nichol. It is isotropic in crossed Nichols (Figure 3) and has light-gray color and uniform texture in backscattered electrons (Figure 5). It is different in chemical composition from carnegieite (Table VIII). At similar sodia and silica contents it is depleted with alumina and enriched with ferrous oxides. This phase is also satisfactory recalculated to a formula with four oxygen ions and may be referred to ferrous carnegieite.

The core is dark-brown and nearly opaque in transparent cross-sections (Figure 3). This zone is composed of two phases. Phase-1 having light-gray color on SEM images is aggregate of micro-scales (Figure 5). Its chemical composition was determined by scanning over area and is given in Table IX. Chemical composition and structure of this phase is similar to the previous ones. Phase- 2 of the core is represented by dendrite crystals of spinel up to $10 \mu \mathrm{m}$ in size (Figures 5 and 6). This phase is not appeared on XRD patterns due to low content in glass.

Glasses B2, D1 and D2 are homogeneous (Figures 7-9). Chemical compositions determined by EDS scanning over areas shown on Figure 9 (right) are given in Tables VIII-X. 


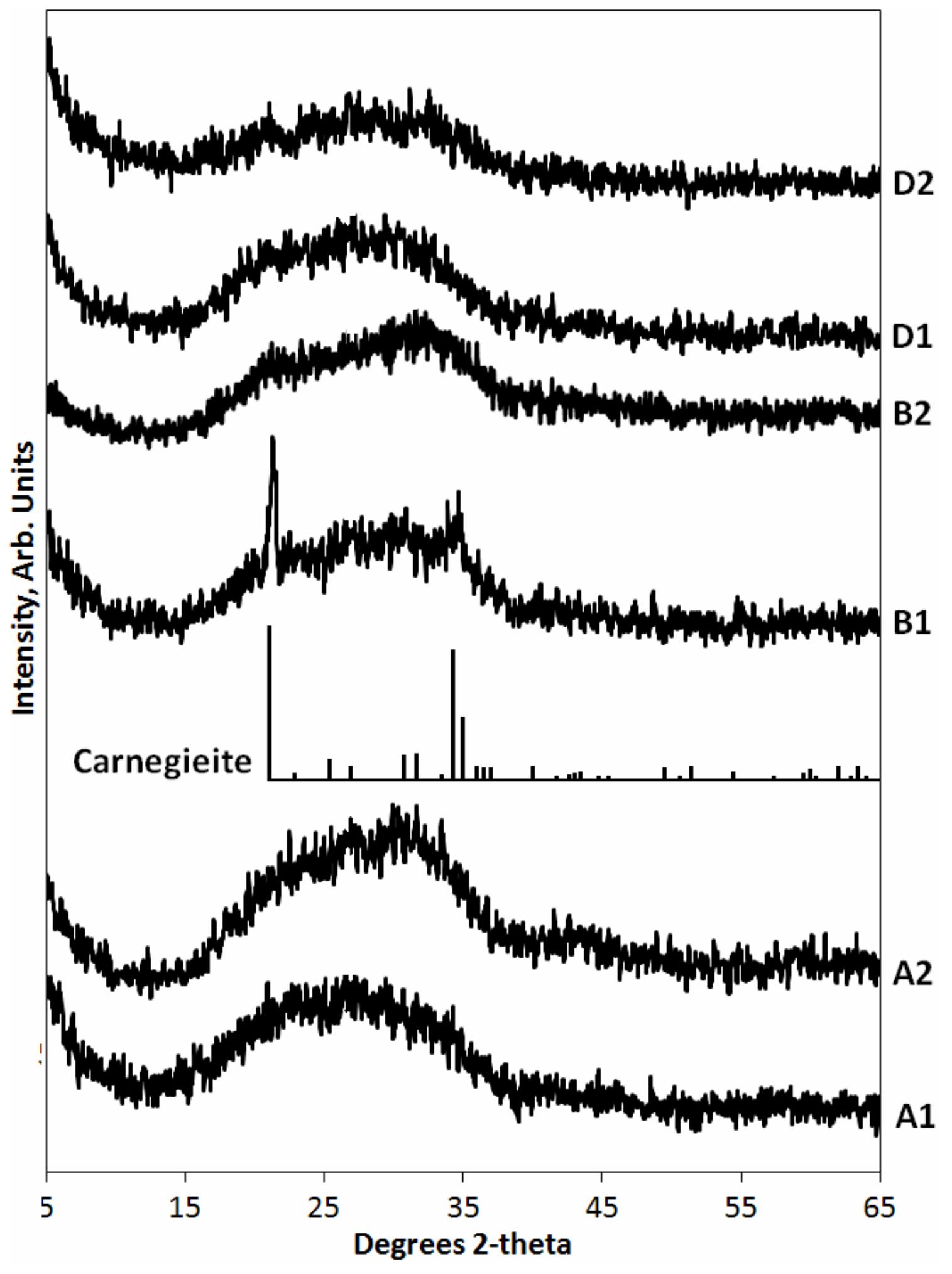

Figure 1. XRD Patterns of Glass Samples. 


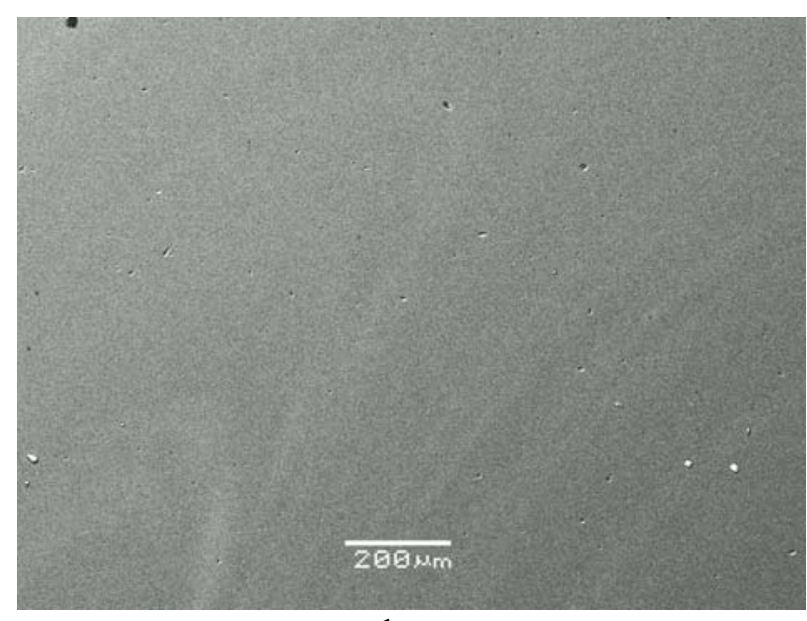

1

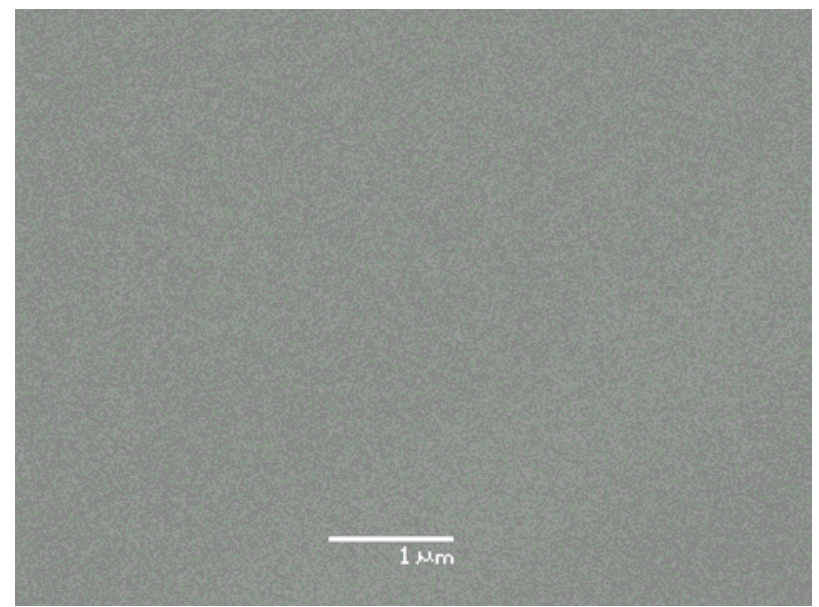

3

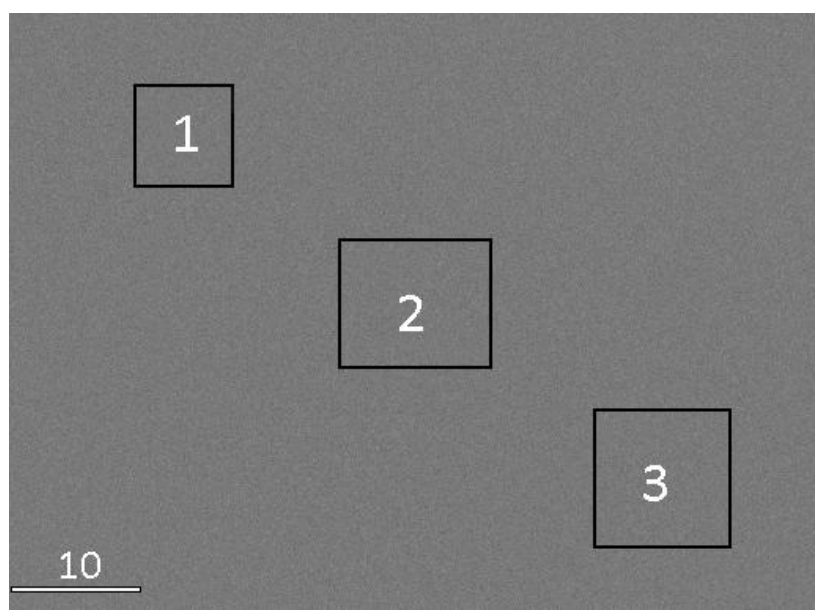

2

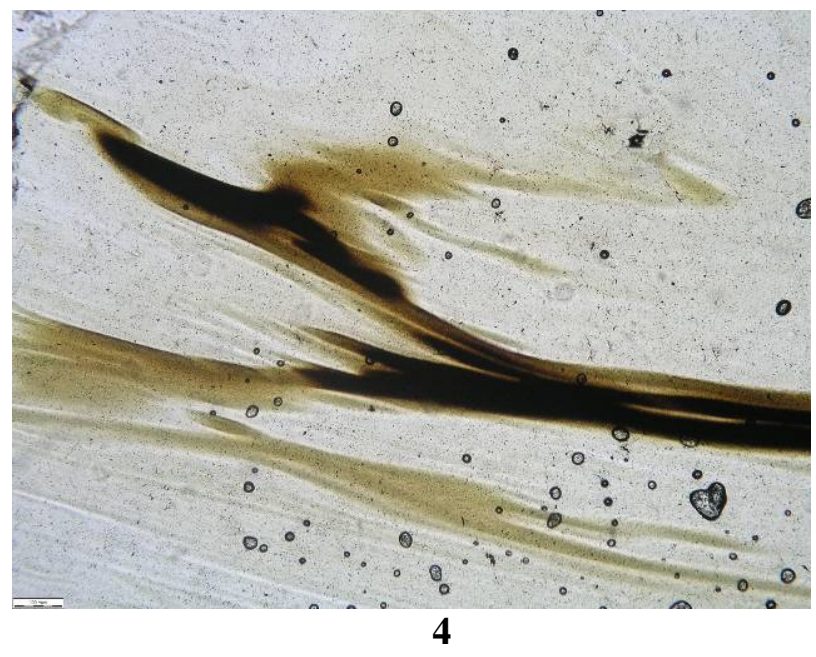

Figure 2. SEM Image in Backscattered Electrons (1-3) and Optical Microscopy Image (4) of Sample A1 at Various Magnifications.

Scale bar on he middle photo is given in microns. 


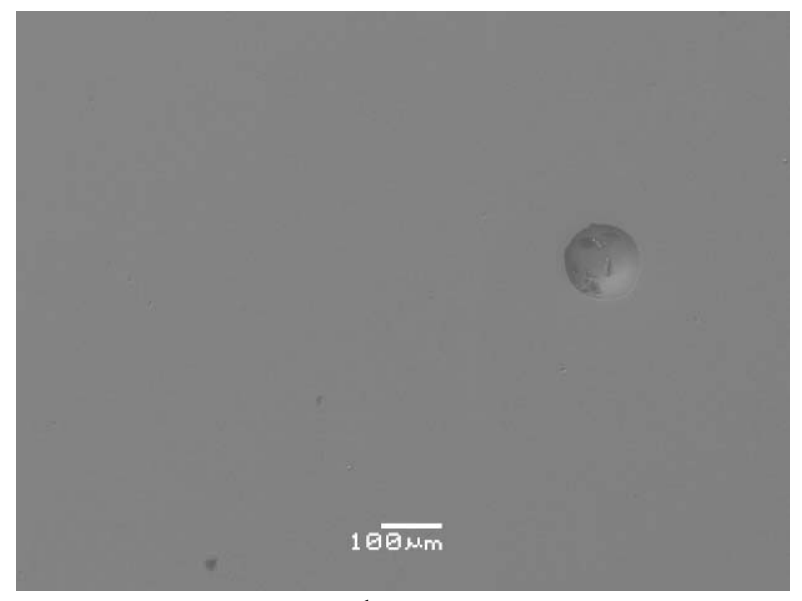

1

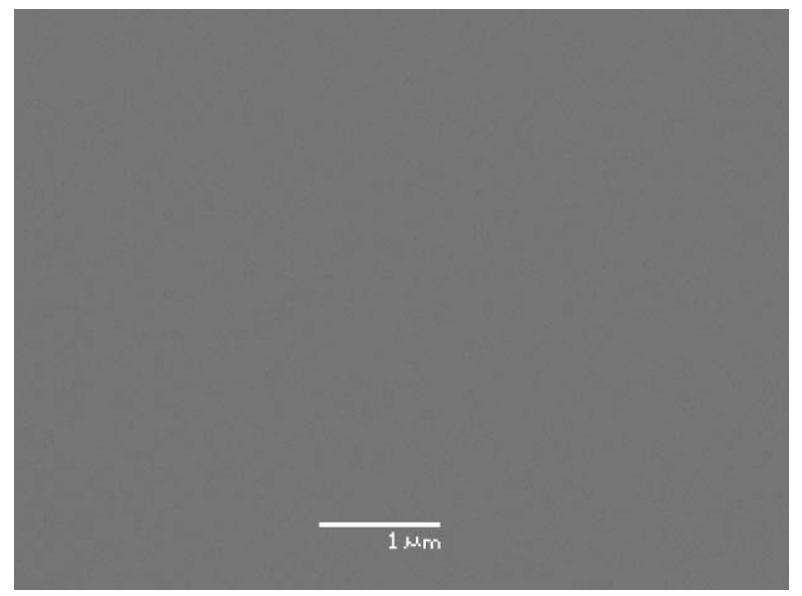

3

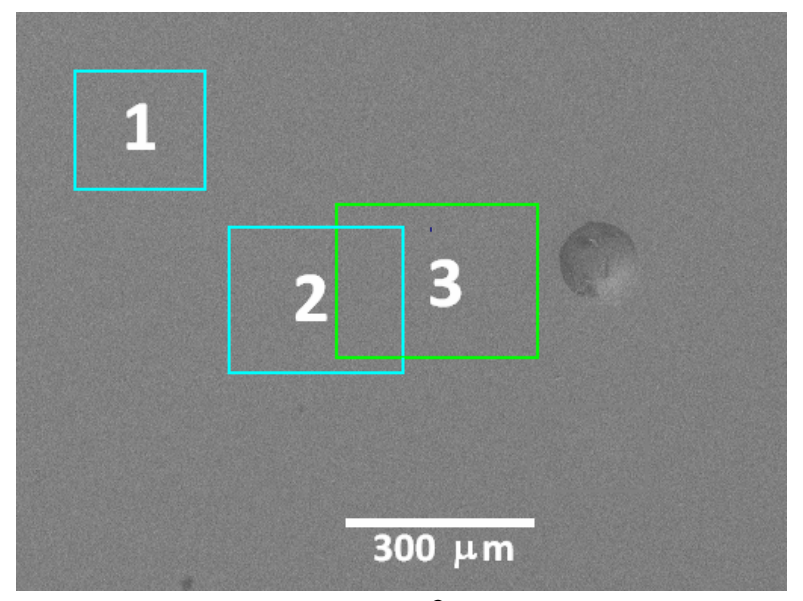

2

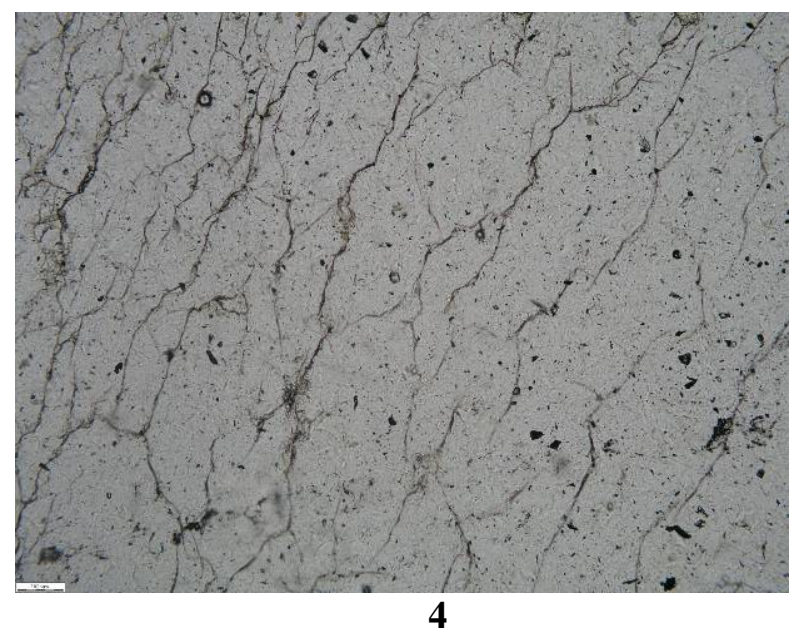

Figure 3. SEM Image in Backscattered Electrons (1-3) and Optical Miscoscopy Image (4) of Sample A2 at Various Magnifications.

Scale bars are given in microns. 
Table IV. Chemical Composition of Sample A1 by SEM/EDS Data.

\begin{tabular}{|c|c|c|c|c|c|c|c|}
\hline \multirow{2}{*}{ Oxides } & \multicolumn{2}{|c|}{ Target } & \multirow{2}{*}{$\begin{array}{c}\text { Actual } \\
\end{array}$} & mol.\% & wt.\% & \multicolumn{3}{|c|}{ Scanned Areas on Fig. 2 } & \multirow{2}{*}{ Average } \\
& 25.0 & 22.27 & 21.45 & 20.74 & 20.71 & 20.51 & 20.65 \\
\hline $\mathrm{Na}_{2} \mathrm{O}$ & 8.5 & 12.46 & 12.50 & 14.11 & 13.8 & 13.98 & 13.96 \\
\hline $\mathrm{Al}_{2} \mathrm{O}_{3}$ & 56.5 & 48.80 & 48.30 & 48.45 & 48.95 & 48.37 & 48.59 \\
\hline $\mathrm{SiO}_{2}$ & 5.0 & 11.48 & 10.35 & 8.66 & 8.40 & 8.26 & 8.44 \\
\hline $\mathrm{Fe}_{2} \mathrm{O}_{3}$ & 5.0 & 5.00 & 4.88 & ND & ND & ND & ND \\
\hline $\mathrm{B}_{2} \mathrm{O}_{3}$ & 5.0 & 100.00 & 97.48 & 91.96 & 91.86 & 91.12 & 91.64 \\
\hline Sum & 100.0 & & & & & \\
\hline
\end{tabular}

ND - not determined

Table V. Chemical Composition of Sample A2 by SEM/EDS Data.

\begin{tabular}{|c|c|c|c|c|c|c|c|}
\hline \multirow{2}{*}{ Oxides } & \multicolumn{2}{|c|}{ Target, } & Actual, & \multicolumn{3}{|c|}{ Scanned areas on Fig. 3 } & Average, \\
& mol.\% & wt.\% & wt.\% & 1 & 2 & 3 & wt.\% \\
\hline $\mathrm{Na}_{2} \mathrm{O}$ & 26.5 & 25.31 & 23.80 & 22.9 & 22.08 & 22.00 & 22.33 \\
\hline $\mathrm{Al}_{2} \mathrm{O}_{3}$ & 9.0 & 14.14 & 14.30 & 15.07 & 15.54 & 15.02 & 15.21 \\
\hline $\mathrm{Fe}_{2} \mathrm{O}_{3}$ & - & - & 0.08 & 0.08 & 0.04 & 0.09 & 0.07 \\
\hline $\mathrm{SiO}_{2}$ & 59.0 & 54.64 & 54.30 & 55.74 & 53.84 & 55.39 & 54.99 \\
\hline $\mathrm{B}_{2} \mathrm{O}_{3}$ & 5.5 & 5.90 & 5.58 & ND & ND & ND & ND \\
\hline $\mathrm{Sum}$ & 100 & 100 & 98.06 & 93.79 & 91.50 & 92.50 & 92.60 \\
\hline
\end{tabular}




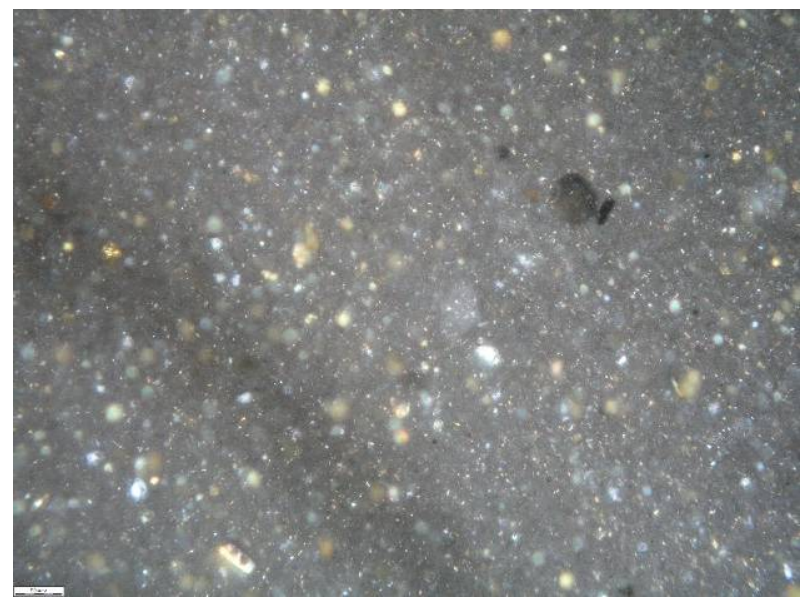

a

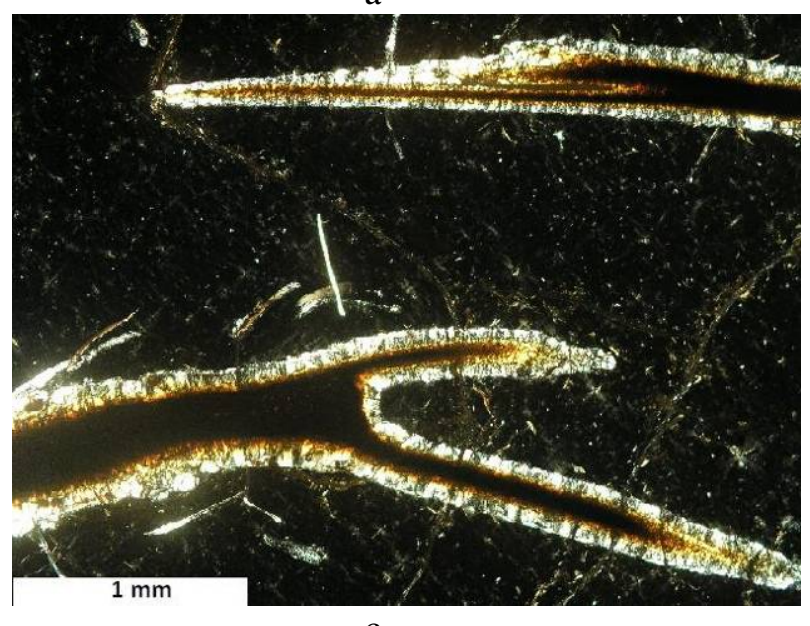

C

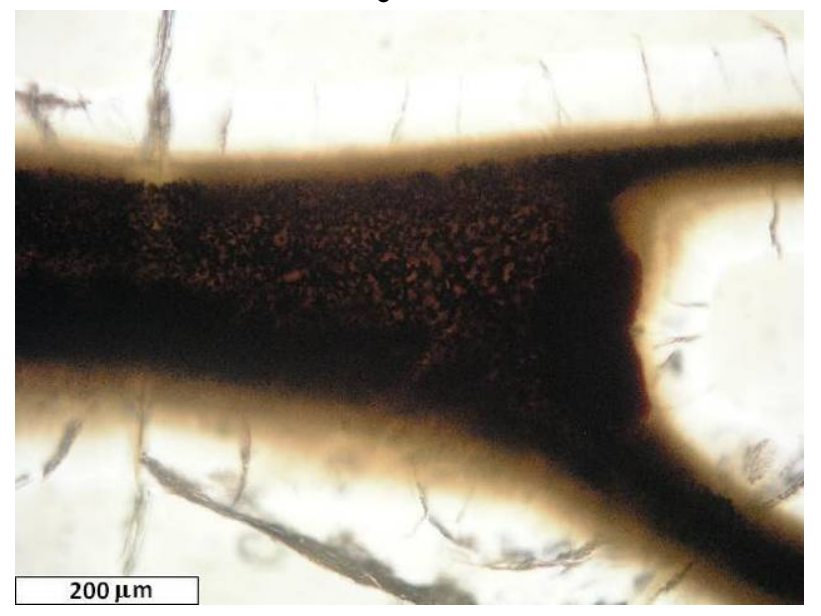

e

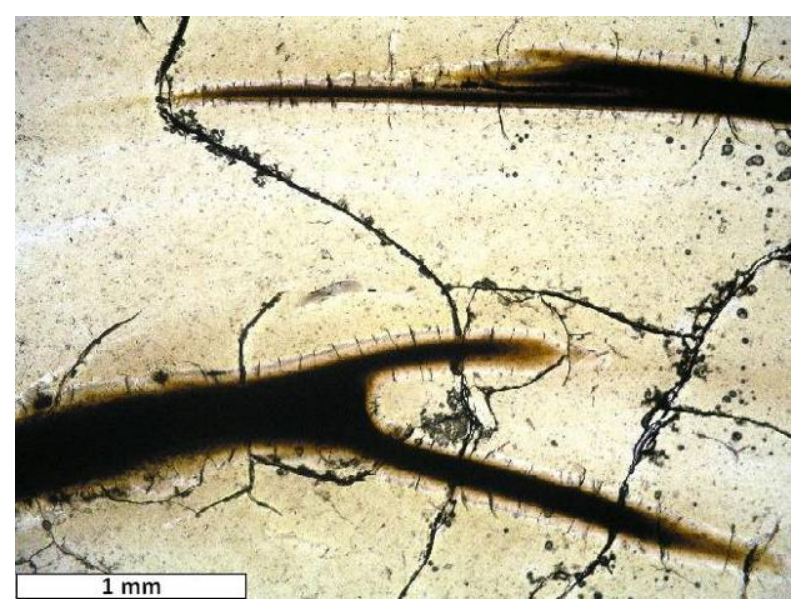

$\mathrm{b}$

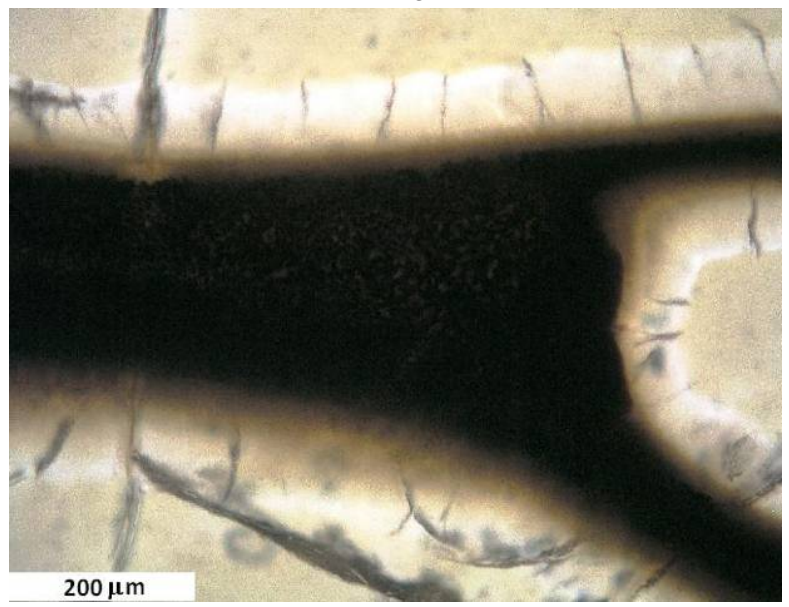

d

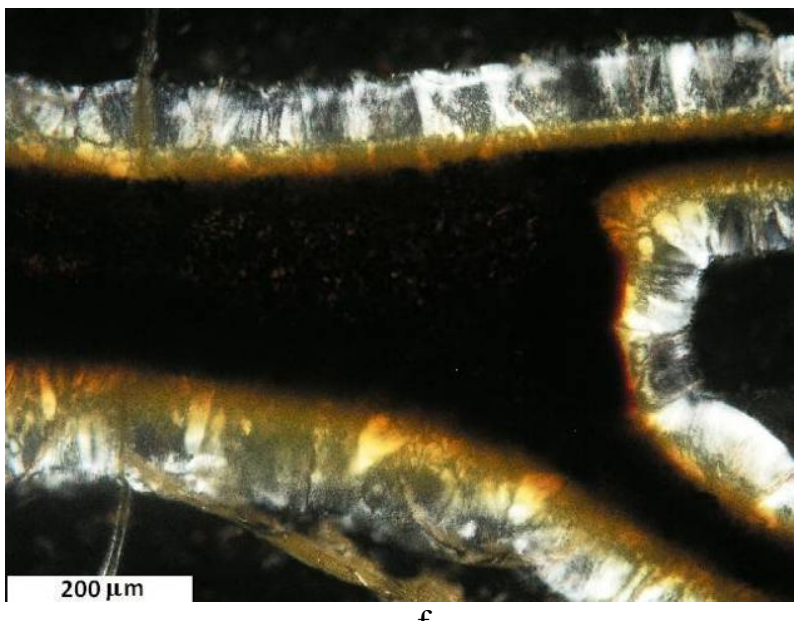

f

Figure 4. Optical Microscopy Images in Transparent Cross-Sections of Sample B1 at One Nichol (a) and in Parallel (b, c, e) and Crossed Nichols (d, f). 

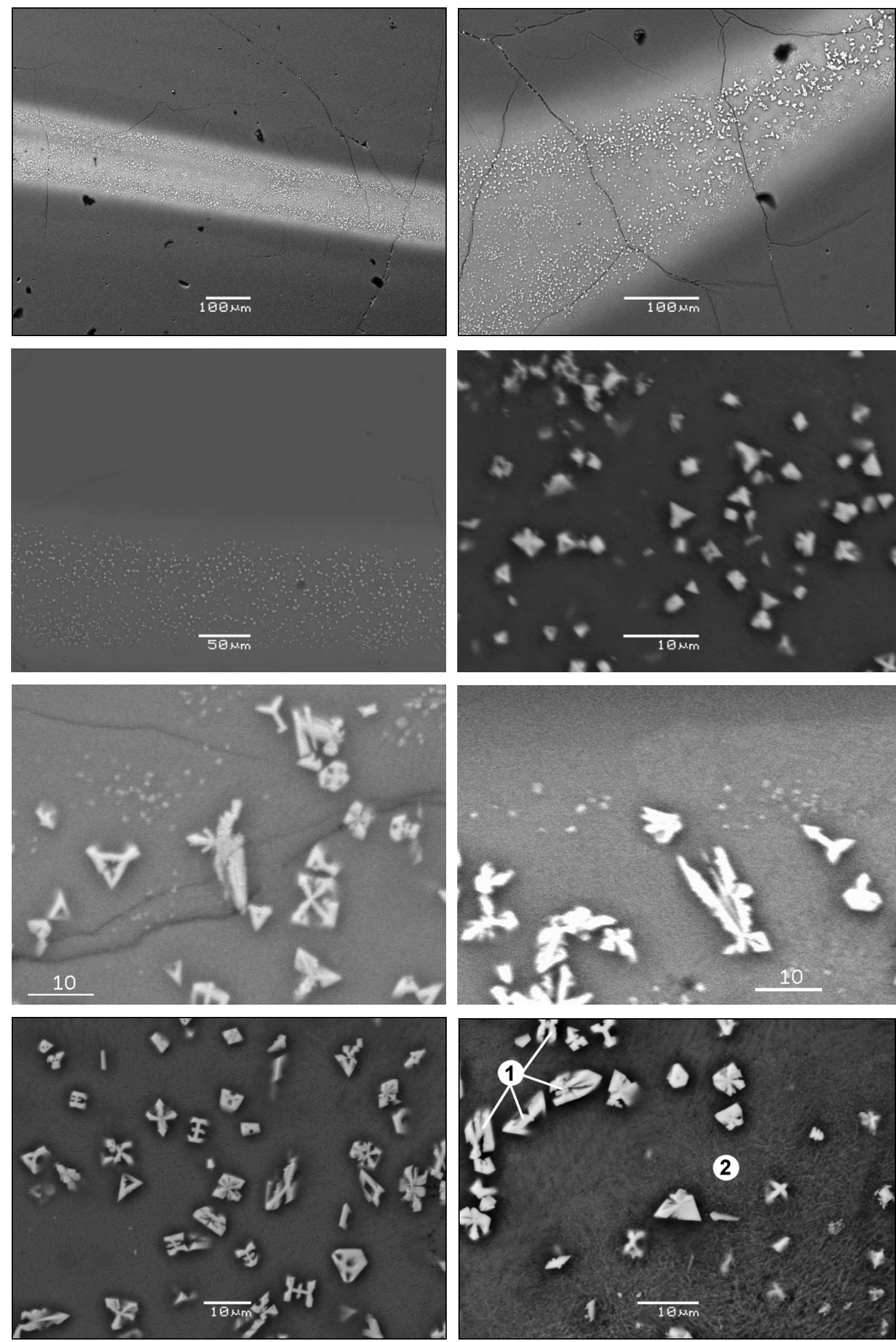

Figure 5. SEM Images in Backscattered Electrons of Sample B1 at Various Magnifications. 


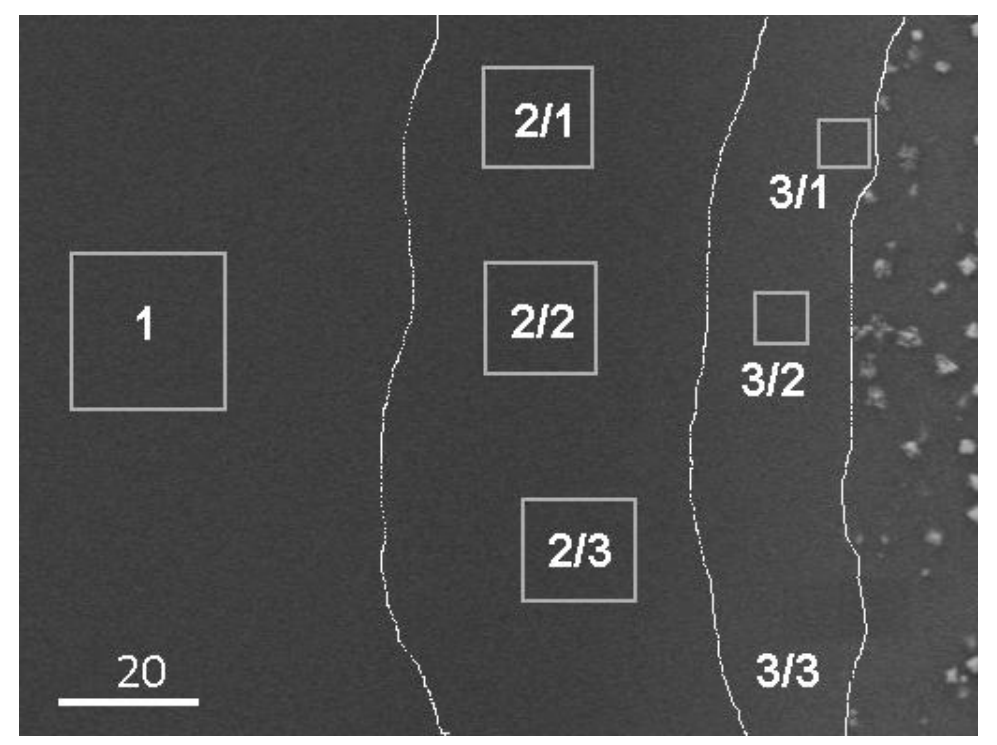

Figure 6. Zones in Bulk of Sample B1. Scale Bar is in Microns. 


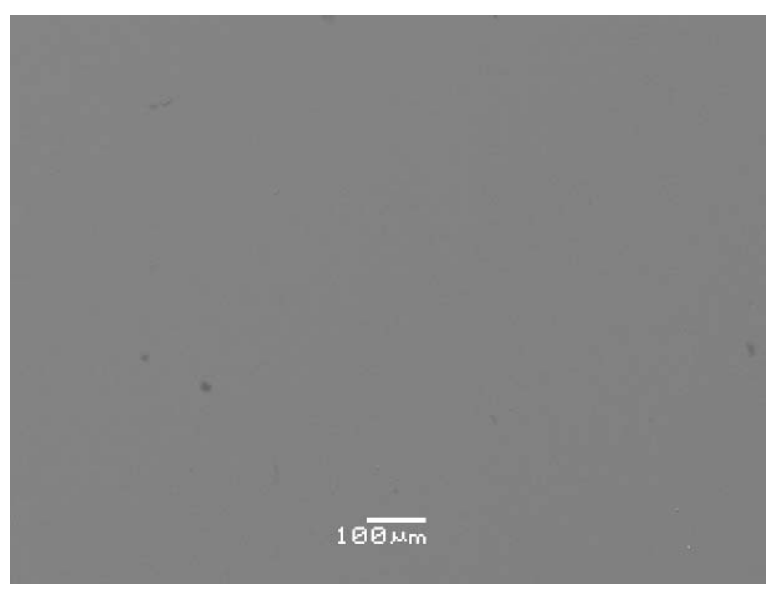

1

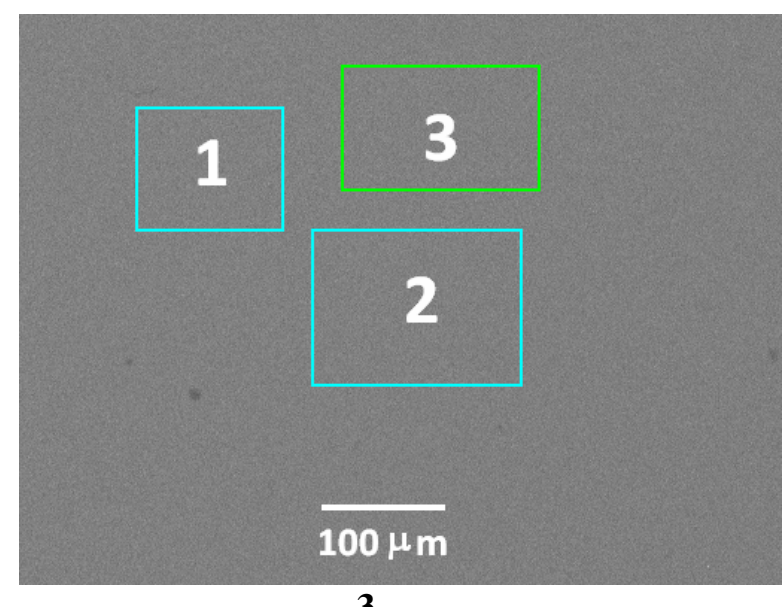

3
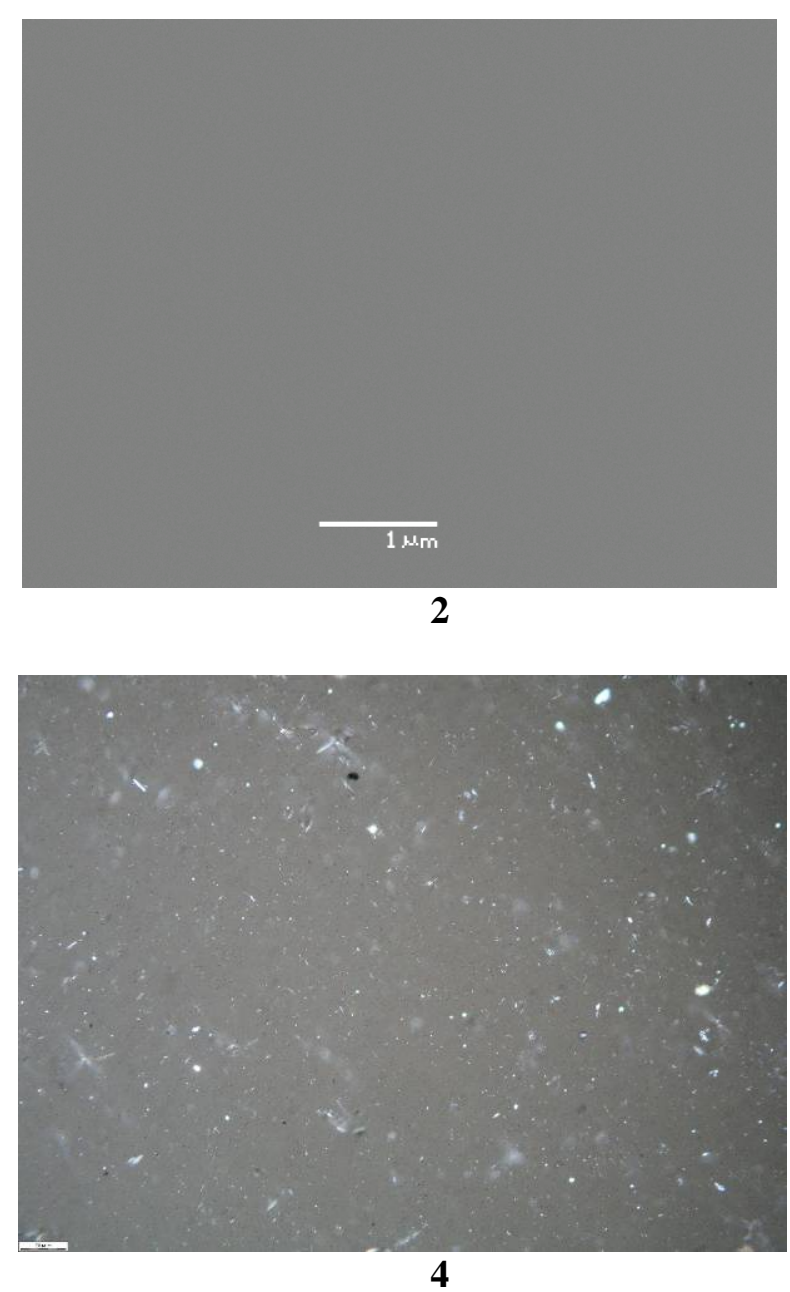

Figure 7. SEM Images in Backscattered Electrons of Sample B2 at Various Magnifications (1-3) and Optical Microscopy Image (4). 
Table VI. Chemical Composition of Various Zones in Sample B1 by SEM/EDS Data.

\begin{tabular}{|c|c|c|c|c|c|c|c|c|c|c|c|c|}
\hline \multirow{2}{*}{ Oxides } & \multicolumn{2}{|c|}{ Target } & Actual & Glass & \multicolumn{4}{|c|}{ Carnegieite } & \multicolumn{3}{c|}{ Carnegieite + Spinel } \\
\cline { 2 - 14 } & mol.\% & wt.\% & wt.\% & 1 & $2 / 1$ & $2 / 2$ & $2 / 3$ & Aver. & $3 / 1$ & $3 / 2$ & $3 / 3$ & Aver. \\
\hline $\mathrm{Na}_{2} \mathrm{O}$ & 29.5 & 25.18 & 24.05 & 23.48 & 22.16 & 22.07 & 21.55 & 21.93 & 19.72 & 18.95 & 19.94 & 19.54 \\
\hline $\mathrm{Al}_{2} \mathrm{O}_{3}$ & 15.0 & 21.06 & 21.00 & 23.34 & 24.12 & 23.74 & 23.65 & 23.84 & 16.75 & 19.73 & 17.41 & 17.96 \\
\hline $\mathrm{SiO}_{2}$ & 46.0 & 38.07 & 36.00 & 37.41 & 37.29 & 37.12 & 37.02 & 37.14 & 29.89 & 32.3 & 29.87 & 30.69 \\
\hline $\mathrm{Fe}_{2} \mathrm{O}_{3}$ & 5.3 & 11.66 & 11.05 & 10.77 & 11.01 & 11.45 & 11.96 & 11.47 & 24.91 & 19.96 & 24.2 & 23.02 \\
\hline $\mathrm{B}_{2} \mathrm{O}_{3}$ & 4.2 & 4.03 & 3.80 & ND & ND & ND & ND & ND & ND & ND & ND & ND \\
\hline $\mathrm{Sum}$ & 100.0 & 100.00 & 95.90 & 95.00 & 94.58 & 94.38 & 94.18 & 94.38 & 91.27 & 90.94 & 91.42 & 91.21 \\
\hline
\end{tabular}

Table VII. Chemical Composition of Various Zones in Sample B2 by SEM/EDS Data.

\begin{tabular}{|c|c|c|c|c|c|c|c|}
\hline \multirow{2}{*}{ Oxides } & \multicolumn{2}{|c|}{ Target, } & \multirow{2}{*}{$\begin{array}{c}\text { Actual, } \\
\text { wt.\% }\end{array}$} & \multicolumn{3}{|c|}{ Scanned areas on Fig. 7, wt.\% } & \multirow{2}{*}{$\begin{array}{c}\text { Average, } \\
\text { wt. \% }\end{array}$} \\
\hline & mol.\% & wt.\% & & 1 & 2 & 3 & \\
\hline $\mathrm{Na}_{2} \mathrm{O}$ & 31.0 & 28.34 & 26.80 & 25.52 & 24.34 & 24.86 & 24.91 \\
\hline $\mathrm{Al}_{2} \mathrm{O}_{3}$ & 16.0 & 24.06 & 24.05 & 28.19 & 26.5 & 26.78 & 27.16 \\
\hline $\mathrm{Fe}_{2} \mathrm{O}_{3}$ & - & - & 0.12 & 0.13 & 0.08 & 0.09 & 0.10 \\
\hline $\mathrm{SiO}_{2}$ & 48.5 & 42.98 & 43.30 & 43.56 & 41.3 & 41.02 & 41.96 \\
\hline $\mathrm{B}_{2} \mathrm{O}_{3}$ & 4.5 & 4.62 & 4.35 & ND & ND & ND & ND \\
\hline Sum & 100.0 & 100.00 & 98.62 & 97.40 & 92.22 & 92.75 & 94.13 \\
\hline
\end{tabular}


Table VIII. Chemical Compositions and Formulae of the "Phases" in Sample B1.

\begin{tabular}{|c|c|c|c|c|c|c|}
\hline Oxides & $\begin{array}{c}\text { Target, } \\
\text { mol.\% }\end{array}$ & Target, wt.\% & Actual, wt.\% & Glass & "Phase 1"* & “Phase 2"** \\
\hline $\mathrm{Na}_{2} \mathrm{O}$ & 29.5 & 25.18 & 24.05 & 23.48 & 21.93 & 19.54 \\
\hline $\mathrm{Al}_{2} \mathrm{O}_{3}$ & 15.0 & 21.06 & 21.00 & 23.34 & 23.84 & 17.96 \\
\hline $\mathrm{SiO}_{2}$ & 46.0 & 38.07 & 36.00 & 37.41 & 37.14 & 30.69 \\
\hline $\mathrm{Fe}_{2} \mathrm{O}_{3}$ & 5.3 & 11.66 & 11.05 & 10.77 & 11.00 & 23.02 \\
\hline $\mathrm{B}_{2} \mathrm{O}_{3}$ & 4.2 & 4.03 & 3.80 & He onp. & He oпр. & He опр. \\
\hline $\mathrm{Sum}^{\mathrm{I}}$ & 100.0 & 100.00 & 95.90 & 95.00 & 93.91 & 91.21 \\
\hline $\mathrm{Na}^{+}$ & & & & \multicolumn{3}{|c|}{ Formula Units } \\
\hline $\mathrm{Al}^{3+}$ & & & & 1.21 & 1.13 & 1.10 \\
\hline $\mathrm{Si}^{4+}$ & & & & 0.73 & 0.75 & 0.61 \\
\hline $\mathrm{Fe}^{3+}$ & & & & 0.99 & 0.99 & 0.89 \\
\hline $\mathrm{Total}^{2-}$ & & & & 3.14 & 3.09 & 3.10 \\
\hline $\mathrm{O}^{2-}$ & & & & 4.00 & 4.00 & 4.00 \\
\hline
\end{tabular}

* Phase 1: $\mathrm{Na}_{1.13} \mathrm{Al}_{0.75} \mathrm{Fe}_{0.22} \mathrm{Si}_{0.99} \mathrm{O}_{4}$ - nepheline/carnegieite;

** Phase 2: nepheline/carnegieite + spinel. 


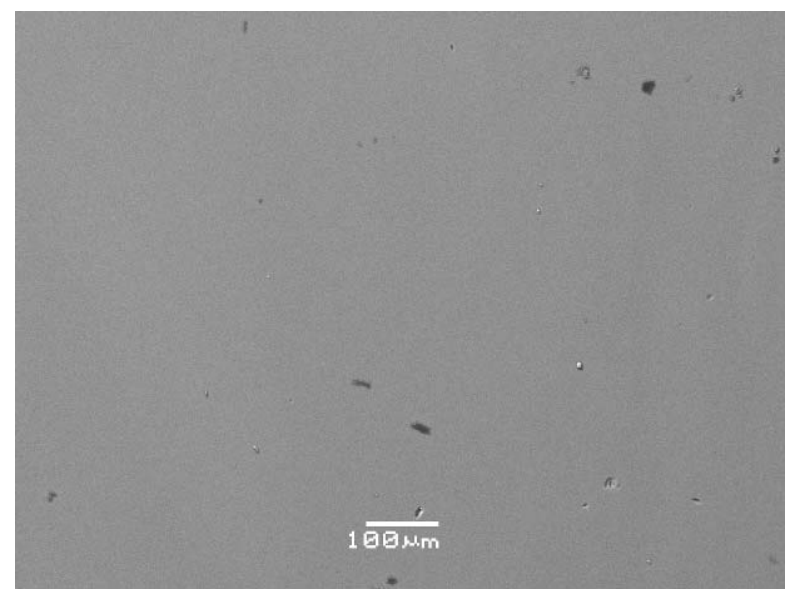

1

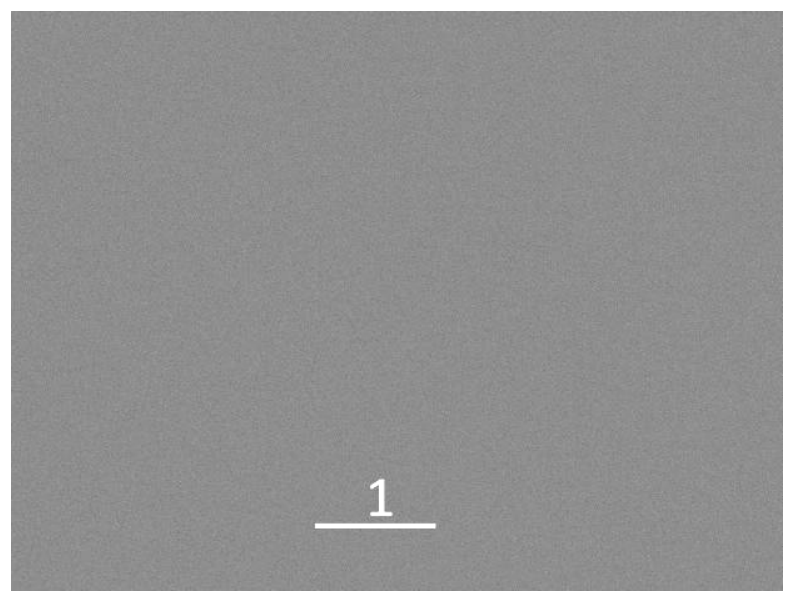

3

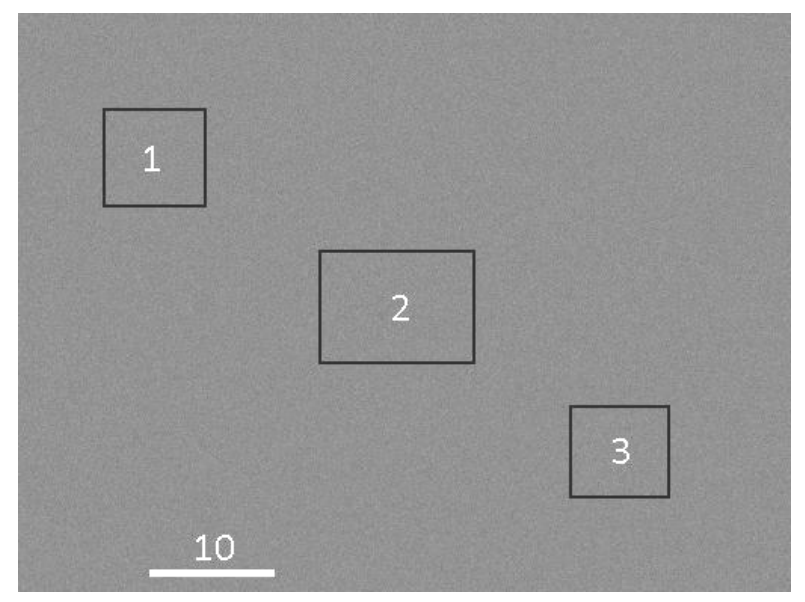

2

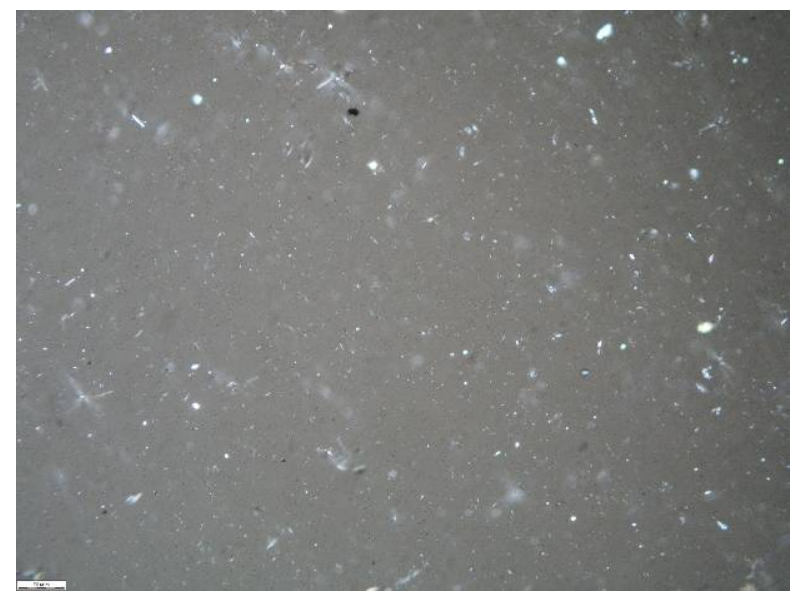

4

Figure 8. SEM Images in Backscattered Electrons (1-3) and Optical Miscroscopy Image (4) of Sample D1.

Scale Bars are given in Microns. 

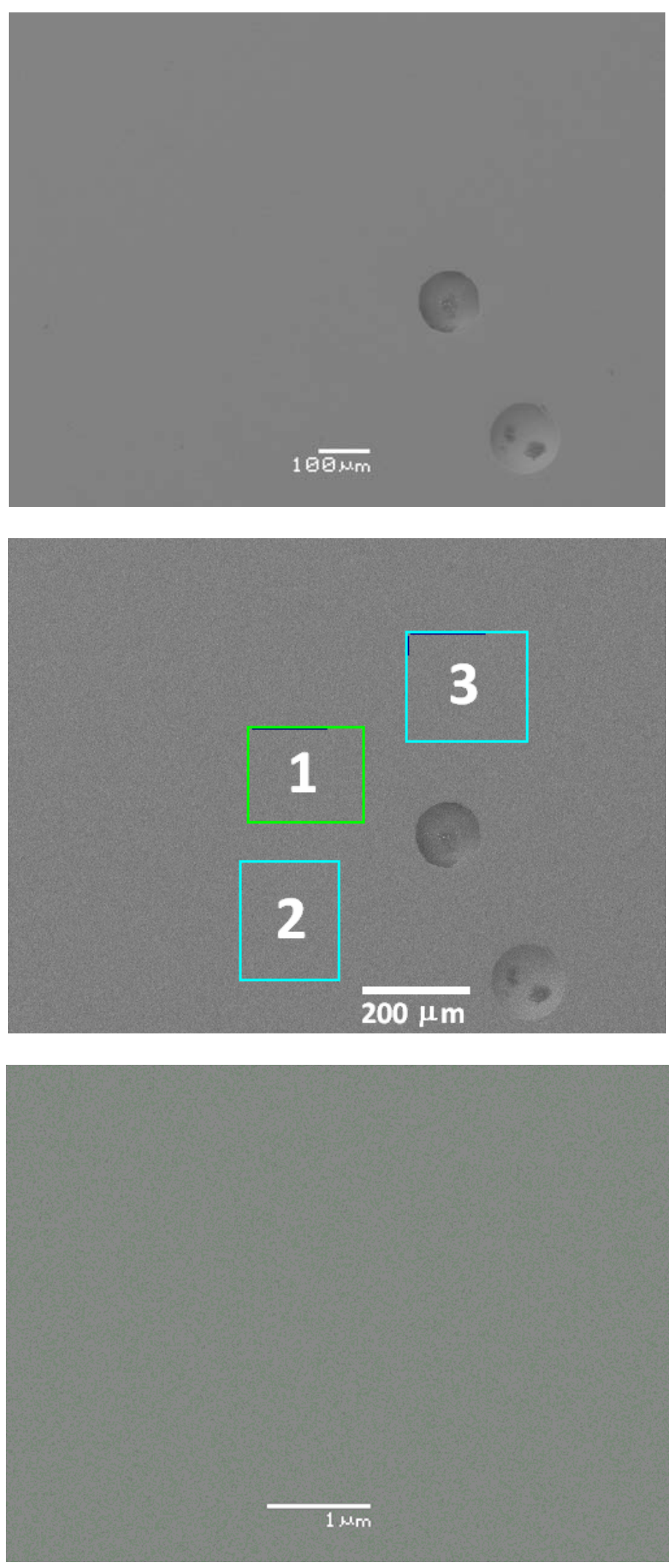

Figure 9. SEM Images in Backscattered Electrons of Sample D2. 
Table IX. Chemical Compositions of Sample D1 by SEM/EDS Data.

\begin{tabular}{|c|c|c|c|c|c|c|c|}
\hline \multirow{2}{*}{ Oxides } & \multicolumn{2}{|c|}{ Target } & \multirow{2}{*}{$\begin{array}{c}\text { Actual } \\
\text { wt.\% }\end{array}$} & \multicolumn{3}{|c|}{ Scanned Areas on Fig. 8} & \multirow{2}{*}{ Average } \\
\hline & mol.\% & wt. \% & & 1 & 2 & 3 & \\
\hline $\mathrm{Na}_{2} \mathrm{O}$ & 8.0 & 6.38 & 20.25 & 18.67 & 19.24 & 18.85 & 18.92 \\
\hline $\mathrm{Al}_{2} \mathrm{O}_{3}$ & 26.4 & 34.62 & 20.60 & 22.08 & 21.98 & 22.00 & 22.02 \\
\hline $\mathrm{SiO}_{2}$ & 35.6 & 27.51 & 37.35 & 36.92 & 36.11 & 36.56 & 36.53 \\
\hline $\mathrm{Fe}_{2} \mathrm{O}_{3}$ & 4.0 & 8.21 & 12.55 & 11.53 & 11.22 & 10.94 & 11.23 \\
\hline $\mathrm{B}_{2} \mathrm{O}_{3}$ & 26.0 & 23.28 & 7.74 & ND & ND & ND & ND \\
\hline Sum & 100.0 & 100.00 & 98.49 & 89.2 & 88.55 & 88.35 & 88.70 \\
\hline
\end{tabular}

Table X. Chemical Compositions of Sample D2 by SEM/EDS Data.

\begin{tabular}{|c|c|c|c|c|c|c|c|}
\hline \multirow{2}{*}{ Oxides } & \multicolumn{2}{|c|}{ Target } & \multirow{2}{*}{$\begin{array}{c}\text { Actual } \\
\text { wt.\% }\end{array}$} & \multicolumn{3}{|c|}{ Scanned Areas on Fig. 9} & \multirow{2}{*}{ Average } \\
\hline & mol.\% & wt.\% & & 1 & 2 & 3 & \\
\hline $\mathrm{Na}_{2} \mathrm{O}$ & 26.5 & 24.10 & 22.95 & 20.88 & 19.59 & 20.52 & 20.33 \\
\hline $\mathrm{Al}_{2} \mathrm{O}_{3}$ & 16.0 & 23.94 & 23.50 & 25.93 & 24.93 & 25.93 & 25.6 \\
\hline $\mathrm{SiO}_{2}$ & 48.5 & 42.77 & 42.35 & 42.45 & 40.68 & 42.95 & 42.03 \\
\hline $\mathrm{Fe}_{2} \mathrm{O}_{3}$ & - & - & 0.05 & 0.04 & 0.06 & 0.05 & 0.05 \\
\hline $\mathrm{B}_{2} \mathrm{O}_{3}$ & 9.0 & 9.19 & 8.98 & ND & ND & ND & ND \\
\hline Sum & 100.0 & 100.00 & 97.83 & 89,30 & 85,26 & 89,45 & 88,01 \\
\hline
\end{tabular}




\section{Effect of Etching on the Structure of the Surface of Glasses}

The polished surfaces of the samples A1, A2, B1, B2, D1 and D2 were etched with $0.1 \mathrm{M} \mathrm{HCl}$ for 1 day and studied by SEM/EDS.

Surface of the glasses after etching is corroded (Figures 10-15). Chemical compositions of corroded layer and unaltered bulk may be determined in the strongest corroded areas (Tables XI and XII).

As follows from theoretical consideration, glasses A1, A2, B1 and B2 should not have a tendency to liquid-liquid phase separation because the $\psi_{\mathrm{B}}$ values for their composition significantly exceed 1 . Corrosion of these glasses proceeds by conventional mechanism with a damage of their surface layers (Figures 10-13) and formation of a rim enriched with silica and depleted with alkali ions. The strongest corrosion takes place along the fractures on the glass surface (Figure 11).

Nevertheless, drop-type structure was observed after etching of the surface of glass B2 (Figure 12) that suggests occurrence of liquid-liquid phase separation: the structure of the glass B2 consists of areas with higher and lower durability to acid attack and, therefore, different in chemical composition. The diameter of the drops is widely varied and reaches $\sim 100 \mu \mathrm{m}$. The drops seems to be higher than the matrix glass, therefore, they have higher chemical durability. 

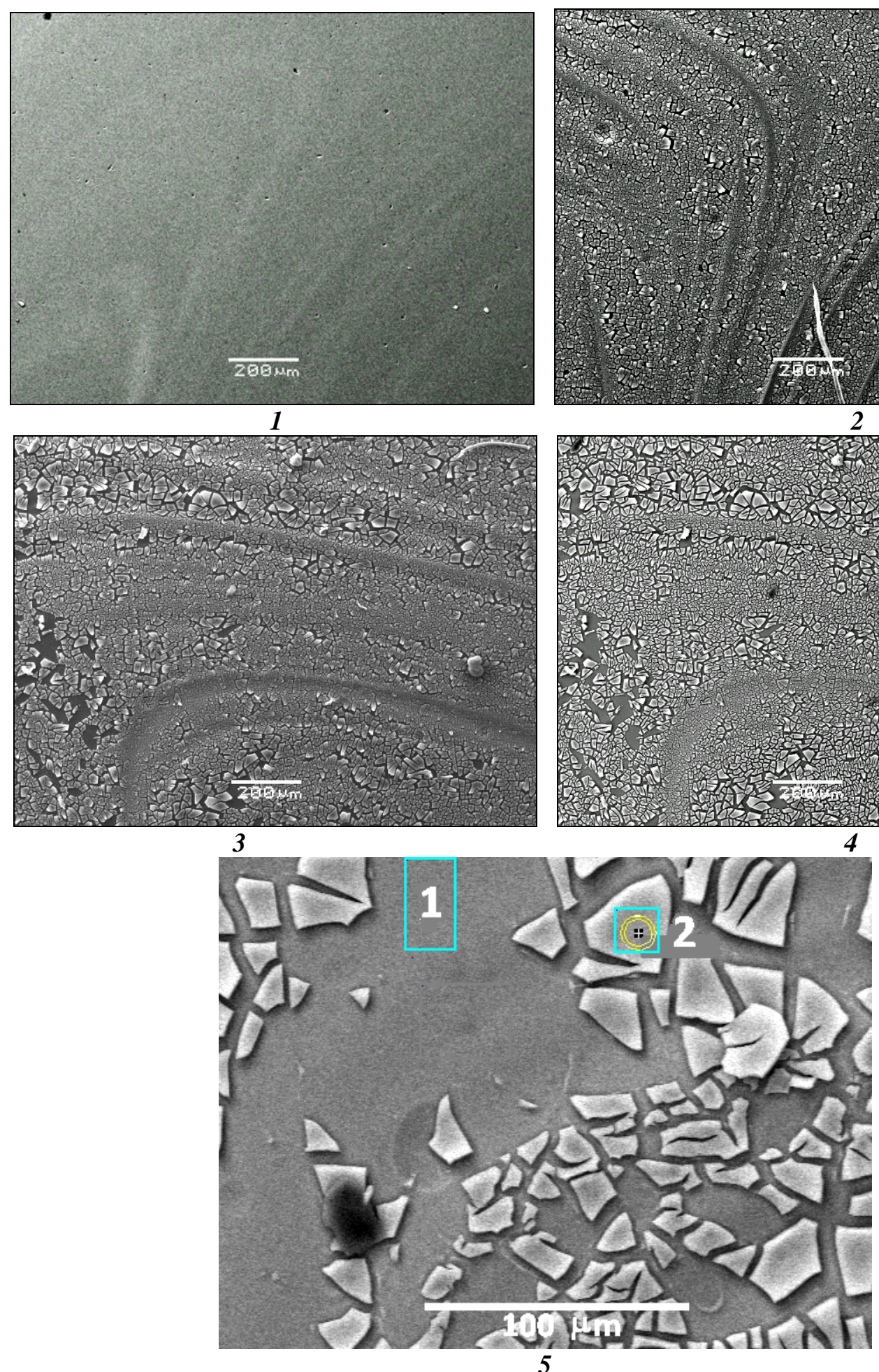

Figure 10. BSE SEM Images of the Surface of the Glass A1 Before (1) and After (2-5) Etching in 0.1 M HCl.

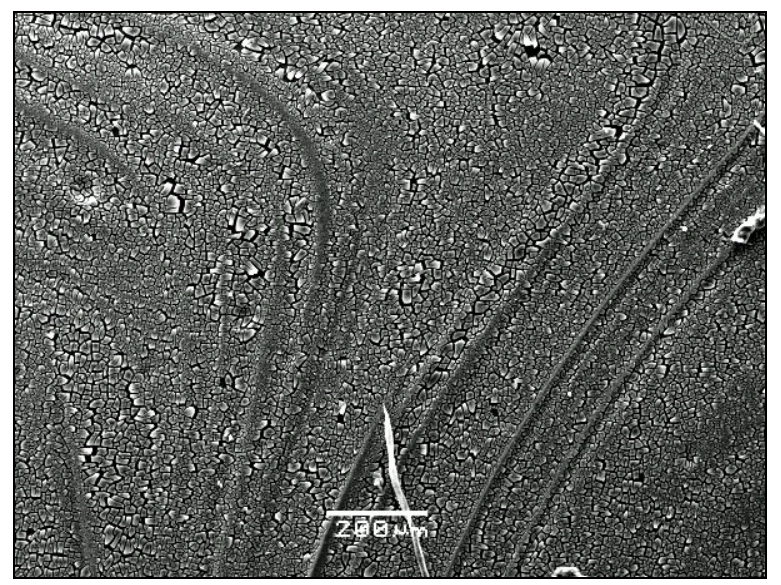

2

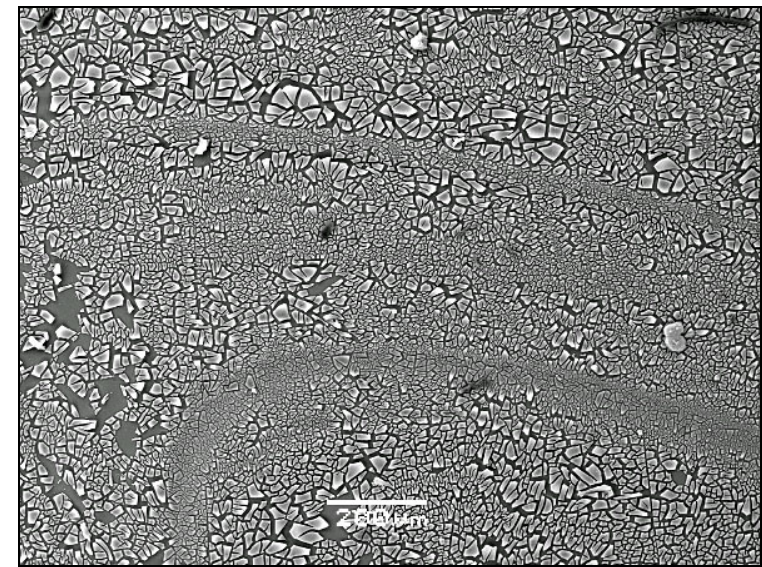

4 


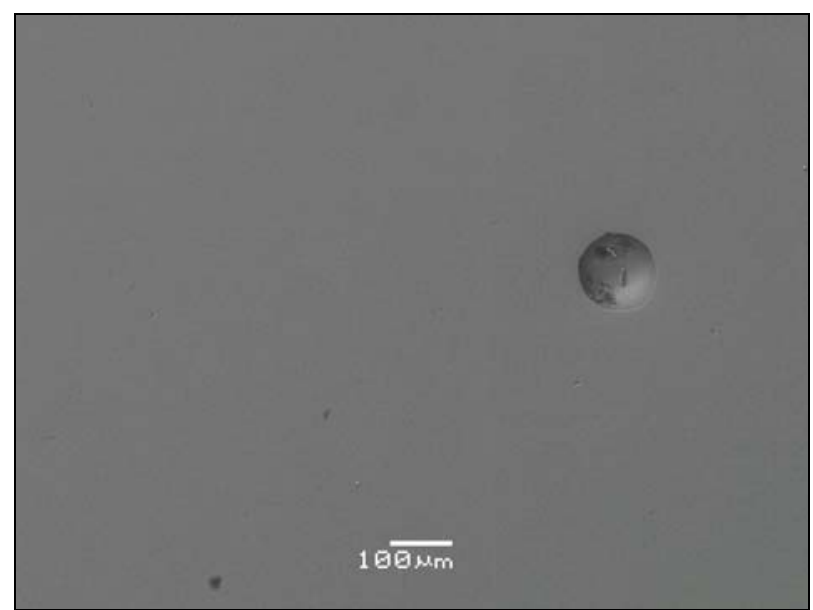

1
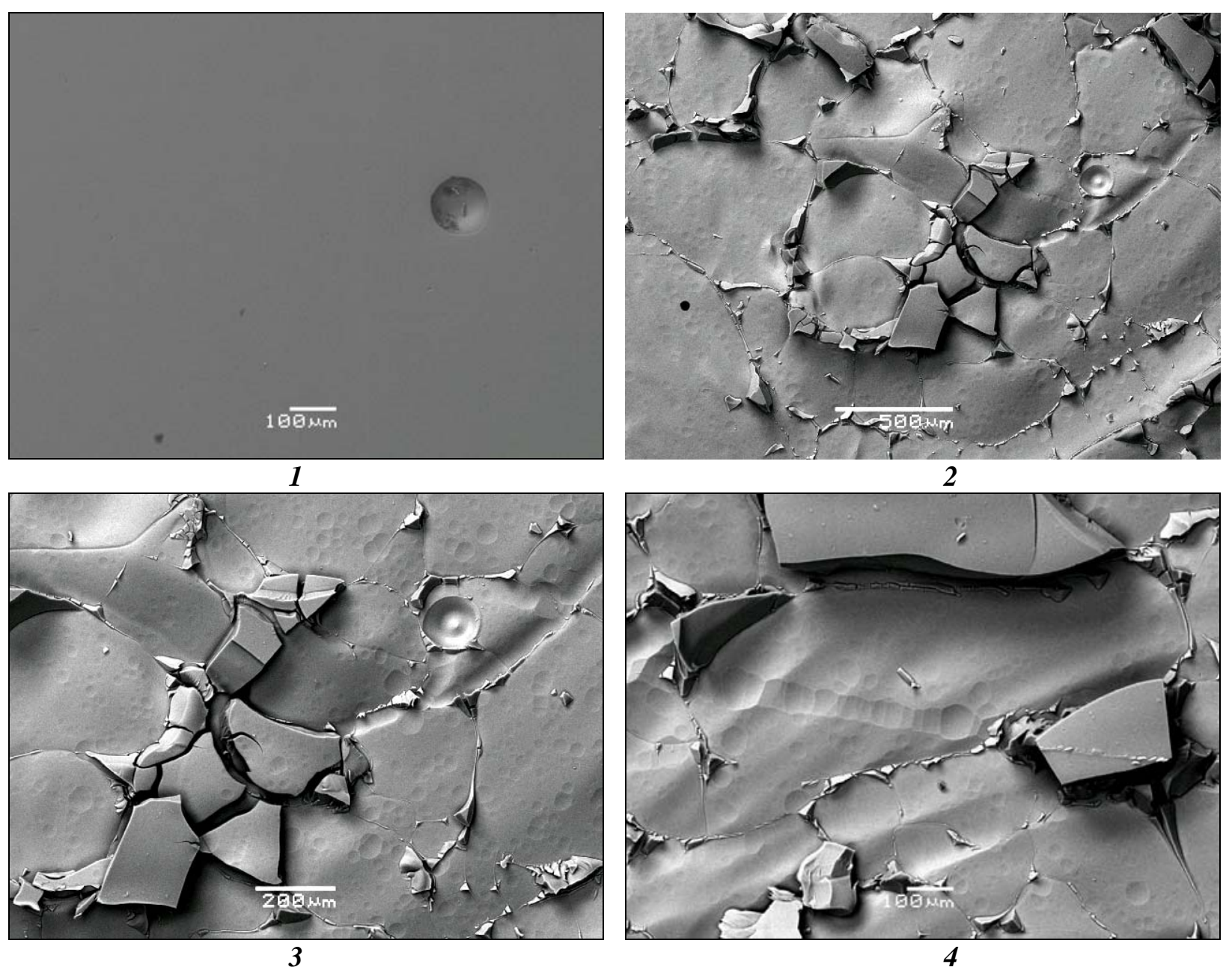

2

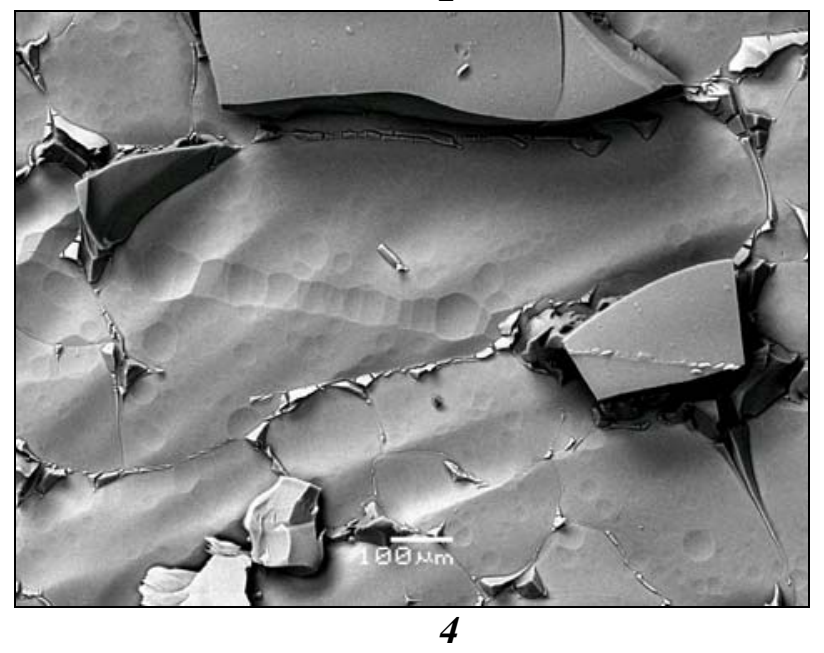

Figure 11. BSE SEM Images of the Surface of the Glass A2 Before (1) and After (2-5) Etching in 0.1 M HCl. 


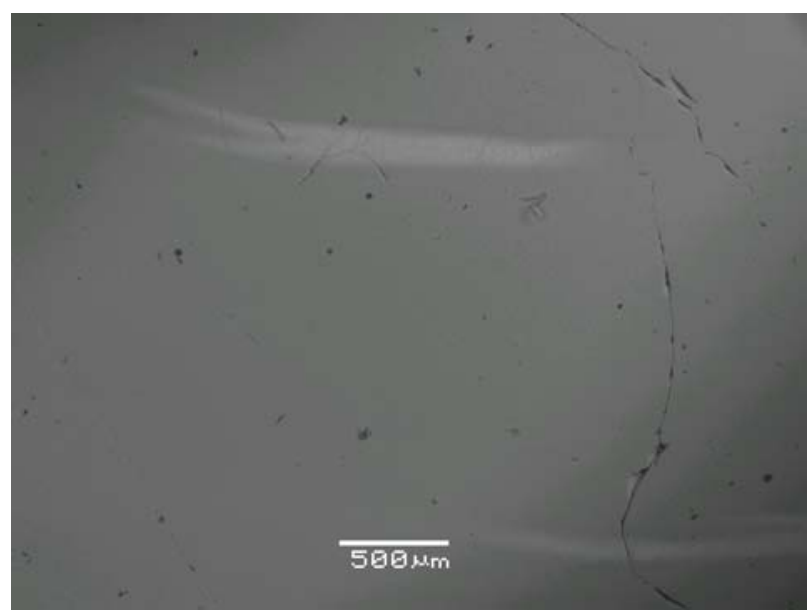

1

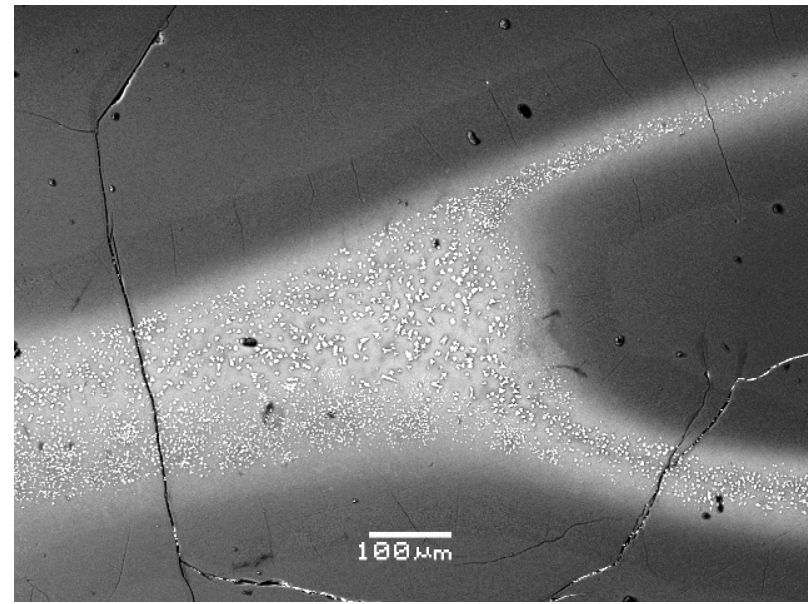

3

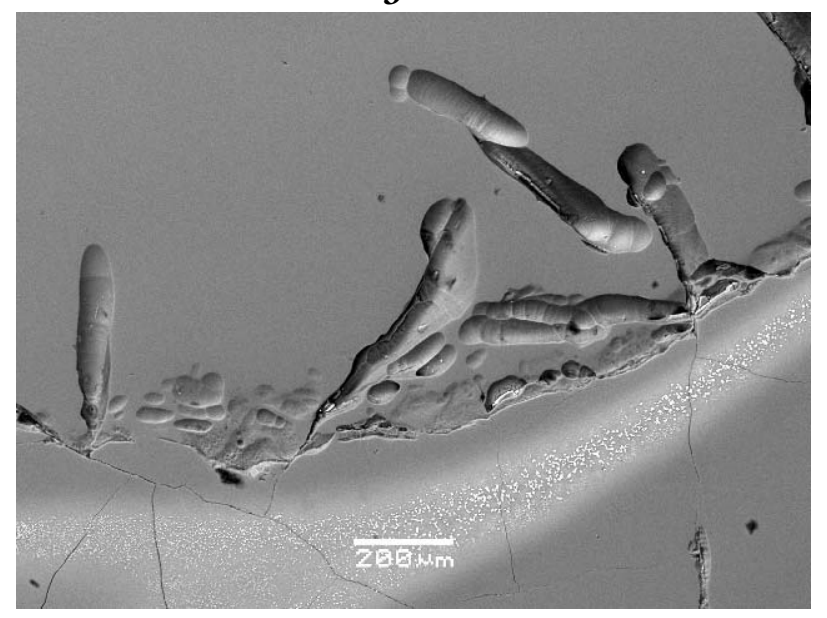

5

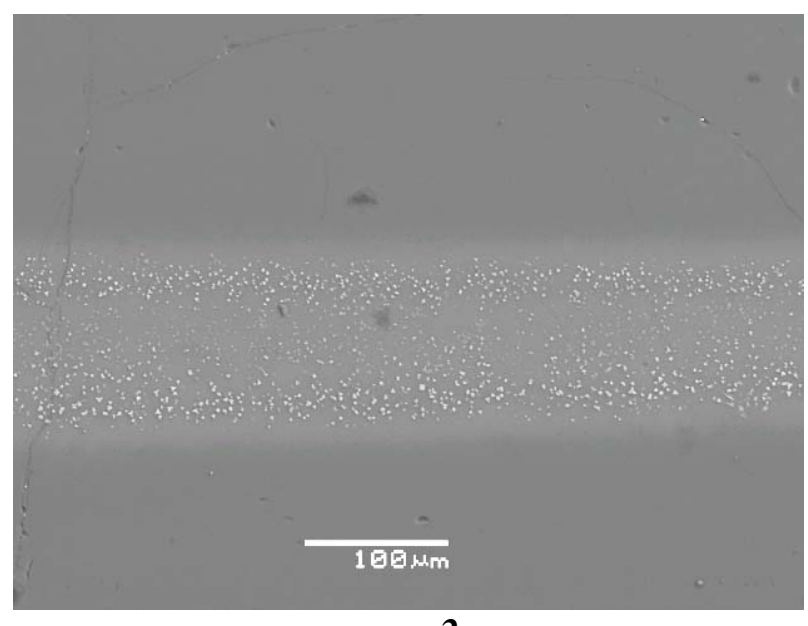

2

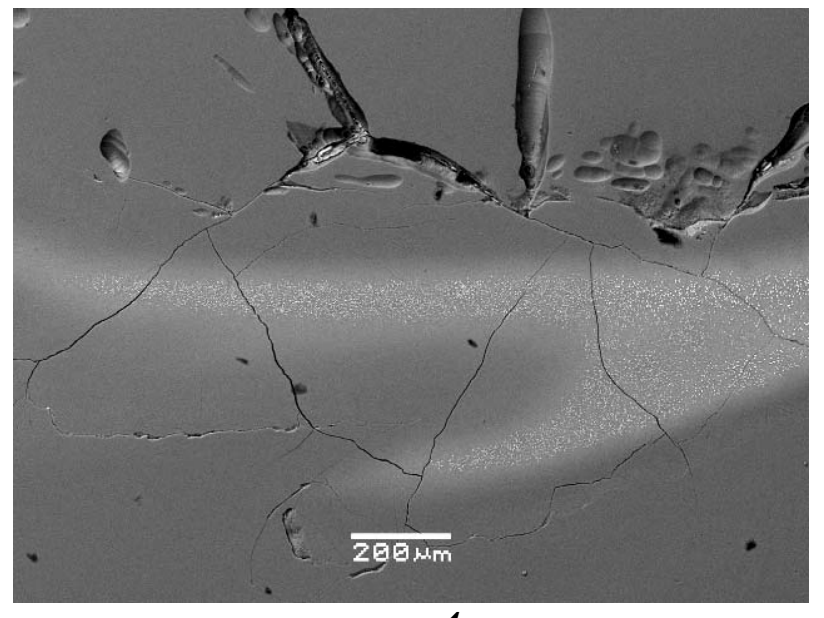

4

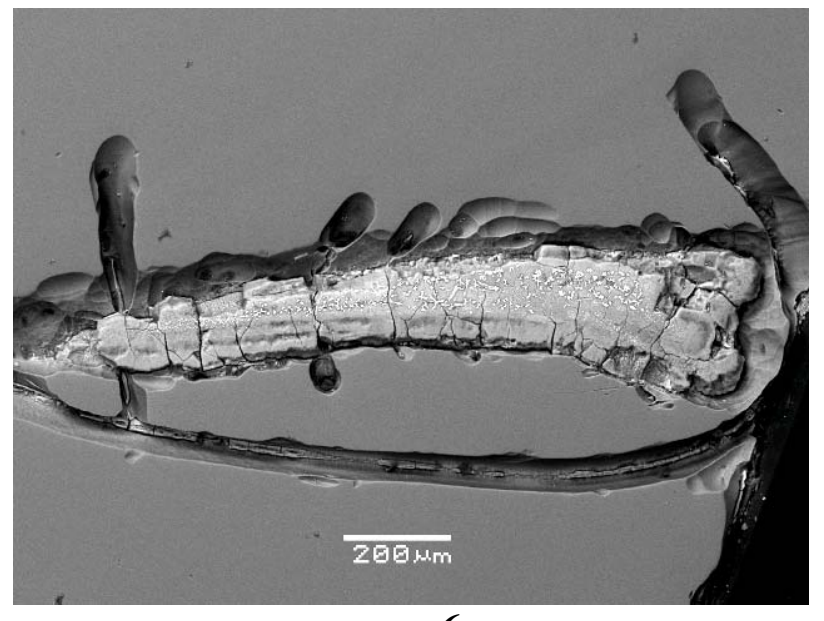

6

Figure 12. BSE SEM Images of the Surface of the Glass B1 Before (1-3) and After (3-6) Etching in 0.1 M HCl. 

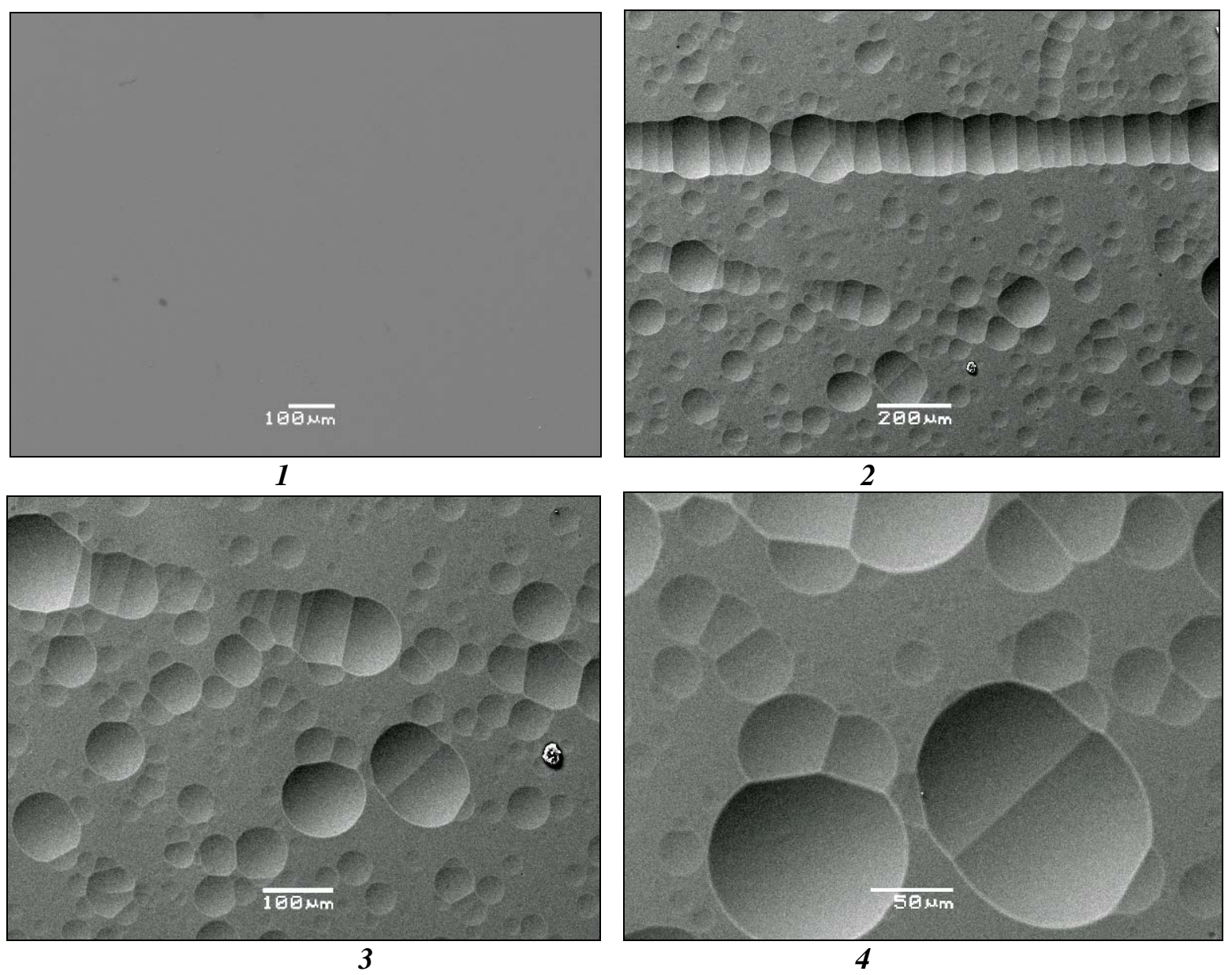

Figure 13. BSE SEM Images of the Surface of the Glass B2 Before (1-3) and After (3-6) Etching in 0.1 M HCl. 

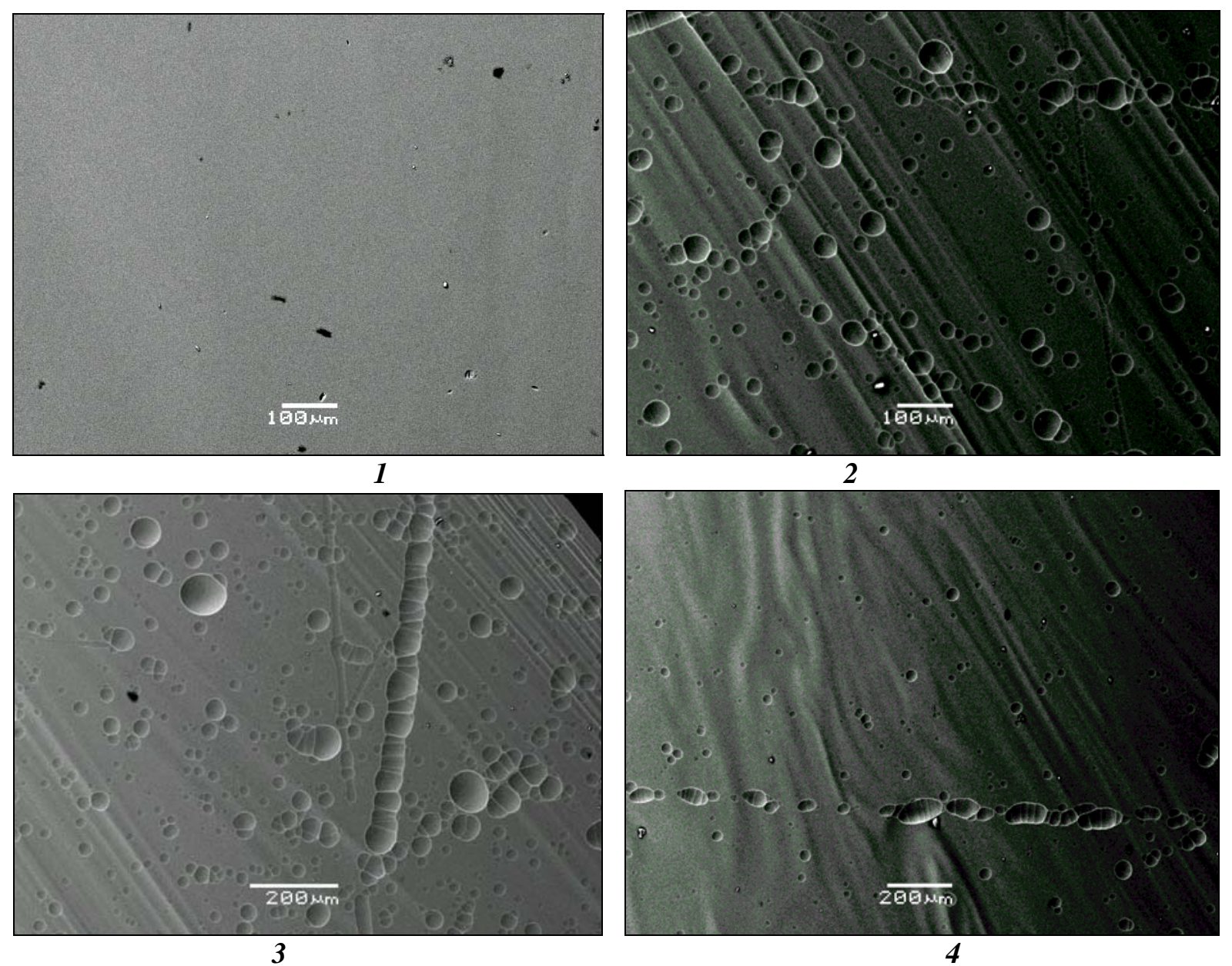

Figure 14. BSE SEM Images of the Surface of the Glass D1 Before (1) and After (2-4) Etching in 0.1 M HCl. 

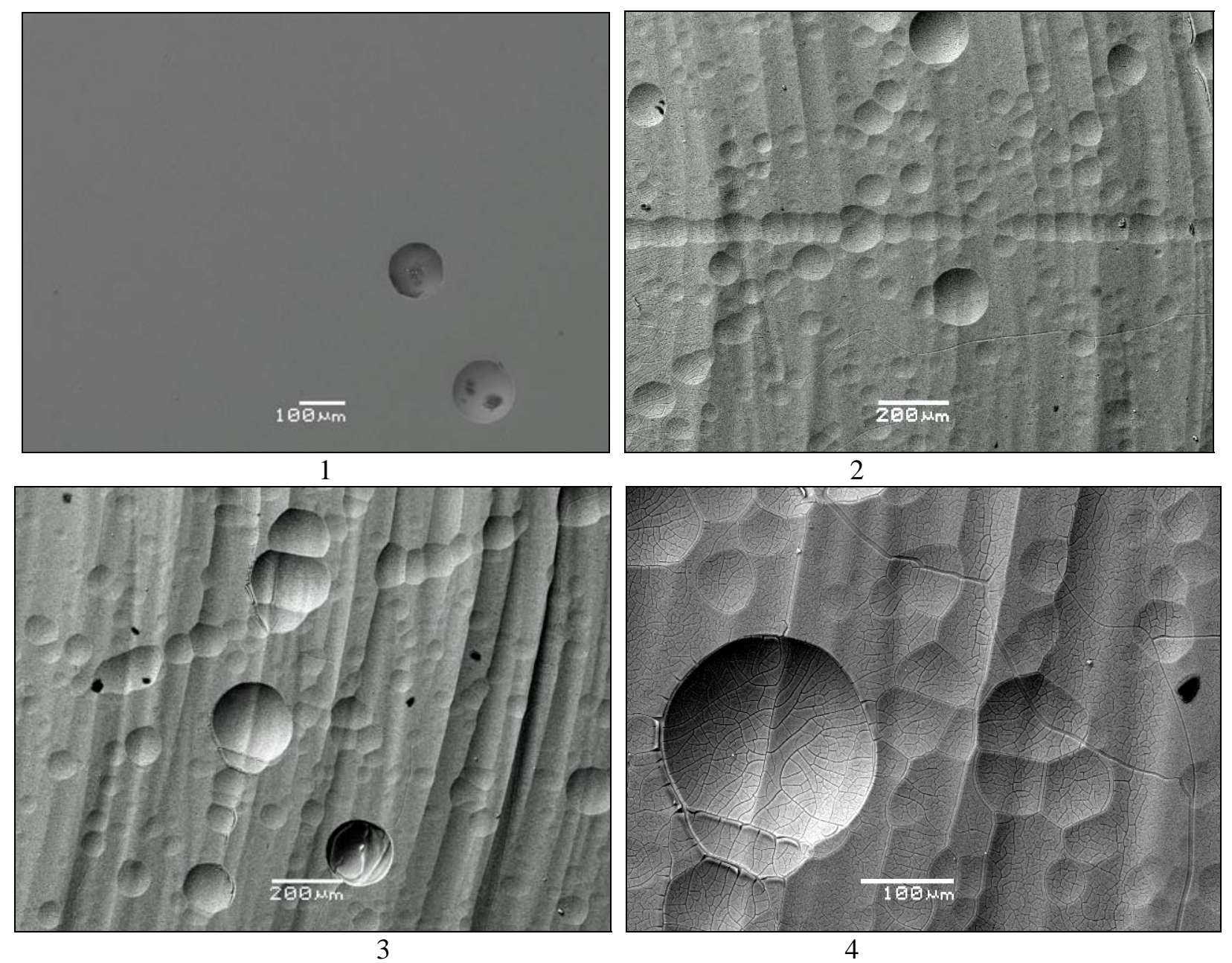

Figure 15. BSE SEM Images of the Surface of the Glass D2 Before (1) and After (2-4) Etching in 0.1 M HCl. 
Table XI. Chemical Composition (wt.\%) by EDS of Various Areas on the Etched Surfaces of the Glass A1.

\begin{tabular}{|c|c|c|c|c|c|}
\hline Oxides & 1 (core) & 2a (rim) & 2b (rim) & 2c (rim) & Average (rim) \\
\hline $\mathrm{Na}_{2} \mathrm{O}$ & 19.14 & 1.57 & - & - & 0.52 \\
\hline $\mathrm{Al}_{2} \mathrm{O}_{3}$ & 14.08 & 2.88 & 1.61 & 2.49 & 2.33 \\
\hline $\mathrm{SiO}_{2}$ & 50.71 & 40.36 & 38.65 & 44.63 & 41.21 \\
\hline $\mathrm{CaO}$ & - & 2.83 & 2.77 & 3.02 & 2.87 \\
\hline $\mathrm{TiO}_{2}$ & - & 3.40 & 3.69 & 3.58 & 3.56 \\
\hline $\mathrm{Fe}_{2} \mathrm{O}_{3}$ & 8.92 & 18.38 & 18.51 & 18.52 & 18.47 \\
\hline $\mathrm{ZnO}_{\mathrm{Sum}}$ & - & 2.81 & 3.10 & 2.81 & 2.91 \\
\hline $\mathrm{B}_{2} \mathrm{O}_{3} *$ & 42.85 & 72.23 & 68.33 & 75.05 & 71.87 \\
\hline & 4.88 & ND & ND & ND & ND \\
\hline
\end{tabular}

* actual content in unaltered glass, ND - not determined.

Table XII. Chemical Composition (wt.\%) by EDS of Various Areas on the Etched Surfaces of the Glass D1.

\begin{tabular}{|c|c|c|c|c|}
\hline Формула & Actual & 1 & 2 & Average \\
\hline $\mathrm{Na}_{2} \mathrm{O}$ & 20.25 & 17.69 & 17.06 & 17.50 \\
\hline $\mathrm{Al}_{2} \mathrm{O}_{3}$ & 20.60 & 21.98 & 19.85 & 20.92 \\
\hline $\mathrm{SiO}_{2}$ & 37.35 & 36.71 & 36.93 & 36.82 \\
\hline $\mathrm{Fe}_{2} \mathrm{O}_{3}$ & 12.55 & 11.87 & 12.87 & 12.37 \\
\hline $\mathrm{B}_{2} \mathrm{O}_{3}$ & 7.73 & ND & ND & ND \\
\hline $\mathrm{Sum}$ & 98.48 & 88.25 & 70.71 & 87.61 \\
\hline
\end{tabular}




\section{IR Spectra of Glasses}

IR spectra of glasses (Figure 16) consist of the bands due to stretching (3100-3600 $\mathrm{cm}^{-1}$ ) and bending modes (1600-1800 $\mathrm{cm}^{-1}$ ) in the molecules of absorbed and structurally bound water, weak bands due to hydrogen bonds in the structure of glasses and numerous bands lower $1600 \mathrm{~cm}^{-1}$ due to stretching and bending modes in the units forming anionic motif of the structure of glasses.

IR spectra of all the glasses within the range of $4000-1600 \mathrm{~cm}^{-1}$ (Figure 8) consist of the bands due to stretching and bending modes in silicon-oxygen, boron-oxygen, aluminum-oxygen and iron-oxygen (in spectra of glasses A1, B1 and D1 only) structural groups. The wavenumber ranges of $1550-1300 \mathrm{~cm}^{-1}$ and $\sim 1260-1270 \mathrm{~cm}^{-1}$ are typical of oscillations in the boron-oxygen groups with trigonally coordinated boron (boron-oxygen triangles $\mathrm{BO}_{3}$ ) [18]. These bands were attributed as components of twice degenerated asymmetric valence $v_{3} \mathrm{O}-\mathrm{B}-\mathrm{O}$ oscillations (stretching modes). The band with components $\sim 710-730$ and 650-670 $\mathrm{cm}^{-1}$ may be associated with twice degenerated asymmetric deformation $\delta\left(v_{4}\right) \mathrm{O}-\mathrm{B}-\mathrm{O}$ vibrations (bending modes) [18]. Strong absorption in both IR and Raman spectra within the range of $1150-850 \mathrm{~cm}^{-1}$ is caused by asymmetric $v_{3}$ oscillations (stretching modes) in silicon-oxygen units bound to zero $\left(850-900 \mathrm{~cm}^{-1}\right)$, one $\left(\sim 900-950 \mathrm{~cm}^{-1}\right)$, two $\left(\sim 950-1050 \mathrm{~cm}^{-1}\right)$, three $\left(\sim 1050-1100 \mathrm{~cm}^{-1}\right)$ and four $\left(\sim 1100-1150 \mathrm{~cm}^{-1}\right)$ neighboring $\mathrm{SiO}_{4}$ tetrahedra $\left(\mathrm{Q}^{0}, \mathrm{Q}^{1}, \mathrm{Q}^{2}, \mathrm{Q}^{3}, \mathrm{Q}^{4}\right.$, respectively) [19] and, in less extent, $\mathrm{BO}_{4}$ tetrahedra (1000-1100 $\mathrm{cm}^{-1}$ ) [18]. In IR spectra of all the glasses the broad band within the range of $\sim 800-1200 \mathrm{~cm}^{-1}$ is multicomponent due to superposition of oscillations (stretching modes) in $\mathrm{SiO}_{4}$ and $\mathrm{BO}_{4}$ tetrahedra. Stretching modes of $\mathrm{Al}-\mathrm{O}$ bonds in $\mathrm{AlO}_{4}$ tetrahedra and $\mathrm{Fe}-\mathrm{O}$ bonds in $\mathrm{FeO}_{4}$ tetrahedra are positioned at 700-800 $\mathrm{cm}^{-1}$ and $550-650 \mathrm{~cm}^{-1}$, respectively. Bending modes of $\mathrm{Si}-\mathrm{O}-\mathrm{Si}$ bonds in $\mathrm{SiO}_{4}$ tetrahedra are positioned within the range of $350-550 \mathrm{~cm}^{-1}$.

In the low-wavenumber range 600-30 $\mathrm{cm}^{-1}$ (Figure 9) numerous weak bands are present and spectra of all the glasses are similar. Some of the bands may be attributed to $\mathrm{Fe}-\mathrm{O}$ bonds in $\mathrm{FeO}_{6}$ octahedra and $\mathrm{Na}-\mathrm{O}$ bonds.

Glasses A1, A2, B1, and B2 are characterized by similar values of the $\psi_{\mathrm{B}}$ factor (3.0-3.3). As follows from theoretical suggestions major boron on these glasses must be four-coordinated on oxygen. In the structure of these glasses $\mathrm{BO}_{4}$ tetrahedra are built in the network or chains of $\mathrm{SiO}_{4}$ tetrahedra forming $\left[\mathrm{BO}_{4 / 2}\right]^{-} \mathrm{Na}^{+}$units. Therefore, these glasses should have similar structure and their IR and Raman spectra should be similar as well.

IR spectra of glasses A1 and A2 are actually very similar. Two strong bands within the ranges of 850$1200 \mathrm{~cm}^{-1}$ and $400-550 \mathrm{~cm}^{-1}$ are due to stretching and bending modes of $\mathrm{Si}-\mathrm{O}-\mathrm{Si}$ and $\mathrm{Si}-\mathrm{O}^{-}$bonds. In IR spectra of both glasses the broad band at $850-1200 \mathrm{~cm}^{-1}$ consists of a shoulder at $\sim 1160 \mathrm{~cm}^{-1}$, three narrower bands centered at 1085, 1055-1056, and 1002-1006 $\mathrm{cm}^{-1}$ and a shoulder at $\sim 890 \mathrm{~cm}^{-1}$ due to asymmetric stretching modes in $\mathrm{Q}^{4}, \mathrm{Q}^{3}, \mathrm{Q}^{2}$, and $\mathrm{Q}^{1}$ units, including valence oscillations of $\mathrm{Si}-\mathrm{O}-\mathrm{Si}(\mathrm{Al})$ bridging bonds (970-1100 $\left.\mathrm{cm}^{-1}\right)$ and non-bridging $\mathrm{Si}-\mathrm{O}^{-}$bonds $\left(850-950 \mathrm{~cm}^{-1}\right)$. As it is seen from relative intensity of the bands $\mathrm{Q}^{2}$ units dominate. However, it should be taken into account that oscillations (stretching modes) of $\mathrm{Si}-\mathrm{O}-\mathrm{B}$ bridges linking $\mathrm{SiO}_{4}$ and $\mathrm{BO}_{4}$ tetrahedra are also positioned at 950-1000 $\mathrm{cm}^{1}$ and may make a contribution to this band, although due to low content of $\mathrm{B}_{2} \mathrm{O}_{3}$ in glasses this contribution should be minor. There is also a weak absorption within the range of 1300-1550 $\mathrm{cm}^{-1}, 1250-1300$ 


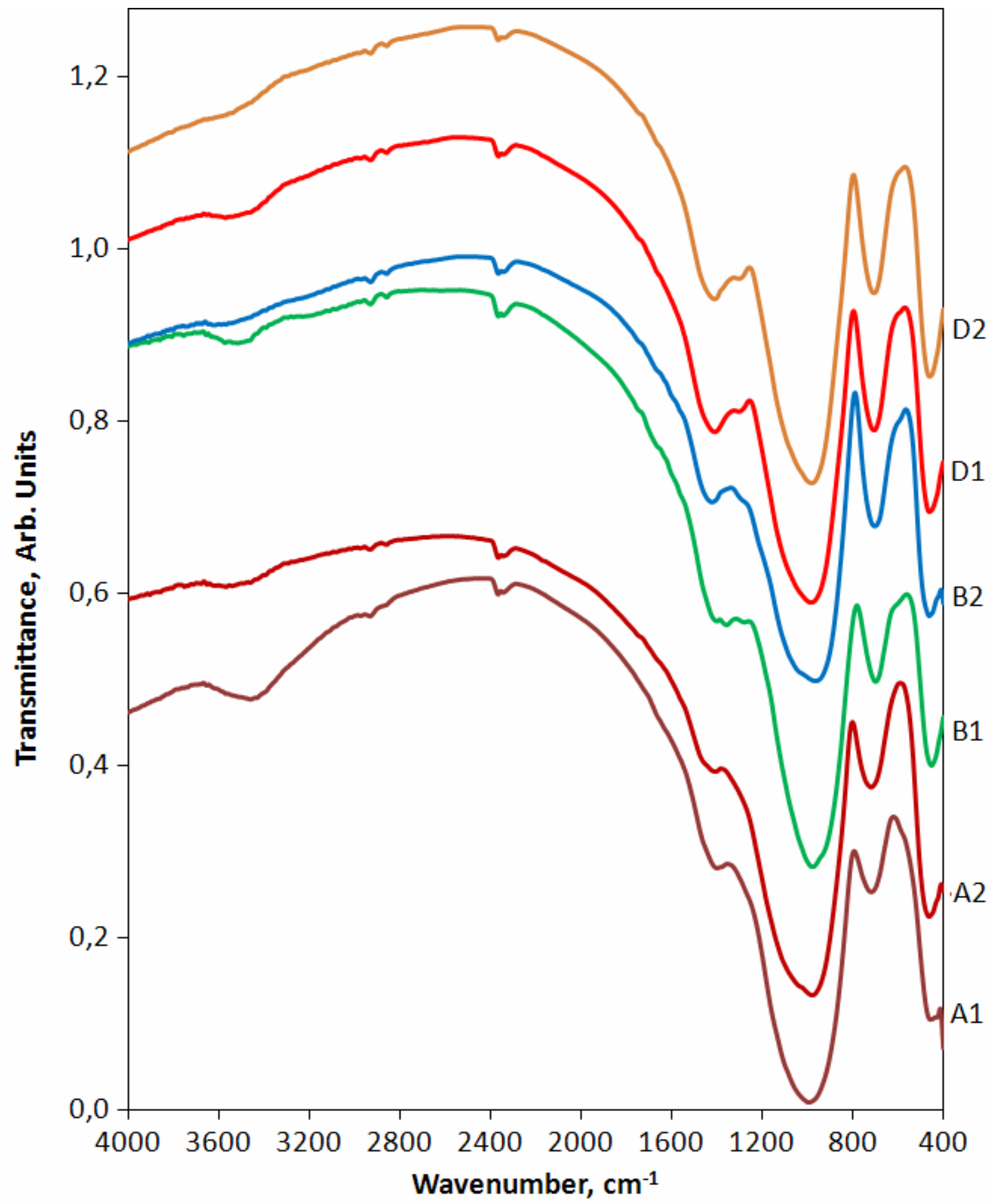

Figure 7. Infrared Spectra of Glasses within the Range of $4000-400 \mathrm{~cm}^{-1}$. 


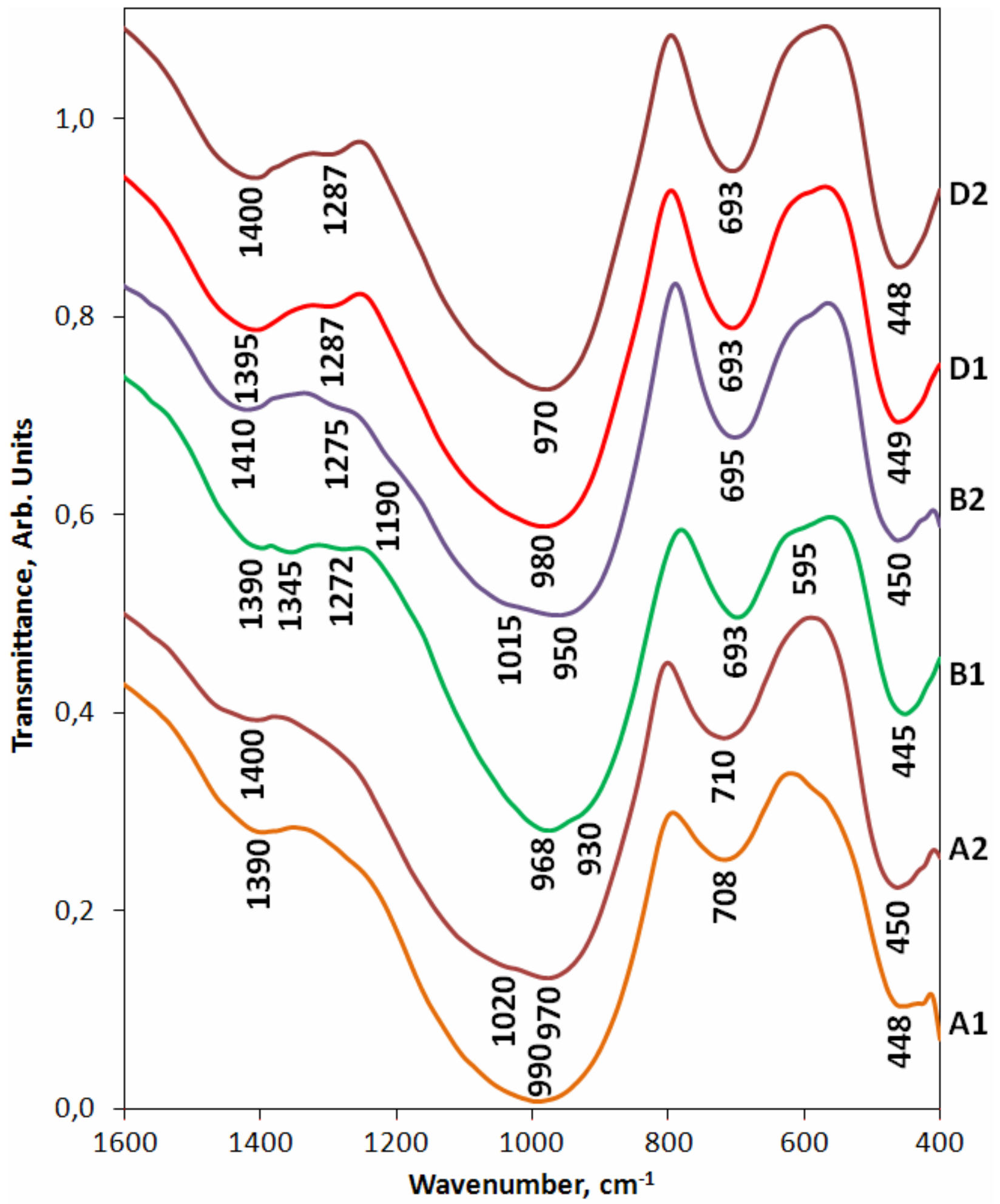

Figure 8. Fragments of Infrared Spectra of Glasses within the Range of $1600-400 \mathrm{~cm}^{-1}$. 
$\mathrm{cm}^{-1}$ and stronger band within the range of $650-800 \mathrm{~cm}^{-1}$. Because these bands are associated with ternary coordinated boron, it may be concluded that its amount is low that is consistent well with theoretical representations. Nevertheless, major contribution to the band at $650-800 \mathrm{~cm}^{-1}$ is made by $\mathrm{Al}-\mathrm{O}$ oscillations in $\mathrm{AlO}_{4}$ tetrahedra and symmetric stretching modes of $\mathrm{Si}-\mathrm{O}^{-}$bonds. Incorporation of 5 mol.\% $\mathrm{Fe}_{2} \mathrm{O}_{3}$ in glass does not effect on its IR spectra with the exception of very weak absorption near $575 \mathrm{~cm}^{-1}$ which may be assigned to oscillations of $\mathrm{Fe}-\mathrm{O}$ bonds in $\mathrm{FeO}_{4}$ tetrahedra [20].

In the whole, the structure of $\mathrm{A} 1$ and $\mathrm{A} 2$ glasses is formed by network of $\mathrm{SiO}_{4}$ and $\mathrm{AlO}_{4}$ tetrahedra with minor contribution of $\mathrm{BO}_{4}$ tetrahedra; some of them enters complex borate groups with $\mathrm{BO}_{3}$ triangles.

IR spectra of glasses B1 and B2 are also similar (Figures 7-9) but some different from those of glasses A1 and A2. We observe weak band centered at $1390-1410 \mathrm{~cm}^{-1}$ and a shoulder at $\sim 1272-1275 \mathrm{~cm}^{-1}$ due to oscillations in the units with trigonally coordinated boron, two broad strong bands within the range of $800-1200 \mathrm{~cm}^{-1}$ and $400-550 \mathrm{~cm}^{-1}$ due to stretching and bending modes of $\mathrm{Si}-\mathrm{O}-\mathrm{Si}$ bridges and $\mathrm{Si}-\mathrm{O}^{-}$ bonds and moderate on intensity band at $700-800 \mathrm{~cm}^{-1}$. IR spectra of glasses B1 and B2 within the range of $-800-1200 \mathrm{~cm}^{-1}$ differ in intensities of higher and lower wavenumber components. In the spectrum of glass B1 this band has a maximum at $968 \mathrm{~cm}^{-1}$ and a shoulder at $\sim 930 \mathrm{~cm}^{-1}$ whereas in the spectrum of the glass B2 maximum of this band is positioned at $950 \mathrm{~cm}^{-1}$ while the lower intensity shoulder is located at $\sim 1015 \mathrm{~cm}^{-1}$. Thus, incorporation of $5.3 \mathrm{~mol} . \% \mathrm{Fe}_{2} \mathrm{O}_{3}$ in glass increases fraction of $\mathrm{Q}^{2}$ and $\mathrm{Q}^{1}$ units and, therefore, the number of non-bridging oxygen ions or decrease the degree of polymerization of the structural network although this effect is negligible.

Combining of IR spectra of glass B1 and nepheline [21] it can be shown that no combination of their spectra would allowed to obtain spectra of carnegieite/nepheline containing glass B2 (Figure 10). Increase of nepheline content in glass should result in growth in intensity absorption within the range of 950-1000 $\mathrm{cm}^{-1}$ and formation of additional bands at lower wavenumber values (see spectra 95/05, 90/10, 85/15, $80 / 20$, and $\mathrm{N}$ on Figure 10). However, this does not occur. Therefore, cernegieite/nepheline content in glass is within the accuracy of determination by $\mathrm{XRD}$, i.e. $\leq 5$ vol.\%.

IR spectra of glasses D1 and D2 are some different from those of other glasses. Major difference is much stronger absorption in wavenumber range of $1250-1550 \mathrm{~cm}^{-1}$. If in the spectra of glasses A1, A2, B1 and B2 a weak shoulder a $\sim 1280-1285$ is present, then in the spectra of glasses D1 and D1 well-formed band centered at $\sim 1285-1300 \mathrm{~cm}^{-1}$ occurs. Because the bands centered at $\sim 1400$ and $\sim 1270-1300 \mathrm{~cm}^{-1}$ are due to ternary coordinated boron, it may be concluded that the fraction of trigonally coordinated boron in D1 and D2 glasses is much higher than in other glasses. This is in a good agreement with theoretical suggestions - the $\psi_{\mathrm{B}}$ factor for these glasses is about 1 whereas for $\mathrm{A}$ and $\mathrm{B}$ glasses it is about 3 . The edge of broad band at $850-1200 \mathrm{~cm}^{-1}$ is shifted to higher wavenumbers pointing to markedly smaller contribution of four-coordinated boron as compared to A and B glasses. High wavenumber side of this band is similar to that of $\mathrm{A} 1$ and $\mathrm{A} 2$ glasses.

In the whole, glasses D1 and D2 have lower degree of connectedness (polymerization) of silicon-oxygen network as follows from lower wavenumber maxima of the band due to vibrations in $\mathrm{SiO}_{4}$ tetrahedra and low intensity of its higher wavenumber component. 


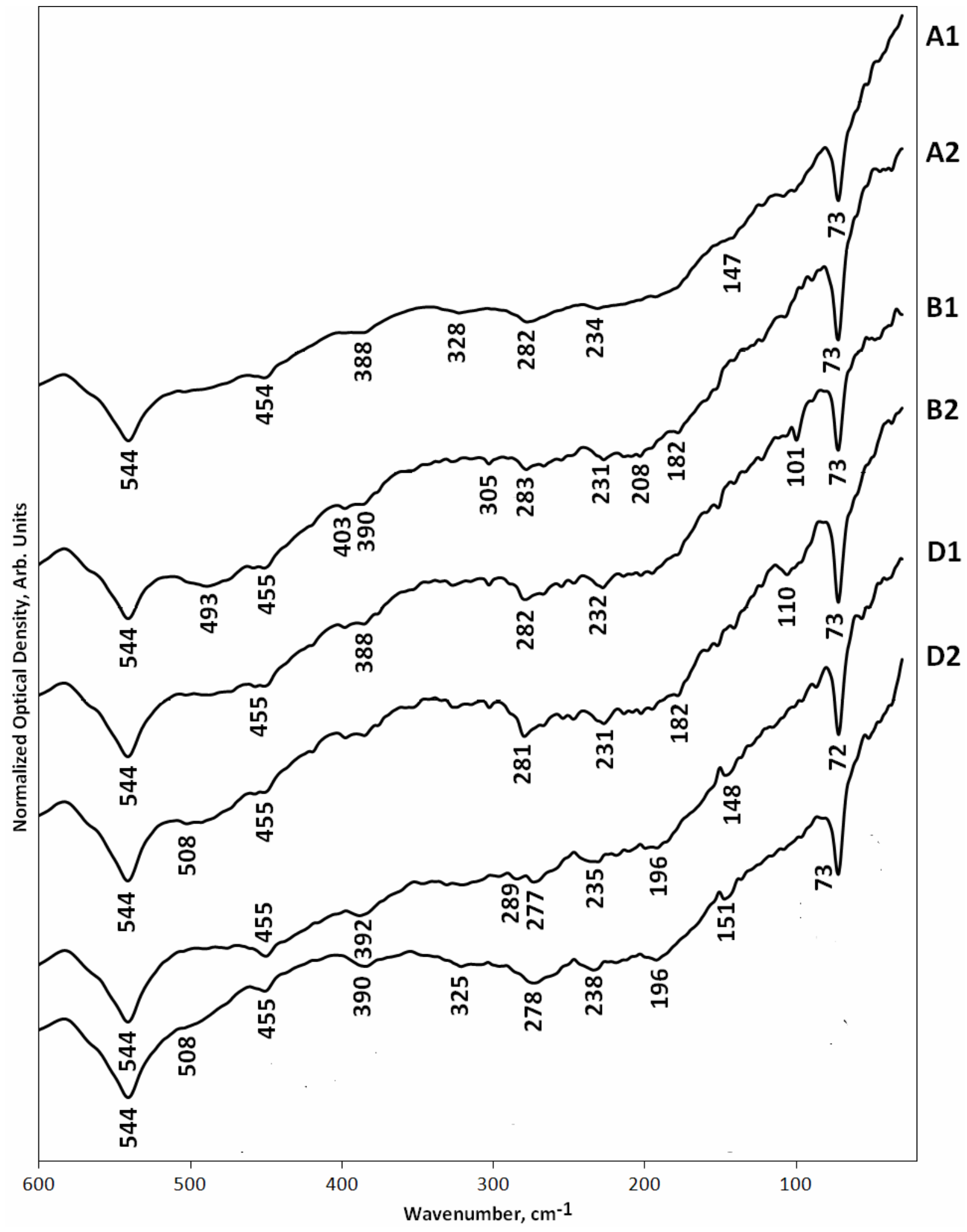

Figure 9. Infrared Spectra of Glasses within the Range of $600-30 \mathrm{~cm}^{-1}$. 


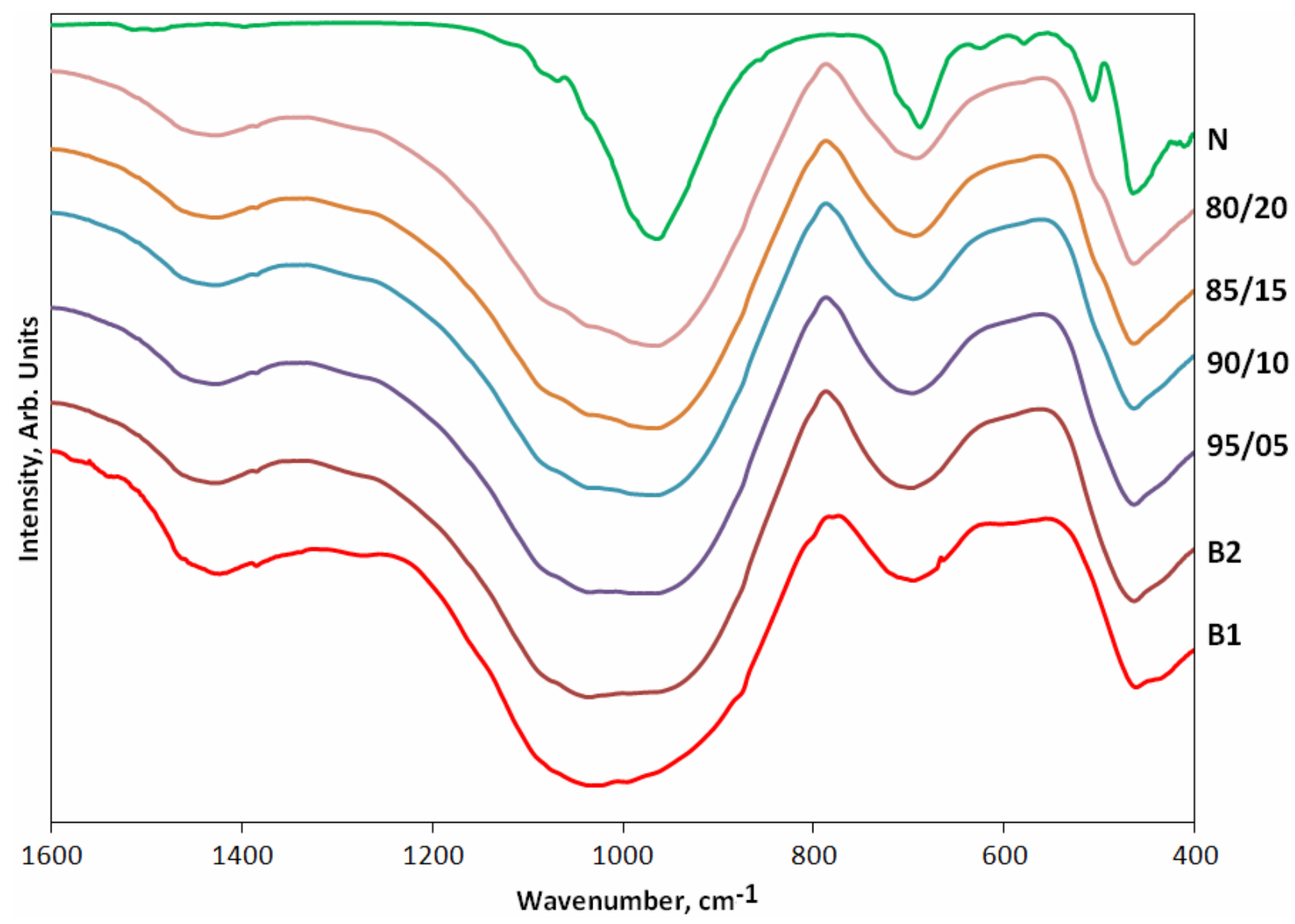

Figure 10. Combination of IR Spectra of Glass B2 and Carnegieite/Nepheline at Various Ratios. N carnegieite/nepheline, the rest spectra are B2/N.

IR spectra of the glasses heat-treated at $500{ }^{\circ} \mathrm{C}$ for $10 \mathrm{hrs}$ were also recorded (Figures 11 and 12). Major difference in spectra of heat-treated glasses is splitting of the bands due to vibrations in $\mathrm{SiO}_{4}$ terahedra. This normally occurs at structural ordering in the glass network due to formation of pre-crystallization areas following by devitrification. Glasses A1, A2 and D2 seem to be structurally ordered in the most extent. The band at $800-1200 \mathrm{~cm}^{-1}$ in spectra of glasses B1, B2 and D1 is worse resolved than in the spectra of glasses A1, A2 and D2. In the spectrum of iron-containing glass B1 its components are 1160 (shoulder), 1045, 1005, 975, 885, and $808 \mathrm{~cm}^{-1}$ (shoulders). Some of them may be assigned to the contribution of nepheline $\left(\sim 1085,1045, \sim 1000, \sim 700, \sim 520\right.$ and $\left.\sim 480 \mathrm{~cm}^{-1}[18,19]\right)$. In the spectrum of iron free glass B2 the band contains components 1082 (shoulder), 1045, 970, and $885 \mathrm{~cm}^{-1}$ (shoulder). The difference in location of the bands may be assigned to the effect of iron.

Shoulders at $\sim 808$ and $788 \mathrm{~cm}^{-1}$ are probably symmetric stretching modes of $\mathrm{Si}-\mathrm{O}-\mathrm{Al}$ or $\mathrm{Si}-\mathrm{O}-\mathrm{B}$ bridges whereas a weak band at $\sim 600 \mathrm{~cm}^{-1}$ in the spectrum of glass $\mathrm{B} 1$ is due to contribution of $\mathrm{Fe}-\mathrm{O}$ bonds in $\mathrm{FeO}_{4}$ tetrahedra. Weak splitting of the band at $650-750 \mathrm{~cm}^{-1}$ is due possibly to formation of $\mathrm{AlO}_{4}$ tetrahedra with various number of non-bridging oxygen ions. 
SRNL-STI-2010-00805

Revision 0

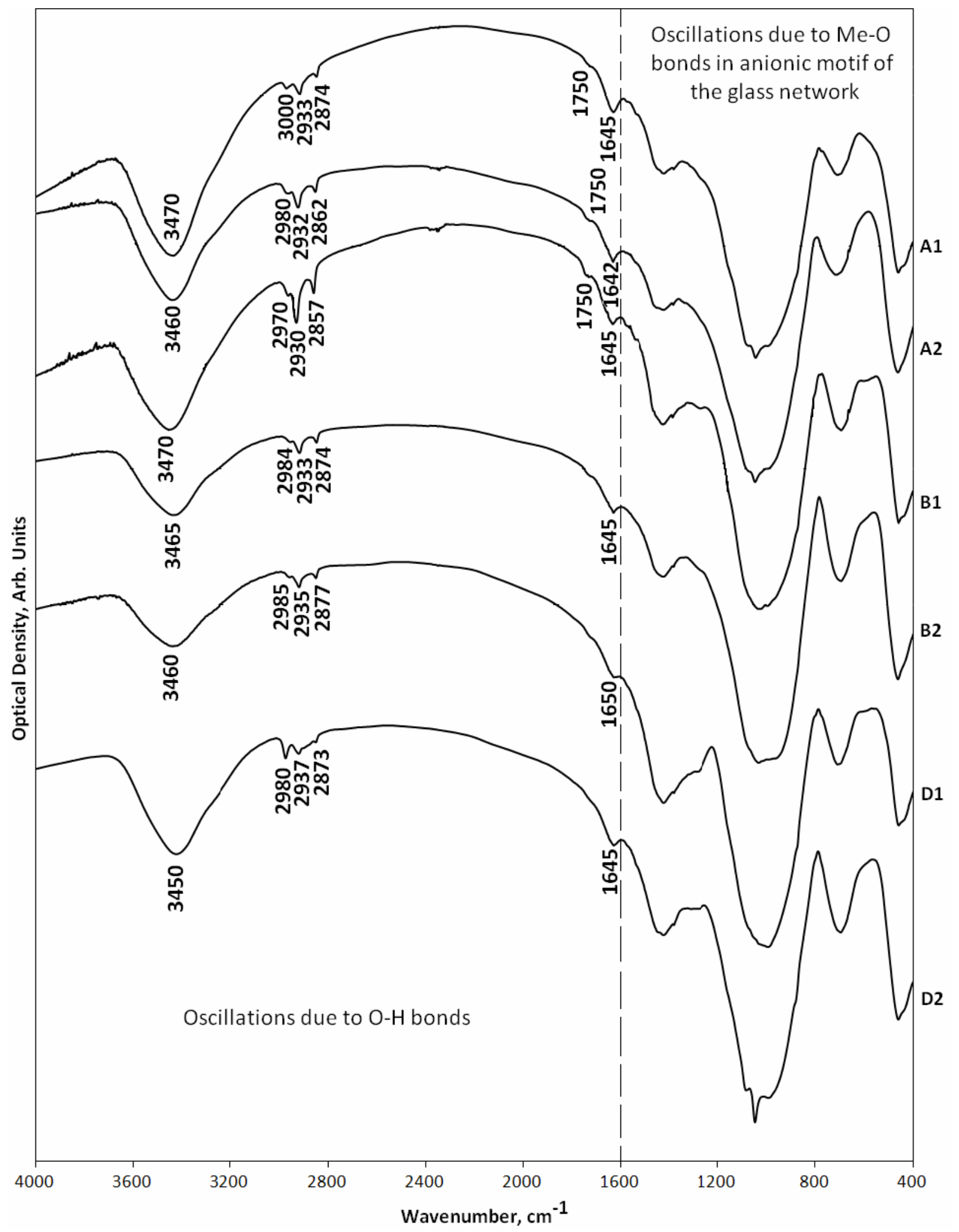

Figure 11. IR Spectra of Glasses Heat-Treated at $500{ }^{\circ} \mathrm{C}$. 


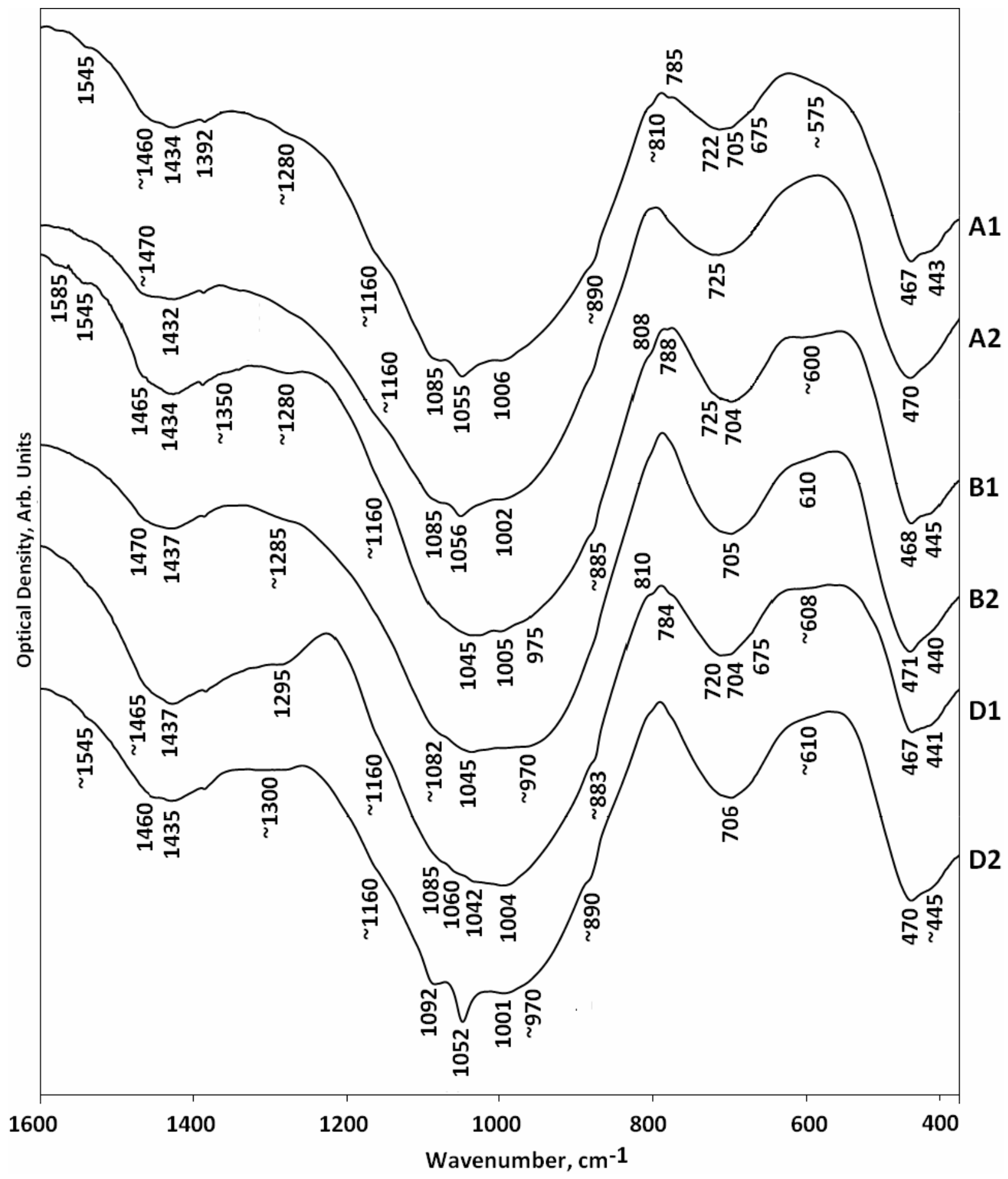

Figure 12. Fragments within the Range of $1600-400 \mathrm{~cm}^{-1}$ of IR Spectra of Glasses Heat-Treated at $500{ }^{\circ} \mathrm{C}$. 


\section{Raman Spectra of Glasses}

Raman spectra of the glasses studied are shown on Figure 13. Like FTIR spectra Raman spectra consist of strong bands within the ranges of 300-600 and 850-1200 $\mathrm{cm}^{-1}$ and weaker bands at 700-800 and 1250$1550 \mathrm{~cm}^{-1}$ but unlike FTIR spectra in the Raman spectra we may see different location of major bands due to stretching and bending modes in various structural units of glasses. There is a significant difference between Raman spectra of iron-containing and iron-free glasses especially within the range of 850-1200 $\mathrm{cm}^{-1}$. The band at $850-1200 \mathrm{~cm}^{-1}$ consists of two major components at lower (850-1000 $\mathrm{cm}^{-1}$ ) and higher (1000-1200 $\left.\mathrm{cm}^{-1}\right)$ wavenumber ranges. In the spectra of iron free glasses the second component is stronger than the first one whereas in the spectra of iron-containing glasses - on the contrary. Since these components correspond to stretching modes in $\mathrm{Q}^{0}+\mathrm{Q}^{1}+\mathrm{Q}^{2}$ units and $\mathrm{Q}^{3}+\mathrm{Q}^{4} \mathrm{SiO}_{4}$ units, respectively, it may be concluded that $\mathrm{Fe}^{3+}$ (and $\mathrm{Fe}^{2+}$ ions if present) offer destructive effect on structural network of these glasses.

Within the range of 300-600 $\mathrm{cm}^{-1}$ bending modes in $\mathrm{SiO}_{4}$ and $\mathrm{AlO}_{4}$ tetrahedra are observed. In iron free glasses this band is multicomponent. Incorporation of $\mathrm{Fe}_{2} \mathrm{O}_{3}$ in glasses results in broadening of this band and collapse of weak narrow bands in this range due to gaining of absorption at superimposing of the modes due to $\mathrm{Fe}-\mathrm{O}$ bonds.

For understanding of the structure of glasses in more details computer simulation is required. Glasses A1 and A2 are similar in chemical composition but unlike glass A2 glass A1 contains 5 mol.\% $\mathrm{Fe}_{2} \mathrm{O}_{3}$. Raman spectrum of iron free glass A2 may be represented as a superposition of the bands centered at 449, 511 , 578, 631, 695, 771, 941, 1042, 1074, 1333, and $1556 \mathrm{~cm}^{-1}$ (Figure 14). Strong bands centered at 449 (broad) and $511 \mathrm{~cm}^{-1}$ (narrower) may be attributed to bending modes in the $\mathrm{SiO}_{4}$ units with various number of non-bridging oxygen ions. Much weaker bands centered at 578, 695 and $771 \mathrm{~cm}^{-1}$ are due to stretching modes of $\mathrm{Al}-\mathrm{O}^{-}$bonds in $\mathrm{AlO}_{6}$ (first of them) and $\mathrm{AlO}_{4}$ units. The band centered at $631 \mathrm{~cm}^{-1}$ is due to symmetric valence oscillations ( $v_{1}$ stretching modes) of $\mathrm{Si}-\mathrm{O}-\mathrm{Si}(\mathrm{Al})$ bridges in depolymerized silicate or aluminosilicate anions. Weak bands centered at 941,1333 and $1556 \mathrm{~cm}^{-1}$ may be attributed to oscillations of $\mathrm{B}-\mathrm{O}$ bonds in $\mathrm{BO}_{4}$ (first of them) and $\mathrm{BO}_{3}$ units with various number of non-bridging oxygen ions. The bands centered at 1042 and $1074 \mathrm{~cm}^{-1}$ are due to $v_{3}$ stretching modes in $\mathrm{SiO}_{4}$ teterahedra with two $\left(\mathrm{Q}^{2}\right)$ and three $\left(\mathrm{Q}^{3}\right)$ bridging oxygen ions. Broad band centered at $1042 \mathrm{~cm}^{-1}$ may be also given a contribution due to $\mathrm{Q}^{4}(\mathrm{mAl})$ structural units [22].

Raman spectrum of glass A1 is simpler than that of glass A2 (Figure 14). Computer simulation gives the following set of overlapped bands centered at 476, 750, 926, 1031, and $1391 \mathrm{~cm}^{-1}$. It is seen well that the band centered at $476 \mathrm{~cm}^{-1}$ is a superposition of narrower lines due to bending modes in $\mathrm{SiO}_{4}$ units various number of non-bridging oxygen ions (350-550 $\mathrm{cm}^{-1}$ ) and stretching modes of $\mathrm{Fe}-\mathrm{O}$ bonds in $\mathrm{FeO}_{4}$ tetrahedra (550-600 $\left.\mathrm{cm}^{-1}\right)$ as well as $v_{1}$ stretching modes of $\mathrm{Si}-\mathrm{O}-\mathrm{Si}(\mathrm{Al})$ bridges. The band centered at $750 \mathrm{~cm}^{-1}$ is due to stretching modes of $\mathrm{Al}-\mathrm{O}^{-}$bonds in $\mathrm{AlO}_{4}$ tetrahedra. Strong broad asymmetric band within the range of $850-1150 \mathrm{~cm}^{-1}$ is a superposition of the bands centered at 926 and $1031 \mathrm{~cm}^{-1}\left(v_{3}\right.$ stretching modes in $\mathrm{Q}^{1}$ and $\mathrm{Q}^{2}$ tetrahedra, respectively). Thus, Raman spectra unambiguously demonstrate depolymerizing effect of $\mathrm{Fe}_{2} \mathrm{O}_{3}$ on glass network resulting in formation of pyro-groups $\mathrm{Si}_{2} \mathrm{O}_{7}{ }^{4-}$ or short chains of $\mathrm{SiO}_{4}$ tetrahedra. Broad band centered at $1391 \mathrm{~cm}^{-1}$ is due to oscillations in $\mathrm{BO}_{3}$ units. 


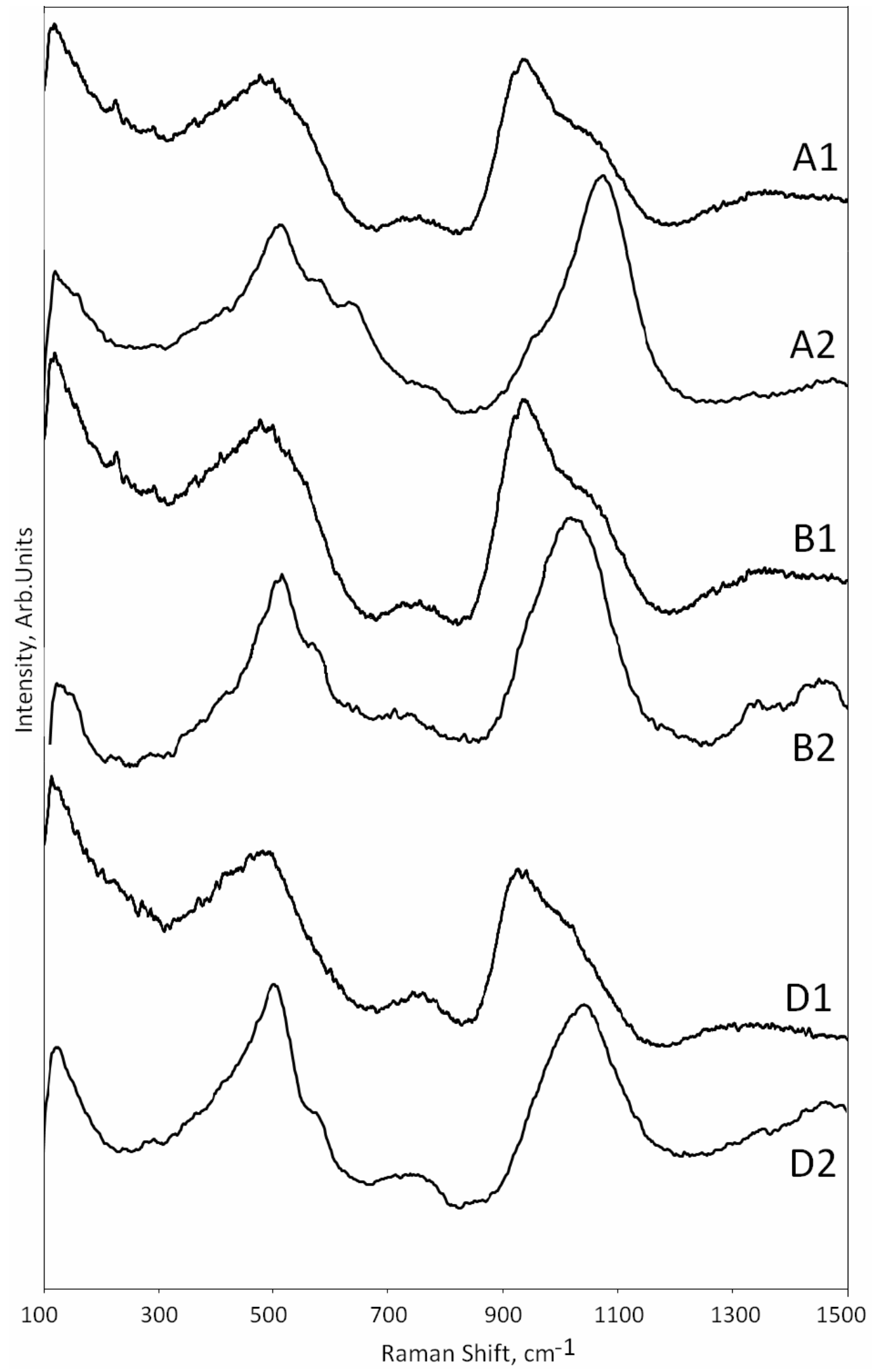

Figure 13. Raman Spectra of Glasses. 

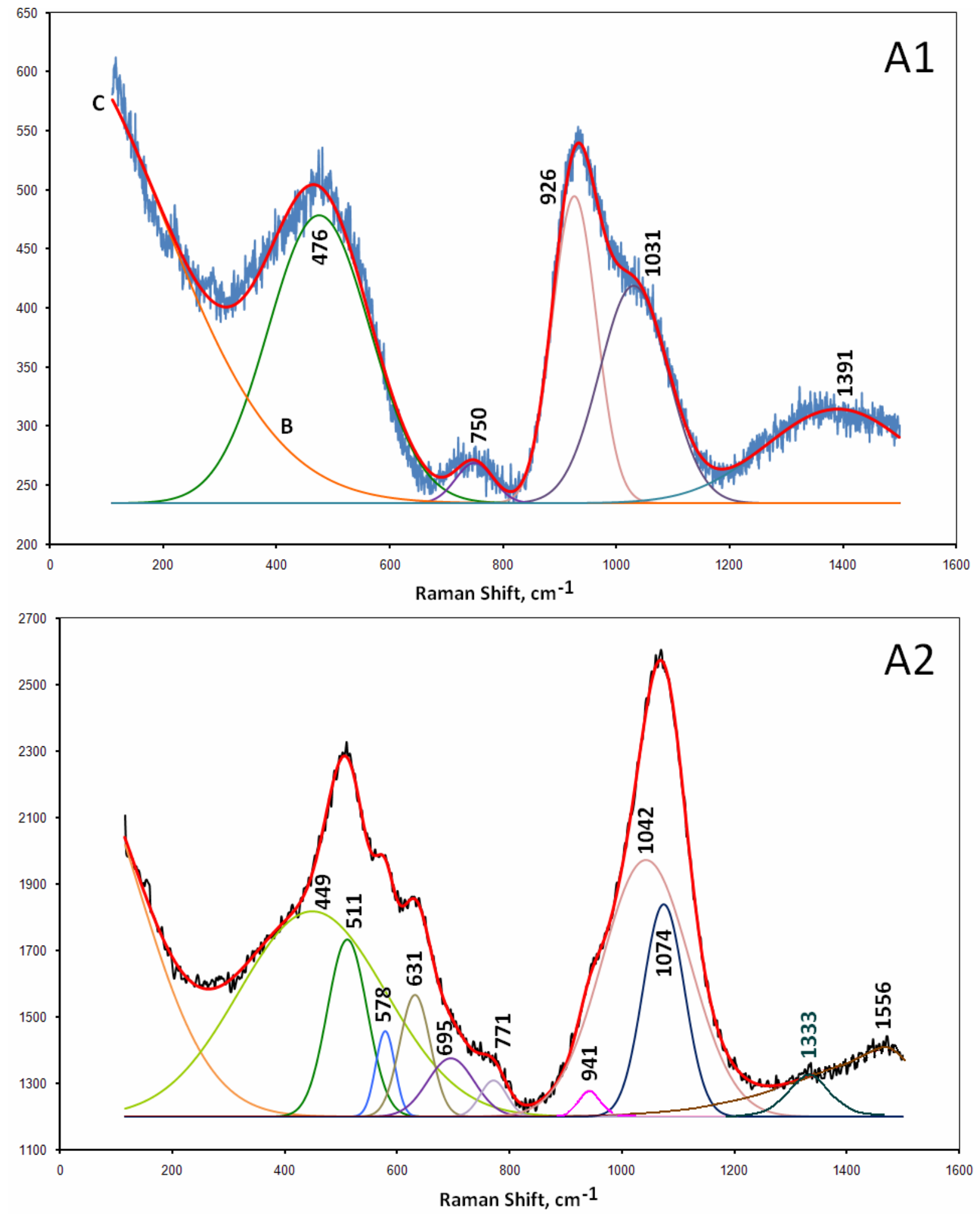

Figure 14. Computer Simulation of Raman Spectra of Glasses A1 and A2.

B - baseline, C - calculated line. 
Like previously considered glasses B1 and B2 have similar chemical composition but glass B1 contains 5.3 mol.\% $\mathrm{Fe}_{2} \mathrm{O}_{3}$. These glasses should have $\mathrm{B}^{\mathrm{III}} / \mathrm{B}^{\mathrm{IV}}$ ratio similar to glasses $\mathrm{A} 1$ and $\mathrm{A} 2$ due to close $\psi_{\mathrm{B}}$ values (Table I).

As follows from computer simulation of Raman spectrum of glass B2 its low wavenumber range is similar to that of glass A2 (Figure 15) with the exception of two weak bands centered at 219 and $228 \mathrm{~cm}^{-1}$. The broad band within the range of 300-600 $\mathrm{cm}^{-1}$ may be resolved into components 449, 511, 573, 618 and $713 \mathrm{~cm}^{-1}$. As it was discussed above the bands centered at 449 and $511 \mathrm{~cm}^{-1}$ are due bending modes of $\mathrm{Si}-\mathrm{O}$ bonds in $\mathrm{SiO}_{4}$ tetrahedra. The band centered at $573 \mathrm{~cm}^{-1}$ may be identified as the band at 578 $\mathrm{cm}^{-1}$ in glass $\mathrm{A} 2$ and assigned to stretching modes of $\mathrm{Al}-\mathrm{O}^{-}$bonds on $\mathrm{AlO}_{6}$ octahedra, whereas the band centered at $713 \mathrm{~cm}^{-1}$ is due to stretching modes of $\mathrm{Al}-\mathrm{O}^{-}$bonds on $\mathrm{AlO}_{4}$ tetrahedra. Unlike Raman spectrum of glass A2 in spectrum of B2 glass the band within the range of $850-1150 \mathrm{~cm}^{-1}$ is nearly symmetric Gaussian with a maximum at $1012 \mathrm{~cm}^{-1}$ pointing to predominant $\mathrm{Q}^{2}$ tetrahedra in its structure. Two bands in high wavenumber range centered at 1335 and $1446 \mathrm{~cm}^{-1}$ are due to $\mathrm{BO}_{3}$ triangles predominantly isolated and bound three-dimensionally, respectively.

Incorporation of $5.3 \mathrm{~mol} . \% \mathrm{Fe}_{2} \mathrm{O}_{3}$ in glass (over 100 mol.\%) yields spectrum very similar to that of glass A1 (Figures 14 and 15). In low wavenumber range of spectrum of glass B2 a strong broad band centered at $488 \mathrm{~cm}^{-1}$ due to bending modes of $\mathrm{Si}-\mathrm{O}^{-}$and $\mathrm{Si}-\mathrm{O}-\mathrm{Si}$ bonds occurs. The band centered at $746 \mathrm{~cm}^{-1}$ is due to stretching modes of $\mathrm{Al}-\mathrm{O}$ bonds in $\mathrm{AlO}_{4}$ tetrahedra. Strong band due to oscillations in $\mathrm{SiO}_{4}$ tetrahedra becomes asymmetric and is composed of components at 902 and $988 \mathrm{~cm}^{-1}$ which may be attributed to $v_{3}$ stretching modes of $\mathrm{Si}-\mathrm{O}$ bonds in $\mathrm{Q}^{1}$ and $\mathrm{Q}^{2}$ units, respectively. In spite of $\mathrm{Q}^{2}$ units remain major constituent of the structure of glass $\mathrm{B} 2$, formation of $\mathrm{Q}^{1}$ units shows destructing effect of $\mathrm{Fe}^{3+}$ ions on glass network. Occurrence of $\mathrm{BO}_{3}$ triangles is responsible for weak band centered at 1327 $\mathrm{cm}^{-1}$. Minor contribution may be also brought by $\mathrm{BO}_{4}$ tetrahedra into the edge of major band within the range of $900-1000 \mathrm{~cm}^{-1}$.

For the spectrum of iron free glass D2 the best fit was achieved at a set of lines centered at 354, 480, 503, 577, 658, 744, 943, 1028, 1275, and $1491 \mathrm{~cm}^{-1}$ (Figure 16). As discussed above, the bands in low wavenumber range are due to bending modes in $\mathrm{SiO}_{4}$ tetrahedra and stretching modes in $\mathrm{AlO}_{4}$ tetrahedra. In the spectrum of iron-containing glass D1 this range is approximated by the only band with a maximum at $474 \mathrm{~cm}^{-1}$ due to superposition of several bands including stretching modes of $\mathrm{Fe}-\mathrm{O}$ bonds. However their contribution is minor due to low $\mathrm{Fe}_{2} \mathrm{O}_{3}$ content in glass.

Major band in high wavenumber range is resolved into components at 915 and $992 \mathrm{~cm}^{-1}$. They may be attributed to $v_{3}$ stretching modes of $\mathrm{Si}-\mathrm{O}$ bonds in $\mathrm{Q}^{1}$ and $\mathrm{Q}^{2}$ tetrahedra, respectively. Because the band centered at $992 \mathrm{~cm}^{-1}$ is broader, it may be suggested that it contains some contribution of stretching modes of $\mathrm{B}-\mathrm{O}$ bonds in $\mathrm{BO}_{4}$ tetrahedra. Two weak overlapped bands with maxima at 1246 and $1323 \mathrm{~cm}^{-1}$ are due to oscillations in $\mathrm{BO}_{3}$ triangles.

In the whole, in all the glasses studied incorporation of $\mathrm{Fe}_{2} \mathrm{O}_{3}$ offers destructive effect on glass network. 

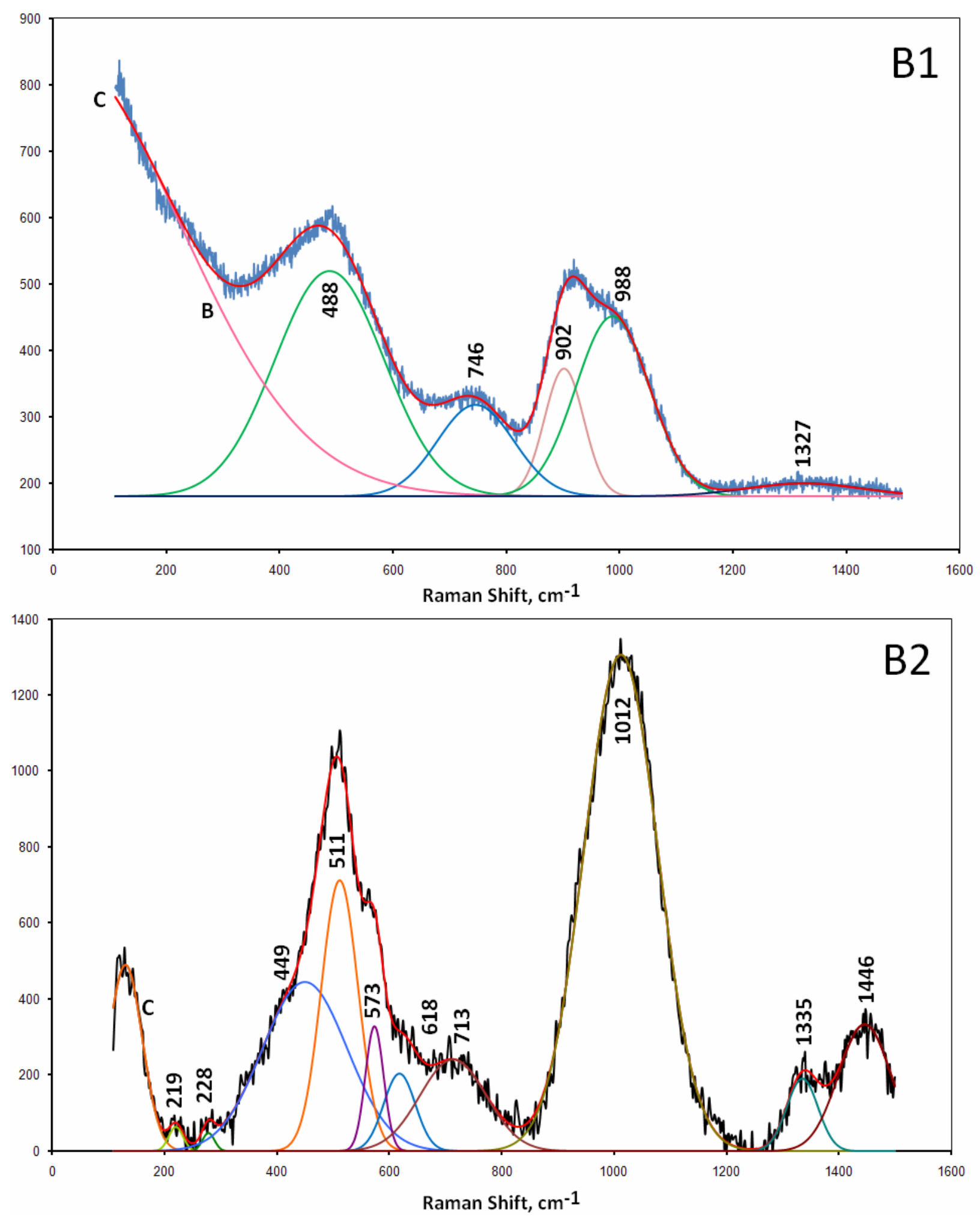

Figure 15. Computer Simulation of Raman Spectra of Glasses B1 and B2.

B - baseline, C - calculated line. 

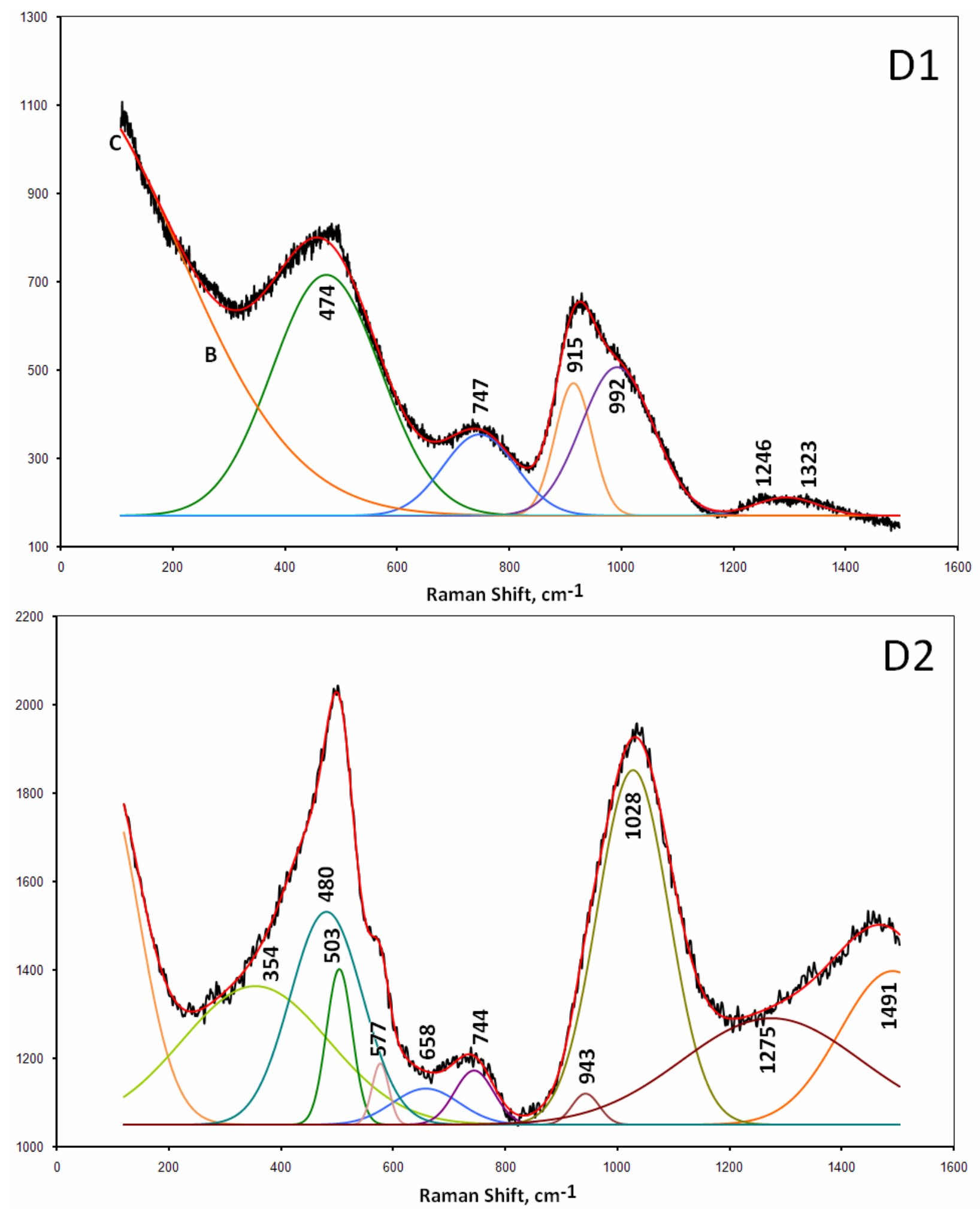

Figure 16. Raman Spectra of Glasses D1 and D2.

B - baseline, C - calculated line.

\section{XAS Study}


XANES spectra of Fe K edge in glasses A1, B1 and D1 and their first derivatives are shown on Figures 17 and 18, respectively. Spectrum of Fe K edge in glass D1 is slightly different from spectra of glasses $\mathrm{A} 1$ and B1. As follows from comparison with reference data [23] spectra may be attributed to $\mathrm{Fe}^{3+}$ ions in mixed tetrahedral and octahedral oxygen environment. Minor $\mathrm{Fe}^{2+}$ ions may be also present, especially in glass D1.

Comparison of first derivatives (FD) of XANES spectra (Figure 18) with reference data [24] demonstrates that FD of Fe K XANES spectra of glass A1 is similar to that of glass with $\mathrm{NaFeSi}_{2} \mathrm{O}_{6}$ formulation. FD of spectra of glass $\mathrm{B} 1$ is intermediate between those of glasses with $\mathrm{NaFeSi}_{2} \mathrm{O}_{6}\left(\mathrm{Fe}^{3+}\right)$ and $\mathrm{CaFeSiO}_{4}$ or $\mathrm{CaFeSi}_{2} \mathrm{O}_{6}\left(\mathrm{Fe}^{2+}\right)$ formulations. FD of spectra of glass D1 demonstrates some higher contribution due to $\mathrm{Fe}^{2+}$.

Fourier transform (FT) EXAFS spectra of Fe K edge in glasses are shown on Figure 19. It is seen well that only first coordination shell is appeared. Therefore, Fe ions are quite homogeneously distributed over glass bulk.

Computer fitting (Table XIII) of the Fe K Edge EXAFS Spectra shows that Fe in glass A1 has average coordination number (CN) 5.5, i.e. $\sim 75 \% \mathrm{Fe}$ ions have $\mathrm{CN}=6$ and $\sim 25 \% \mathrm{Fe}-\mathrm{CN}=4$. Major Fe ions have distorted octahedral oxygen environment with symmetry close to rhombic. In the structure of glass B1 average Fe $\mathrm{CN}=4.6$, i.e. $~ 70 \%$ Fe ions occupy tetrahedral sites and $\sim 30 \%$ - octahedral sites. In the glass $\mathrm{D} 1$ average $\mathrm{CN}=3.7$ pointing to tetrahedral oxygen environment of Fe ions. At that, in the structure of glass B1 Fe environment is the least distorted.

Second coordination shell actually exists even though is weakly manifested. The nearest neighbor (oxygen or different element) is located at a distance of 3.59-3.66 $\AA$ with $\mathrm{CN}=1.5-1.9$. This neighboring atom is better seen on Morlet-Wavelet transforms (Figure 20). 


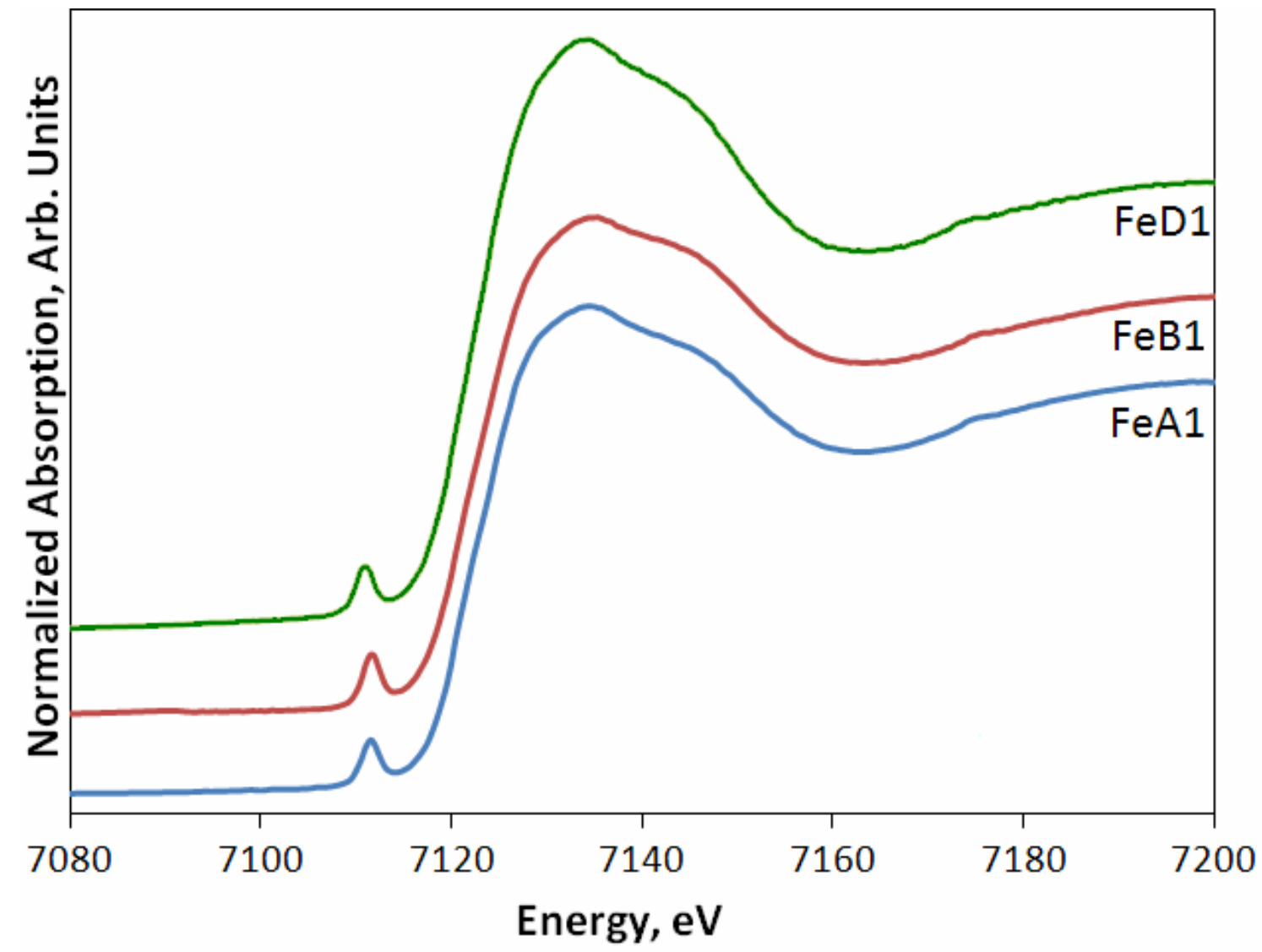

Figure 17. XANES Spectra of Fe K Edge in Glasses. 


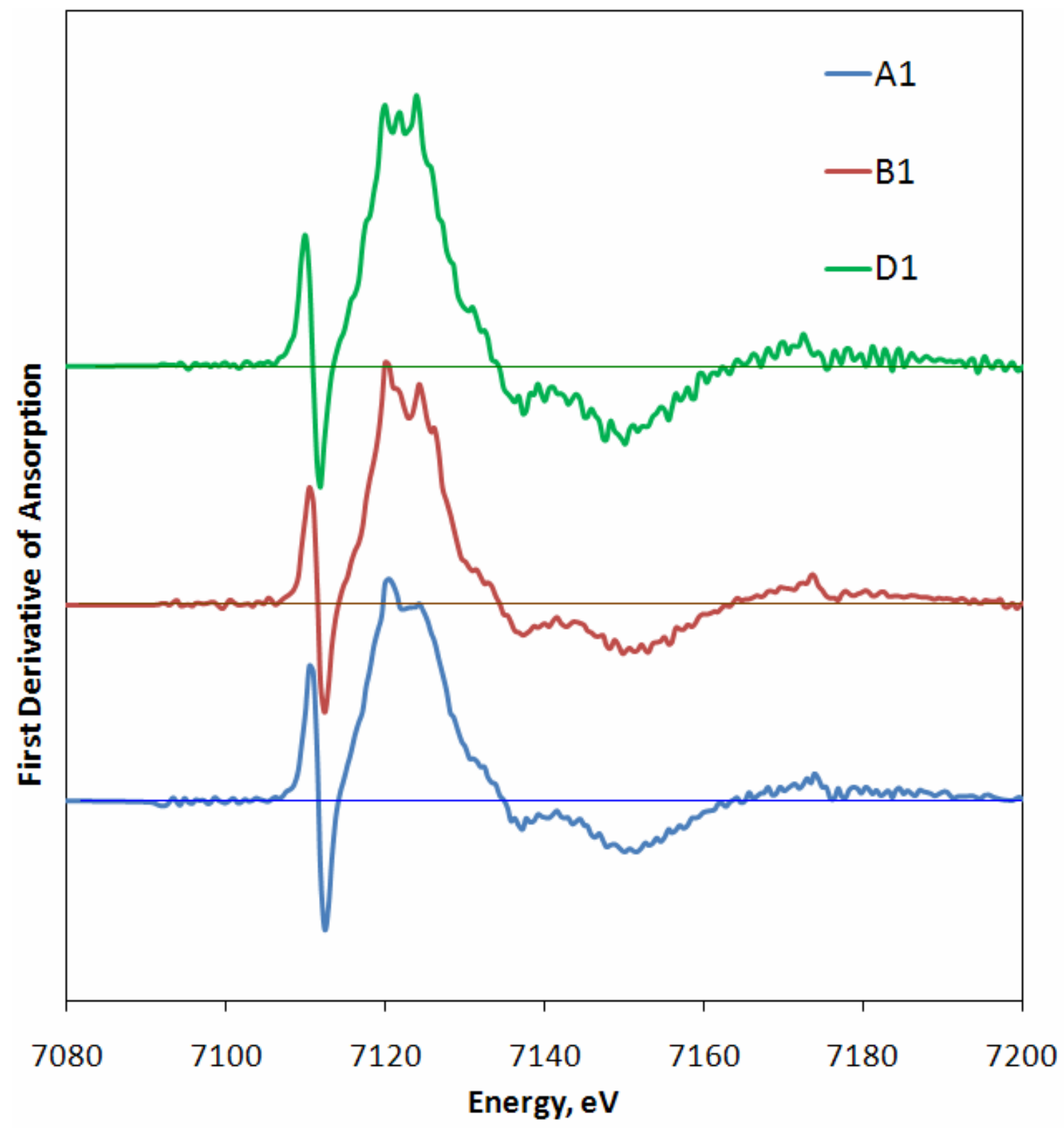

Figure 18. Differential XANES spectra of Fe K edge in glasses. 
Table XIII. Fitting of the Fe K Edge EXAFS Spectra of Glasses.*

\begin{tabular}{|c|c|c|c|c|c|c|}
\hline Glass & \multicolumn{2}{|c|}{$\mathrm{A} 1$} & \multicolumn{2}{c|}{$\mathrm{B} 1$} & \multicolumn{2}{c|}{$\mathrm{D} 1$} \\
\hline Bond & $\mathrm{CN}$ & $\mathrm{R}-\mathrm{O}, \AA$ & $\mathrm{CN}$ & $\mathrm{R}-\mathrm{O}, \AA$ & $\mathrm{CN}$ & $\mathrm{R}-\mathrm{O}, \AA$ \\
\hline Fe-O1 & $2.9 \pm 0.2$ & $1.75 \pm 0.01$ & $2.7 \pm 0.1$ & $1.83 \pm 0.01$ & $2.1 \pm 0.3$ & $1.81 \pm 0.01$ \\
\hline Fe-O2 & $2.6 \pm 0.1$ & $1.85 \pm 0.01$ & $1.9 \pm 0.1$ & $1.85 \pm 0.01$ & $1.6 \pm 0.2$ & $1.87 \pm 0.01$ \\
\hline Fe-O3(Me) & $1.5 \pm 0.2$ & $3.66 \pm 0.03$ & $1.9 \pm 0.2$ & $3.59 \pm 0.03$ & $1.6 \pm 0.1$ & $3.6 \pm 0.1$ \\
\hline
\end{tabular}

* Debye-Waller factor was assumed to be $0.005 \AA^{-1}$. 


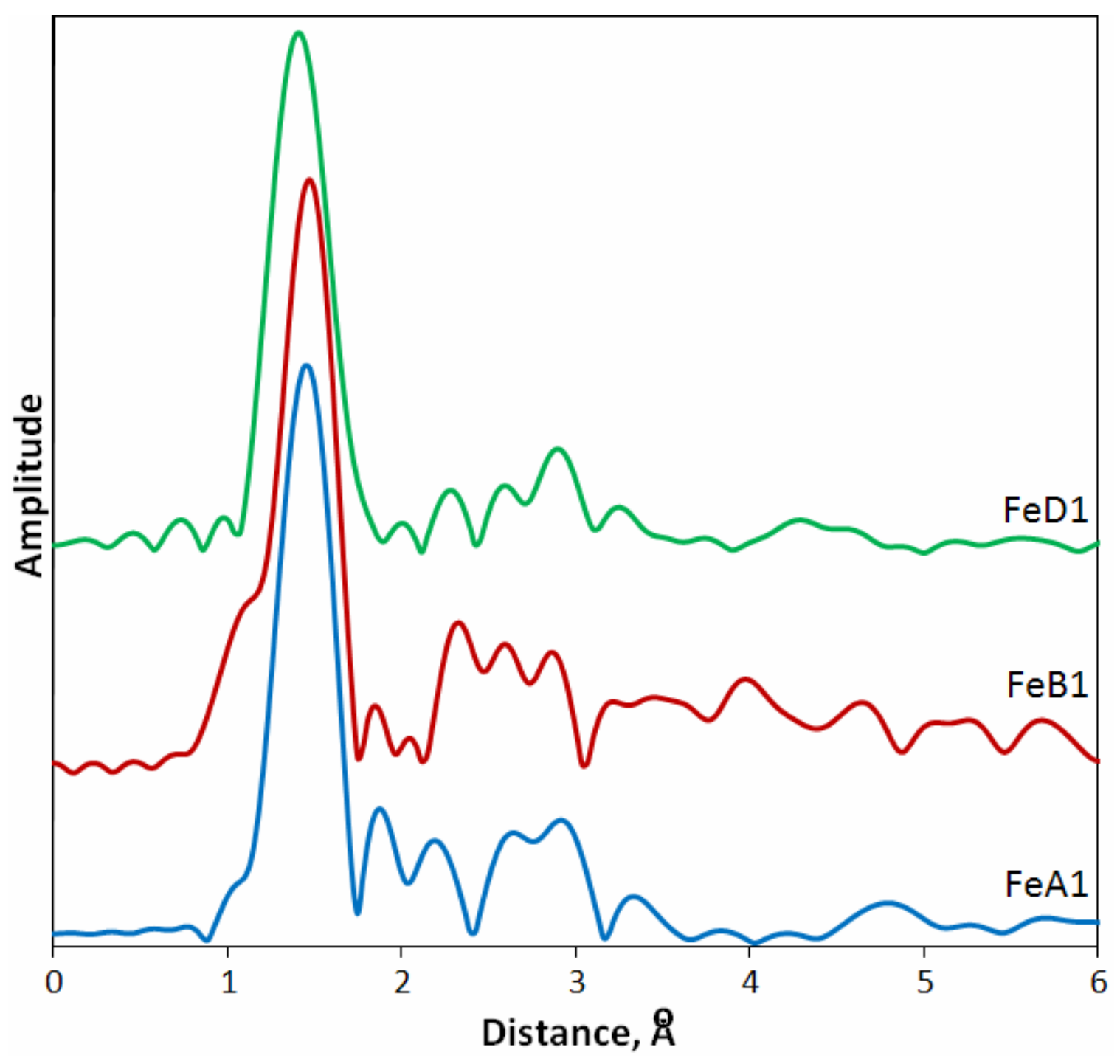

Figure 19. FT EXAFS of Fe K Edge in Glasses.

No phase shift correction. 

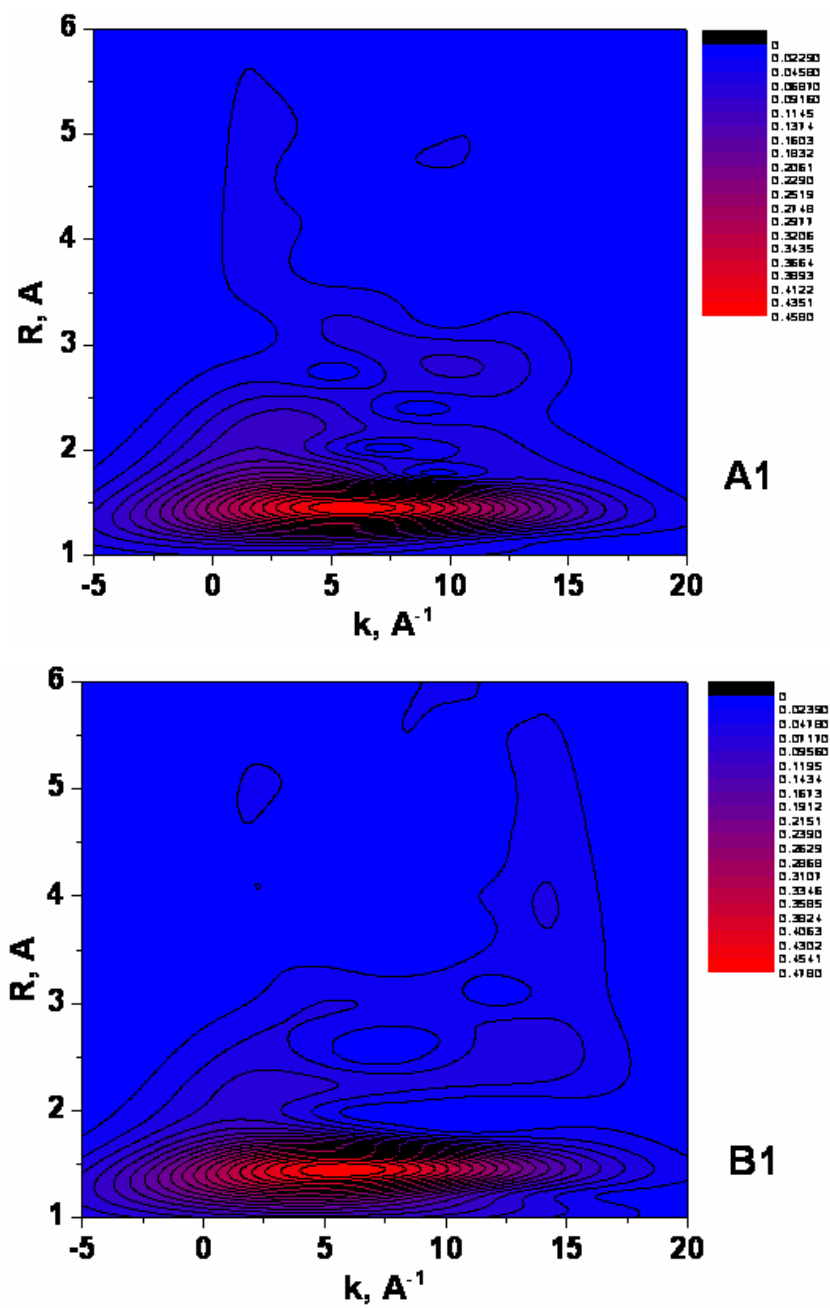

B1
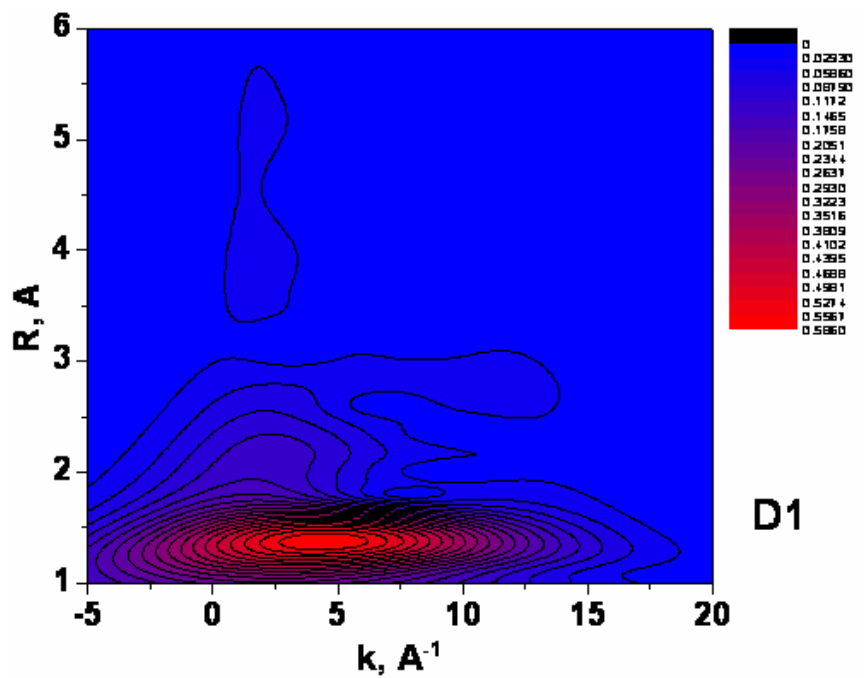

D1

Figure 20. Morlet Wavelet Transform of Fe K Edge EXAFS Spectra of Glasses A1, B1 and D1. 


\section{CONCLUSIONS}

- $\quad$ Materials A1, A2, B2, D1, D2 are X-ray amorphous (glasses); the material B1 is also amorphous but contains trace of crystalline phases carnegieite/nepheline and spinel;

- No liquid-liquid phase separation in glasses was found;

- FTIR spectra show minor effect of $\mathrm{Fe}_{2} \mathrm{O}_{3}$ on the structure of the anionic motif of the glasses studied;

- As follows from Raman spectra incorporation of Fe ions offers destructive effect on glass network increasing the number of non-bridging oxygen ions and thus fraction of $\mathrm{SiO}_{4}$ tetrahedra with lower degree of connectedness;

- Fe occurs predominantly in a trivalent form as $\mathrm{Fe}^{3+}$ ions but some minor fraction of $\mathrm{Fe}^{2+}$ is also present; the highest fraction of $\mathrm{Fe}^{2+}$ ions was found in glass D1;

- In the structure of glass $\mathrm{A} 1 \mathrm{Fe}^{3+}$ ions have $\mathrm{CN}=5.5$ (75\% Fe ions occupy octahedral sites and $25 \%$ - tetrahedral), in the glass B1 average $\mathrm{CN}=4.6$ (70 Fe ions occupy tetrahedral sites and $30 \%$ - octahedral), in the glass D1 average $\mathrm{CN}=3.7\left(\mathrm{Fe}^{3+}\right.$ ions are octahedrally coordinated);

- Both tetrahedral and octahedral Fe sites undergo majorly rhombic distortion with short $\mathrm{Fe}-\mathrm{O}$

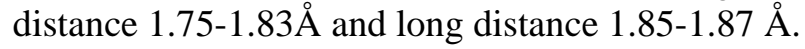

- Second coordination shell of Fe ions is not clearly manifested, therefore, Fe ions are quite homogeneously distributed within the glass bulk;

- The nearest to Fe ion neighbor (oxygen or heavier element) is located at a distance of 3.59-3.66 $\AA$ with $\mathrm{CN}=1.5-1.9$. 


\section{REFERENCES}

1. H. Li, P. Hrma, J.D. Vienna, M. Qian, Y. Su, D.E. Smith, J. Non-Cryst. Solids, 331 (2003) $202-216$.

2. J.C. Marra, D.K. Peeler, T.B. Edwards, A.L. Youchak, J.H. Gillam, Jr., J.D. Vienna, S.V. Stefanovsky, A.S. Aloy, Mat. Res. Soc. Symp. Proc. 1107 (2008) 231-238.

3. S.V. Stefanovsky and J.C. Marra, Waste Management '07. Proc. Int. Conf. Tucson, AZ, 2007. ID 7132. CD-ROM.

4. J. Wong, C.A. Angell, Glass Structure by Spectroscopy, Marcel Dekker, N.Y. (1976).

5. J.G. Darab, J.C. Linehan, B.P. McGrail, Mat. Res. Soc. Symp. Proc. 556 (1999) 337-344.

6. D. Holland, B.G. Parkinson, M.M. Islam, A. Duddridge, J.M. Roderick, A.P. Howes, C.R. Scales, Mater. Res. Soc. Symp. Proc. 1107 (2008) 199-206.

7. B. Ravel and M. Newville, J. Synchrotron Radiat. 12 537-541 (2005).

8. A.L. Ankudinov and J.J. Rehr, Phys. Rev. B 56 1712-1716 (1997).

9. H. Funke, A.C. Scheinost and M. Chukalina, Phys. Rev. B, 71, 094110 (2005).

10. H. Funke, M. Chukalina and A.C. Scheinost, J. Synchrotron Radiat. 14, 426-432 (2007).

11. www.esrf.fr/exp_facilities/BM20/Software/Wavelets.html.

12. A.A. Appen, Chemistry of Glass (Russ.), Khimiya, Leningrad (1974).

13. S.V. Stefanovskii, O.A. Knyazev, T.N. Lashchenova, and S. Merlin, J. Adv. Mater. 3 [6] (1996) 479487.

14. G.B. Bokiy, Crystal Chemistry, (Russ., Moscow State University Publ., 1960).

15. R.D. Shannon, Acta Cryst. A32 (1976) 751-767.

16. A.P. Kobelev, S.V. Stefanovsky, V.V. Lebedev, M.A. Polkanov, O.A. Knyazev, J.C. Marra. Cold Crucible Vitrification of the Savannah River Site SB2 HLW Surrogate at High Waste Loading, Glass Tech.: Eur. J. Glass Sci. Technol. A. 50 [1] (2009) 47-52.

17. S.V. Stefanovsky, J.C. Marra, A.A. Akatov, Characterization of Vitrified Savannah River Site SB4 Waste Surrogate Produced in Cold Crucible, Materials Science and Technology '08 Conf. Pittsburg, PA (2008) 486020.

18. V.A. Kolesova, Glass Phys. Chem. (Russ.) 12 [10] 4-13 (1986).

19. V.N. Anfilogov, V.N. Bykov, and A.A. Osipov, Silicate Melts (Russ.), Nauka, Moscow (2005).

20. I.I. Plyusnina, Infrared Spectra of Minerals (Russ.), MGU, Moscow (1977).

21. http://rruff.info/nepheline/display=default/R040025

22. P.F. McMillan, B. Piriou, A. Navrotsky, Geochim Cosmochim. Acta. 46 (1982) 2021-2037.

23. G.E. Brown, Jr., G.A. Waychunas, C.W. Ponader, W.E. Jackson, and D.A. McKeown, EXAFS and Near Edge Structure IV - J. de Physique. 47 C8, suppl. Au n²12, C8-661 - C8668 (1986).

24. N. Binsted, G.N. Greaves, and C.M.B. Henderson, EXAFS and Near Edge Structure IV - J. de Physique. 47 C8, suppl. Au n²12, C8-837 - C8-840 (1986). 
Appendix B. Final Report from SIA Radon on Task 2:

Electron Microscopy and Spectroscopy Studies of Amorphous Glasses with Poor Durability 
SRNL-STI-2010-00805

Revision 0

FINAL REPORT

Subcontract Number AC69549N

Task 2: Electron Microscopy and Spectroscopy Studies of Amorphous Glasses with Poor Durability

\section{Glass Structural Characterization and Analysis}

\section{INTRODUCTION}

Vitrtification is one of the most perspective methods of nuclear waste volume reduction providing for production of glass waste form with high chemical durability, good radiation resistance and strong mechanical integrity. Currently two technologies based on Joule heated ceramic and inductively heated metallic melters are implemented at industrial scale. One more perspective technology - cold crucible inductive melting (CCIM) is under consideration and trial testing now. While the CCIM technology is applied for vitrification of low/intermediate waste at SIA Radon in Russia, feasibility study tests with high level waste (HLW) are still being conducted. At that, selection of appropriate glass composition is one of the key elements of the vitrification process. Savannah River National Laboratory (SRNL) has identified a small number of simulated, multi-component waste glass compositions that, while amorphous via XRD, have unusually poor chemical durability. The cause of the reduction in durability is not known, but is suspected to be amorphous phase separation. The objective of this task would be to recreate 4-6 of the previously identified glass compositions and characterize them using SEM in an attempt to screen for amorphous phase separation. If phase separation can be identified using SEM, EDS would be used to approximate the compositions of each phase. Fourier Transform Infra Red (FTIR) and Raman Spectroscopy would also be used in order to identify any changes in the chemistry and structure of these anomalous glasses and possibly each phase. 


\section{EXPERIMENTAL}

Samples of glasses were delivered by customer (SRNL). Their target and actual chemical compositions are given in Table I.

Actual chemical compositions of the glasses were determined at SRNL using a Perkin-Elmer 403 ICPAAS spectrometer. Samples were examined by X-ray diffraction (XRD) using a Rigaku D / Max 2200 diffractometer ( $\mathrm{Cu} \mathrm{K \alpha}$ radiation, $40 \mathrm{keV}$ voltage, $20 \mathrm{~mA}$ current, stepwise 0.02 degrees 20), scanning electron microscopy with energy dispersive spectrometry using a JSM-5610LV+JED-2300 analytical unit, Fourier-transform infrared spectroscopy using a Perkin-Elmer 2000 Fourier spectrophotometer (compaction of glass powders in pellets with $\mathrm{KBr}$ at recording within the range of $4000-350 \mathrm{~cm}^{-1}$, and placement of micron-sized powder between two glass plates at recording within the range of $600-30 \mathrm{~cm}^{-1}$ ), and Raman spectroscopy using a Jobin Yvon U1000 spectrophotometer operated at an excitation wavelength of $532 \mathrm{~nm}$.

X-ray absorption (XAS) spectra were recorded at the Structural Materials Science (STM) Beamline of the synchrotron source at RRC "Kurchatov Institute". The glass samples were measured at room temperature either as dispersed powder or as pellets pressed from powder mixed with sucrose in the transmission mode using a $\mathrm{Si}(220)$ channel-cut monochromator and two air-filled ionization chambers. Fluorescence spectra were also acquired. Powders of chemically pure $\mathrm{Fe}$ oxides $\mathrm{Fe}_{2} \mathrm{O}_{3}$ and $\mathrm{FeO}$ were used as standards and measured under identical conditions. Experimental XAFS spectra were fitted in R-space using an IFEFFIT package [1] and crystal structures of corresponding oxides and silicates. In the fitting, ab initio photoelectron backscattering amplitudes and phases calculated self-consistently using FEFF8 [2] were used.

Wavelet transform (WT) is commonly applied to evaluation of complex time-frequency signals. As shown in refs [3,4], WT is easily adapted to EXAFS analysis, and the expression of the WT of the $\mathrm{k}^{\mathrm{n}}$ weighted EXAFS data takes the form:

$$
W_{\chi}^{\psi}(k, r)=(2 r)^{1 / 2} \int_{-\infty}^{\infty} \chi\left(k^{\prime}\right) k^{\prime n} \psi^{*}\left[2 r\left(k^{\prime}-k\right)\right] d k^{\prime},
$$

where $\chi(\mathrm{k})$ is the EXAFS signal and $\psi^{*}\left[2 r\left(k^{\prime}-k\right)\right]$ is the complex wavelet function.

The WT is able to resolve the $\mathrm{k}$ dependence of the absorption signal, which potentially allows separation of contributing backscattering atoms even situated at the same distances from the core. One of the advantages of the wavelet analysis is the visualization of the WT modulus in a k-R plot, which provides an easy way to interpret the results. Our analysis of EXAFS data for Pu and Hf were performed using the FORTRAN program HAMA employing Morlet wavelet algorithm [5]. The Morlet wavelet is well-suited for EXAFS signal since it consists of a slowly varying amplitude term and a fast oscillating phase term. Its mathematical description is broadly analogous to the Fourier transform. The Morlet wavelet is obtained by taking a complex sine wave with frequency $\eta$ (as in FT) and by confining it with a Gaussian envelope with the half width $\sigma$,

$$
\psi(k)=\frac{1}{(2 \pi)^{1 / 2} \sigma} \exp (i \eta k) \exp \left(-k^{2} / 2 \sigma^{2}\right) .
$$

The choice of the $\eta$ and $\sigma$ parameters is important for data analysis since, besides other issues, it determines resolution in $\mathrm{k}-\mathrm{R}$ space. Various combinations of these parameters were used in an attempt to resolve contributions from atoms at close distances from the central atom. As shown in ref.[4] use of higher k-weighting decreases resolution in the k-space, since backscattering amplitudes become flattened and shifted to higher values. Nevertheless, WT modulus plots for different $\mathrm{k}$ weights are shown to emphasize contributions of light and heavy backscatterers. Note, that in all plots of the WT modulus the interatomic distances are given without phase shift correction. 
Table I. Chemical Compositions of Glasses in Series 21.

\begin{tabular}{|c|c|c|c|c|c|c|c|c|c|}
\hline \multirow{3}{*}{ Oxides } & \multicolumn{3}{|c|}{ FY09EM 21-02 } & \multicolumn{3}{|c|}{ FY09EM 21-07 } & \multicolumn{3}{|c|}{ FY09EM 21-21 } \\
\hline & \multicolumn{2}{|c|}{ Target } & \multirow{2}{*}{$\begin{array}{c}\text { Actual } \\
\text { Wt.\% }\end{array}$} & \multicolumn{2}{|c|}{ Target } & \multirow{2}{*}{$\begin{array}{c}\text { Actual } \\
\text { Wt.\% }\end{array}$} & \multicolumn{2}{|c|}{ Target } & \multirow{2}{*}{$\begin{array}{c}\text { Actual } \\
\text { Wt. } \%\end{array}$} \\
\hline & Mol.\% & Wt.\% & & Mol.\% & Wt.\% & & Mol.\% & Wt.\% & \\
\hline $\mathrm{Al}_{2} \mathrm{O}_{3}$ & 2.71 & 4.01 & 4.31 & 3.25 & 4.87 & 5.07 & 3.21 & 4.86 & 4.75 \\
\hline $\mathrm{B}_{2} \mathrm{O}_{3}$ & 5.03 & 5.07 & 5.30 & 13.62 & 13.92 & 13.75 & 8.71 & 9.01 & 8.78 \\
\hline $\mathrm{BaO}$ & 0.04 & 0.08 & 0.08 & - & - & - & 0.04 & 0.08 & 0.07 \\
\hline $\mathrm{CaO}$ & - & - & 0.02 & 4.76 & 3.92 & 3.98 & - & - & 0.02 \\
\hline $\mathrm{CdO}$ & 0.16 & 0.30 & 0.28 & - & - & - & 0.16 & 0.30 & 0.27 \\
\hline $\mathrm{Ce}_{2} \mathrm{O}_{3}$ & 0.16 & 0.36 & 0.40 & - & - & - & 0.16 & 0.36 & 0.38 \\
\hline $\mathrm{Cr}_{2} \mathrm{O}_{3}$ & - & - & - & - & - & - & 0.09 & 0.20 & 0.20 \\
\hline $\mathrm{CuO}$ & 0.11 & 0.13 & 0.14 & - & - & - & 0.11 & 0.13 & 0.13 \\
\hline $\mathrm{Fe}_{2} \mathrm{O}_{3}$ & 8.92 & 20.63 & 22.25 & 7.67 & 17.98 & 17.85 & 8.41 & 19.95 & 23.40 \\
\hline $\mathrm{La}_{2} \mathrm{O}_{3}$ & 0.02 & 0.10 & 0.09 & - & - & - & 0.02 & 0.10 & 0.08 \\
\hline $\mathrm{Li}_{2} \mathrm{O}$ & 9.24 & 4.00 & 3.99 & 9.12 & 4.00 & 3.89 & 15.77 & 7.00 & 6.63 \\
\hline $\mathrm{MgO}$ & 2.57 & 1.50 & 1.51 & 2.53 & 1.50 & 1.47 & - & - & - \\
\hline $\mathrm{MnO}$ & 0.29 & 0.30 & 0.40 & 5.28 & 5.50 & 5.34 & 0.95 & 1.00 & 1.23 \\
\hline $\mathrm{Na}_{2} \mathrm{O}$ & 20.03 & 17.98 & 18.00 & 13.97 & 12.71 & 12.50 & 15.94 & 14.67 & 13.65 \\
\hline $\mathrm{Nb}_{2} \mathrm{O}_{5}$ & - & - & 1.20 & - & - & 1.16 & - & - & 1.12 \\
\hline $\mathrm{NiO}$ & 2.31 & 2.50 & - & - & - & - & - & - & - \\
\hline $\mathrm{PbO}$ & 0.07 & 0.22 & 0.22 & - & - & - & 0.07 & 0.22 & 0.21 \\
\hline $\mathrm{SO}_{4}$ & 0.41 & 0.48 & 0.55 & - & - & 0.07 & 0.40 & 0.48 & 0.53 \\
\hline $\mathrm{SiO}_{2}$ & 45.97 & 40.02 & 38.70 & 38.09 & 33.60 & 32.20 & 44.05 & 39.31 & 36.20 \\
\hline $\mathrm{TiO}_{2}$ & 1.73 & 2.00 & 1.97 & 1.71 & 2.00 & 1.90 & 1.69 & 2.01 & 1.84 \\
\hline $\mathrm{ZnO}$ & 0.11 & 0.13 & 0.13 & - & - & - & 0.11 & 0.13 & 0.12 \\
\hline $\mathrm{ZrO}_{2}$ & 0.12 & 0.21 & 0.21 & - & - & - & 0.11 & 0.21 & 0.19 \\
\hline Total & 100 & 100 & 99.75 & 100 & 100 & 99.18 & 100 & 100 & 99.80 \\
\hline$\psi_{\mathrm{B}}$ & $\sim 4$ & & & $\sim 1$ & & & $\sim 2$ & & \\
\hline$\psi_{\mathrm{B}}(\mathrm{Fe})$ & $\sim 3.5$ & & & $\sim 0.8$ & & & $\sim 1.7$ & & \\
\hline
\end{tabular}




\section{THEORETICAL REMARKS}

There are several structural parameters characterizing some features of the structure of glasses. The most important among them are degree of connectedness of the silica-oxygen network $\left(f_{\mathrm{si}}\right)$ for silicate-based and relative fraction of four-coordinated boron $\left(\psi_{\mathrm{B}}\right)$ for borate and borosilicate glasses [6]:

$$
\psi_{\mathrm{B}}=\left\{\left(\mathrm{Na}_{2} \mathrm{O}+\mathrm{K}_{2} \mathrm{O}+\mathrm{BaO}\right)+\left[0.7(\mathrm{CaO}+\mathrm{SrO})+[0.3(\mathrm{MgO}+\mathrm{ZnO}+\mathrm{PbO})]-\mathrm{Al}_{2} \mathrm{O}_{3}\right\} / \mathrm{B}_{2} \mathrm{O}_{3}\right.
$$

Formally, boron is three-coordinated if $0 \leq \psi_{\mathrm{B}} \leq 1 / 3$ and forms boron-oxygen triangles. At $1 / 3<\psi_{\mathrm{B}}<1$ both three- and four-coordinated boron atoms co-exist and are present in complex borate groups. At $\psi_{\mathrm{B}} \geq$ 1 all the boron is four-coordinated and forms boron-oxygen tetrahedra associated with alkali and, in less extent, alkali earth cations as, for example, $\mathrm{Me}^{+}\left[\mathrm{BO}_{4 / 2}\right]$ units. Actually, significant excess of alkali or/and alkali earth oxides as oxygen donors to form $\mathrm{BO}_{4}$ tetrahedra and convert all the boron into fourcoordinated state is needed. This process depends also on silica content in glass. At relatively high silica content (60-80 wt.\%) the $\psi_{\mathrm{B}}$ value is estimated to be 1.5-2. At lower silica contents (44-60 wt.\%) this value should be much higher. We have demonstrated using IR and electron paramagnetic resonance (EPR) spectroscopy that in borosilicate glasses for high-sodium intermediate level waste immobilization containing 40-50 wt.\% $\mathrm{SiO}_{2}$ minor fraction of trigonally coordinated boron is present even at $\psi_{\mathrm{B}} \cong 4 \div 5$ [7].

Aluminum offers negative effect on transformation of trigonally coordinated boron into tetragonally coordinated one. Due to higher strength of $\mathrm{Al}-\mathrm{O}$ bond as compared to $\mathrm{B}-\mathrm{O}$ bond oxygen delivered by alkali oxides is firstly spent for formation of $\mathrm{AlO}_{4}$ tetrahedra and at relatively high $\mathrm{Al}_{2} \mathrm{O}_{3}$ concentrations major boron remains three-coordinated [6]. Nevertheless this does not offer negative effect on chemical durability of glasses, because aluminosilicate glass network built from $\mathrm{SiO}_{4}$ and $\mathrm{AlO}_{4}$ tetrahedra with associated alkali ions is leach resistant [8,9].

Effect of iron oxides on boron coordination in borosilicate glasses is more complicated. $\mathrm{Fe}^{3+}$ ions being network-formers act similarly to $\mathrm{Al}^{3+}$ ions forming $\mathrm{FeO}_{4}$ tetrahedra and suppressing $\mathrm{B}^{\mathrm{III}} \rightarrow \mathrm{B}^{\mathrm{IV}}$ conversion. However, since strength of $\mathrm{Fe}^{3+}-\mathrm{O}$ bond is lower then that of $\mathrm{Al}-\mathrm{O}$ bond, the effect of $\mathrm{Fe}_{2} \mathrm{O}_{3}$ on $\mathrm{B}^{\mathrm{III}} \rightarrow$ $\mathrm{B}^{\mathrm{IV}}$ conversion is weaker. Molar concentration of $\mathrm{Fe}_{2} \mathrm{O}_{3}$ should be subtracted like $\mathrm{Al}_{2} \mathrm{O}_{3}$ in eq. (3) but with coefficient less than 1 . Taking into account that energy of $\mathrm{Fe}^{3+}-\mathrm{O}$ bond is lower than that of $\mathrm{Al}-\mathrm{O}$ bond by $\sim 3$ times, this coefficient may be suggested to be $\sim 3$ as well. Therefore, in the numerator of the eq. (3) we have to subtract additionally $\sim 0.3 \times\left[\mathrm{Fe}_{2} \mathrm{O}_{3}\right]$. Thus in the presence of $\mathrm{Fe}_{2} \mathrm{O}_{3}$ the $\psi_{\mathrm{B}}$ values for the glasses studied are somewhat lower (Table I). At high concentrations in glasses $\mathrm{Fe}^{3+}$ ions may become network-modifiers with higher coordination number $(\mathrm{CN}=6)$ or form separate crystalline phase - hematite $\left(\mathrm{Fe}_{2} \mathrm{O}_{3}\right)$ or spinel, especially in the presence of $\mathrm{Fe}^{2+}$ ions or different transition metal ions $\left(\mathrm{Mn}^{2+}, \mathrm{Ni}^{2+}\right.$, $\mathrm{Co}^{2+}, \mathrm{Cu}^{2+}, \mathrm{Zn}^{2+}$ ) as well as $\mathrm{Mg}^{2+}$ and $\mathrm{Al}^{3+}$ ions. $\mathrm{Fe}^{2+}$ ions, if present, are network-modifiers, but often form spinel type phase. 
SRNL-STI-2010-00805

Revision 0

\section{RESULTS AND DISCUSSION}

\section{Chemical composition and XRD patterns}

All three glasses have similar $\mathrm{Al}_{2} \mathrm{O}_{3}$ target and actual contents. The glass 21-02 has the lowest $\mathrm{B}_{2} \mathrm{O}_{3}$ and highest $\mathrm{Na}_{2} \mathrm{O}$ and $\mathrm{SiO}_{2}$ contents. The glass 21-07 is high- $\mathrm{B}_{2} \mathrm{O}_{3}$ and low- $\mathrm{Na}_{2} \mathrm{O}$ and $\mathrm{SiO}_{2}$. The glass 21-21 has similar $\mathrm{Na}_{2} \mathrm{O}$ and $\mathrm{Li}_{2} \mathrm{O}$ molar concentrations and therefore appearance of mixed alkali effect may be expected in the most extent. All the glasses have comparable both weight and molar $\mathrm{Fe}_{2} \mathrm{O}_{3}$ concentrations. Although weight concentrations of $\mathrm{Fe}_{2} \mathrm{O}_{3}$ are rather high, their molar concentrations are not too high and XRD patterns of all three glasses demonstrate typical amorphous scattering with strong background at low angular range and "humps" in the vicinity of 30-32 degrees $2 \theta$ pointing to minor chemical ordering in glasses (Figure 1).

Optical Microscopy Images banded texture of the samples. Thee are different in quantitative ratios between transparent and opaque glasses. It should be noted occurrence of clear borders between differently colored glasses that may be due to different viscosity of melt layers with various content of iron oxides. No devitrification was observed.

As follows from optical microscopy image the sample 21-02 is predominantly composed of light transparent glass with a layer and small oval red-brown-colored area (Figure 2, left). The colored glass has layered texture appeared as the bands with red-brown and light-brown colorings. Light glass contains a lot of randomly distributed small gas bubbles up to $40 \mu \mathrm{m}$ in diameter.

Thin section of the glass 21-07 is composed of non-uniformly, predominantly brown, colored glass with spots of light-brown and clear transparent glass. It was revealed at high magnifications that the coloring is du to the finest red-brown colored particles and the intensity of coloring is directly proportional to particles concentration.

Thin section of the glass 21-21 (Figure 2, right) is composed of banded glass with variable coloring of the bands. Major area is taken with the bands of transparent and red-brown colored glasses. Minor area of the thin section is filled with glasses with different coloring. The banded (layered) texture was probably formed during pouring of molten glasses onto a metal plate.

SEM photomicrographs demonstrate homogeneity of glasses at least at a level of $~ 50-100 \mathrm{~nm}$ (Figure 3). No phase separation has been found. Elemental concentrations by EDS data were obtained by scanning over areas $100 \mu \mathrm{m} \times 100 \mu \mathrm{m}$ followed by recalculation to oxide concentrations (Tables II, III, and IV).

In the whole, there is a satisfactory agreement between the data obtained by ICP-AES and SEM/EDS taking into account that light elements (lighter than F) are not determined by EDS. Major elements are uniformly distributed over glass bulk whereas concentrations of some minor elements ( $\mathrm{S}, \mathrm{Mn}, \mathrm{Ni}, \mathrm{Cu}, \mathrm{Zn}$, $\mathrm{Zr}, \mathrm{Cd}, \mathrm{Ba}, \mathrm{La}, \mathrm{Ce}, \mathrm{Pb}$ ) vary markedly. Most of these elements are present in amounts not influencing on the structure of glass. 


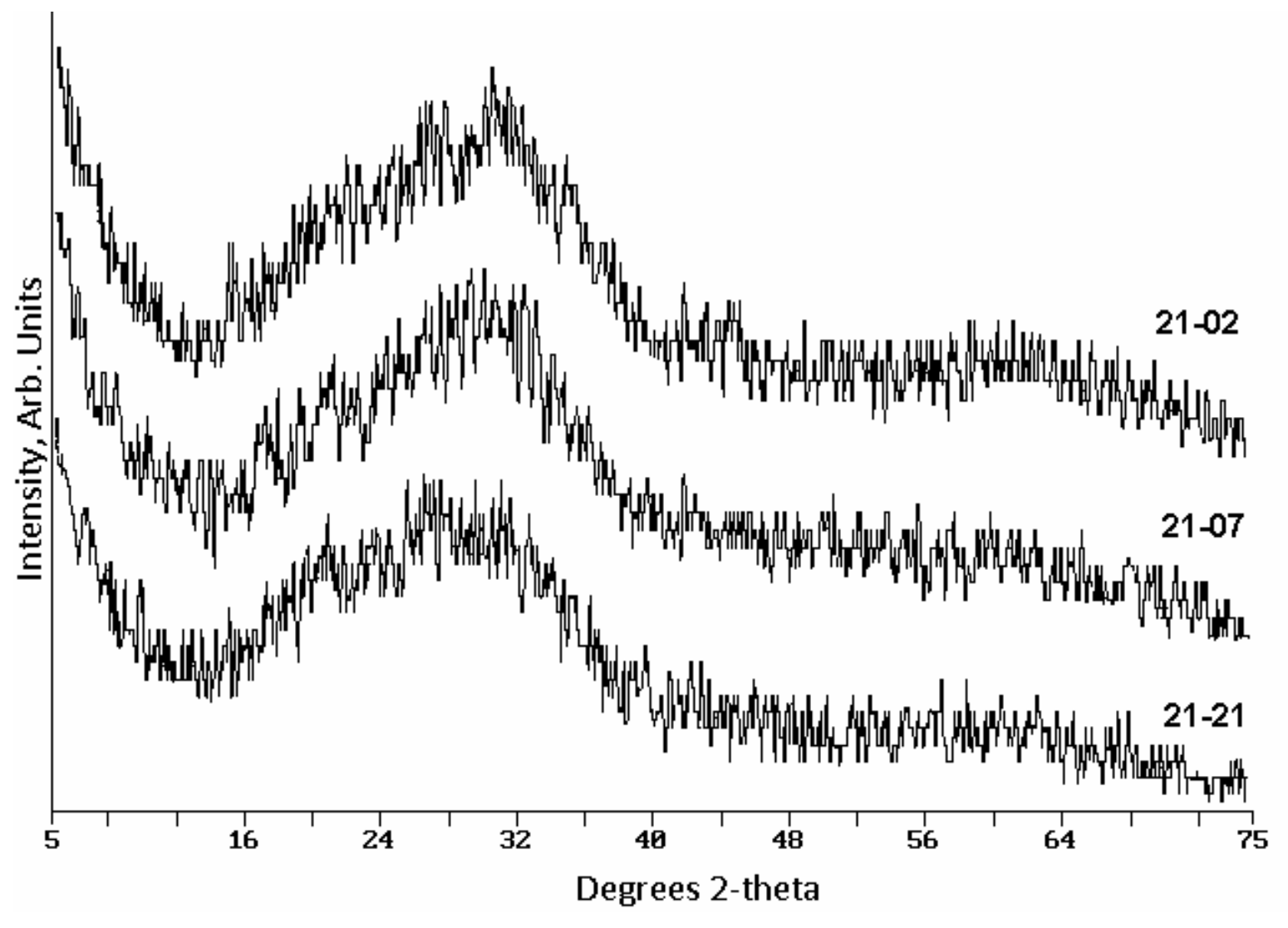

Figure 1. XRD Patterns of Samples in Series 21.
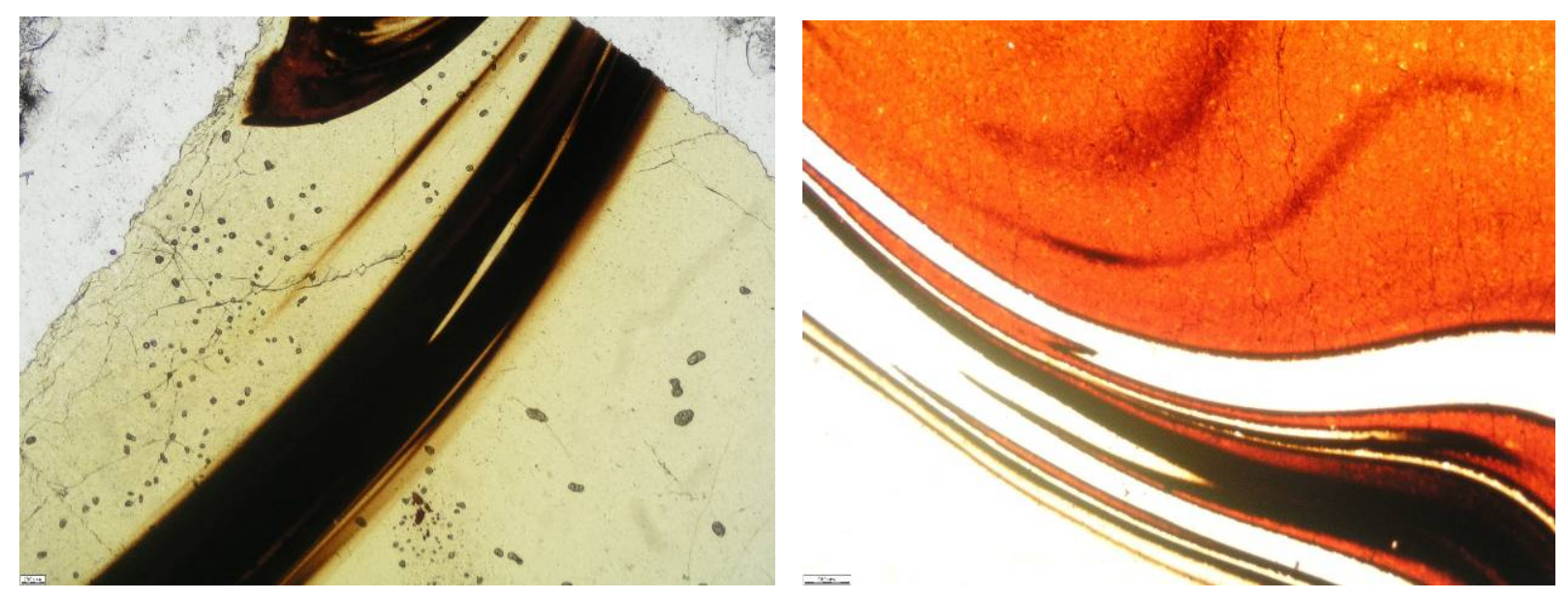

Figure 2. Optical Microscopy Images of Glasses 21-02 (left) and 21-21 (right). 


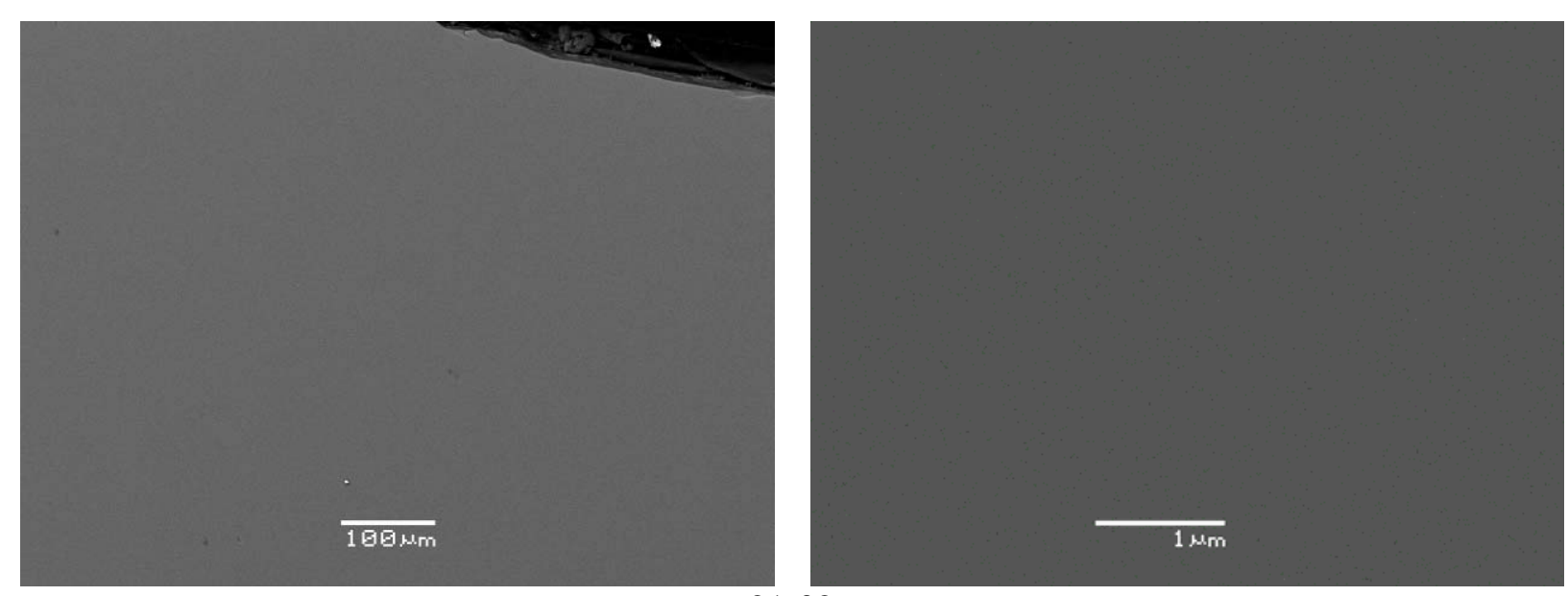

21-02

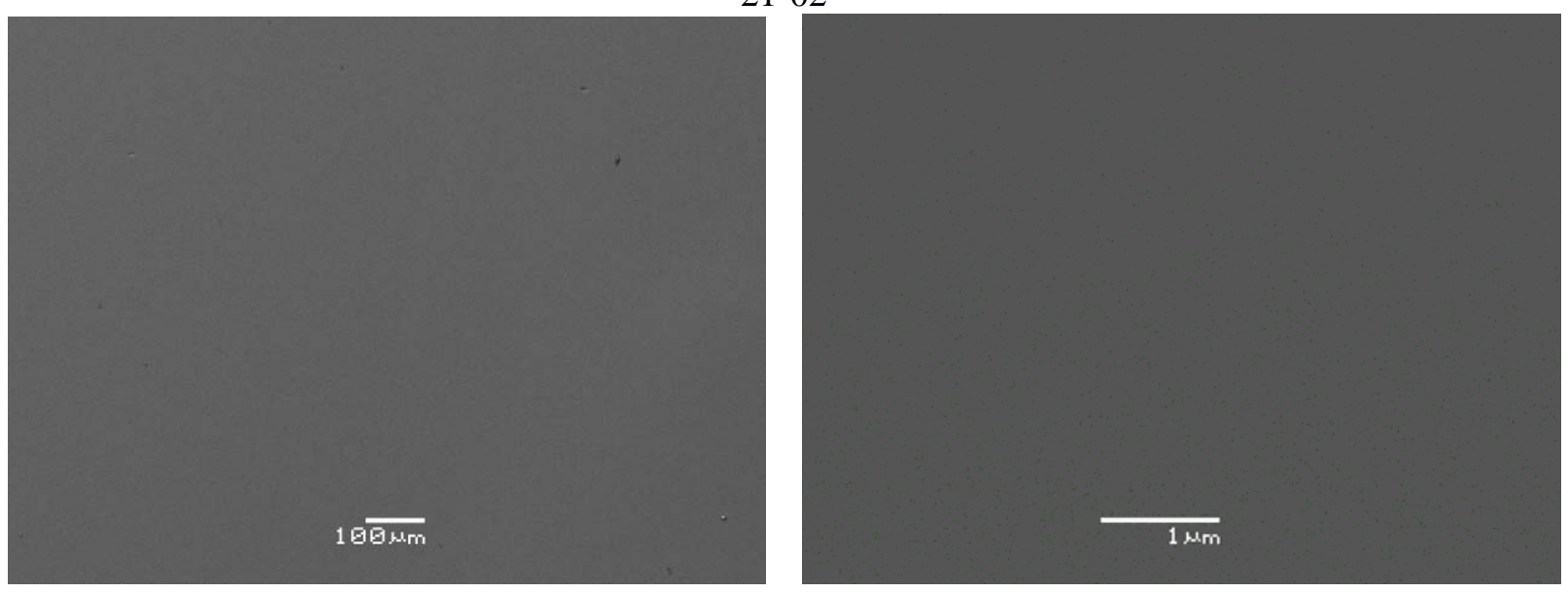

21-07

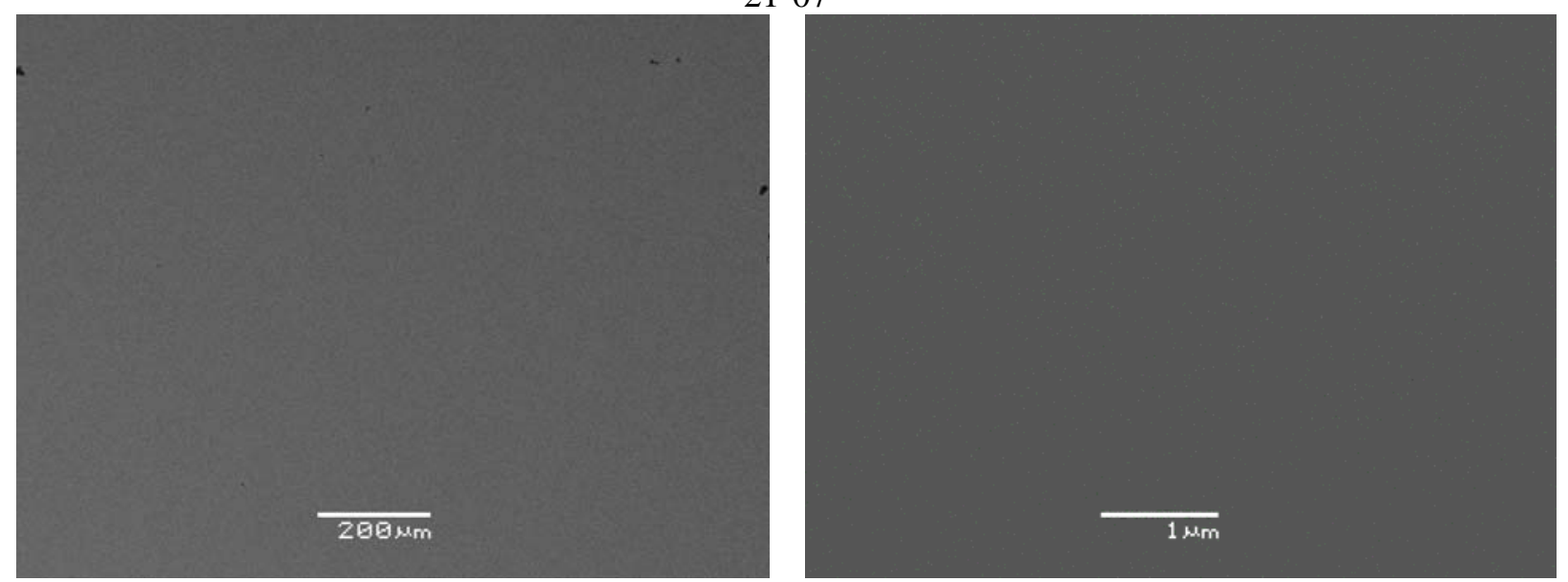

$21-21$

Figure 3. SEM Images of Samples in Series 21. 
Table II. Chemical Composition of Sample 21-02.

\begin{tabular}{|c|c|c|c|c|c|c|c|c|}
\hline \multirow[b]{2}{*}{ Oxides } & \multicolumn{6}{|c|}{ SEM/EDS data } & \multirow{2}{*}{$\begin{array}{l}\text { Target } \\
\text { comp. }\end{array}$} & \multirow{2}{*}{$\begin{array}{c}\text { ICP-AES } \\
\text { Actual } \\
\end{array}$} \\
\hline & Sigma \% & Scan 1 & Scan 2 & Scan 3 & Scan 4 & Average & & \\
\hline $\mathrm{Na}_{2} \mathrm{O}$ & 0.40 & 19.03 & 20.00 & 19.01 & 18.44 & 19.12 & 17.98 & 18.00 \\
\hline $\mathrm{MgO}$ & 0.13 & 1.81 & 1.73 & 1.76 & 1.80 & 1.78 & 1.50 & 1.51 \\
\hline $\mathrm{Al}_{2} \mathrm{O}_{3}$ & 0.13 & 5.16 & 4.99 & 5.04 & 5.09 & 5.07 & 4.01 & 4.31 \\
\hline $\mathrm{SiO}_{2}$ & 0.23 & 43.43 & 43.98 & 43.04 & 43.89 & 43.59 & 40.02 & 38.70 \\
\hline $\mathrm{SO}_{3}$ & 0.06 & 0.58 & 0.38 & 0.50 & 0.27 & 0.43 & 0.48 & 0.55 \\
\hline $\mathrm{TiO}_{2}$ & 0.10 & 2.33 & 2.10 & 1.98 & 2.13 & 2.14 & 2.00 & 1.97 \\
\hline $\mathrm{MnO}$ & 0.07 & 0.31 & 0.31 & 0.17 & 0.39 & 0.30 & 0.30 & 0.40 \\
\hline $\mathrm{Fe}_{2} \mathrm{O}_{3}$ & 0.21 & 19.91 & 20.19 & 19.56 & 19.91 & 19.89 & 20.63 & 22.25 \\
\hline $\mathrm{NiO}$ & 0.07 & 0.13 & 0.00 & 0.00 & 0.00 & 0.03 & 2.50 & 0.00 \\
\hline $\mathrm{CuO}$ & 0.09 & 0.10 & 0.16 & 0.07 & 0.07 & 0.10 & 0.13 & 0.14 \\
\hline $\mathrm{ZnO}$ & 0.11 & 0.18 & 0.29 & 0.00 & 0.18 & 0.16 & 0.13 & 0.13 \\
\hline $\mathrm{ZrO}_{2}$ & 0.19 & 0.23 & 0.16 & 0.00 & 0.00 & 0.10 & 0.21 & 0.21 \\
\hline $\mathrm{CdO}$ & 0.12 & 0.40 & 0.42 & 0.27 & 0.38 & 0.37 & 0.30 & 0.28 \\
\hline $\mathrm{BaO}$ & 0.21 & 0.36 & 0.00 & 0.29 & 0.00 & 0.16 & 0.08 & 0.08 \\
\hline $\mathrm{La}_{2} \mathrm{O}_{3}$ & 0.20 & 0.00 & 0.00 & 0.13 & 0.23 & 0.09 & 0.10 & 0.09 \\
\hline $\mathrm{Ce}_{2} \mathrm{O}_{3}$ & 0.16 & 0.19 & 0.47 & 0.33 & 0.38 & 0.34 & 0.36 & 0.40 \\
\hline $\mathrm{PbO}$ & 0.24 & 0.38 & 0.00 & 0.4 & 0.38 & 0.29 & 0.22 & 0.22 \\
\hline $\mathrm{B}_{2} \mathrm{O}_{3}$ & ND & ND & ND & ND & ND & ND & 5.07 & 5.30 \\
\hline $\mathrm{Li}_{2} \mathrm{O}$ & ND & ND & ND & ND & ND & ND & 4.00 & 3.99 \\
\hline Total & - & 94.53 & 95.18 & 92.55 & 93.54 & 93.95 & 100.00 & 99.75 \\
\hline
\end{tabular}


Table III. Chemical Composition of Sample 21-07.

\begin{tabular}{|c|c|c|c|c|c|c|}
\hline \multirow[b]{2}{*}{ Oxides } & \multicolumn{4}{|c|}{ SEM/EDS } & \multirow{2}{*}{$\begin{array}{l}\text { Target } \\
\text { comp. }\end{array}$} & \multirow{2}{*}{$\begin{array}{c}\text { ICP-AES } \\
\text { Actual }\end{array}$} \\
\hline & Scan 1 & Scan 2 & Scan 3 & Average & & \\
\hline $\mathrm{Al}_{2} \mathrm{O}_{3}$ & 5.80 & 6.14 & 5.61 & 5.85 & 4.87 & 5.07 \\
\hline $\mathrm{B}_{2} \mathrm{O}_{3}$ & ND & ND & ND & ND & 13.92 & 13.75 \\
\hline $\mathrm{CaO}$ & 4.31 & 4.12 & 4.15 & 4.19 & 3.92 & 3.98 \\
\hline $\mathrm{Fe}_{2} \mathrm{O}_{3}$ & 16.44 & 16.33 & 16.59 & 16.45 & 17.98 & 17.85 \\
\hline $\mathrm{Li}_{2} \mathrm{O}$ & ND & ND & ND & ND & 4.00 & 3.89 \\
\hline $\mathrm{MgO}$ & 1.37 & 1.77 & 1.89 & 1.68 & 1.50 & 1.47 \\
\hline $\mathrm{MnO}$ & 5.49 & 5.71 & 5.45 & 5.56 & 5.50 & 5.34 \\
\hline $\mathrm{Na}_{2} \mathrm{O}$ & 13.51 & 13.62 & 12.99 & 13.37 & 12.71 & 12.50 \\
\hline $\mathrm{SiO}_{2}$ & 36.15 & 36.05 & 35.65 & 35.95 & 33.60 & 32.20 \\
\hline $\mathrm{TiO}_{2}$ & 2.14 & 2.05 & 2.30 & 2.16 & 2.00 & 1.90 \\
\hline Total & 85.21 & 85.79 & 84.63 & 85.21 & 100.00 & 99.18 \\
\hline
\end{tabular}


Table IV. Chemical Composition of Sample 21-21.

\begin{tabular}{|c|c|c|c|c|c|c|c|}
\hline \multirow[b]{2}{*}{ Oxides } & \multicolumn{5}{|c|}{ SEM/EDS } & \multirow{2}{*}{$\begin{array}{l}\text { Target } \\
\text { comp. }\end{array}$} & \multirow{2}{*}{$\begin{array}{c}\text { ICP-AES } \\
\text { Actual }\end{array}$} \\
\hline & Sigma $\%$ & Scan 1 & Scan 2 & Scan 3 & Average & & \\
\hline $\mathrm{Na}_{2} \mathrm{O}$ & 0.37 & 15.54 & 15.31 & 15.85 & 15.57 & 14.67 & 13.65 \\
\hline $\mathrm{Al}_{2} \mathrm{O}_{3}$ & 0.14 & 6.33 & 6.21 & 6.35 & 6.30 & 4.86 & 4.75 \\
\hline $\mathrm{SiO}_{2}$ & 0.23 & 43.73 & 42.66 & 43.07 & 43.15 & 39.31 & 36.20 \\
\hline $\mathrm{SO}_{3} / \mathrm{SO}_{4}$ & 0.06 & 0.37 & 0.57 & 0.40 & 0.45 & 0.48 & 0.53 \\
\hline $\mathrm{TiO}_{2}$ & 0.09 & 1.90 & 2.00 & 1.82 & 1.91 & 2.01 & 1.84 \\
\hline $\mathrm{MnO}$ & 0.08 & 1.03 & 0.89 & 1.04 & 0.99 & 1.00 & 1.23 \\
\hline $\mathrm{Fe}_{2} \mathrm{O}_{3}$ & 0.20 & 18.45 & 18.85 & 18.69 & 18.66 & 19.95 & 23.40 \\
\hline $\mathrm{CuO}$ & 0.09 & 0.00 & 0.00 & 0.12 & 0.04 & 0.13 & 0.13 \\
\hline $\mathrm{ZnO}$ & 0.11 & 0.24 & 0.18 & 0.26 & 0.23 & 0.13 & 0.12 \\
\hline $\mathrm{ZrO}_{2}$ & 0.20 & 0.26 & 0.20 & 0.35 & 0.27 & 0.21 & 0.19 \\
\hline $\mathrm{CdO}$ & 0.12 & 0.09 & 0.18 & 0.31 & 0.19 & 0.30 & 0.27 \\
\hline $\mathrm{BaO}$ & 0.20 & 0.31 & 0.14 & 0.30 & 0.25 & 0.01 & 0.07 \\
\hline $\mathrm{La}_{2} \mathrm{O}_{3}$ & 0.19 & 0.6 & 0.24 & 0.00 & 0.28 & 0.10 & 0.08 \\
\hline $\mathrm{Ce}_{2} \mathrm{O}_{3}$ & 0.15 & 0.48 & 0.15 & 0.00 & 0.21 & 0.36 & 0.38 \\
\hline $\mathrm{PbO}$ & 0.24 & 0.35 & 0.18 & 0.00 & 0.18 & 0.22 & 0.21 \\
\hline $\mathrm{B}_{2} \mathrm{O}_{3}$ & ND & ND & ND & ND & ND & 9.01 & 8.78 \\
\hline $\mathrm{Li}_{2} \mathrm{O}$ & ND & ND & ND & ND & ND & 7.00 & 6.63 \\
\hline Total & - & 89.68 & 87.76 & 88.56 & 88.67 & 100.00 & 99.80 \\
\hline
\end{tabular}




\section{Effect of etching on the structure of the surface of glasses}

The polished surfaces of the samples 21-02, 21-07 and 21-21 were etched with $0.1 \mathrm{M} \mathrm{HCl}$ for 1 day and studied by SEM/EDS. General view of the samples is shown on Figure 4.

Surface of the glasses after etching is coated with a mesh of micron-sized cracks (Figures 5-7). As follows from SEM/EDS data (Table V), the rim is strongly depleted with $\mathrm{Na}_{2} \mathrm{O}$ and enriched with $\mathrm{SiO}_{2}$ i.e. this is a typical surface layer remaining on the surface of glass after leaching. Chemical composition of the core is similar to that of the bulk of unaltered glass. No phase separation was found. 

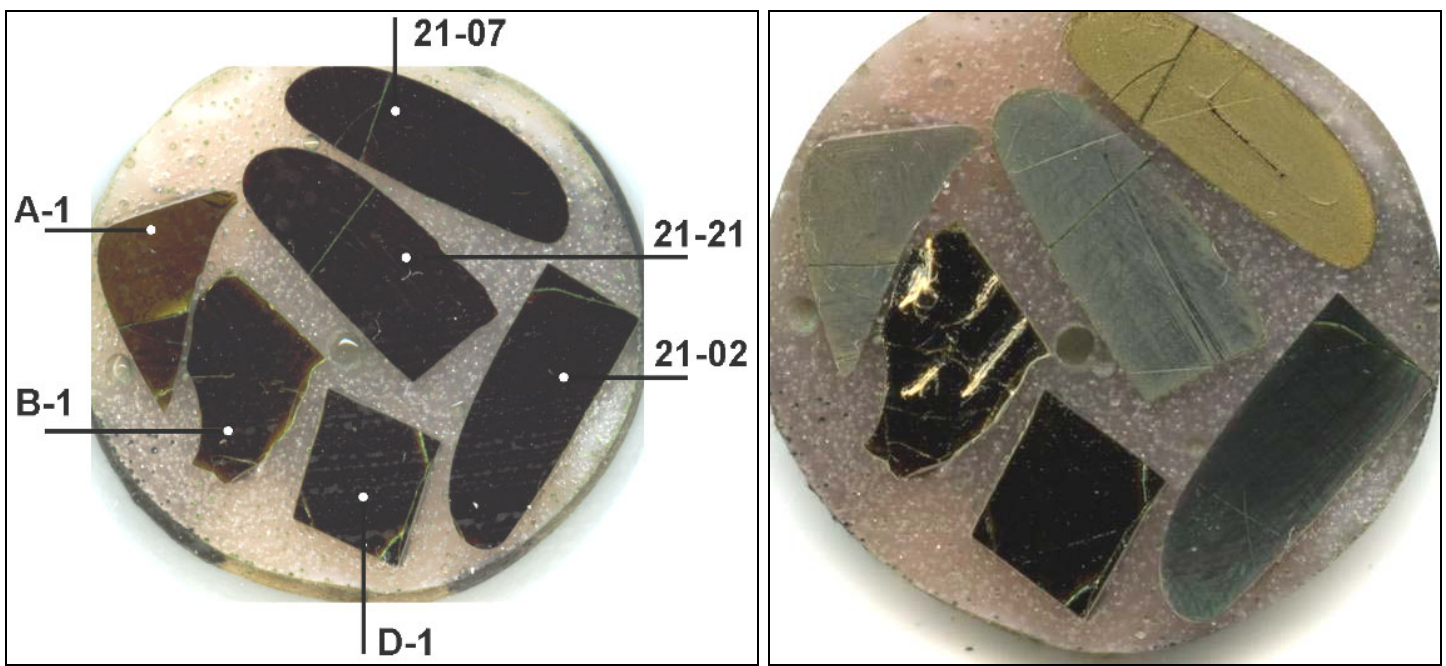

Figure 4. View of the samples before (left) and after etching (right).

Glasses A1, B1 and D1 will be described in a separate report. 

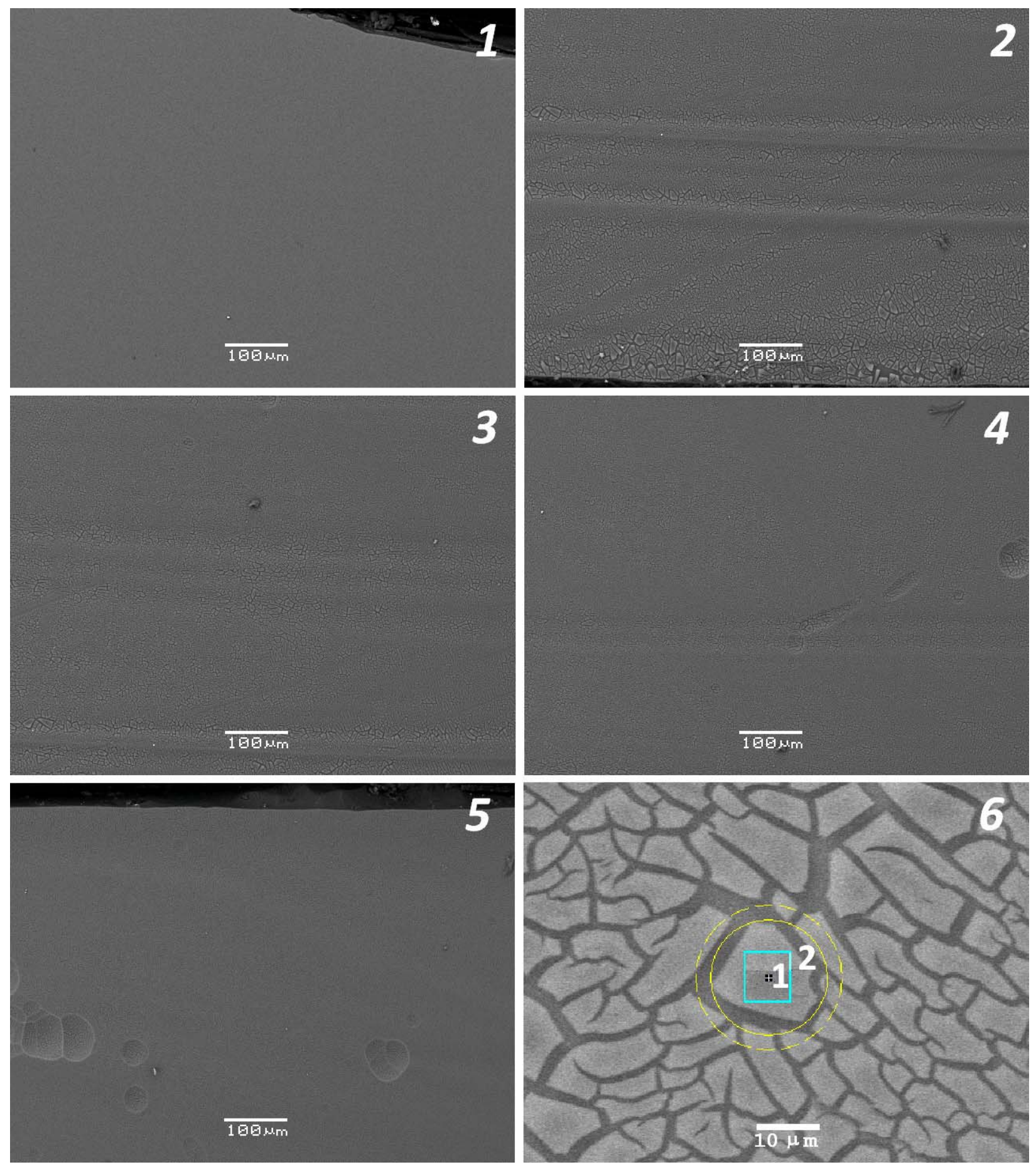

Figure 5. BSE SEM images of the surface of the glass 21-02 before (1) and after (2-5) etching in 0.1 M HCl. 

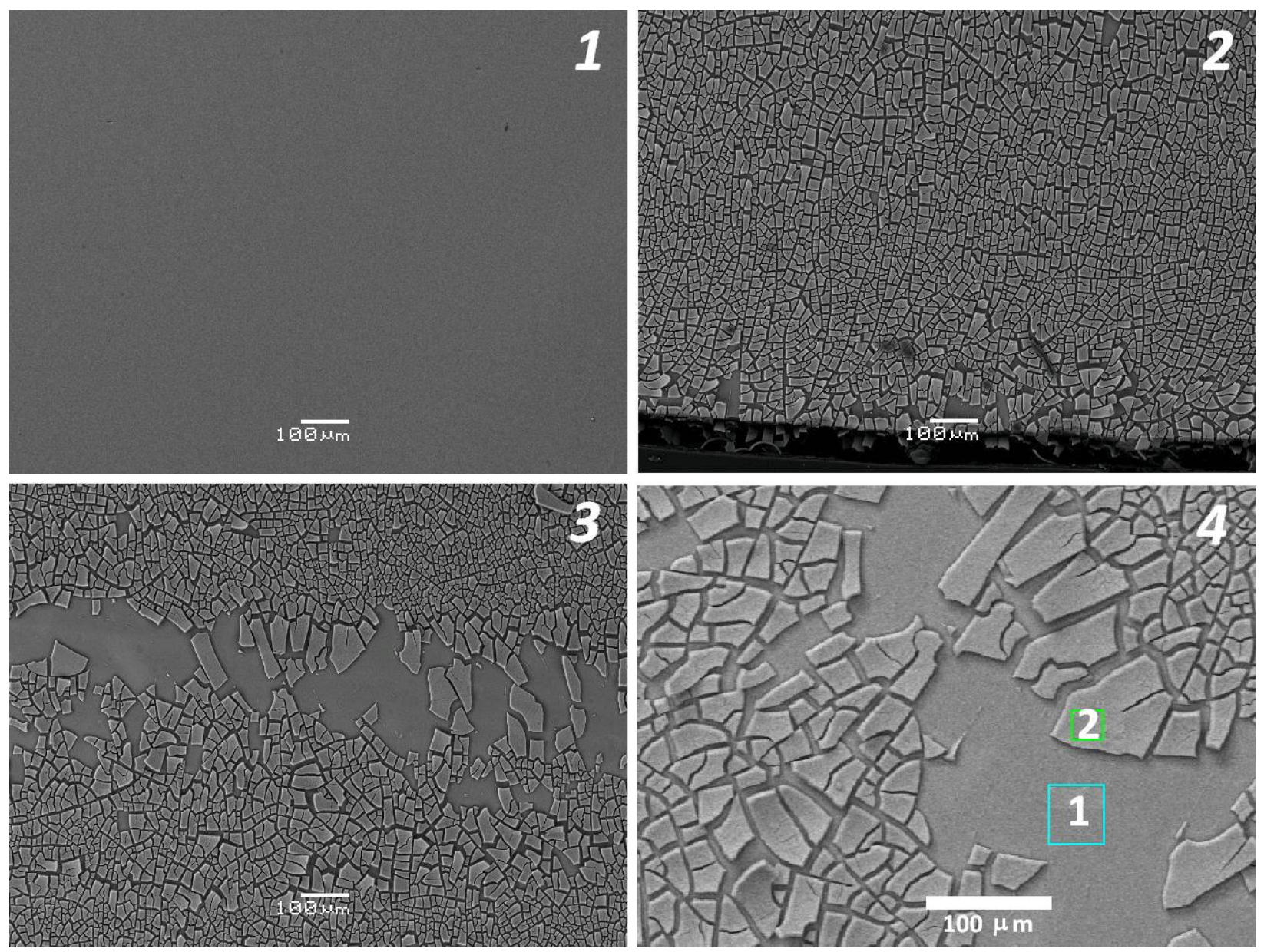

Figure 6. BSE SEM Image of the surface of the glass 21-07 before (1) and after (2-4) etching in 0.1 M HCl. 

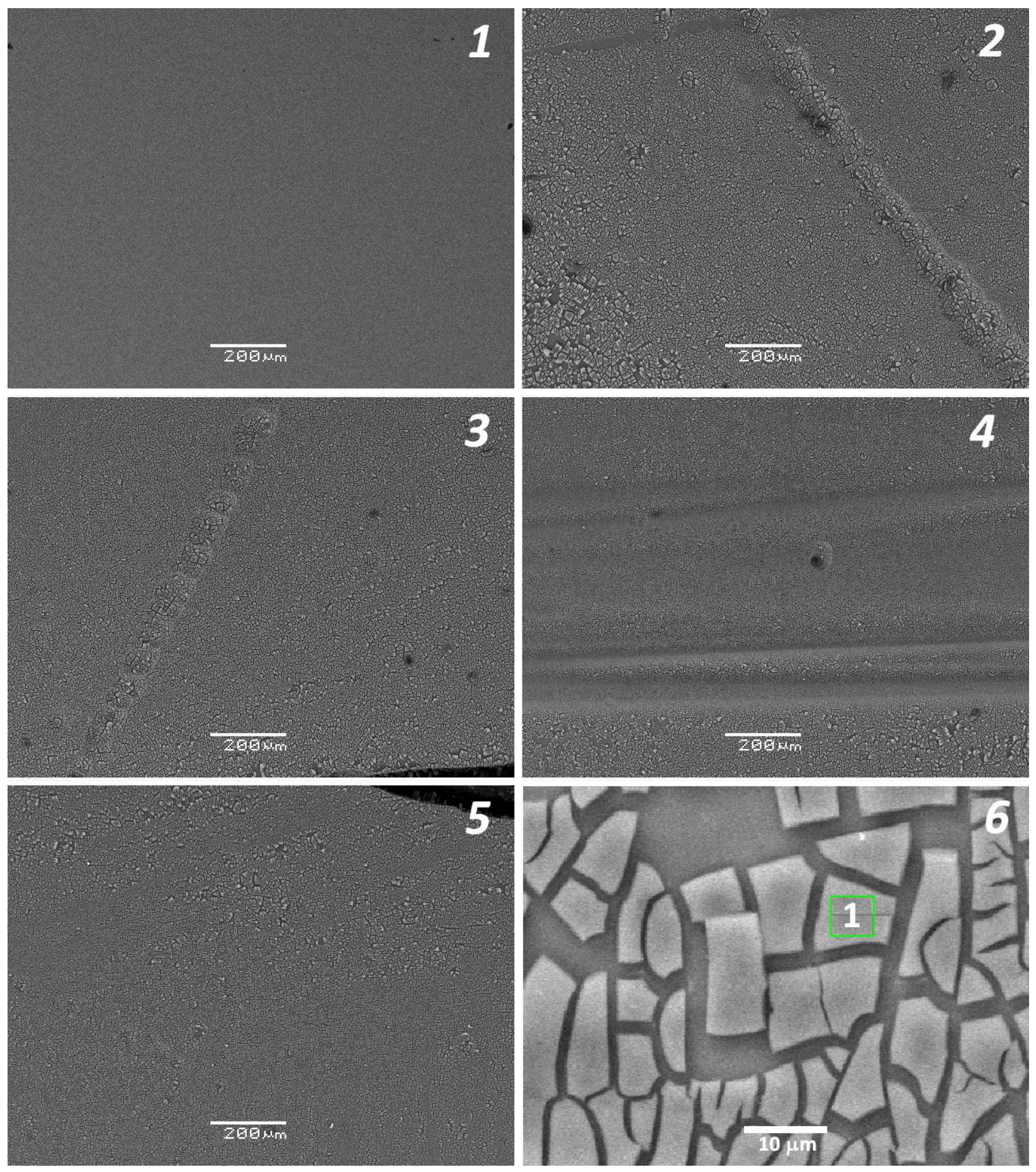

Figure 7. BSE SEM Image of the surface of the glass 21-21 before (1) and after (2-6) etching in 0.1 M HCl. 
Table V. Chemical composition by EDS of various areas on the surfaces of etched glasses.

\begin{tabular}{|c|c|c|c|c|c|c|c|c|}
\hline \multirow{2}{*}{ Oxides } & \multicolumn{3}{|c|}{ 21-02 } & \multicolumn{3}{|c|}{$21-07$} & \multicolumn{2}{|c|}{$21-21$} \\
\hline & 1 (rim) & 2 (rim+core) & Glass* & 1 (core) & 2 (rim) & Glass* & 1 (rim) & Glass* \\
\hline $\mathrm{Na}_{2} \mathrm{O}$ & 7.93 & 6.56 & 18.00 & 11.35 & 0.47 & 12.50 & 2.43 & 13.65 \\
\hline $\mathrm{MgO}$ & 1.23 & 1.26 & 1.51 & 1.63 & 0.34 & 1.47 & - & - \\
\hline $\mathrm{Al}_{2} \mathrm{O}_{3}$ & 3.34 & 3.47 & 4.31 & 5.09 & 0.54 & 5.07 & 2.52 & 4.75 \\
\hline $\mathrm{SiO}_{2}$ & 40.71 & 40.39 & 38.70 & 32.93 & 35.78 & 32.20 & 36.29 & 36.20 \\
\hline $\mathrm{CaO}$ & 0.74 & 0.92 & 0.02 & 3.8 & 3.64 & 3.98 & - & 0.02 \\
\hline $\mathrm{TiO}_{2}$ & 3.96 & 3.81 & 1.97 & 1.95 & 5.61 & 1.90 & 4.14 & 1.84 \\
\hline $\mathrm{MnO}$ & 0.33 & 0.36 & 0.40 & 5.06 & 0.15 & 5.34 & 0.69 & 1.23 \\
\hline $\mathrm{Fe}_{2} \mathrm{O}_{3}$ & 18.62 & 19.64 & 22.25 & 19.72 & 32.56 & 17.85 & 18.69 & 23.40 \\
\hline $\mathrm{NiO}$ & 0.10 & - & - & - & - & - & - & \\
\hline $\mathrm{ZnO}$ & 1.24 & 1.64 & 0.13 & - & 1.98 & - & 2.29 & 0.12 \\
\hline $\mathrm{ZrO}_{2}$ & 0.23 & 0.24 & 0.21 & - & - & - & - & 0.19 \\
\hline $\mathrm{BaO}$ & 0.20 & 0.39 & 0.08 & - & - & - & 0.65 & 0.07 \\
\hline $\mathrm{PbO}$ & 0.75 & 0.48 & 0.22 & - & - & - & 0.32 & 0.21 \\
\hline Sum & 79.38 & 79.16 & 87.80 & 81.53 & 81.07 & 80.31 & 68.02 & 81.68 \\
\hline $\mathrm{Li}_{2} \mathrm{O}$ & nd & nd & 3.99 & nd & nd & 3.89 & nd & 6.63 \\
\hline $\mathrm{B}_{2} \mathrm{O}_{3}$ & nd & nd & 5.30 & nd & nd & 13.75 & nd & 8.78 \\
\hline Total & & & 97.09 & & & 97.95 & & 97.09 \\
\hline
\end{tabular}

* actual concentration in glass measured by ICP-OES. 


\section{FTIR and Raman spectra}

IR spectra within the range of 4000-400 $\mathrm{cm}^{-1}$ (Figure 8) are composed of bands within the range of 3600$3200 \mathrm{~cm}^{-1}$ and $1650-1600 \mathrm{~cm}^{-1}$ due to stretching and bending modes in molecules of absorbed and structurally bound water and hydroxyl groups [10], weak bands at $2950-2800 \mathrm{~cm}^{-1}$ due to oscillations of hydrogen bonds and bonds located lower than $1600 \mathrm{~cm}^{-1}$ due to oscillations of bonds forming anionic motif of the structure of glasses. This range is considered in more details (Figure 9). The spectra within the range of $600-30 \mathrm{~cm}^{-1}$ were recorded separately (Figure 9).

As follows from chemical composition of glasses (Table I) the glass 21-07 has the lowest concentrations of $\mathrm{SiO}_{2}$ and $\mathrm{Na}_{2} \mathrm{O}$ and the highest fraction of trigonally coordinated boron among all three glasses studied. IR spectrum of this sample has strong absorption at $1350-1500 \mathrm{~cm}^{-1}$ whereas absorption within the same range in the spectra of sample 21-21 and 21-02 is weaker. The wavenumber ranges of $1500-1300 \mathrm{~cm}^{-1}$ and $\sim 1260-1270 \mathrm{~cm}^{-1}$ are typical of oscillations in the boron-oxygen groups with trigonally coordinated boron (boron-oxygen triangles $\mathrm{BO}_{3}$ ) [11]. In Raman spectra (Figure 6) a weak band is observed at 1250$1450 \mathrm{~cm}^{-1}$. Its intensity decreases with the increase of the $\psi_{\mathrm{B}}$ value and becomes negligible in the spectrum of glass 21-02 with the highest $\psi_{\mathrm{B}}$ value. These bands were attributed as components of twice degenerated asymmetric valence $v_{3} \mathrm{O}-\mathrm{B}-\mathrm{O}$ vibrations (stretching modes). The band with components $\sim 710-730$ and $650-670 \mathrm{~cm}^{-1}$ may be associated with twice degenerated asymmetric deformation $\delta\left(v_{4}\right)$ $\mathrm{O}-\mathrm{B}-\mathrm{O}$ vibration (bending modes) [11]. Valence $v_{1} \mathrm{O}-\mathrm{B}-\mathrm{O}$ vibrations at $\sim 805-810 \mathrm{~cm}^{-1}$ are inactive in IR spectra [10] but may be observable if symmetry decreases. In our spectrum this band is very weak but clearly appeared. The shoulder at $\sim 520 \mathrm{~cm}^{-1}$ and the band with a maximum at $\sim 470-475 \mathrm{~cm}^{-1}$ are components of symmetric deformation $\delta\left(v_{2}\right) \mathrm{O}-\mathrm{B}-\mathrm{O}$ vibration. Their appearance exhibits distortion of $\mathrm{BO}_{3}$ units linked in network.

Strong absorption in both IR and Raman spectra within the range of $1150-850 \mathrm{~cm}^{-1}$ is caused by asymmetric $v_{3}$ vibrations in silicon-oxygen units bonded to zero $\left(850-900 \mathrm{~cm}^{-1}\right)$, one $\left(\sim 900-950 \mathrm{~cm}^{-1}\right)$, two $\left(\sim 950-1050 \mathrm{~cm}^{-1}\right)$, three $\left(\sim 1050-1130 \mathrm{~cm}^{-1}\right)$ and four $\left(\sim 1130-1200 \mathrm{~cm}^{-1}\right)$ neighboring $\mathrm{SiO}_{4}$ tetrahedra $\left(\mathrm{Q}^{0}, \mathrm{Q}^{1}, \mathrm{Q}^{2}, \mathrm{Q}^{3}, \mathrm{Q}^{4}\right.$, respectively) [12] and, in less extent, $\mathrm{BO}_{4}$ tetrahedra $\left(1000-1100 \mathrm{~cm}^{-1}\right)$ [11]. In IR spectra of all the glasses the broad band within the range of $\sim 800-1200 \mathrm{~cm}^{-1}$ is multicomponent due to superposition of oscillations in $\mathrm{SiO}_{4}$ and $\mathrm{BO}_{4}$ tetrahedra. The strongest absorption takes place within the range of $980-1150 \mathrm{~cm}^{-1}$. Absorption within the range of $\sim 800-980 \mathrm{~cm}^{-1}$ is the strongest in the spectrum of glass 21-07 and the lowest - in the spectrum of glass 21-02 that is consistent with variation of silica content in glass and $\psi_{\mathrm{B}}$ value, i.e. relation of intensities of these two bands is changed in favor of higher wavenumber band with increasing of $\psi_{\mathrm{B}}$ value. This may be accounted for increase of fraction of fourcoordinated boron (absorption at 1000-1100 $\mathrm{cm}^{-1}$ ), in particular, increase of the number of bridging $\mathrm{Si}-\mathrm{O}-\mathrm{B}$ bonds linking $\mathrm{SiO}_{4}$ and $\mathrm{BO}_{4}$ tetrahedra in common network. At that, the number of $\mathrm{Q}^{0}$ and $\mathrm{Q}^{1}$ tetrahedra decreases and glass network renders higher degree of connectedness (polymerization). 


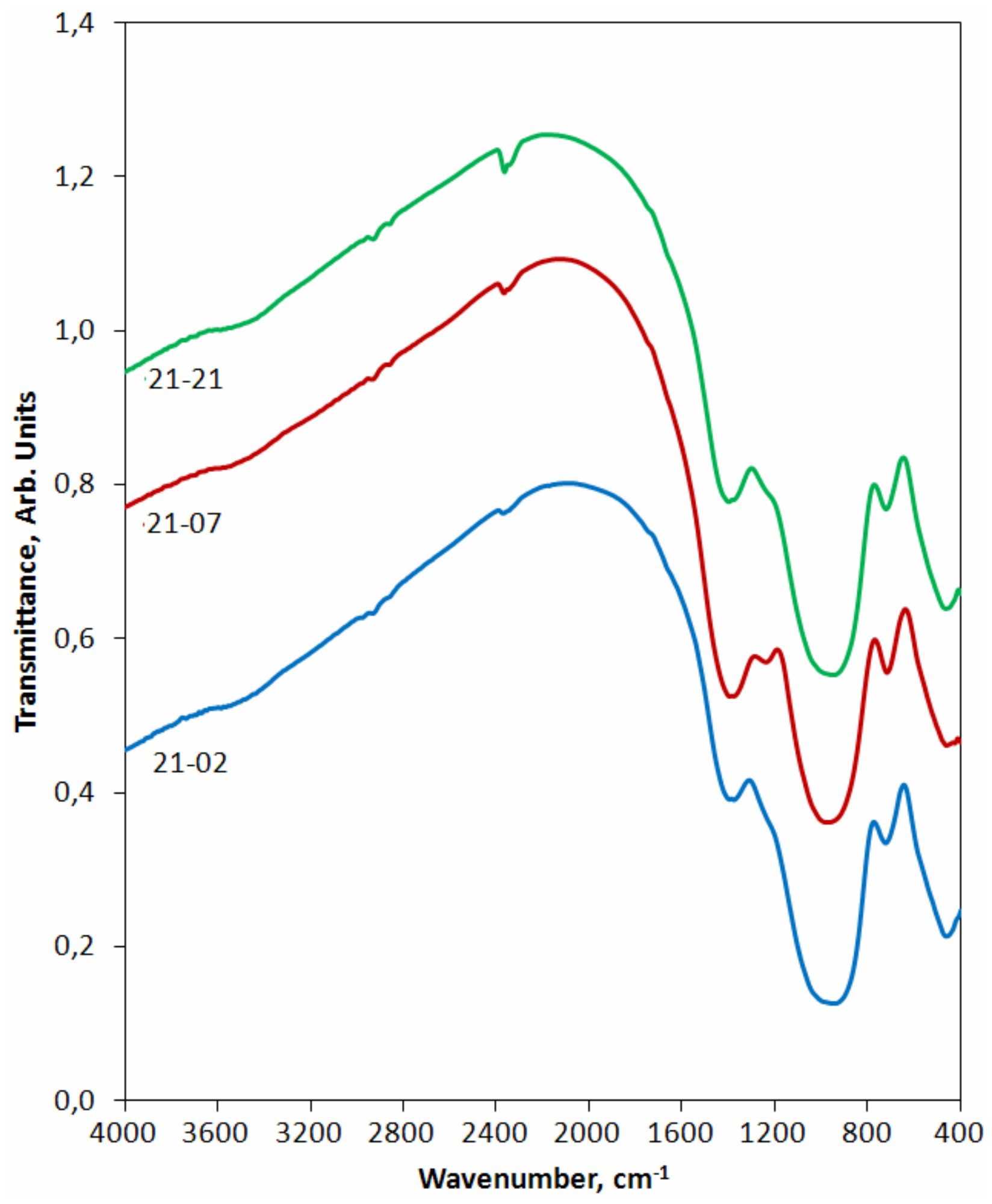

Figure 8. IR spectra of Glasses in Series 21. 


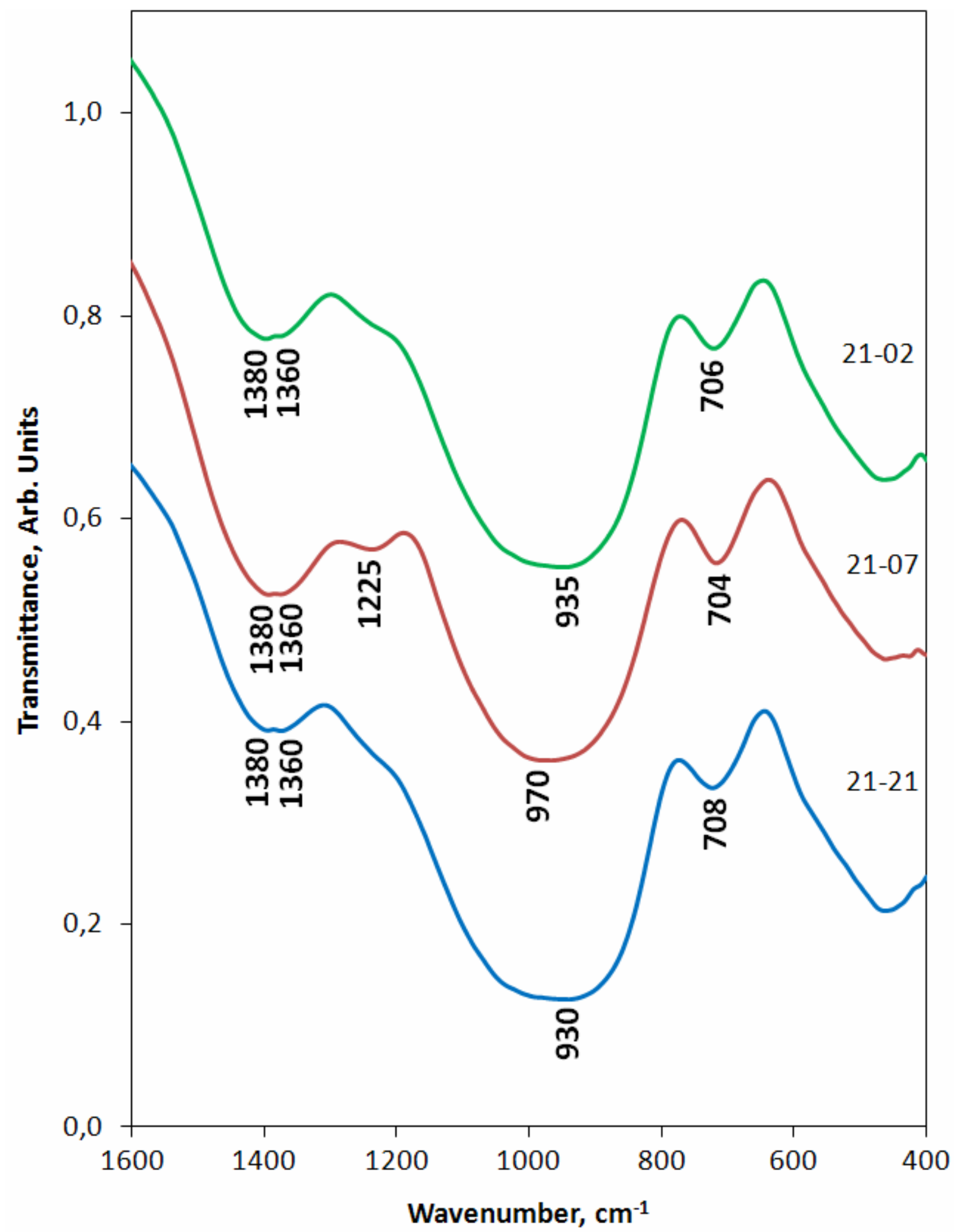

Figure 9. Fragments of IR Spectra of glasses in series 21 within the range of $400-1600 \mathrm{~cm}^{-1}$. 


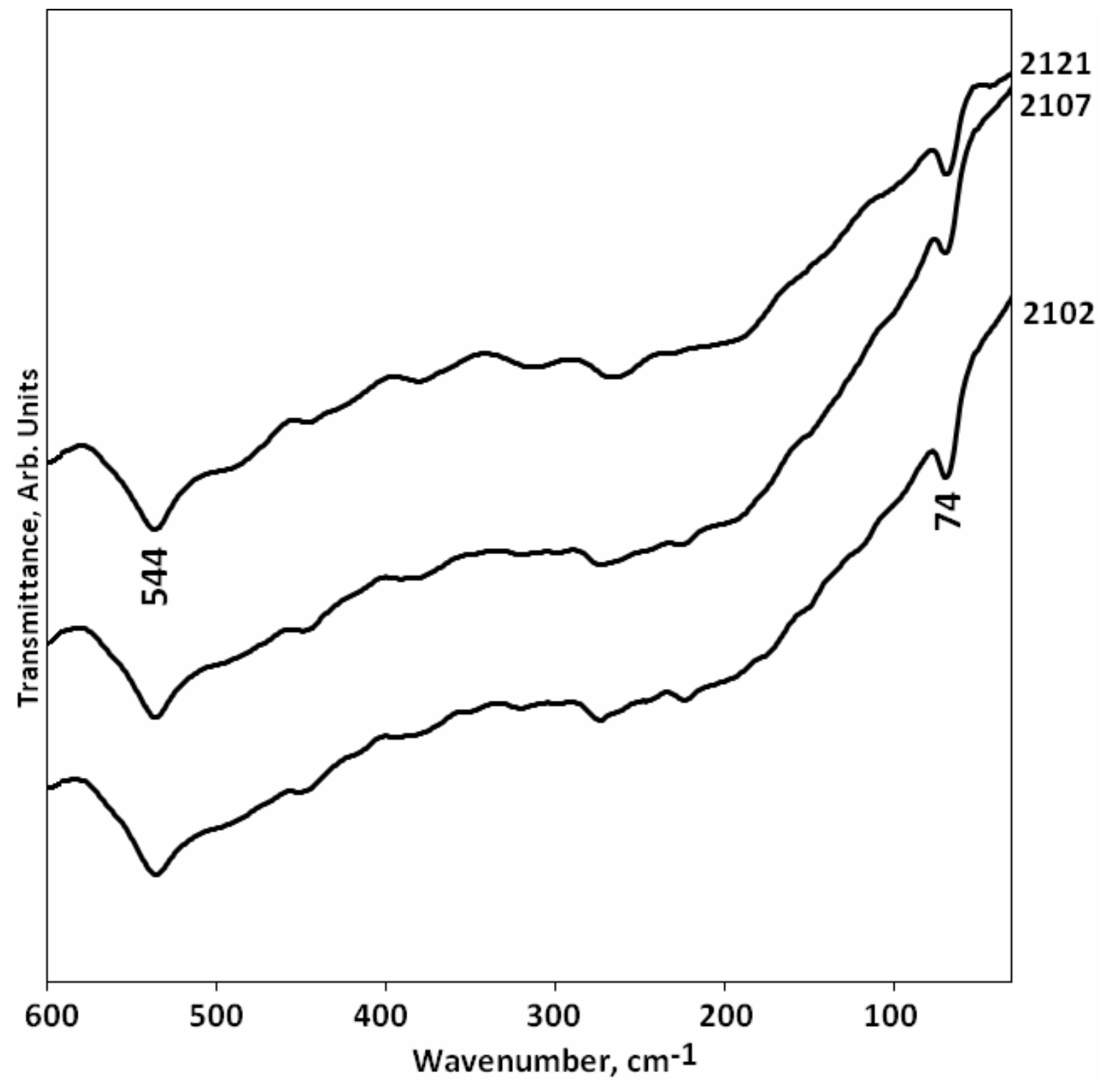

Figure 10. IR spectra of glasses in series 21 within the range of $30-600 \mathrm{~cm}^{-1}$. 
IR spectra of the glasses heat-treated at $500{ }^{\circ} \mathrm{C}$ for 10 hrs were also recorded (Figures 11 and 12). They consist of the bands in same ranges as spectra of initial glasses but most of the bands are split due to structural ordering in the glass network pointing to chemical differentiating and running of precrystallization processes.

As follows from comparison of Figures 8 and 11, heat-treatment decrease markedly chemical durability of glasses. Such conclusion may be done on the basis of much higher intensity in the spectra of heattreated glasses of the bands within high-wavenumber range due to vibrations in molecules of structurally bound or/and absorbed water or in hydroxyl groups (3600-3200 $\mathrm{cm}^{-1}$ and $\left.1700-1600 \mathrm{~cm}^{-1}\right)$ and hydrogen bonds $\left(3000-2800 \mathrm{~cm}^{-1}\right)$.

In Raman spectra (Figure 13) a strong asymmetric band within the range of $850-1150 \mathrm{~cm}^{-1}$ is a superposition of the bands due to stretching modes in $\mathrm{BO}_{4}$ and $\mathrm{SiO}_{4}$ tetrahedra with various number of bridging oxygen ions and $\mathrm{Si}-\mathrm{O}-\mathrm{B}$ bridges linking $\mathrm{SiO}_{4}$ and $\mathrm{BO}_{4}$ tetrahedra. The band at $400-550 \mathrm{~cm}^{-1}$ in both Raman and IR spectra is due to bending modes in $\mathrm{SiO}_{4}$ tetrahedra [10,11]. Major changes in Raman spectra of glasses with increase of the $\psi_{\mathrm{B}}$ value are separation and growth in intensity of the band with a maximum at $\sim 980 \mathrm{~cm}^{-1}$, shift of maximum of the band due to stretching modes from $\sim 935$ to 900 $\mathrm{cm}^{-1}$ and growth in intensity the band within the range of $700-800 \mathrm{~cm}^{-1}$.

Computer simulation of Raman spectra (Figure 14) shows differences in the structure of the glasses. The strongest responses within the ranges of 300-600 and $800-1200 \mathrm{~cm}^{-1}$ due to bending and stretching modes of $\mathrm{Si}-\mathrm{O}-\mathrm{Si}$ bonds are normally superpositions of at least two bands due to $\mathrm{SiO}_{4}$ units with various number of bridging oxygen ions. The glass 21-02 has the highest alkali oxides content among all the glasses studied (Table I). Positions of major peaks at 894 and $989 \mathrm{~cm}^{-1}$ demonstrate that the glass network is built from pyro-groups $\left[\mathrm{Si}_{2} \mathrm{O}_{7}\right]$ and short chains of metasilicate $\left[\mathrm{SiO}_{3}\right]$ groups. The component with a maximum at $\sim 748 \mathrm{~cm}^{-1}$ is stronger than it can be expected for so low alumina content ( $\left.3 \mathrm{~mol} . \%\right)$. This band can be suggested to have minor contribution due to response of $\mathrm{BO}_{4}$ tetrahedra. Weak band with a maximum at $\sim 1320 \mathrm{~cm}^{-1}$ is due to $\mathrm{BO}_{3}$ triangles.

Similar simulation was made for the Raman spectrum of the glass 21-07 (Figure 14). Positions of the maxima at 924 and $1028 \mathrm{~cm}^{-1}$ point to higher degree of connectedness of the silicon-oxygen network in the structure of this glass as compared to that in the structure of previous glass 21-02. This is some surprisingly because silica content in this glass is lower ( $38 \mathrm{~mol} . \%)$ than in the glass 21-02. At the same time sum of alkali oxides is also lower. One more explanation may be given in suggestion that this glass has a tendency to phase separation and its structure is composed of high-silica and high-alkali/boron areas of chemical differentiation being anteceding liquid-liquid phase separation. This suggestion is supported by a shift of the maximum of the band due to trigonally coordinated boron to $1362 \mathrm{~cm}^{-1}$ that points to higher degree of polymerization of $\mathrm{BO}_{3}$ units.

A set of simulated lines is similar to those in the Raman spectra of the glasses 21-02 and 21-07 and is intermediate between them. Values of maxima of the components at 893 and $975 \mathrm{~cm}^{-1}$ are close to those in the spectrum of the glass 21-02 but the intensity of the higher wavenumber component in the spectrum of the glass 21-21 is much higher than in the spectrum of the glass 21-02. This shows higher degree of connectedness of the silica-oxygen network in the structure of the glass 21-21 than that in the glass 21-02. Thus, the network of the glass 21-21 is mainly built from metasilicate chains and/or circular structures of $\mathrm{SiO}_{4}$ tetrahedra with preferably two bridging oxygen ions. Position of maximum of the band due to $\mathrm{BO}_{3}$ units is also intermediate between those in the spectra of glasses 21-02 and 21-07. 


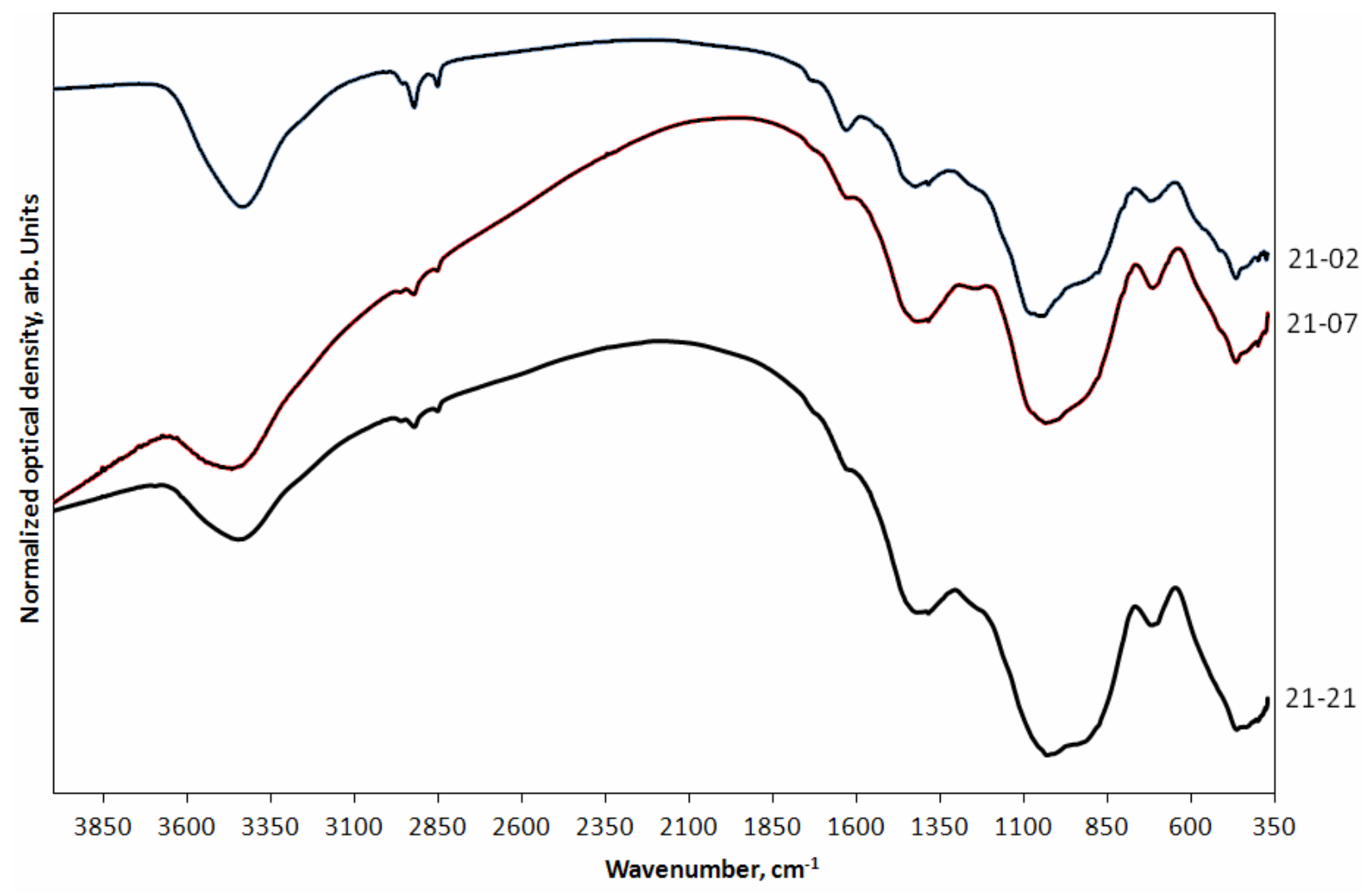

Figure 11. IR spectra of Glasses in Series 21 Heat-Treated at $500{ }^{\circ} \mathrm{C}$. 


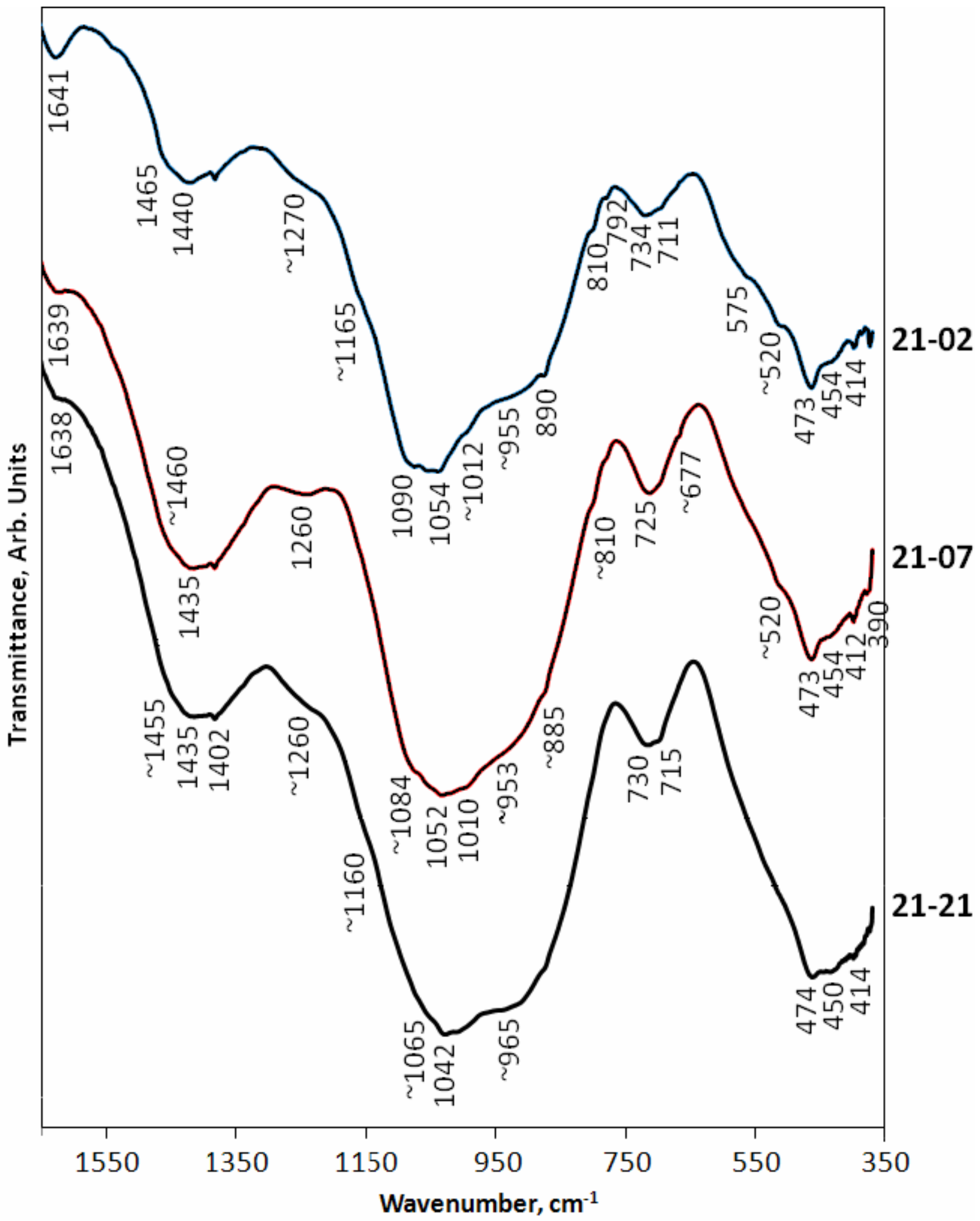

Figure 12. Fragments of IR spectra within the Range of $1600-350 \mathrm{~cm}^{-1}$ of Glasses in Series 21 HeatTreated at $500{ }^{\circ} \mathrm{C}$. 


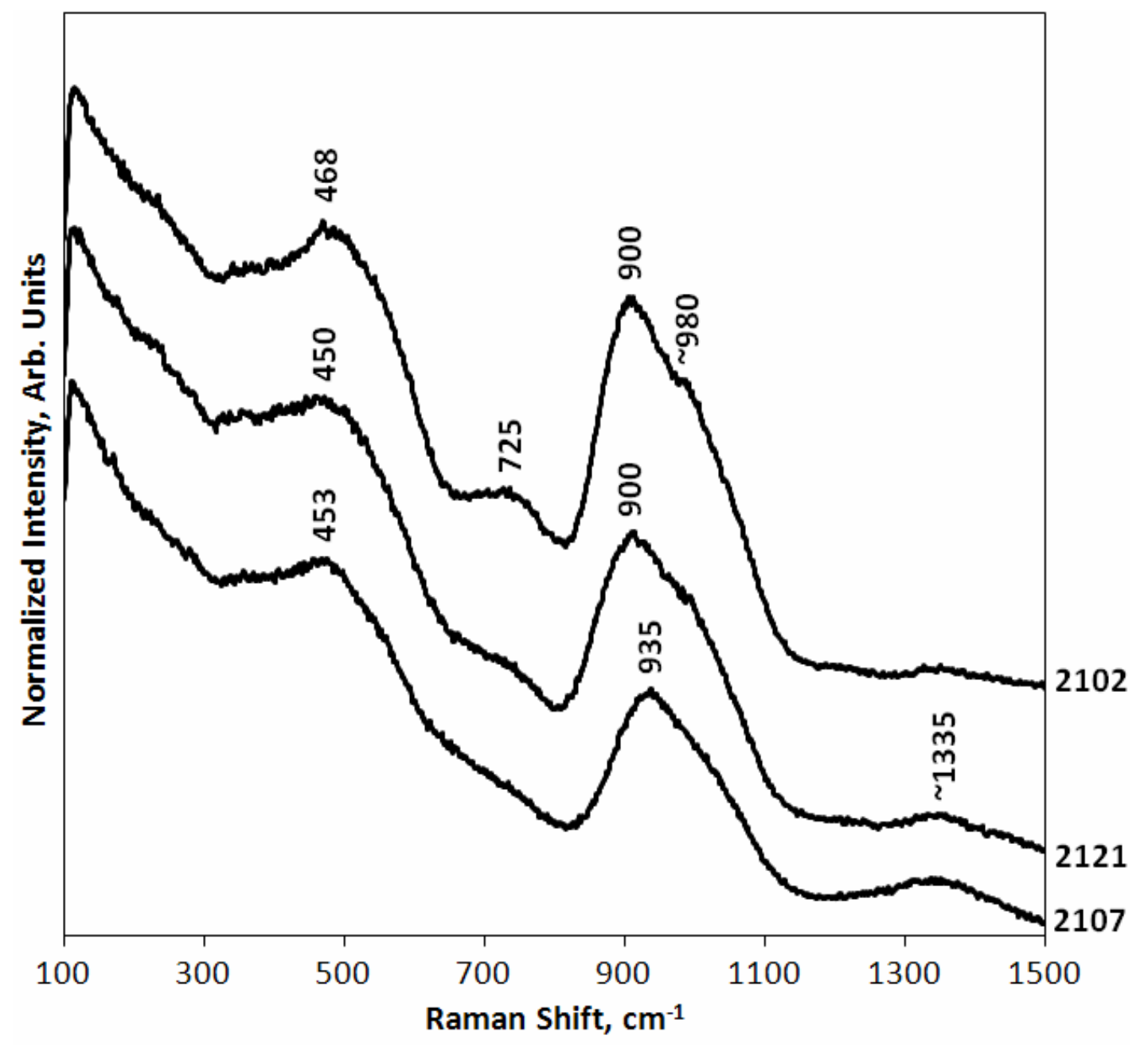

Figure 13. Raman spectra of glasses in series 21. 

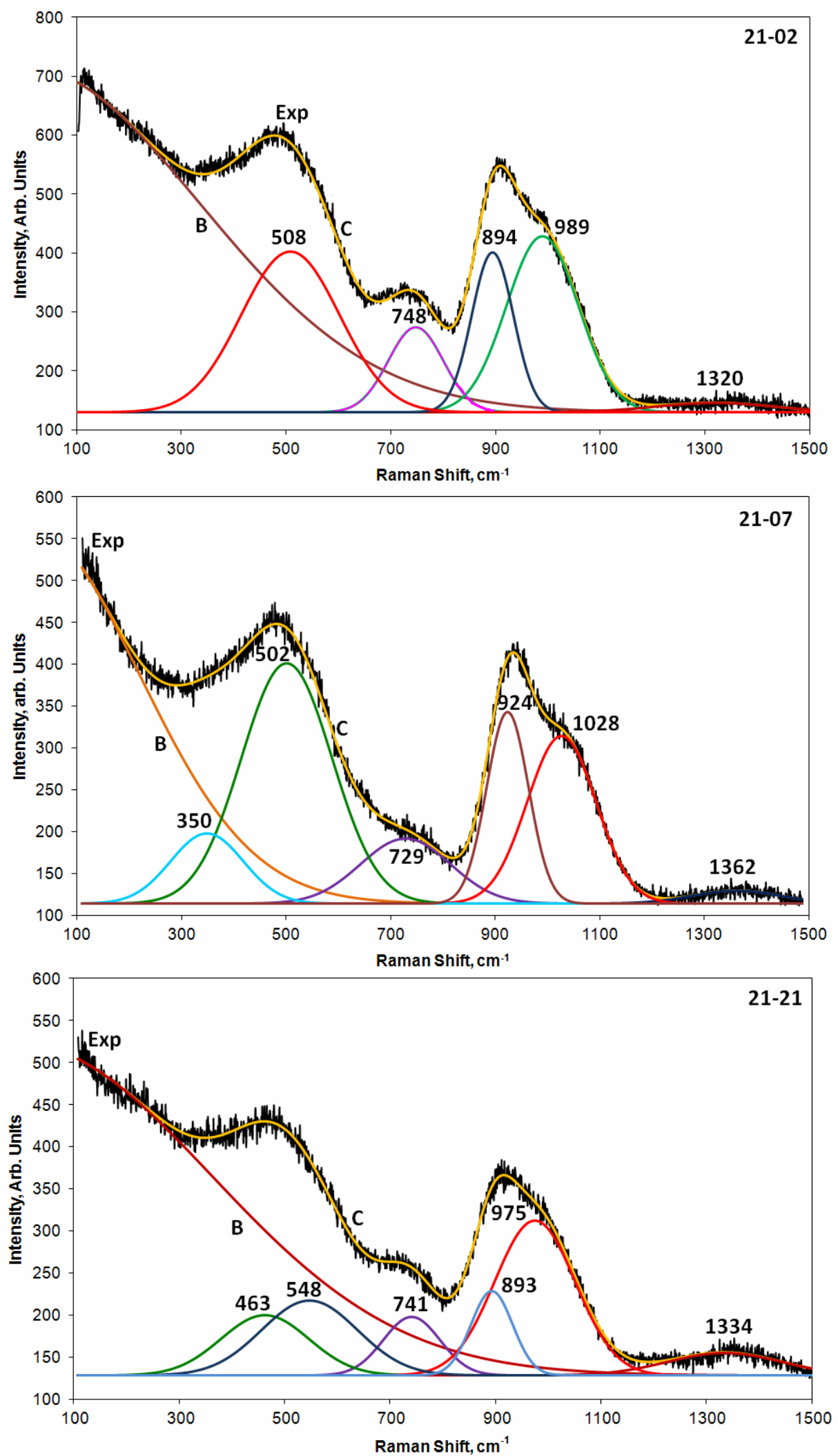

Figure 14. Computer simulation of Raman spectra of the glasses 21-02, 21-07 and 21-21. B - baseline, C - calculated, Exp - experimental. 
Similar behavior of the bands with a maximum at $\sim 980$ and $\sim 725 \mathrm{~cm}^{-1}$ allows to assigning them respectively to asymmetric $\left(v_{3}\right)$ and symmetric $\left(v_{1}\right)$ stretching modes in $\mathrm{SiO}_{4}$ tetrahedra with two bridging oxygen ions $\left(\mathrm{C}_{2 \mathrm{v}}\right.$ symmetry). In the whole the band with a maximum at $\sim 935 \mathrm{~cm}^{-1}$ is split into two components with maxima at $\sim 900$ and $\sim 980 \mathrm{~cm}^{-1}$ due to overall decrease in symmetry of $\mathrm{SiO}_{4}$ units probably because of formation of $\mathrm{Si}-\mathrm{O}-\mathrm{B}$ bridges linking $\mathrm{SiO}_{4}$ and $\mathrm{BO}_{4}$ tetrahedra in common network. However relatively low $\mathrm{B}_{2} \mathrm{O}_{3}$ concentration in glass 21-21 and particularly 21-02 suggests that the effect of these bonds is rather minor because amount of $\mathrm{BO}_{4}$ tetrahedra is insufficient to fix all the alkali ions at these tetrahedral for suppression of their leaching.

Absorption within the range of $600-800 \mathrm{~cm}^{-1}$ may contain contribution due to $\mathrm{Al}-\mathrm{O}$ stretching modes in the $\mathrm{AlO}_{4}$ tetrahedra [10]. Taking into account low $\mathrm{Al}_{2} \mathrm{O}_{3}$ content in glasses, it may be expected that major $\mathrm{Al}$ is four-coordinated. However due to this reason the contribution due to $\mathrm{Al}-\mathrm{O}$ oscillating modes in this band should be minor.

The wavenumber range lower $600 \mathrm{~cm}^{-1}$ is of interest due to possible appearance of $\mathrm{Fe}-\mathrm{O}$ stretching modes in this range [10,13]. Figure 4 demonstrates strong absorption within the range of $350-600 \mathrm{~cm}^{-1}$. Major contribution to this band is made by bending modes in the $\mathrm{SiO}_{4}$ tetrahedra because $\mathrm{SiO}_{2}$ concentration in glasses is much higher than concentrations of different oxides. This band has a number of components mainly due to de-degeneration of bending modes at lowering the symmetry of $\mathrm{SiO}_{4}$ tetrahedra. Nevertheless, there are some additional bands $\left(575,520 \mathrm{~cm}^{-1}\right.$ and at lower wavenumbers) which may be assigned to $\mathrm{Fe}^{\mathrm{IV}}-\mathrm{O}$ stretching modes in $\mathrm{FeO}_{4}$ tetrahedral units which are normally appeared within this wavenumber range [14]. $\mathrm{Fe}^{\mathrm{VI}}$ - $\mathrm{O}$ stretching modes in $\mathrm{FeO}_{6}$ octahedra are positioned at lower wavenumber range $\left(300-500 \mathrm{~cm}^{-1}\right)$ [13].

Low wavenumber IR (Figure 10) and Raman (Figure 13) spectra involve strong bands with maxima at 544 and 450-470 $\mathrm{cm}^{-1}$ and numerous weaker bands due to bending modes in distorted $\mathrm{SiO}_{4}$ tetrahedra and possibly stretching modes in $\mathrm{FeO}_{4}$ tetrahedra. Some weak lines within the range of $200-400 \mathrm{~cm}^{-1}$ may be attributed as stretching modes in $\mathrm{FeO}_{6}$ octahedra, but as follows from very low intensity of these bands the number of such octahedra is negligible.

\section{Iron valence and environment in glasses}

Fe K edge X-ray absorption spectra are shown on Figure 15. Fe K edge XANES spectra (Figure 16) are typical of trivalent iron ( $\mathrm{Fe}^{3+}$ ions) in tetrahedral oxygen environment $[14,15]$ but minor fraction of divalent iron may be also present in samples 21-07 and 21-21. This is also see from the first derivatives of XANES spectra (Figure 17) where positions of components of major peak due to Fe ions in 21-07 and 2121 glasses are similar but some different from those for 21-02 glass.

FT of Fe K edge EXAFS in glasses demonstrate minor second coordination cell of Fe ions in all the glasses (Figure 18). The second cell is the weakest in glass 21-02. The first coordination cell in all the glasses is split into two components. Computer simulation (Table VI) indicates two Fe $-\mathrm{O}$ distances shorter at $\sim 1.72 \AA$ and longer at $\sim 1.90 \AA$ in the structure of glasses 21-02 and 21-07 and slightly longer distances in the structure of glass 21-21: $\sim 1.76$ and $\sim 1.94 \AA$, respectively. These values are similar to those measured earlier in various silicate and borosilicate glasses including nuclear waste glasses [16-21]. 


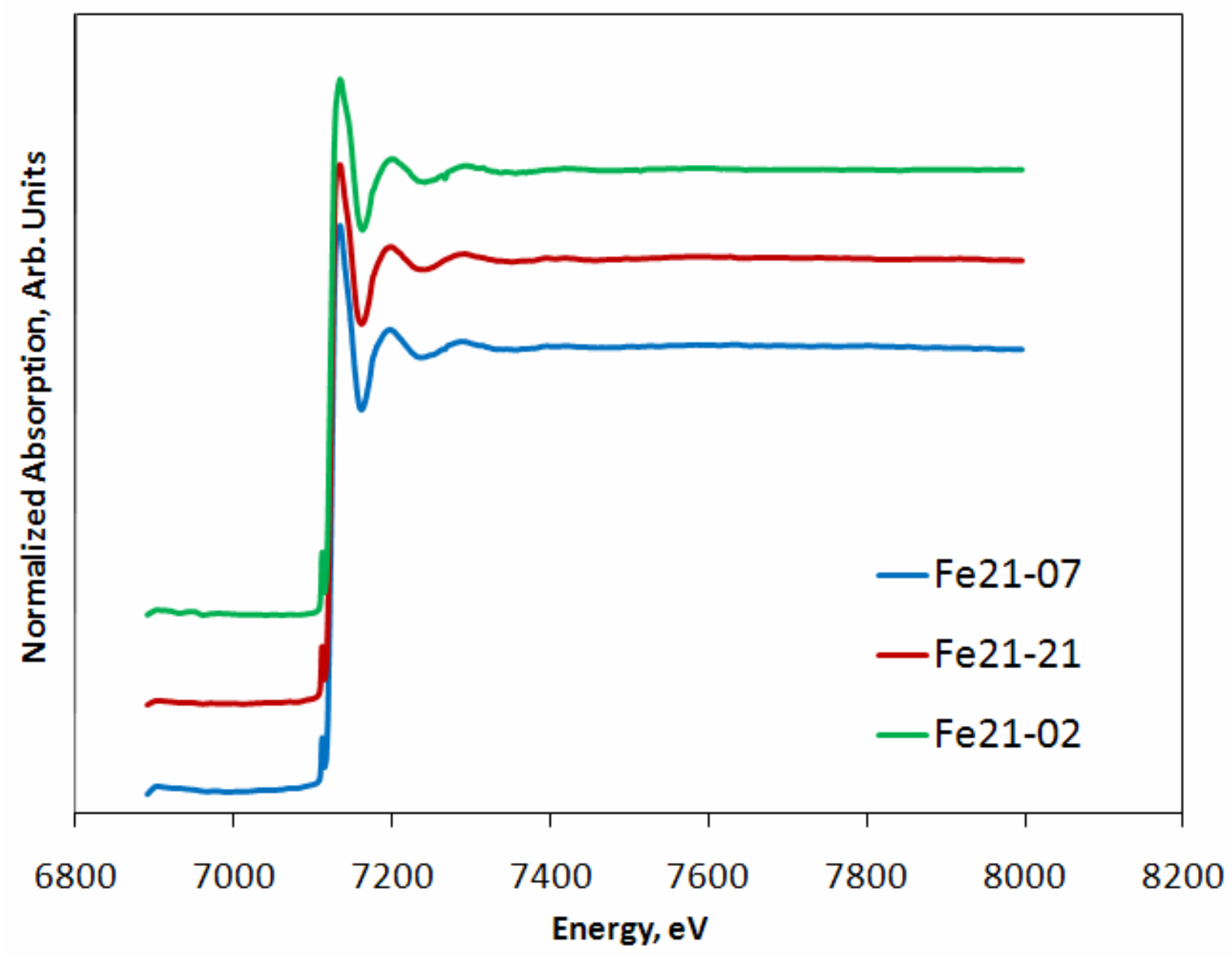

Figure 15. XAFS spectra of Fe K edge of glasses in series 21. 


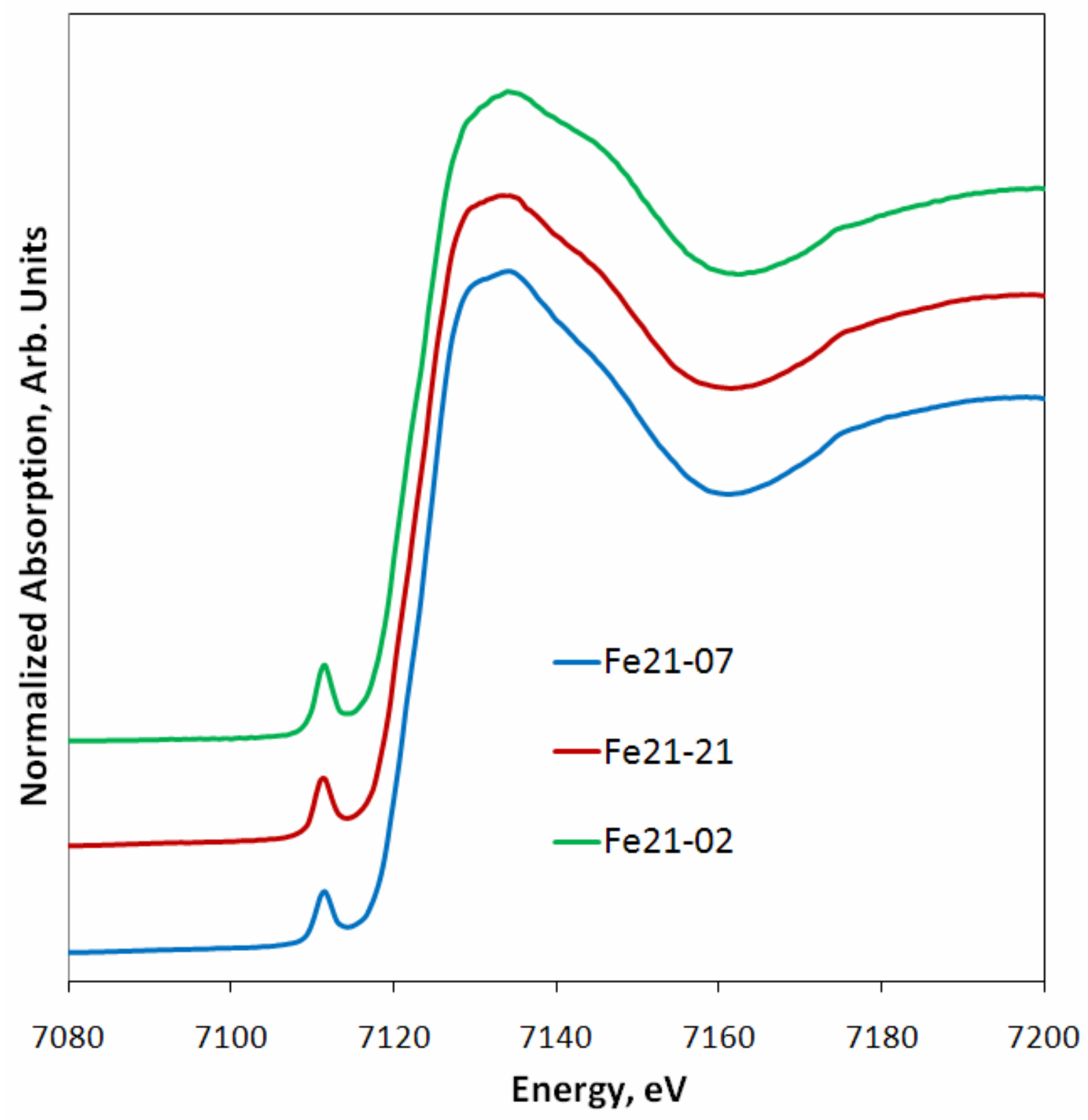

Figure 16. XANES spectra of Fe K edge of glasses in series 21. 


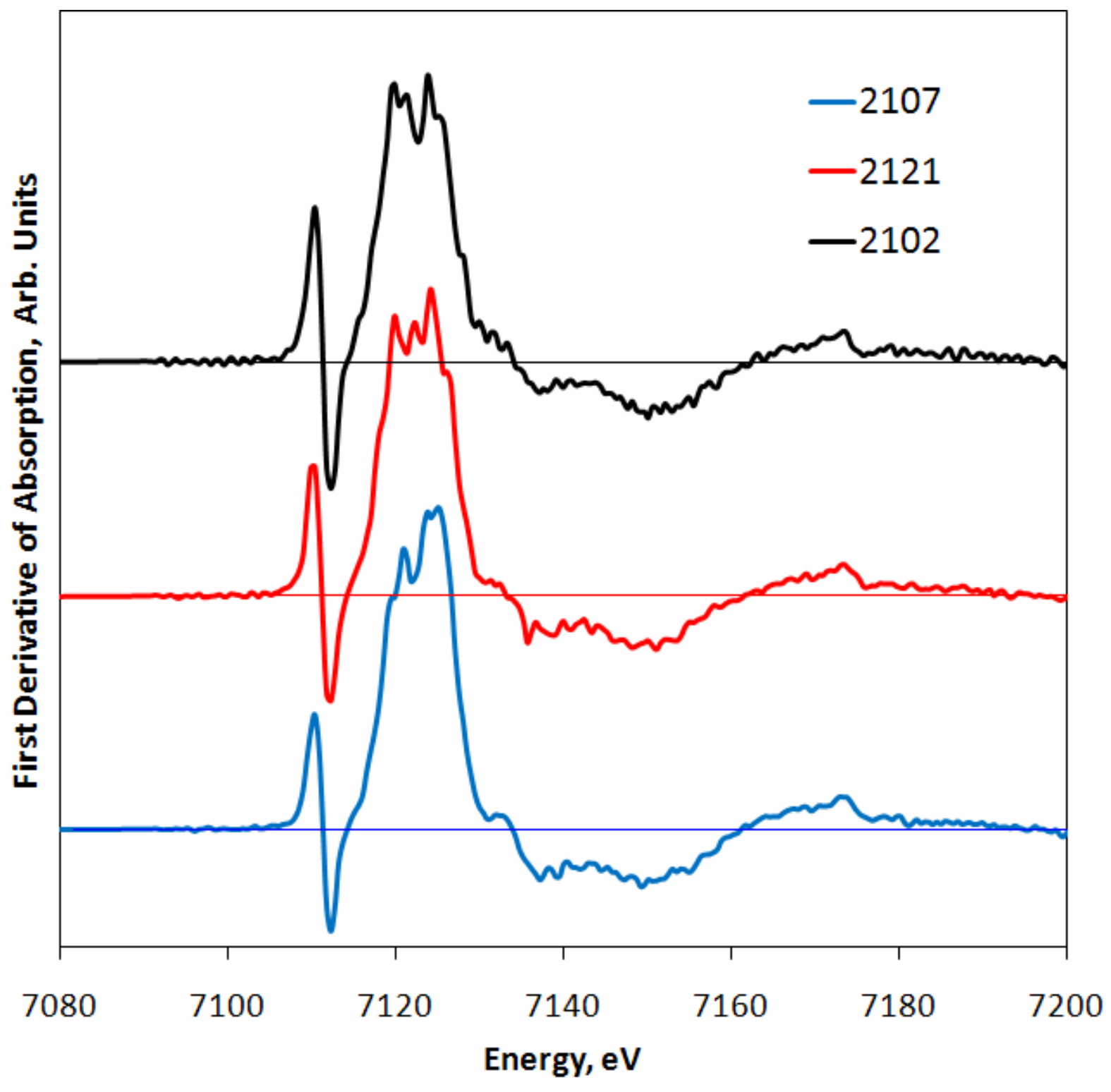

Figure 17. Differential XANES spectra of Fe K edge of glasses in series 21. 


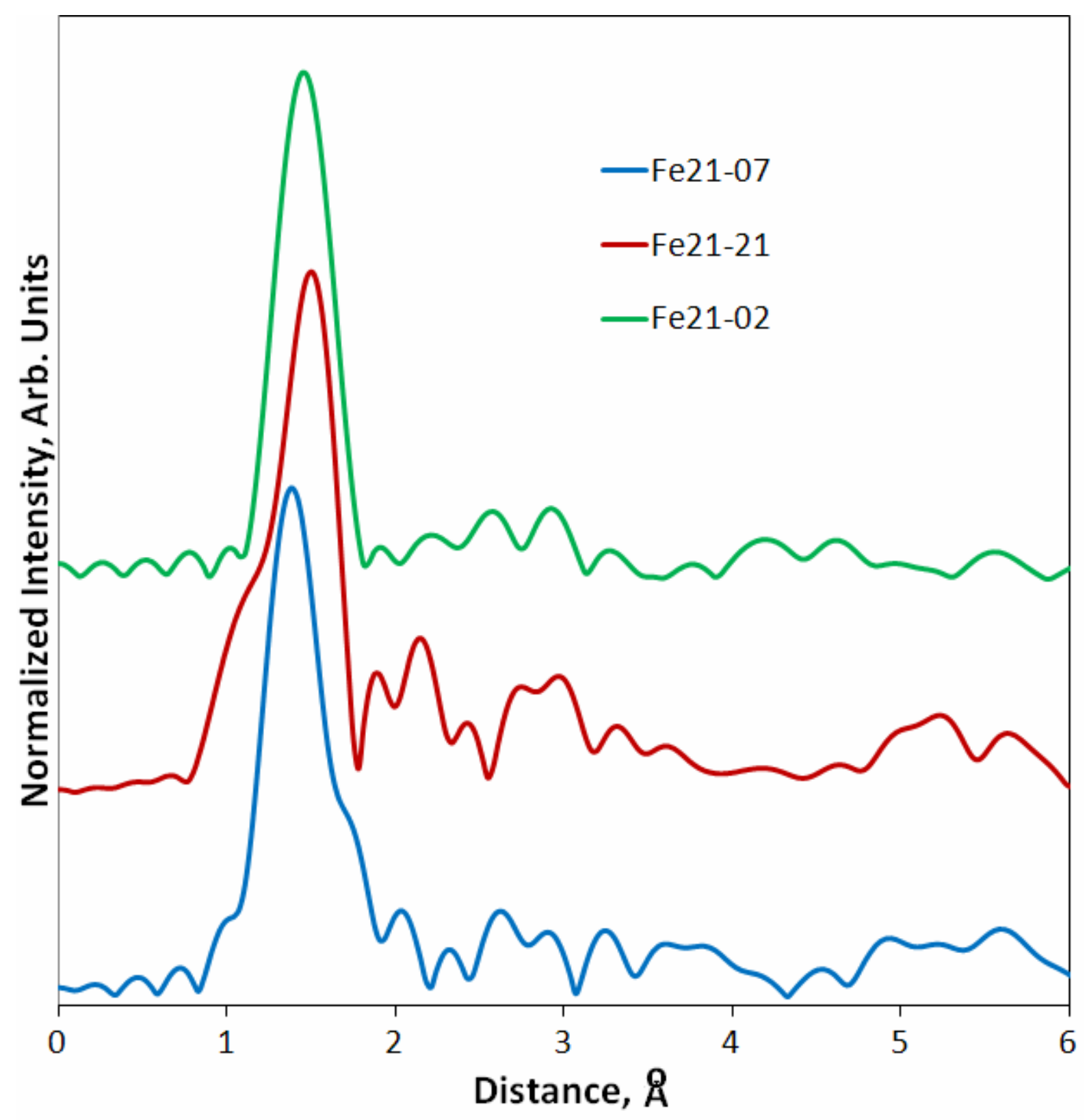

Figure 18. FT EXAFS of Fe K edge of glasses in series 21.

No phase shift correction. 
Table VI. Fitting of the Fe K Edge EXAFS Spectra of Glasses in Series 21.

\begin{tabular}{|c|c|c|c|c|c|c|}
\hline Glass & \multicolumn{2}{|c|}{2102} & \multicolumn{2}{c|}{2107} & \multicolumn{2}{c|}{2121} \\
\hline Bond & $\mathrm{CN}$ & $\mathrm{R}-\mathrm{O}, \AA$ & $\mathrm{CN}$ & $\mathrm{R}-\mathrm{O}, \AA$ & $\mathrm{CN}$ & $\mathrm{R}-\mathrm{O}, \AA$ \\
\hline Fe-O1 & $1.84 \pm 0.09$ & $1.72 \pm 0.01$ & 1.41 & $1.72 \pm 0.01$ & 1.82 & $1.76 \pm 0.01$ \\
\hline Fe-O2 & $2.13 \pm 0.13$ & $1.90 \pm 0.01$ & 2.59 & $1.90 \pm 0.01$ & 2.18 & $1.94 \pm 0.01$ \\
\hline Fe-O3(Me) & $\sim 1$ & $3.64 \pm 0.05$ & $\sim 1.3$ & $3.22 \pm 0.04$ & $\sim 1.48$ & $3.25 \pm 0.04$ \\
\hline
\end{tabular}


In the structure of all the glasses coordination number of Fe on oxygen is 4 or nearly 4 and Fe ions are located in distorted tetrahedral environment (Table VI). In the glasses 21-02 and 21-21 $\mathrm{FeO}_{4}$ tetrahedra experience rhombic distortion (symmetry $\mathrm{C}_{2 \mathrm{v}}$ ) whereas distortion of $\mathrm{FeO}_{4}$ tetrahedra in the structure of glass 21-07 is closer to axial (symmetry $\mathrm{C}_{3 \mathrm{v}}$ ).

The second coordination cell of Fe ions is not clearly expressed indicating their rather homogeneous distribution (Figure 19). In the most "disordered" glass 21-02 the nearest neighboring ion of either oxygen or heavier element is positioned at a distance of $\sim 3.64 \AA$ with average $\mathrm{CN} \approx 1$. In more "ordered" glasses 21-07 and 21-21 the nearest Fe ion neighbor is located at a distance of 3.22-3.25 $\AA$ with $\mathrm{CN}=$ $1.3 \div 1.5$. 

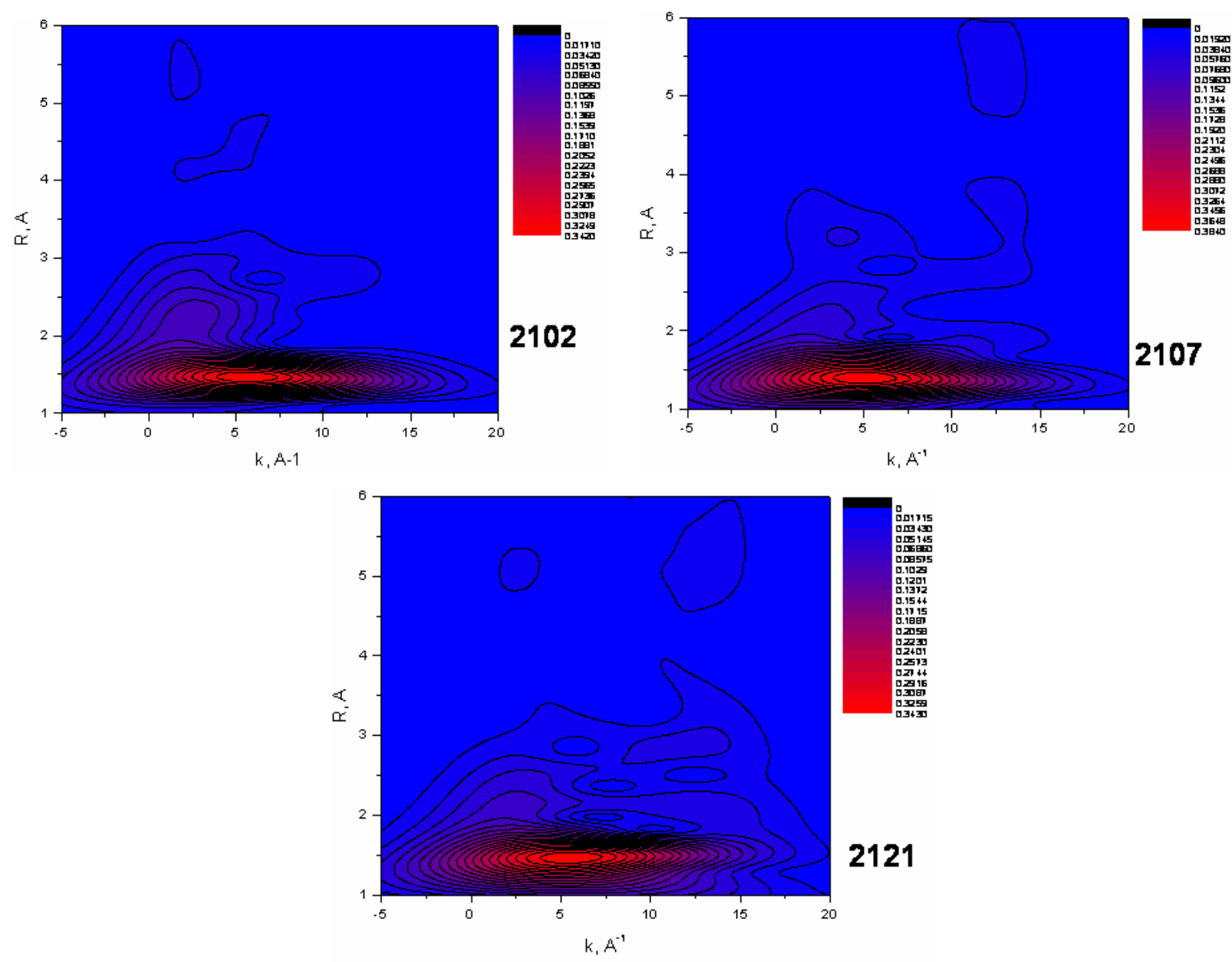

Figure 19. Morlet Wavelet Transform of Fe K Edge EXAFS Spectra of Glasses in Series 21. 


\section{CONCLUSION}

- actual chemical composition of glasses is close to target one;

- glasses are homogeneous, no crystalline phases or liquid-liquid phase separation were found both in initial and heat-treated and etched glasses;

- the degree of connectedness of the network of coordination polyhedra is the highest for the glass 21-02 and reduces for the glass 21-21 and further 21-07;

- $\quad$ both trigonally and tetrahedrally coordinated boron are present in the structure of glasses;

- fraction of tetrahedrally coordinated boron in the glasses reduces in the row: 21-02 > 21-21 > 2107 ;

- aluminum is tetrahedrally coordinated in all glasses and forms $\mathrm{AlO}_{4}$ units built in silicon-oxygen chains;

- ferrous ions are rather homogeneously distributed in the glass network; the nearest neighbor is positioned at a distance of 3.22-3.25 $\AA$ (glasses 21-07, 21-21) or 3.64 $\AA$ (glass 21-02);

- iron in glasses is predominantly trivalent and tetrahedrally coordinated with axial or rhombic distortion of the structural tetrahedron: $\mathrm{Fe}-\mathrm{O} 1=1.72-1.76 \AA$ and $\mathrm{Fe}-\mathrm{O} 2=1.90-1.94 \AA$.

- possible reason of low chemical durability of the glasses is relatively low fraction of tetrahedrally coordinated boron and concentration of $\mathrm{Al}_{2} \mathrm{O}_{3}$ forming $\left[\mathrm{BO}_{4 / 2}\right]^{-} \mathrm{Me}^{+}$and $\left[\mathrm{AlO}_{4 / 2}\right]^{-} \mathrm{Me}^{+}$tetrahedral units fixing alkali ions and thus reducing their leaching. 
SRNL-STI-2010-00805

Revision 0

\section{REFERENCES}

1. B. Ravel and M. Newville, J. Synchrotron Radiat. 12 537-541 (2005).

2. A.L. Ankudinov and J.J. Rehr, Phys. Rev. B 56 1712-1716 (1997).

3. H. Funke, A.C. Scheinost and M. Chukalina, Phys. Rev. B, 71, 094110 (2005).

4. H. Funke, M. Chukalina and A.C. Scheinost, J. Synchrotron Radiat. 14, 426-432 (2007).

5. $\quad$ www.esrf.fr/exp_facilities/BM20/Software/Wavelets.html.

6. A.A. Appen, Chemistry of Glass (Russ.), Khimiya, Leningrad (1974).

7. S.V. Stefanovskii, O.A. Knyazev, T.N. Lashchenova, and S. Merlin, J. Adv. Mater. 3 [6] 479-487 (1996).

8. S.V. Stefanovsky and J.C. Marra, Waste Management '07 Conf. February 25 - March 1, 2007, Tucson, AZ, ID 7132 (2007).

9. A.P. Kobelev, S.V. Stefanovsky, V.V. Lebedev, D.Y. Suntsov, M.A. Polkanov, O.A. Knyazev, and J.C. Marra, MS\&T 2009 Ceramic Transactions (in press).

10. K. Nakamoto, Infrared Spectra of Inorganic and Coordination Compounds, John Wiley \& Sons, Inc. New York - London (2009).

11. V.A. Kolesova, Glass Phys. Chem. (Russ.) 12 [10] 4-13 (1986).

12. V.N. Anfilogov, V.N. Bykov, and A.A. Osipov, Silicate Melts (Russ.), Nauka, Moscow (2005).

13. I.I. Plyusnina, Infrared Spectra of Minerals (Russ.), MGU, Moscow (1977).

14. G.N. Greaves, J. Non-Cryst. Solids, 71, 203-217 (1985).

15. G.E. Brown, Jr., G.A. Waychunas, C.W. Ponader, W.E. Jackson, and D.A. McKeown, EXAFS and Near Edge Structure IV - J. de Physique. 47 C8, suppl. Au n¹2, C8-661 - C8-668 (1986).

16. D.J. Lam, B.W. Veal, H. Chen, and G.S. Knapp, Scientific Basis for Nuclear Waste Management, 1, 97-107 (1979).

17. G.N. Greaves, EXAFS and Near Edge Structure I, 248-258 (1982).

18. G. Licheri, G. Paschina, G. Piccaluga, G. Pinna, M. Magini, and G. Cocco, J. Non-Cryst. Solids, 72, 211-220 (1985).

19. J. Petiau, G. Calas, T. Dumas, and A.M. Heron, EXAFS and Near Edge Structure III, 291-296 (1984).

20. G.A. Waychunas and G.E. Brown, Jr., EXAFS and Near Edge Structure III, 336-342 (1983).

21. N. Binsted, G.N. Greaves, and C.M.B. Henderson, EXAFS and Near Edge Structure IV - J. de Physique. 47 C8, suppl. Au n²12, C8-837 - C8-840 (1986). 
Appendix C. Final Report from SIA Radon on Task 3:

Chemistry and Structure of Simulated HLW Glass Systems 


\section{Designing-Constructing and Industrial-Inculcating Enterprise}

\section{«Daymos, Ltd.»}

Office: \#9 Kurchatova Street, Room 340, St.Petersburg, Russia

Telephone Number: (812) 550-41-59; (812) 550-41-64 Facsimile Number: (812) 550-41-59

E-Mail Address: daymos@mail.wplus.net

\section{FINAL REPORT}

\section{Glass Structural Characterization and Analysis}

Subcontract Number AC69549N together with Change Notice Number 1

Task 3: Chemistry and Structure of Simulated HLW Glass Systems

3.2. Provide interim data report on analyses completed on glass samples

3.3. Provide final report describing analytical techniques utilized, measurement results and data interpretation for glass samples studied 


\section{INTRODUCTION}

The partitioning of boron between trigonal and tetrahedral coordination in aluminoborosilicate glass systems can be determined quantitatively using the nuclear magnetic resonance (NMR) technique. However, the presence of iron in HLW glasses at concentrations greater than $5 \mathrm{wt} \%$ prevents the use of NMR. The objective of this task is to apply the insight gained from Task 1 in studying the impact of varying levels of boron, alkali, and some additives such as Ca and Mn on the coordination chemistry of simulated HLW glass systems using XPS, XANES, EXAFS, EPR, IR and Raman spectroscopy.

Sample glasses have been made using SB6 simulant (high in both Al and Fe) with 12 different frit compositions at a constant waste loading of $36 \mathrm{wt} . \%$ (Tables I and II). The baseline frit composition is Frit 418 and the remaining frit compositions contain 8-16 wt $\% \mathrm{~B}_{2} \mathrm{O}_{3}, 4-8 \mathrm{wt} \% \mathrm{Na}_{2} \mathrm{O}, 0-4 \mathrm{wt} \% \mathrm{MnO}$ and 0-2 wt\% CaO. Glasses were delivered by customer (SRNL).

Table I. Glass compositions, wt.\%

\begin{tabular}{|c|c|c|c|c|c|c|c|c|c|c|c|c|}
\hline Oxides & 35 & 36 & 37 & 38 & 39 & 40 & 41 & 42 & 43 & 44 & 45 & 46 \\
\hline $\mathrm{Li}_{2} \mathrm{O}$ & 5.12 & 5.12 & 5.12 & 5.12 & 5.76 & 5.12 & 5.12 & 5.12 & 5.12 & 5.12 & 5.12 & 5.12 \\
\hline $\mathrm{B}_{2} \mathrm{O}_{3}$ & 5.12 & 8.96 & 7.04 & 7.04 & 7.04 & 5.12 & 5.12 & 5.12 & 5.12 & 5.12 & 5.12 & 10.24 \\
\hline $\mathrm{Na}_{2} \mathrm{O}$ & 12.59 & 12.59 & 12.59 & 11.31 & 10.67 & 12.59 & 11.95 & 11.31 & 11.95 & 11.31 & 11.31 & 10.03 \\
\hline $\mathrm{MgO}$ & 0.27 & 0.27 & 0.27 & 0.27 & 0.27 & 0.27 & 0.27 & 0.27 & 0.27 & 0.27 & 0.27 & 0.27 \\
\hline $\mathrm{Al}_{2} \mathrm{O}_{3}$ & 10.78 & 10.78 & 10.78 & 10.78 & 10.78 & 10.78 & 10.78 & 10.78 & 10.78 & 10.78 & 10.78 & 10.78 \\
\hline $\mathrm{SiO}_{2}$ & 48.75 & 44.91 & 46.83 & 46.83 & 45.55 & 48.11 & 48.11 & 47.47 & 47.47 & 47.47 & 46.19 & 46.19 \\
\hline $\mathrm{SO}_{3}$ & 0.33 & 0.33 & 0.33 & 0.33 & 0.33 & 0.33 & 0.33 & 0.33 & 0.33 & 0.33 & 0.33 & 0.33 \\
\hline $\mathrm{K}_{2} \mathrm{O}$ & 0.03 & 0.03 & 0.03 & 0.03 & 0.03 & 0.03 & 0.03 & 0.03 & 0.03 & 0.03 & 0.03 & 0.03 \\
\hline $\mathrm{CaO}$ & 0.48 & 0.48 & 0.48 & 0.48 & 0.48 & 0.48 & 0.48 & 0.48 & 1.76 & 1.76 & 1.76 & 0.48 \\
\hline $\mathrm{TiO}_{2}$ & 0.01 & 0.01 & 0.01 & 0.01 & 0.01 & 0.01 & 0.01 & 0.01 & 0.01 & 0.01 & 0.01 & 0.01 \\
\hline $\mathrm{MnO}$ & 2.75 & 2.75 & 2.75 & 4.03 & 5.31 & 3.39 & 4.03 & 5.31 & 3.39 & 4.03 & 5.31 & 2.75 \\
\hline $\mathrm{Fe} \mathrm{O}_{3}$ & 9.73 & 9.73 & 9.73 & 9.73 & 9.73 & 9.73 & 9.73 & 9.73 & 9.73 & 9.73 & 9.73 & 9.73 \\
\hline $\mathrm{NiO}$ & 1.16 & 1.16 & 1.16 & 1.16 & 1.16 & 1.16 & 1.16 & 1.16 & 1.16 & 1.16 & 1.16 & 1.16 \\
\hline $\mathrm{CuO}$ & 0.08 & 0.08 & 0.08 & 0.08 & 0.08 & 0.08 & 0.08 & 0.08 & 0.08 & 0.08 & 0.08 & 0.08 \\
\hline $\mathrm{SrO}$ & 0.02 & 0.02 & 0.02 & 0.02 & 0.02 & 0.02 & 0.02 & 0.02 & 0.02 & 0.02 & 0.02 & 0.02 \\
\hline $\mathrm{ZrO}$ & 0.11 & 0.11 & 0.11 & 0.11 & 0.11 & 0.11 & 0.11 & 0.11 & 0.11 & 0.11 & 0.11 & 0.11 \\
\hline $\mathrm{Sum}$ & 97.33 & 97.33 & 97.33 & 97.33 & 97.33 & 97.33 & 97.22 & 97.33 & 97.33 & 97.33 & 97.33 & 97.33 \\
\hline
\end{tabular}


Table II. Glass compositions, mol.\%

\begin{tabular}{|c|c|c|c|c|c|c|c|c|c|c|c|c|}
\hline Oxides & 35 & 36 & 37 & 38 & 39 & 40 & 41 & 42 & 43 & 44 & 45 & 46 \\
\hline $\mathrm{Li}_{2} \mathrm{O}$ & 11.41 & 11.47 & 11.44 & 11.46 & 12.83 & 11.42 & 11.43 & 11.45 & 11.41 & 11.42 & 11.44 & 11.49 \\
\hline $\mathrm{B}_{2} \mathrm{O}_{3}$ & 4.90 & 8.62 & 6.75 & 6.76 & 6.73 & 4.90 & 4.91 & 4.91 & 4.89 & 4.90 & 4.91 & 9.86 \\
\hline $\mathrm{Na}_{2} \mathrm{O}$ & 13.52 & 13.60 & 13.56 & 12.20 & 11.45 & 13.54 & 12.86 & 12.20 & 12.83 & 12.16 & 12.18 & 10.85 \\
\hline $\mathrm{MgO}$ & 0.45 & 0.45 & 0.45 & 0.45 & 0.45 & 0.45 & 0.45 & 0.45 & 0.45 & 0.45 & 0.45 & 0.45 \\
\hline $\mathrm{Al}_{2} \mathrm{O}_{3}$ & 7.04 & 7.08 & 7.06 & 7.07 & 7.03 & 7.05 & 7.05 & 7.07 & 7.04 & 7.04 & 7.06 & 7.09 \\
\hline $\mathrm{SiO}_{2}$ & 54.01 & 50.05 & 52.03 & 52.12 & 50.43 & 53.36 & 53.40 & 52.80 & 52.58 & 52.63 & 51.32 & 51.53 \\
\hline $\mathrm{SO}_{3}$ & 0.27 & 0.28 & 0.28 & 0.28 & 0.27 & 0.27 & 0.27 & 0.28 & 0.27 & 0.27 & 0.28 & 0.28 \\
\hline $\mathrm{K}_{2} \mathrm{O}$ & 0.02 & 0.02 & 0.02 & 0.02 & 0.02 & 0.02 & 0.02 & 0.02 & 0.02 & 0.02 & 0.02 & 0.02 \\
\hline $\mathrm{CaO}$ & 0.57 & 0.57 & 0.57 & 0.57 & 0.57 & 0.57 & 0.57 & 0.57 & 2.09 & 2.09 & 2.10 & 0.57 \\
\hline $\mathrm{TiO}_{2}$ & 0.01 & 0.01 & 0.01 & 0.01 & 0.01 & 0.01 & 0.01 & 0.01 & 0.01 & 0.01 & 0.01 & 0.01 \\
\hline $\mathrm{MnO}$ & 2.58 & 2.60 & 2.59 & 3.80 & 4.98 & 3.18 & 3.79 & 5.00 & 3.18 & 3.78 & 5.00 & 2.60 \\
\hline $\mathrm{Fe} \mathrm{O}_{3}$ & 4.06 & 4.08 & 4.07 & 4.07 & 4.05 & 4.06 & 4.06 & 4.07 & 4.06 & 4.06 & 4.07 & 4.08 \\
\hline $\mathrm{NiO}$ & 1.03 & 1.04 & 1.04 & 1.04 & 1.03 & 1.04 & 1.04 & 1.04 & 1.03 & 1.03 & 1.04 & 1.04 \\
\hline $\mathrm{CuO}$ & 0.07 & 0.07 & 0.07 & 0.07 & 0.07 & 0.07 & 0.07 & 0.07 & 0.07 & 0.07 & 0.07 & 0.07 \\
\hline $\mathrm{SrO}$ & 0.01 & 0.01 & 0.01 & 0.01 & 0.01 & 0.01 & 0.01 & 0.01 & 0.01 & 0.01 & 0.01 & 0.01 \\
\hline $\mathrm{ZrO} 2$ & 0.06 & 0.06 & 0.06 & 0.06 & 0.06 & 0.06 & 0.06 & 0.06 & 0.06 & 0.06 & 0.06 & 0.06 \\
\hline $\mathrm{Sum}$ & 100.00 & 100.00 & 100.00 & 100.00 & 100.00 & 100.00 & 100.00 & 100.00 & 100.00 & 100.00 & 100.00 & 100.00 \\
\hline$\psi_{\mathrm{B}}{ }^{*}$ & 2,14 & 1.22 & 1.56 & 1.35 & 1.25 & 2.14 & 2.00 & 1.86 & 2.00 & 1.86 & 1.86 & 0.79 \\
\hline$\psi_{\mathrm{B}}(\mathrm{Fe})^{* *}$ & 1.89 & 1.08 & 1.37 & 1.17 & 1.07 & 1.89 & 1.75 & 1.61 & 1.75 & 1.61 & 1.61 & 0.66 \\
\hline
\end{tabular}

$* \psi_{\mathrm{B}}=\left\{\left(\mathrm{Na}_{2} \mathrm{O}+\mathrm{K}_{2} \mathrm{O}+\mathrm{BaO}\right)+\left[0.7(\mathrm{CaO}+\mathrm{SrO}+\mathrm{CdO}+\mathrm{PbO})+\left[0.3\left(\mathrm{Li}_{2} \mathrm{O}+\mathrm{MgO}+\mathrm{ZnO}\right)\right]-\mathrm{Al}_{2} \mathrm{O}_{3}\right\} / \mathrm{B}_{2} \mathrm{O}_{3}[1]\right.$

$* * \psi_{\mathrm{B}}(\mathrm{Fe})=\left\{\left(\mathrm{Na}_{2} \mathrm{O}+\mathrm{K}_{2} \mathrm{O}+\mathrm{BaO}\right)+\left[0.7(\mathrm{CaO}+\mathrm{SrO}+\mathrm{CdO}+\mathrm{PbO})+\left[0.3\left(\mathrm{Li}_{2} \mathrm{O}+\mathrm{MgO}+\mathrm{ZnO}\right)\right]-\mathrm{Al}_{2} \mathrm{O}_{3}-0_{2} 3 \mathrm{Fe}_{2} \mathrm{O}_{3}\right\}\right.$ $/ \mathrm{B}_{2} \mathrm{O}_{3}$

The $\psi_{\mathrm{B}}$ and $\psi_{\mathrm{B}}(\mathrm{Fe})$ values range between 0.79 and 2.14 and between 0.66 abd 1.89, respectively at moderate silica contents (50-54 mol.\%) that points to significant fraction of trigonally coordinated boron. The glasses \#35 and \#40 should have th highest fraction of tetrahedrally coordinated boron, whereas the glass \#46 - the lowest one.

\section{EXPERIMENTAL}

Samples were examined by X-ray diffraction (XRD) using a Rigaku D / Max 2200 diffractometer (Cu K $\alpha$ radiation, $40 \mathrm{keV}$ voltage, $20 \mathrm{~mA}$ current, stepwise 0.02 degrees $2 \theta$ ). Glasses were studied by optical microscopy using an OLYMPUS BX51 polarizing microscope, infrared spectroscopy using a modernized IKS-29 spectrophotometer (compaction of powdered glasses in pellets with $\mathrm{KBr}$ ) within the range of 4000-400 $\mathrm{cm}^{-1}$ and Raman spectroscopy using a Jobin Yvon U1000 spectrophotometer operated at an excitation wavelength of $532 \mathrm{~nm}$.

X-ray absorption (XAS) spectra were recorded at the Structural Materials Science (STM) Beamline of the synchrotron source at RRC "Kurchatov Institute". The glass samples were measured at room temperature either as dispersed powder or as pellets pressed from powder mixed with sucrose in the transmission mode using a $\mathrm{Si}(220)$ channel-cut monochromator and two air-filled ionization chambers. Fluorescence spectra were also acquired. Powders of chemically pure $\mathrm{Fe}$ oxides $\mathrm{Fe}_{2} \mathrm{O}_{3}$ and $\mathrm{FeO}$ were used as standards and measured under identical conditions. Experimental XAFS spectra were fitted in R-space using an 
IFEFFIT package [2] and crystal structures of corresponding oxides and silicates. In the fitting, ab initio photoelectron backscattering amplitudes and phases calculated self-consistently using FEFF8 [3] were used.

Wavelet transform (WT) is commonly applied to evaluation of complex time-frequency signals. As shown in refs [4,5], WT is easily adapted to EXAFS analysis, and the expression of the WT of the $\mathrm{k}^{\mathrm{n}}$ weighted EXAFS data takes the form:

$$
W_{\chi}^{\psi}(k, r)=(2 r)^{1 / 2} \int_{-\infty}^{\infty} \chi\left(k^{\prime}\right) k^{\prime n} \psi^{*}\left[2 r\left(k^{\prime}-k\right)\right] d k^{\prime},
$$

where $\chi(\mathrm{k})$ is the EXAFS signal and $\psi^{*}\left[2 r\left(k^{\prime}-k\right)\right]$ is the complex wavelet function.

The WT is able to resolve the $\mathrm{k}$ dependence of the absorption signal, which potentially allows separation of contributing backscattering atoms even situated at the same distances from the core. One of the advantages of the wavelet analysis is the visualization of the WT modulus in a k-R plot, which provides an easy way to interpret the results. Our analysis of EXAFS data for Pu and Hf were performed using the FORTRAN program HAMA employing Morlet wavelet algorithm [6]. The Morlet wavelet is well-suited for EXAFS signal since it consists of a slowly varying amplitude term and a fast oscillating phase term. Its mathematical description is broadly analogous to the Fourier transform. The Morlet wavelet is obtained by taking a complex sine wave with frequency $\eta$ (as in FT) and by confining it with a Gaussian envelope with the half width $\sigma$,

$$
\psi(k)=\frac{1}{(2 \pi)^{1 / 2} \sigma} \exp (i \eta k) \exp \left(-k^{2} / 2 \sigma^{2}\right)
$$

The choice of the $\eta$ and $\sigma$ parameters is important for data analysis since, besides other issues, it determines resolution in k-R space. Various combinations of these parameters were used in an attempt to resolve contributions from atoms at close distances from the central atom. As shown in ref.[5] use of higher k-weighting decreases resolution in the k-space, since backscattering amplitudes become flattened and shifted to higher values. Nevertheless, WT modulus plots for different $\mathrm{k}$ weights are shown to emphasize contributions of light and heavy backscatterers. Note, that in all plots of the WT modulus the interatomic distances are given without phase shift correction.

\section{RESULTS AND DISCUSSION}

\section{$X R D$ study}

XRD patterns show that all the samples are composed of major glass and minor spinel structure phase (Figure 1). Because lattice parameter of the spinel phase is same in all the samples, it may be suggested that chemical composition of this phase is similar in all the samples as well. 


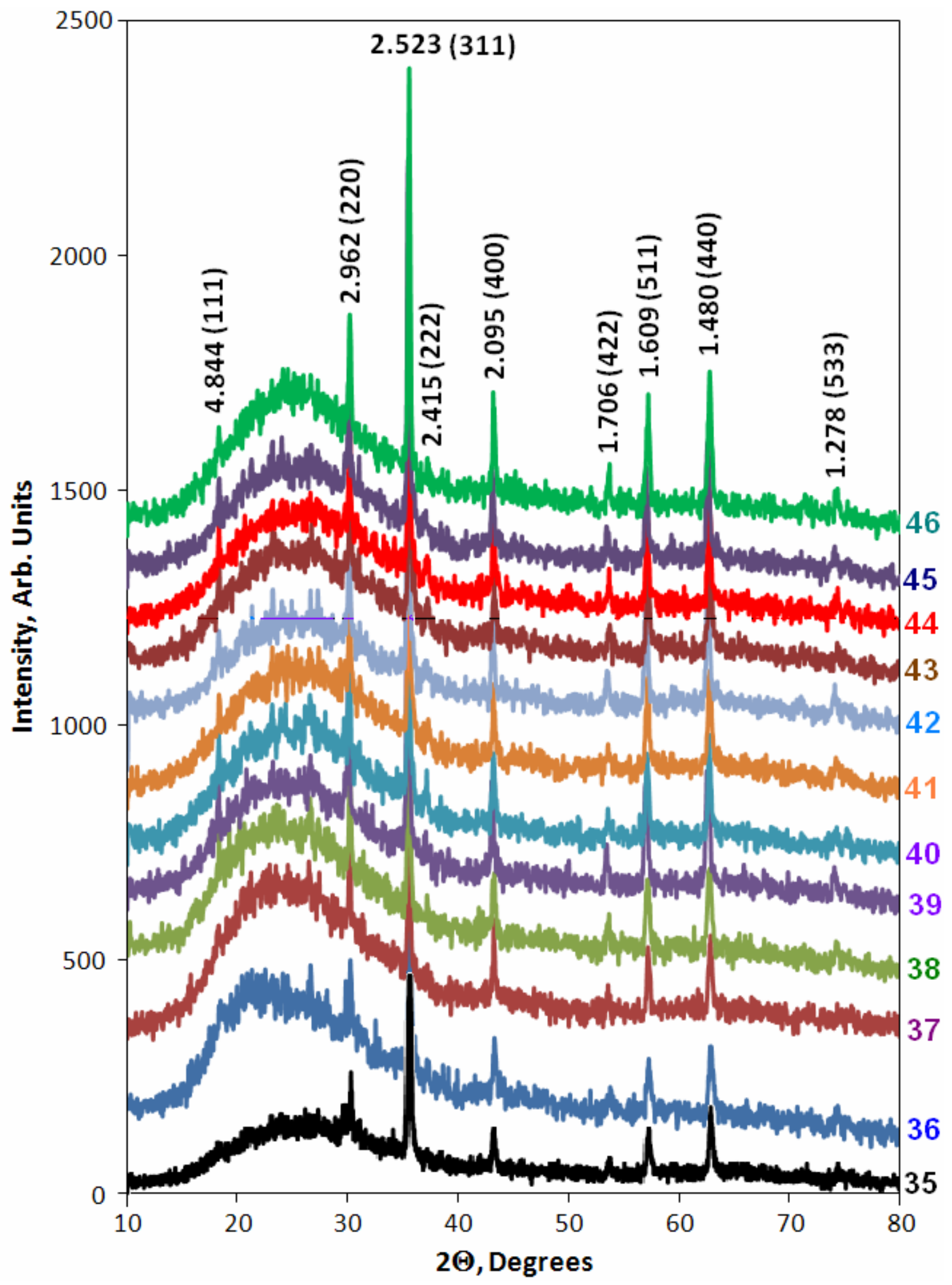

Figure 1. XRD patterns of the samples. 


\section{Optical Microscopy Study}

Microphotograph of the general view of sample \#35 (Figure 2a) shows dominance of light transparent glass containing spinel occurred as both isometric grains tens of microns in size and the finest crystals of about $1 \mu \mathrm{m}$ in size. Glass matrix contains wavy bands displaying features of melt flowing and differing in amount of fine crystals in glass. Wavy-banded distribution of microcrystals causes fluidal texture of the glass which is typical for glassy volcanic rocks. Moreover gas bubbles from tens to hundreds microns in diameter are seen well in the lapping.
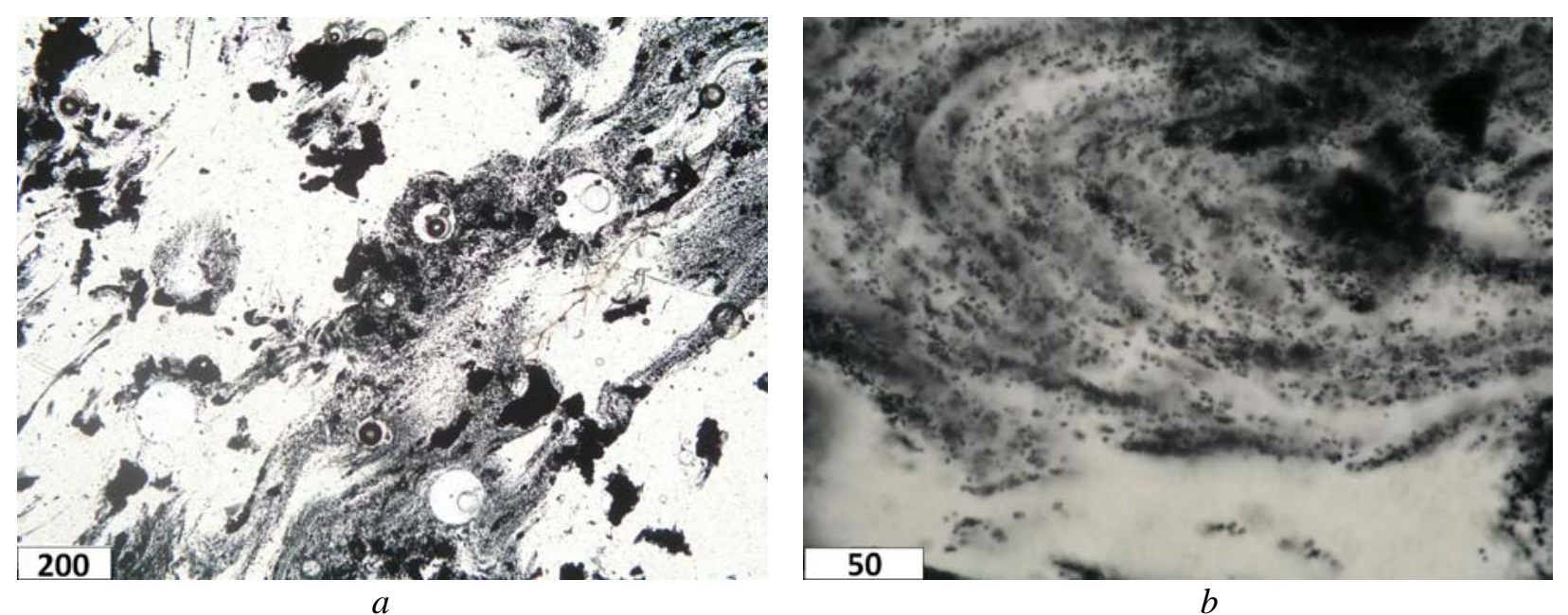

Figure 2. Microphotographs at single Nichol of the lapping of the sample \#35.

A detail of the lapping on Figure $2 a$ at higher magnification demonstrates that microcrystals of the spinel phase are the finest cubic crystals about $1 \mu \mathrm{m}$ in size. This microphotograph clearly characterizes features of distribution of microcrystals in glass.

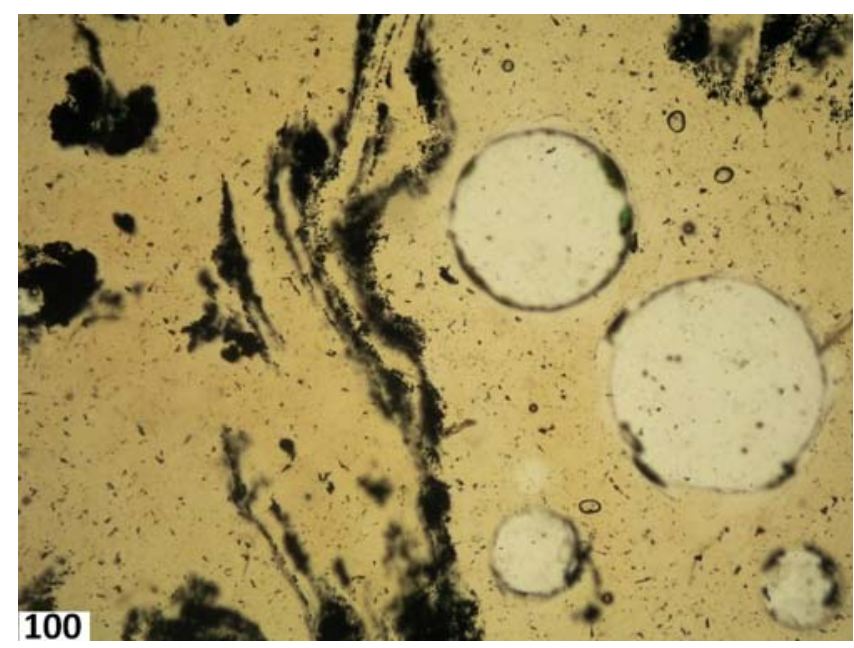

Figure 3. Microphotograph at single Nichol of the lapping of the sample \#36.

Specific feature of the glassy matrix in the sample \#36 are light-brown coloring of glass and relatively low content of spinel (Figure 3). Spinel forms either irregular grains or elongated wavy-type grains 
emphasizing elements of the fluidal texture. Minor cubic microcrystals of spinel are also present. Gas bubbles 50-200 $\mu \mathrm{m}$ in diameter occurred in the vitreous and are non-uniformly distributed.

Figure 4a demonstrates general view of the lapping of sample \#37. Glassy matrix is characterized by clearly appeared fluidal texture and light-brown coloring. Spinel is rather non-uniformly distributed over the bulk and occurs predominantly as fine ( $\sim 1 \mu \mathrm{m}$ in size) crystals. Glass contains numerous gas bubbles up to $0.5 \mathrm{~mm}$ in diameter.

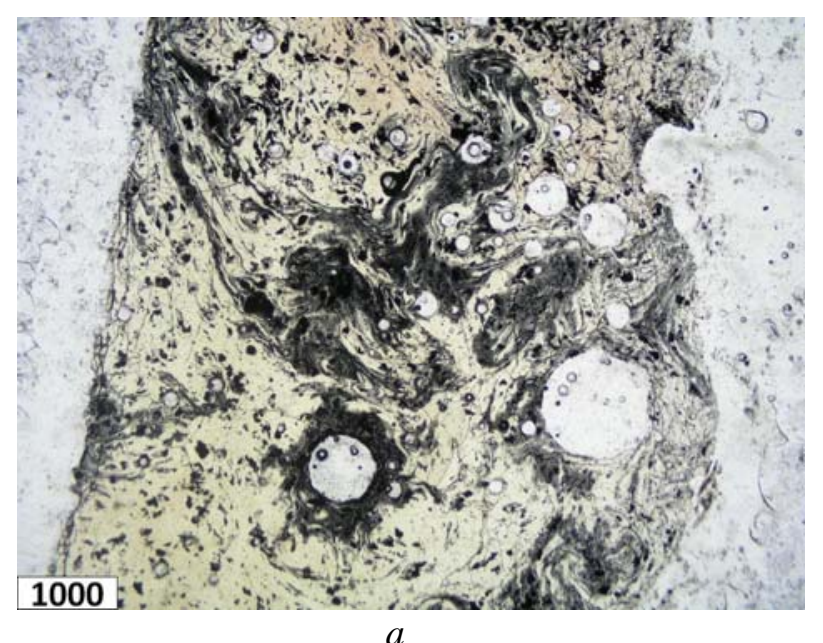

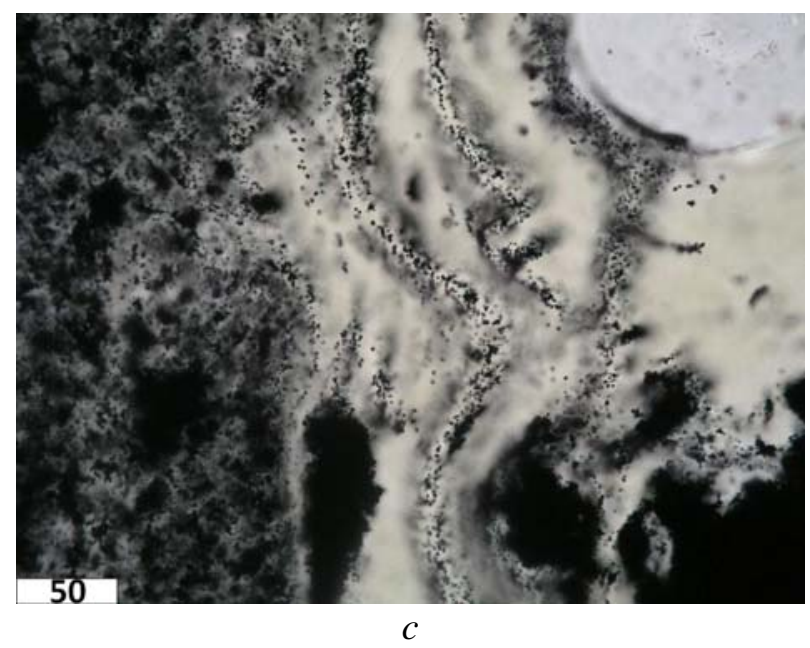

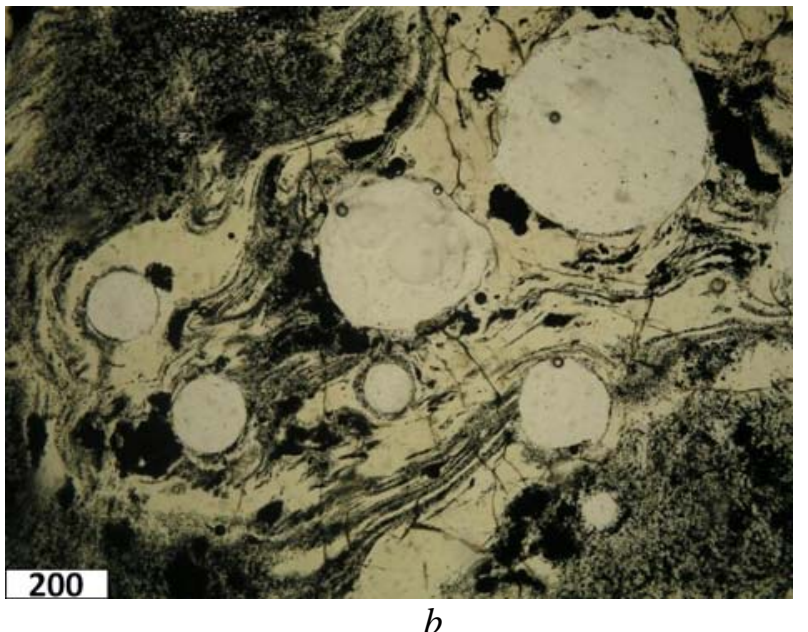

$b$

Figure 4. Microphotographs at single Nichol of the lapping of the sample \#37.

Figure $4 b$ demonstrates fragment of the same lapping enriched with spinel. It is seen well that fluidity is represented by alternation of wavy bands enriched and depleted with fine cubic spinel crystals. Dense aggregates of cubic spinel crystals are occasionally occur. As seen at higher magnification (Figure 4c) spinel occurs as both individual cubic crystals about $1 \mu \mathrm{m}$ in size and aggregates of fine crystals forming dense opaque areas.

Glass in the lapping of the sample \#38 has light-brown coloring and is characterized by strong cracking showing high mechanical stress (Figure 5). Amount of spinel is rather minor. Major fraction of spinel is represented by isometric grains. Fine cubic crystals are concentrated at small area of the lapping. Wavybanded distribution of cubic microcrystals determines fluidal texture of this area. 
The lapping of the sample \#39 is a light-brown glass with high contents of spinel and gas bubbles (Figure 6). Spinel is present as both isometric grains and cubic microcrystals. There are areas both enriched with microcrystals and free of crystals. The first of them have clear fluidal texture. Cracking is negligible.

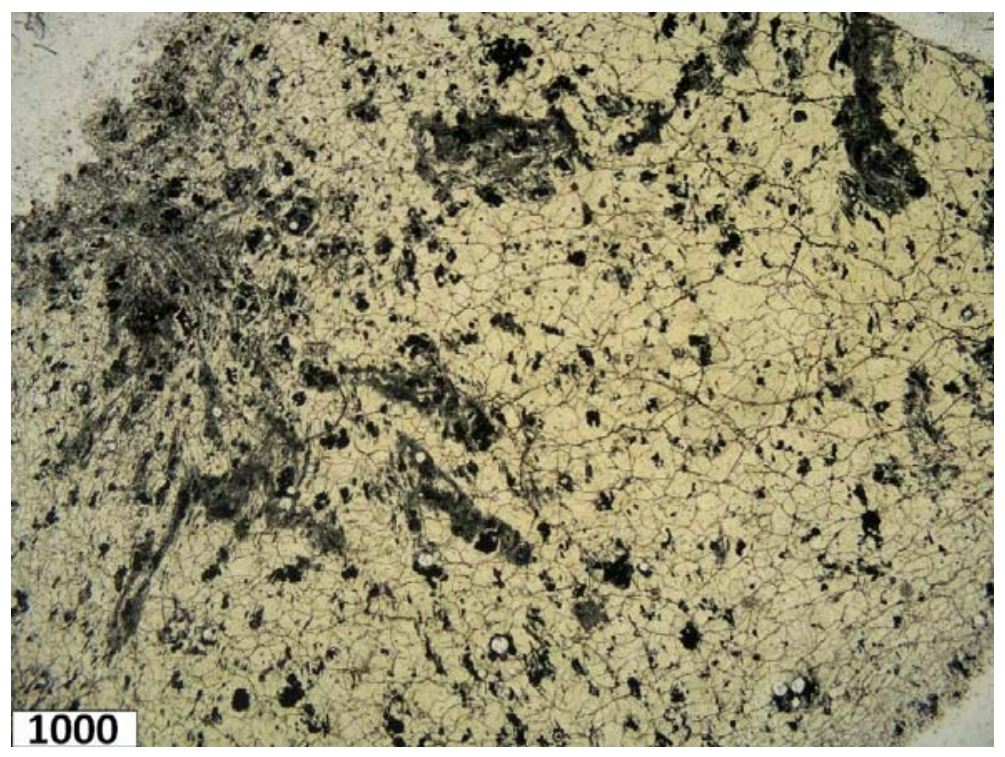

Figure 5. Microphotograph at single Nichol of the lapping of the sample \#38.

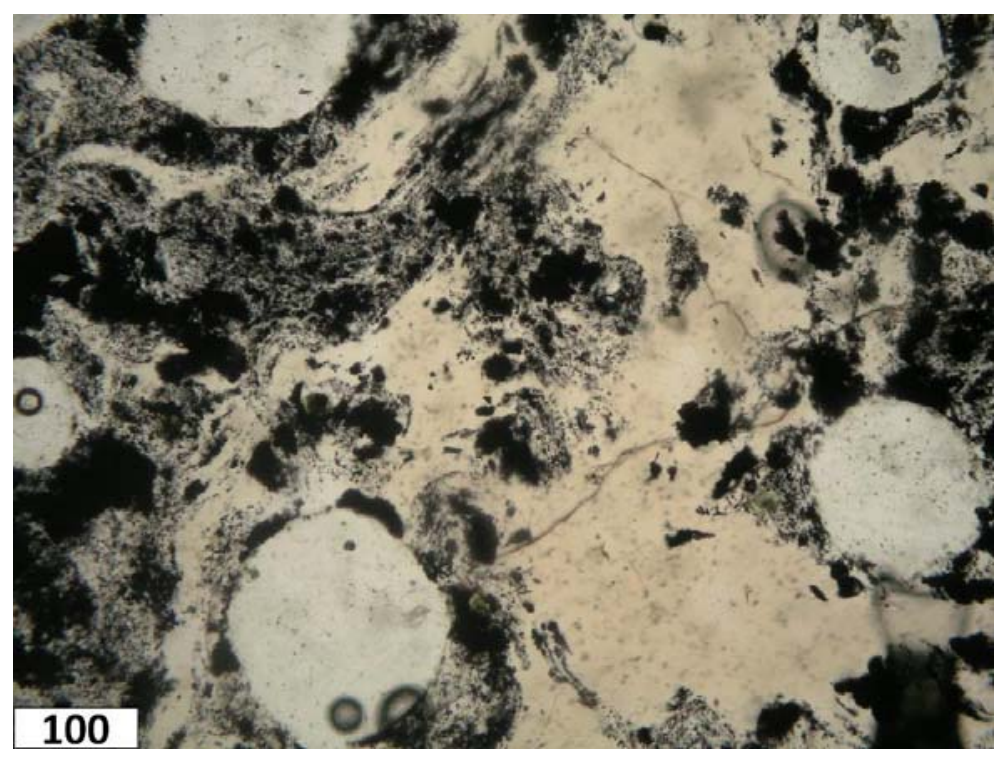

Figure 6. Microphotograph at single Nichol of the lapping of the sample \#39.

Glassy matrix in the lapping of the sample \#40 is strongly enriched with spinel (Figure 7). Spinel occurs as both isometric grains and cubic microcrystals. Fluidity is appeared locally. Areas not containing spinel are small in size and occur rarely. In spite of high spinel content glass is light and transparent. This demonstrates absence of the dependence between iron oxides content in the glassy matrix and glass coloring. Microcracking of the glass is negligible. 
Glassy matrix in the lapping of the sample \#41 (Figure 8) has low spinel content ( $<10$ vol.\%). Nearly all the spinel forms isometric grains. Amount of microcrystals is negligible. Glass has light brown-green coloring and numerous cracks due to mechanical stresses.

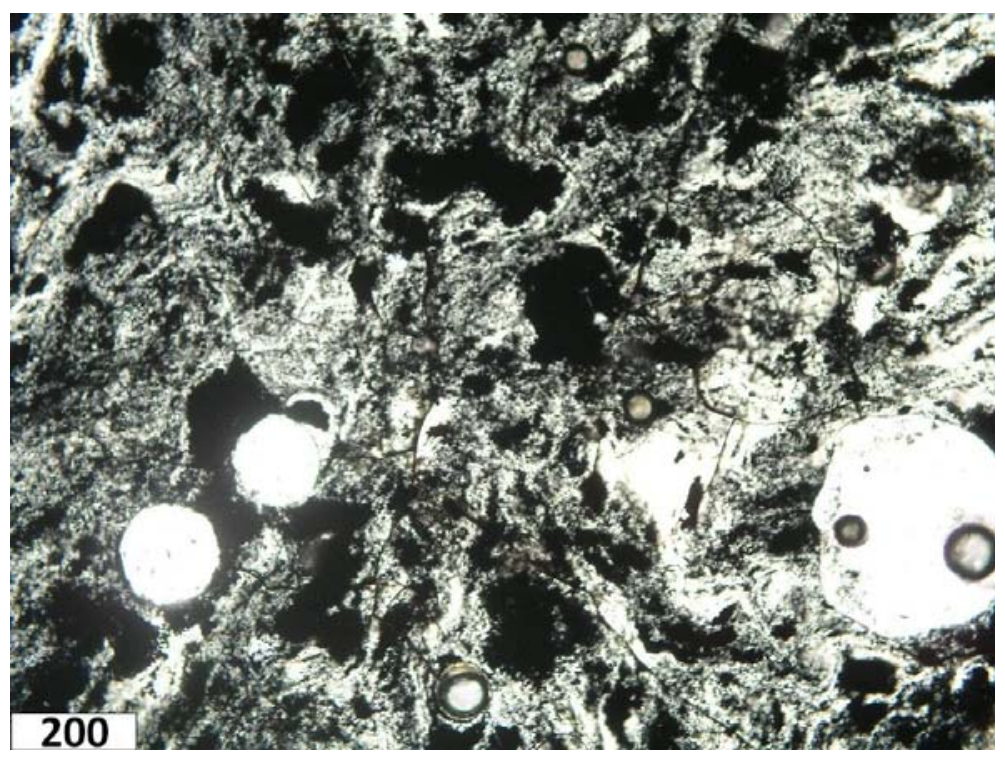

Figure 7. Microphotograph at single Nichol of the lapping of the sample \#40.

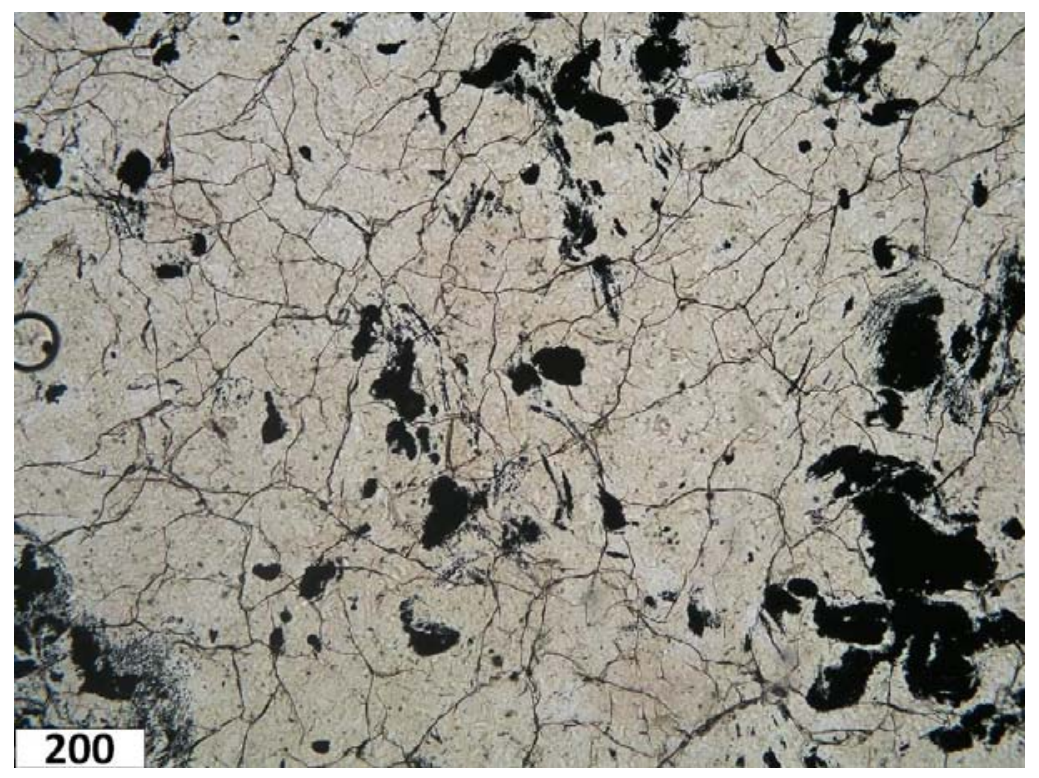

Figure 8. Microphotograph at single Nichol of the lapping of the sample \#41.

The lapping of the sample \#42 is represented by glass with high content of spinel and gas bubbles (Figure 9). Bubbles are up to $200 \mu \mathrm{m}$ in size. Glass has brown color, fluidity is poorly appeared. Spinel forms predominantly isomeric grains. Content of cubic microcrystals is negligible.

The lapping of the sample \#43 is composed of poorly colored brown-green glass with minor spinel forming isometric grains (Figure 10). Spinel content may be evaluated as 6-8 vol.\%. Rare aggregates of microcrystals and gas bubbles up to $200 \mu \mathrm{m}$ in diameter also occur. Cracking is negligible. 
The lapping of the sample \#44 is composed of green-brown glass with high spinel content (25-30 vol.\%). Major spinel is represented by isometric randomly distributed grains. Minor cubic microcrystals determine fluidal texture of the glassy matrix due to their wavy-banded distribution over the matrix. Large (up to $1.5 \mathrm{~mm}$ in diameter) gas bubbles are also present. Microcracking is nearly absent (Figure 11).

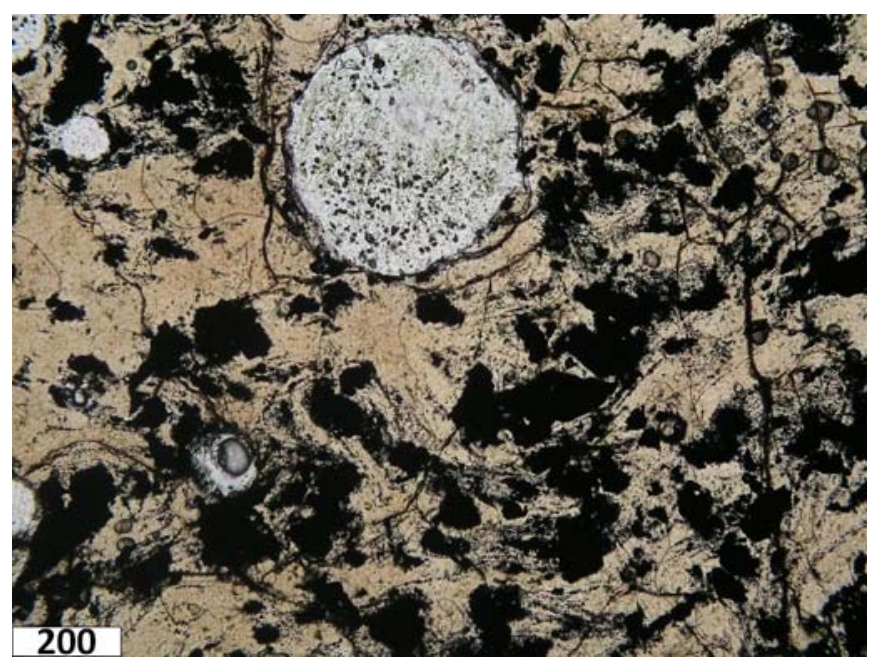

Figure 9. Microphotograph at single Nichol of the lapping of the sample \#42.

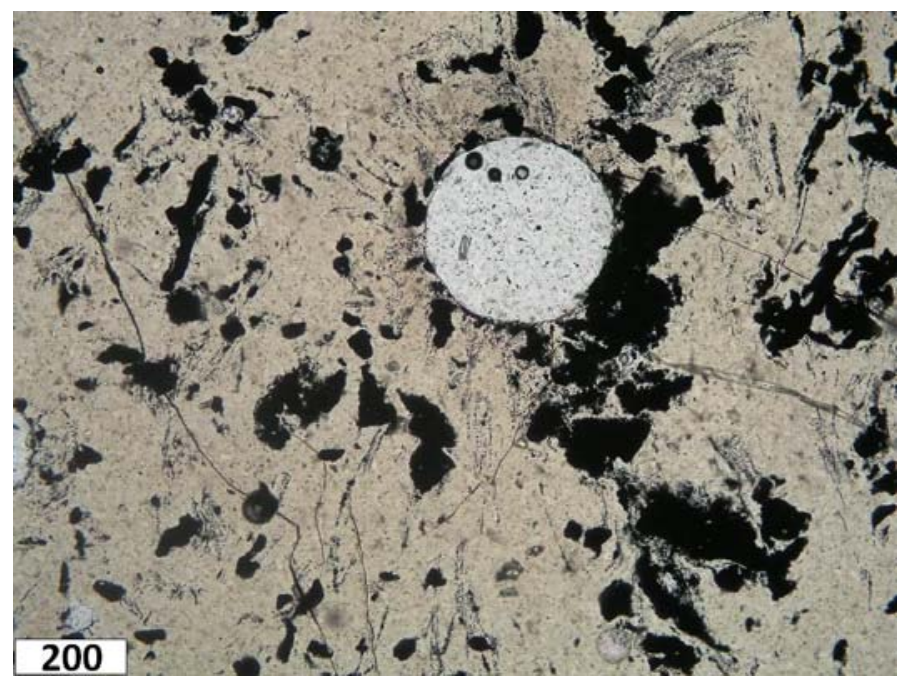

Figure 10. Microphotograph at single Nichol of the lapping of the sample \#43.

The lapping of the sample \#45 is composed of yellow-green glass with minor spinel content ( 10 vol.\%) - see Figure 12. Major spinel forms isomeric grains. Cubic microcrystals with wavy-banded distribution are present in local areas. Isolated gas bubbles 10-20 $\mu \mathrm{m}$ in diameter also occur. In crossed Nichols areas with weakly appeared double reflection probably due to initial stage of glass devitrification were found.

The lapping of the sample \#46 (Figure 13) is composed of non-uniformly colored (from clear transparent to light-yellow) glass with minor spinel (5-10 vol.\%). Major spinel is isometric randomly distributed grains. Minor spinel is is cubic microcrystals occurred in local areas. The latter forms short discontinuous bands. Glass contains numerous small gas bubbles. Most of them are $<20 \mu \mathrm{m}$ in diameter. 


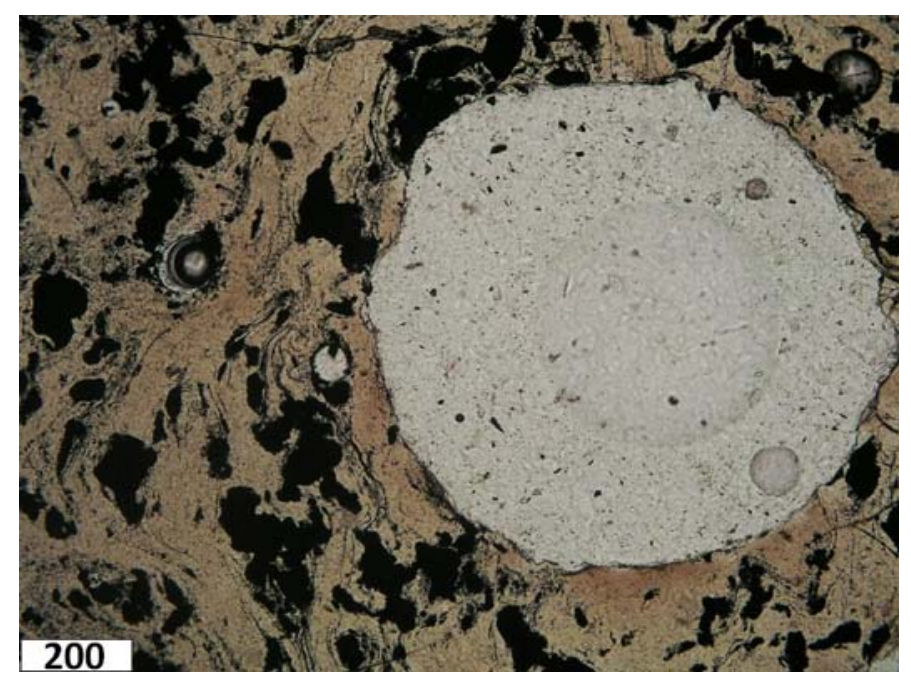

Figure 11. Microphotograph at single Nichol of the lapping of the sample \#44.

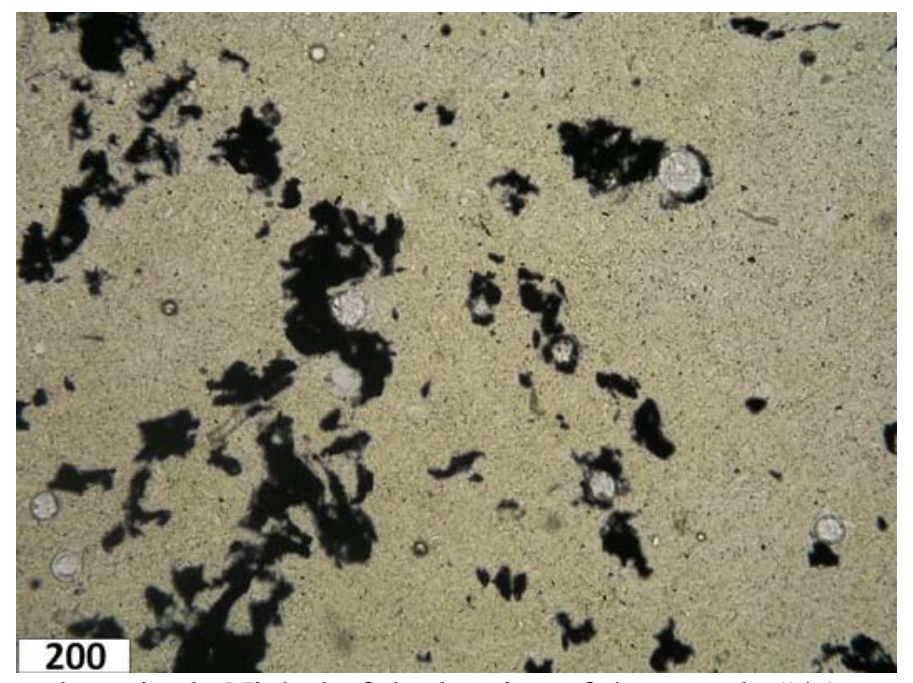

Figure 12. Microphotograph at single Nichol of the lapping of the sample \#45.

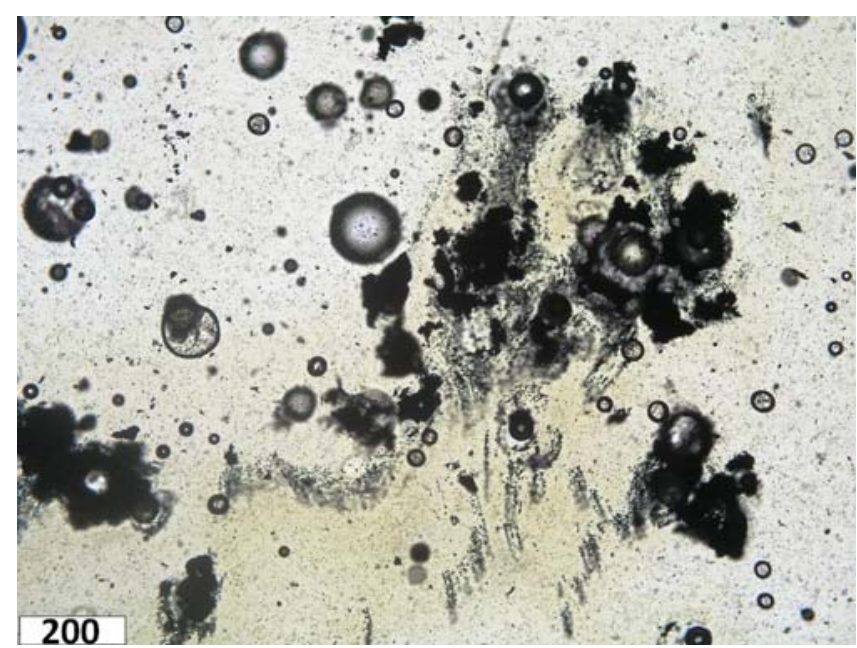

Figure 13. Microphotograph at single Nichol of the lapping of the sample \#46. 
Major features of all the samples are as follows:

- All the samples are composed of major glass and minor spinel;

- All the samples contain gas bubbles with variable diameter (from $<10 \mu \mathrm{m}$ to $>1 \mathrm{~mm}$ );

- Coloring of glass varies from nearly clear to brown;

- Spinel forms both isometric grains and cubic microcrystals $(\sim 1 \mu \mathrm{m})$;

- Microcrystals are aggregated in bands with variable glass and spinel contents;

- Relative location of the bands is caused by flowing of various portion of glassmelt with various viscosity;

- Wavy profile of the bands is similar to that in volcanic glasses with fluidal texture;

- No devitrification of glass was found.

Major differences between the samples are as follows:

- The samples (possibly various parts of the same sample as well) are different in quantitative glass to spinel ratio;

- Significant differences was found in a ratio of isometric grains to cubic microcrystals;

- Fluidal texture is variably appeared; in some samples fluidity takes place only in local areas or absent at all;

- Degree of cracking in the lappings is widely varied.

\section{IR spectroscopic study}

IR spectra of all the samples are similar (Figures 14 and 15). IR spectra of glasses (Figure 16) consist of the bands due to stretching (3100-3600 $\left.\mathrm{cm}^{-1}\right)$ and bending modes $\left(1600-1800 \mathrm{~cm}^{-1}\right)$ in the molecules of absorbed and structurally bound water, weak bands due to hydrogen bonds in the structure of glasses and numerous bands lower $1600 \mathrm{~cm}^{-1}$ due to stretching and bending modes in the units forming anionic motif of the structure of glasses. 


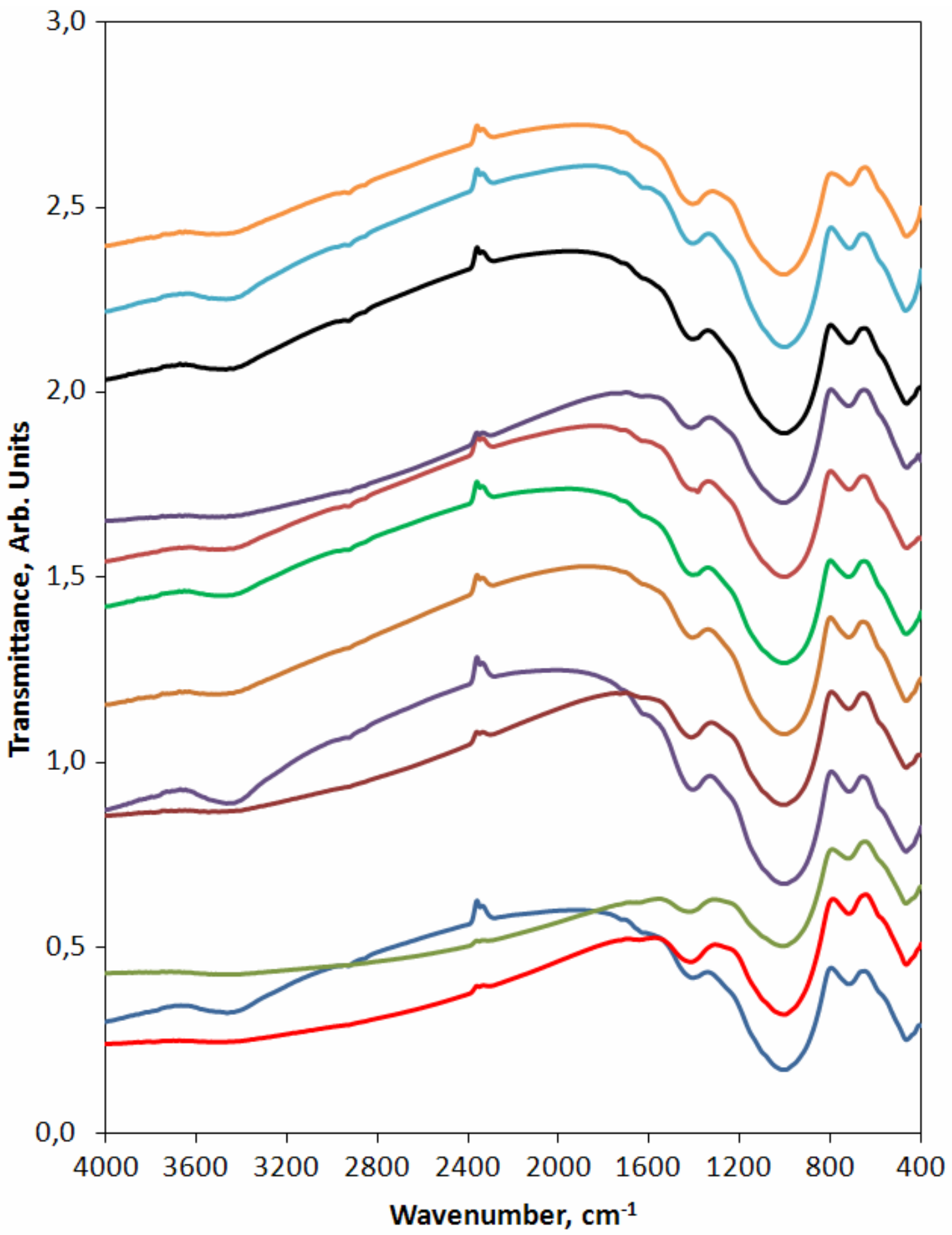

$\begin{array}{lll}\text {-MRF-10-35 } & \text {-MRF-10-36 } & \text {-MRF-10-37 } \\ \text {-MRF-10-38 } & \text {-MRF-10-39 } & \text {-MRF-10-40 } \\ \text {-MRF-10-41 } & \text {-MRF-10-42 } & \text {-MRF-10-43 } \\ \text {-MRF-10-44 } & \text {-MRF-10-45 } & \text {-MRF-10-46 }\end{array}$

Figure 14. IR spectra of the samples within the range of $4000-400 \mathrm{~cm}^{-1}$. 
SRNL-STI-2010-00805

Revision 0

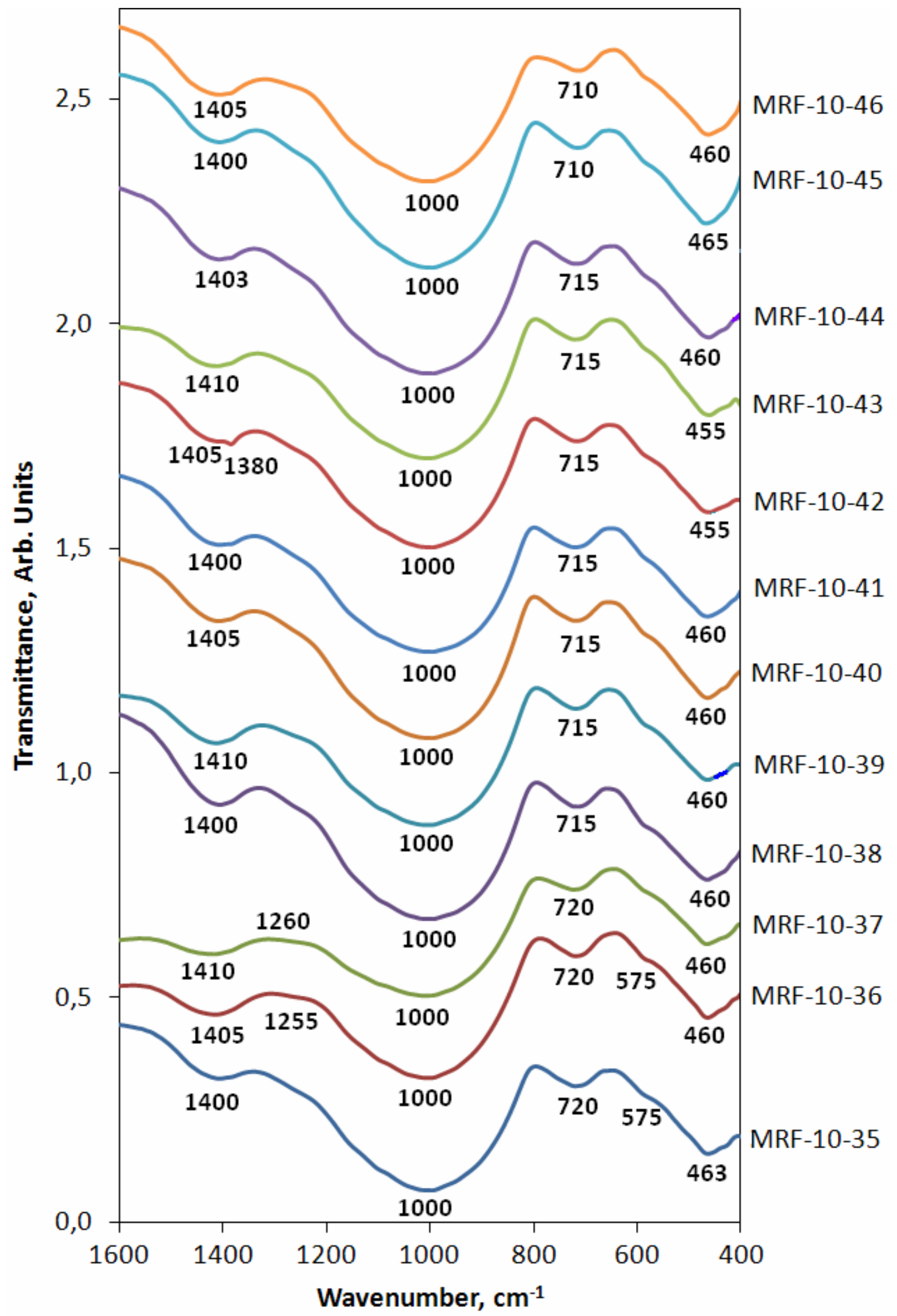

Figure 15. Fragments of IR spectra of the samples within the range of $1600-400 \mathrm{~cm}^{-1}$. 
IR spectra of all the glasses within the range of 4000-1600 $\mathrm{cm}^{-1}$ (Figure 14) consist of the bands due to stretching and bending modes in silicon-oxygen, boron-oxygen, aluminum-oxygen and iron-oxygen (in spectra of glasses A1, B1 and D1 only) structural groups. The wavenumber ranges of $1550-1300 \mathrm{~cm}^{-1}$ and $\sim 1260-1270 \mathrm{~cm}^{-1}$ are typical of vibrations in the boron-oxygen groups with trigonally coordinated boron (boron-oxygen triangles $\mathrm{BO}_{3}$ ) [7]. These bands were attributed as components of twice degenerated asymmetric valence $v_{3} \mathrm{O}-\mathrm{B}-\mathrm{O}$ vibrations (stretching modes). The band with components $\sim 710-730$ and 650-670 $\mathrm{cm}^{-1}$ may be associated with twice degenerated asymmetric deformation $\delta\left(v_{4}\right) \mathrm{O}-\mathrm{B}-\mathrm{O}$ vibrations (bending modes) [7]. Strong absorption in both IR and Raman spectra within the range of $1150-850 \mathrm{~cm}^{-1}$ is caused by asymmetric $v_{3}$ vibrations (stretching modes) in silicon-oxygen units bound to zero $\left(850-900 \mathrm{~cm}^{-1}\right)$, one $\left(\sim 900-950 \mathrm{~cm}^{-1}\right)$, two $\left(\sim 950-1050 \mathrm{~cm}^{-1}\right)$, three $\left(\sim 1050-1100 \mathrm{~cm}^{-1}\right)$ and four $\left(\sim 1100-1150 \mathrm{~cm}^{-1}\right)$ neighboring $\mathrm{SiO}_{4}$ tetrahedra $\left(\mathrm{Q}^{0}, \mathrm{Q}^{1}, \mathrm{Q}^{2}, \mathrm{Q}^{3}, \mathrm{Q}^{4}\right.$, respectively) [8] and, in less extent, $\mathrm{BO}_{4}$ tetrahedra (1000-1100 $\mathrm{cm}^{-1}$ ) [9]. In IR spectra of all the glasses the broad band within the range of $\sim 800-1200 \mathrm{~cm}^{-1}$ is multicomponent due to superposition of vibrations (stretching modes) in $\mathrm{SiO}_{4}$ and $\mathrm{BO}_{4}$ tetrahedra. Stretching modes of $\mathrm{Al}-\mathrm{O}$ bonds in $\mathrm{AlO}_{4}$ tetrahedra and $\mathrm{Fe}-\mathrm{O}$ bonds in $\mathrm{FeO}_{4}$ tetrahedra are positioned at $700-800 \mathrm{~cm}^{-1}$ and $550-650 \mathrm{~cm}^{-1}$, respectively. Bending modes of $\mathrm{Si}-\mathrm{O}-\mathrm{Si}$ bonds in $\mathrm{SiO}_{4}$ tetrahedra are positioned within the range of $350-550 \mathrm{~cm}^{-1}$.

As seen from Figure 14, the bands at $3300-3600 \mathrm{~cm}^{-1}$ and $1620-1650 \mathrm{~cm}^{-1}$ are correlated on intensity and they may be attributed to stretching and bending modes in molecules of absorbed or structurally-bound water [10]. In the spectra of all the glasses the bands due to vibrations in water molecules or $\mathrm{Me}-\mathrm{O}-\mathrm{H}$ bonds have much lower intensity than the bands due to vibration in anionic motif of the glass structure.

The IR spectra of all the glasses within the range of 1600-400 $\mathrm{cm}^{-1}$ are similar (Figure 15). This indicates that all the glasses have similar structure of their anionic motif. As follows from position of major maximum of the strongest band $1200-800 \mathrm{~cm}^{-1}\left(\sim 1000 \mathrm{~cm}^{-1}\right)$ the base of structural network is metasilicate chains and rings where the $\mathrm{Q}^{2}$ units are predominant. Bridging bonds $\mathrm{Si}-\mathrm{O}-\mathrm{Fe}$ and $\mathrm{Si}-\mathrm{O}-\mathrm{Al}$ bonding $\mathrm{SiO}_{4}$ and $\mathrm{FeO}_{4}$ and $\mathrm{AlO}_{4}$ tetrahedra and thus increasing the degree of connectedness of the glass network are positioned within the range of $950-880 \mathrm{~cm}^{-1}$ and may contribute to lower wavenumber edge of the band $1200-800 \mathrm{~cm}^{-1}$. The bans with a maximum at $455-463 \mathrm{~cm}^{-1}$ is due to bending modes in $\mathrm{SiO}_{4}$ tetrahedra and $\mathrm{Si}-\mathrm{O}-\mathrm{Si}$ bonds (in the most extent) and $\mathrm{Si}-\mathrm{O}-\mathrm{Al}$ and $\mathrm{Si}-\mathrm{O}-\mathrm{Fe}$ bonds (in less extent). The band with a maximum at $710-720 \mathrm{~cm}^{-1}$ is due to superposition of symmetric stretching modes in $\mathrm{SiO}_{4}$ tetrahedra and asymmetric stretching modes in $\mathrm{AlO}_{4}$ tetrahedra. Weak band observed as a shoulder at $\sim 575 \mathrm{~cm}^{-1}$ is due to vibrations in $\mathrm{FeO}_{4}$ tetrahedra. Boron in these glasses is predominantly threefold-coordinated and occurs as boron-oxygen triangles. Part of them possibly enters complex borate groups bound with boron-oxygen tetrahedra.

Thus, the structural network is primarily composed of metasilicate chains and rings with embedded $\mathrm{AlO}_{4}$ and $\mathrm{FeO}_{4}$ tetrahedra. Boron-oxygen constituent exists separately.

\section{Raman spectroscopic study}

Raman spectra of the glassy samples are shown on Figure 16. Depolarized spectra are given on Figure 17. Spectra of the samples \#\#39, 40, 44 and 45 differ markedly from the rest spectra. These glasses seem to be higher structured or contain higher amount of crystalline phase (spinel). 


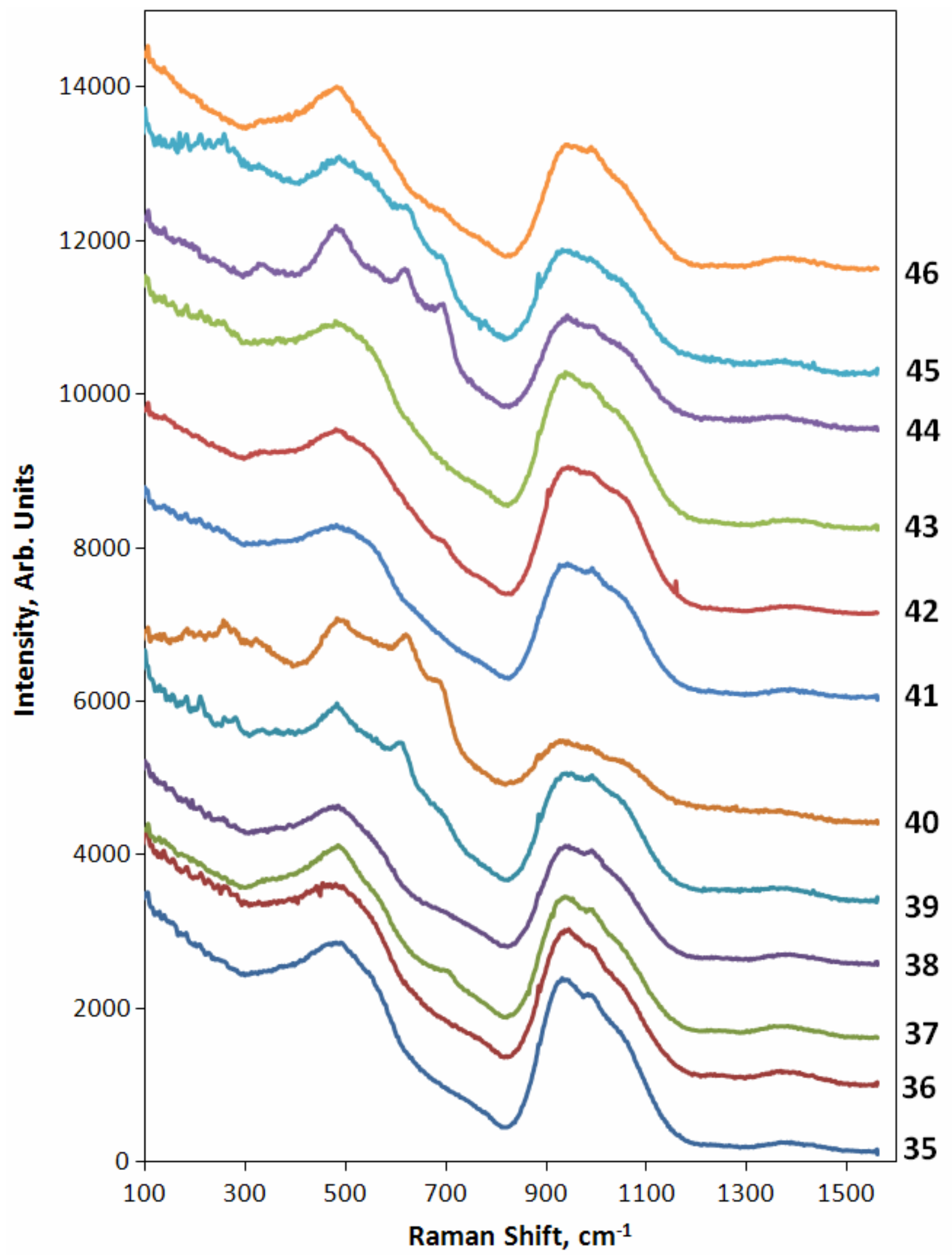

Figure 16. Raman spectra of the samples. 


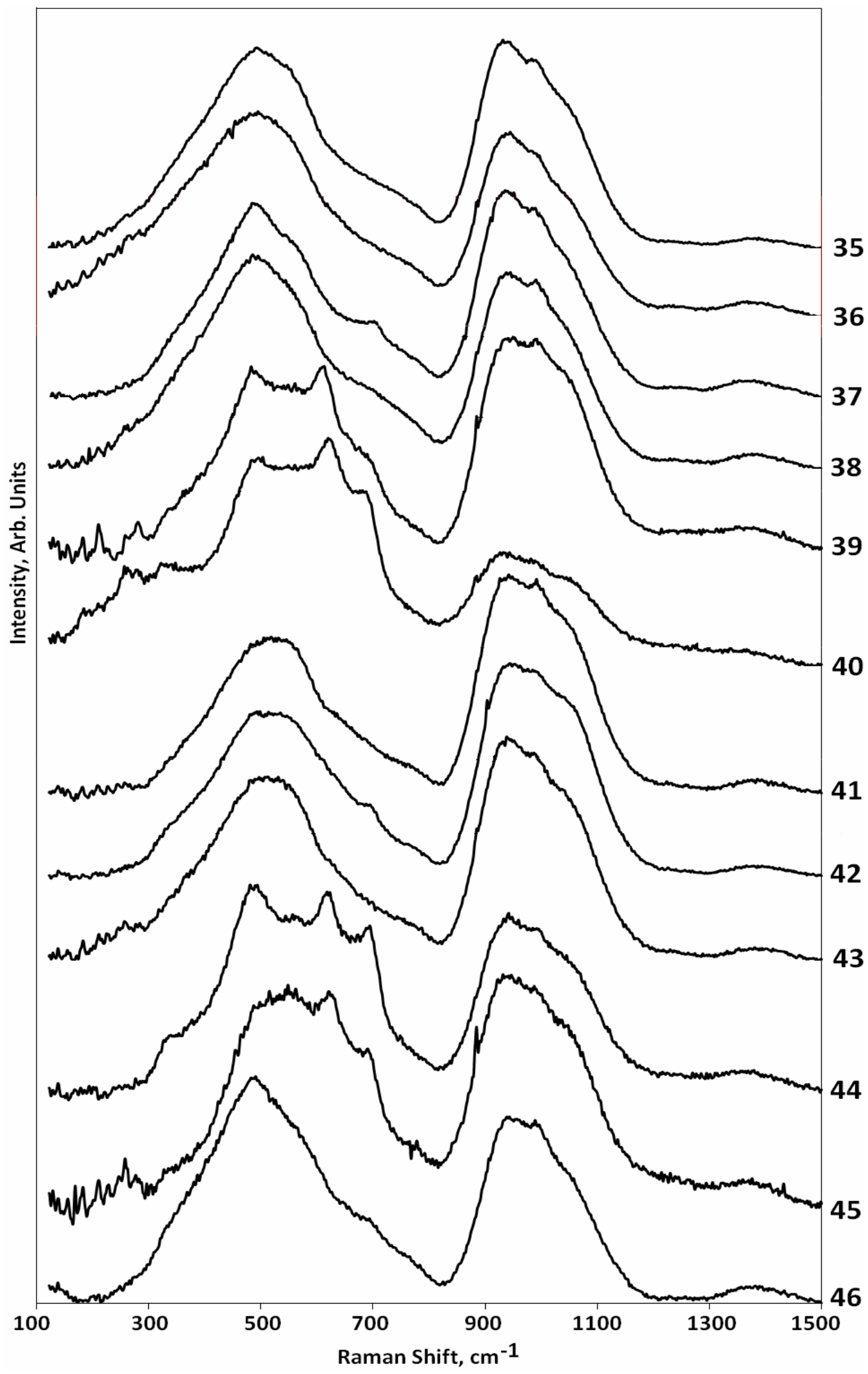

Figure 17. Depolarized Raman spectra of the samples. 
All the spectra consist of the bands within the ranges of 300-600 $\mathrm{cm}^{-1}, 800-1150 \mathrm{~cm}^{-1}$ and weak bands at $650-800 \mathrm{~cm}^{-1}$ and $1200-1300 \mathrm{~cm}^{-1}$ and $1300-1500 \mathrm{~cm}^{-1}$. Like in IR spectra these bands are due to bending and stretching modes in silicon-oxygen network, and vibrations in $\mathrm{AlO}_{4}, \mathrm{FeO}_{4}$ and $\mathrm{BO}_{3}$ units. In the whole Raman spectroscopic data are in a good agreement with IR spectroscopic data but computer fitting allows to distinguishing more details (Figures 18-29).

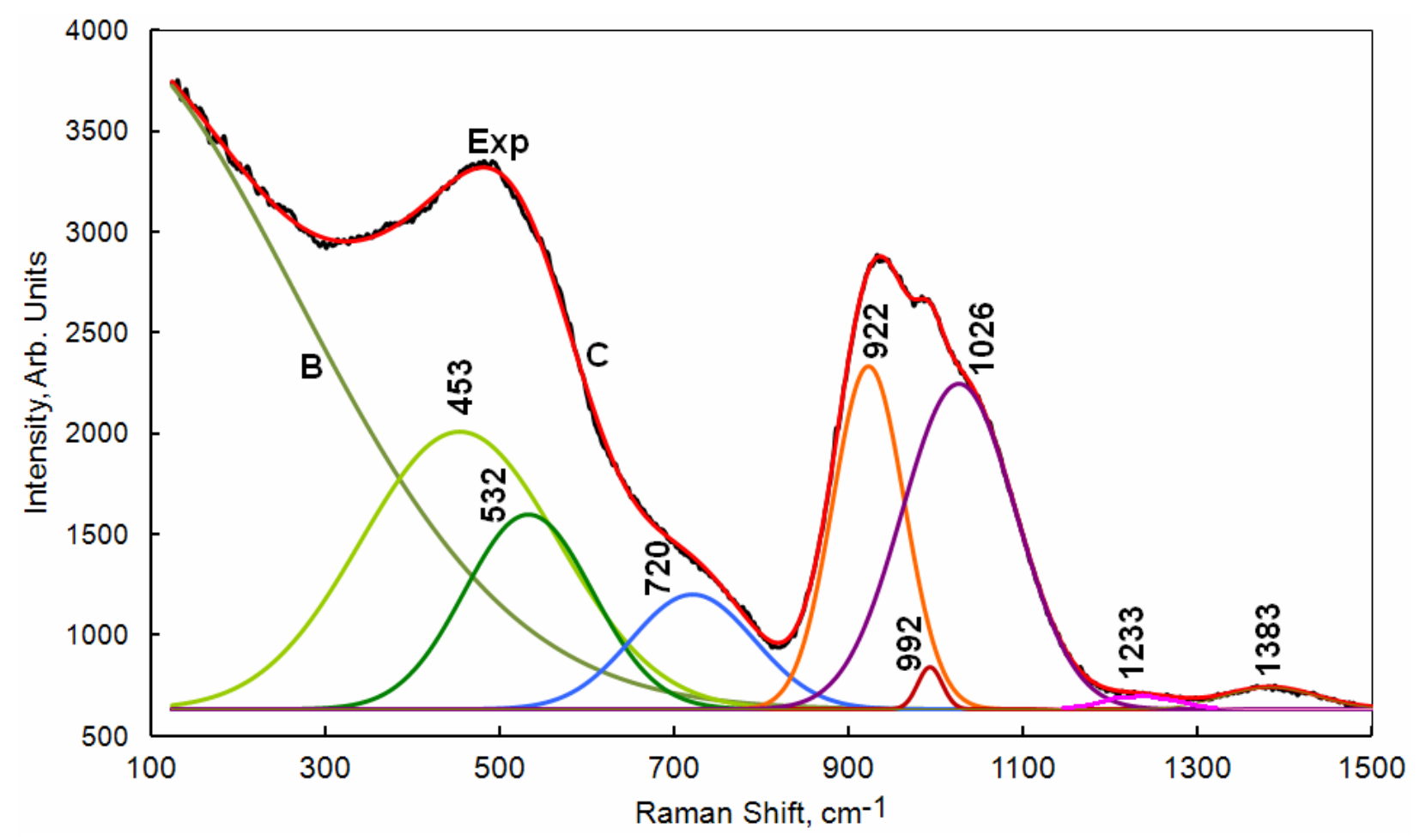

Figure 18. Computer fitting of the Raman spectra of the sample \#35.

In the spectrum of the glassy material \#35 (Figure 18) strong bands with maxima at $453 \mathrm{~cm}^{-1}, 922 \mathrm{~cm}^{-1}$ and $1026 \mathrm{~cm}^{-1}$ are due to bending and stretching modes in $\mathrm{SiO}_{4}$ tetrahedra and bridging bonds $\mathrm{Si}-\mathrm{O}-\mathrm{Si}$ bonding $\mathrm{SiO}_{4}$ tetrahedra. Some contribution to the band with maximum at $922 \mathrm{~cm}^{-1}$ may be made by vibrations of $\mathrm{Si}-\mathrm{O}-\mathrm{Al}$ and $\mathrm{Si}-\mathrm{O}-\mathrm{Fe}$ bridging bonds. The latter were suggested to be responsible for the band with a maximum at $910 \mathrm{~cm}^{-1}$ observed in Raman spectra of Fe-containing silicate glasses [11]. If so, the contribution of such bonds is rather minor because of low $\mathrm{Fe}_{2} \mathrm{O}_{3}$ content in glass. The band with a maximum at $532 \mathrm{~cm}^{-1}$ may be assigned to bending vibrations of $\mathrm{Si}-\mathrm{O}-\mathrm{Si}\left(\mathrm{v}_{4}\right) \mathrm{Si}-\mathrm{O}-\mathrm{Al}$ and $\mathrm{Si}-\mathrm{O}-\mathrm{Fe}$ bridging bonds. The band with a maximum at $720 \mathrm{~cm}^{-1}$ is due probably to bending modes in $\mathrm{AlO}_{4}$ tetrahedra. Weak bands at $1383 \mathrm{~cm}^{-1}$ and $1233 \mathrm{~cm}^{-1}$ are due to vibrations in $\mathrm{BO}_{3}$ units with various degree of polymerization. The band at $1233 \mathrm{~cm}^{-1}$ may be also attributed to stretching vibrations of $\mathrm{B}^{\mathrm{II}}-\mathrm{O}-\mathrm{B}^{\mathrm{IV}}$ bridging bonds. Since glass \#35 has a value of $\psi_{\mathrm{B}}$ factor equal to approximately 2 weak band with a maximum at $992 \mathrm{~cm}^{-1}$ may be assigned to stretching vibrations in $\mathrm{BO}_{4}$ tetrahedra.

Glass \#36 has higher $\mathrm{B}_{2} \mathrm{O}_{3}$ content $\left(8.62\right.$ mol.\%) and lower $\psi_{\mathrm{B}}$ value than the glass \#35 (Table II). Therefore, fraction of trigonally-coordinated boron in them should be higher. It is seen well that intensities of the bands with maxima at $1241 \mathrm{~cm}^{-1}$ and $1376 \mathrm{~cm}^{-1}$ are higher than in the spectrum of the glass \#35 (Figure 19). In the whole the spectra of both glasses are similar and differ slightly only in maxima of the bands. 


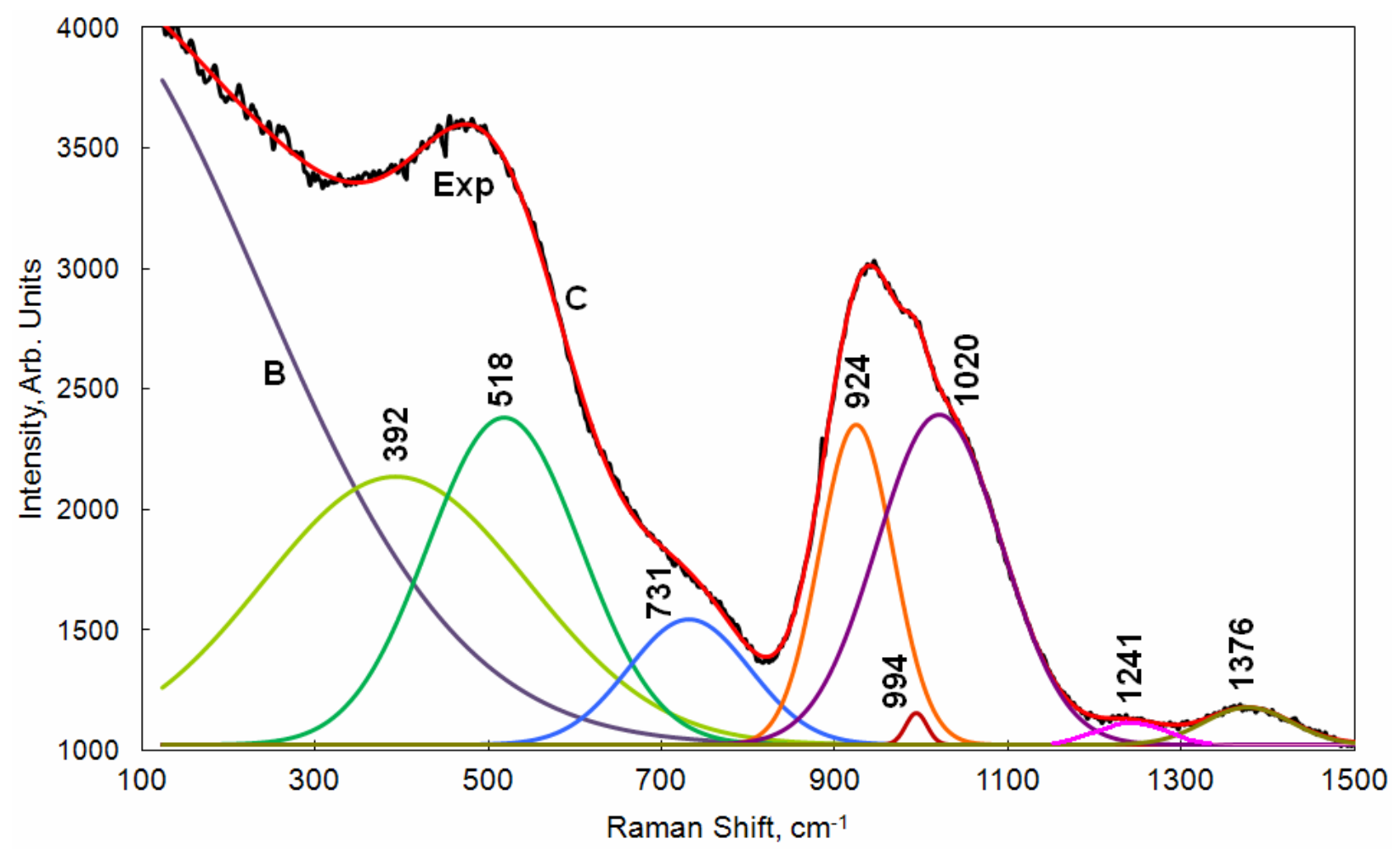

Figure 19. Computer fitting of the Raman spectra of the sample \#36.

The spectrum of the glass \#37 is some more complicated (Figure 20). Except the bands observed in the spectra of the samples \#35 and \#36 (maxima at $503 \mathrm{~cm}^{-1}, 924 \mathrm{~cm}^{-1}, 994 \mathrm{~cm}^{-1}, 1020 \mathrm{~cm}^{-1}, 1241 \mathrm{~cm}^{-1}$ and $1376 \mathrm{~cm}^{-1}$ ) additional bands with maxima $346 \mathrm{~cm}^{-1}, 486 \mathrm{~cm}^{-1}$ were found. The band at $650-800 \mathrm{~cm}^{-1}$ is split into two components: $700 \mathrm{~cm}^{-1}$ and $771 \mathrm{~cm}^{-1}$. Weak bands at $346 \mathrm{~cm}^{-1}, 486 \mathrm{~cm}^{-1}$ and stronger band with a maximum at $700 \mathrm{~cm}^{-1}$ may be attributed to vibrations in $\mathrm{AlO}_{6}, \mathrm{AlO}_{5}$ and $\mathrm{AlO}_{4}$ polyhedra. The band with a maximum at $771 \mathrm{~cm}^{-1}$ is due probably to symmetric stretching $\left(v_{1}\right)$ modes in $\mathrm{SiO}_{4}$ tetrahedra.

The spectrum of the glass \#38 (Figure 21) is similar to those of the glasses \#35 (Figure 18) and \#36 (Figure 19). The difference between them is in positions of maxima of the bands. In the spectrum of the glass \#38 they are as follows: $348 \mathrm{~cm}^{-1}, 507 \mathrm{~cm}^{-1}, 714 \mathrm{~cm}^{-1}, 923 \mathrm{~cm}^{-1}, 995 \mathrm{~cm}^{-1}, 1022 \mathrm{~cm}^{-1}, 1235 \mathrm{~cm}^{-1}$, and $1383 \mathrm{~cm}^{-1}$. If attribution of the bands with maxima at $507 \mathrm{~cm}^{-1}, 714 \mathrm{~cm}^{-1}, 923 \mathrm{~cm}^{-1}, 1022 \mathrm{~cm}^{-1}, 1235 \mathrm{~cm}^{-1}$, and $1383 \mathrm{~cm}^{-1}$ is rather unambiguous, then assignment of the bands with maxima at $348 \mathrm{~cm}^{-1}$ and $995 \mathrm{~cm}^{-}$ ${ }^{1}$ is indefinitive. As in the spectrum of other glasses the band with a maximum at $995 \mathrm{~cm}^{-1}$ may be due to stretching vibrations in $\mathrm{BO}_{4}$ tetrahedra or $\mathrm{Si}-\mathrm{O}-\mathrm{B}$ bridging bonds. This band has low intensity that is consistent well with low $\mathrm{B}_{2} \mathrm{O}_{3}$ content in glasses. 


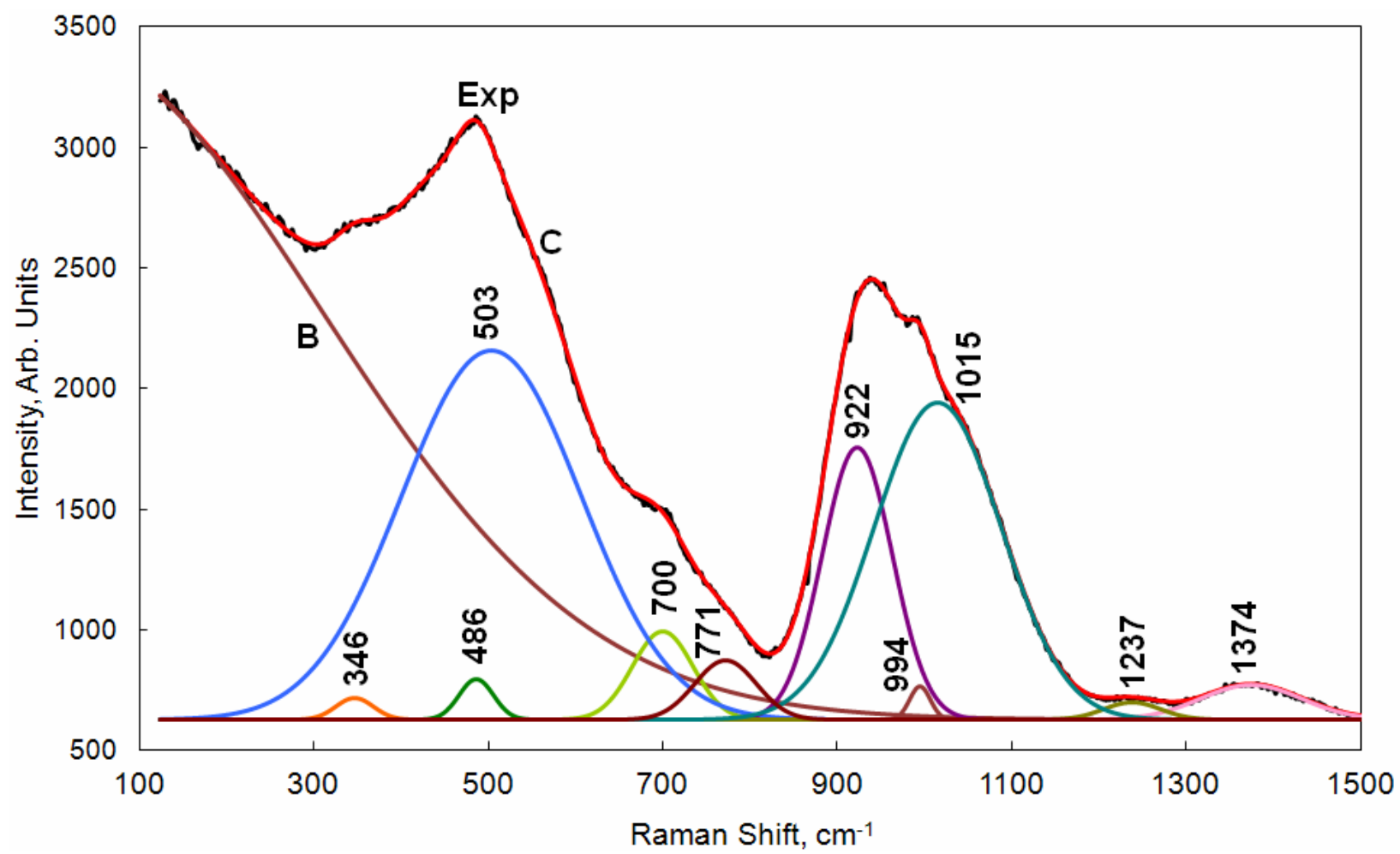

Figure 20. Computer fitting of the Raman spectra of the sample \#37.

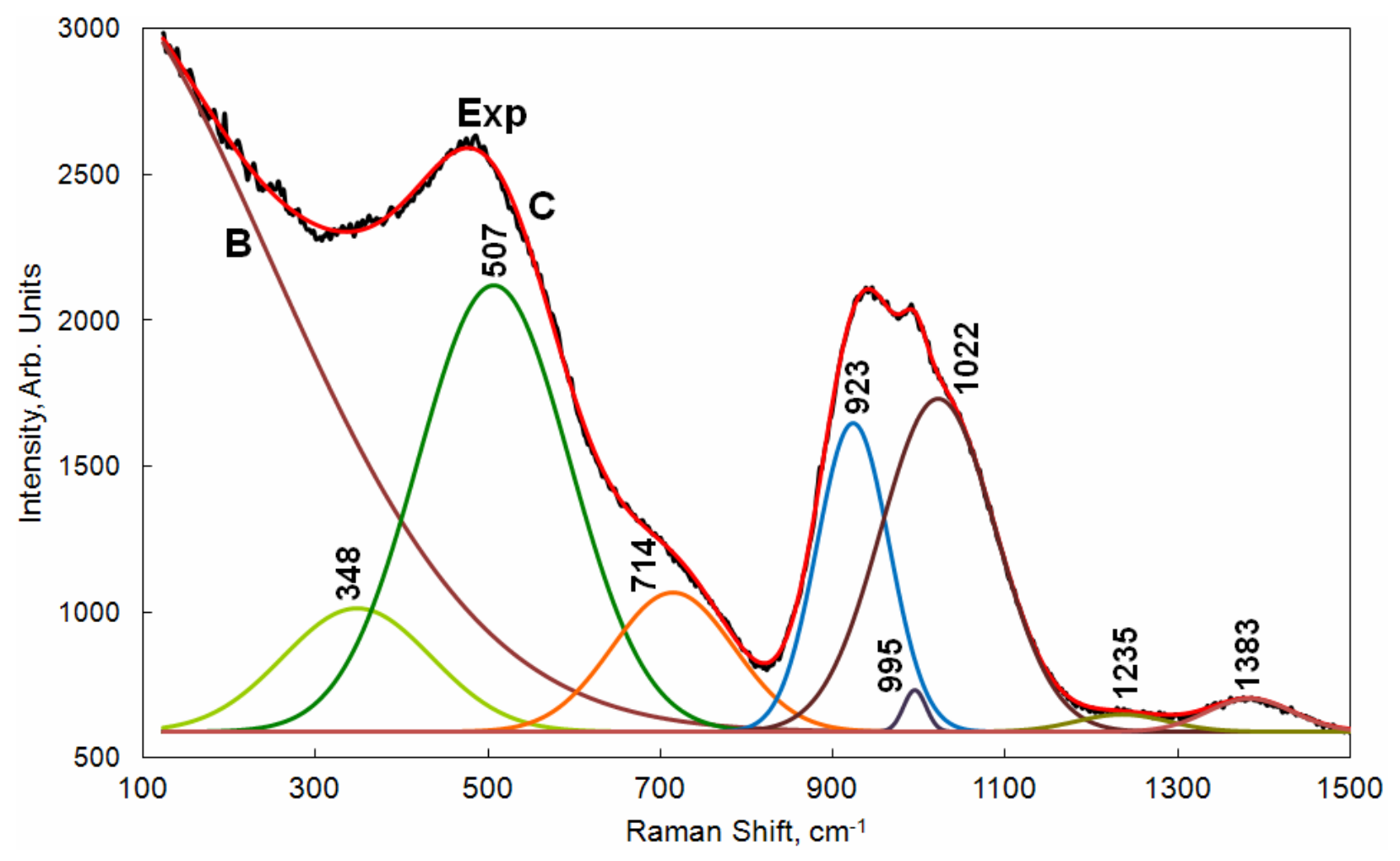

Figure 21. Computer fitting of the Raman spectra of the sample \#38. 
Raman spectrum of the glass \#39 (Figure 22) is markedly different from spectra of previous glasses. Along with the bands observed in spectra of other glasses $\left(539 \mathrm{~cm}^{-1}, 935 \mathrm{~cm}^{-1}, 993 \mathrm{~cm}^{-1}, 1030 \mathrm{~cm}^{-1}, 1246\right.$ $\mathrm{cm}^{-1}, 1386 \mathrm{~cm}^{-1}$ ) it contains weak bands with maxima at $480 \mathrm{~cm}^{-1}, 613 \mathrm{~cm}^{-1}, 687 \mathrm{~cm}^{-1}$, and $890 \mathrm{~cm}^{-1}$. The first three bands may be assigned to vibrations in $\mathrm{AlO}_{6}, \mathrm{AlO}_{5}$ and $\mathrm{AlO}_{4}$ polyhedra, whereas the band with a maximum at $890 \mathrm{~cm}^{-1}$ - to stretching vibrations of $\mathrm{Si}-\mathrm{O}-\mathrm{Al}$ bridging bonds.

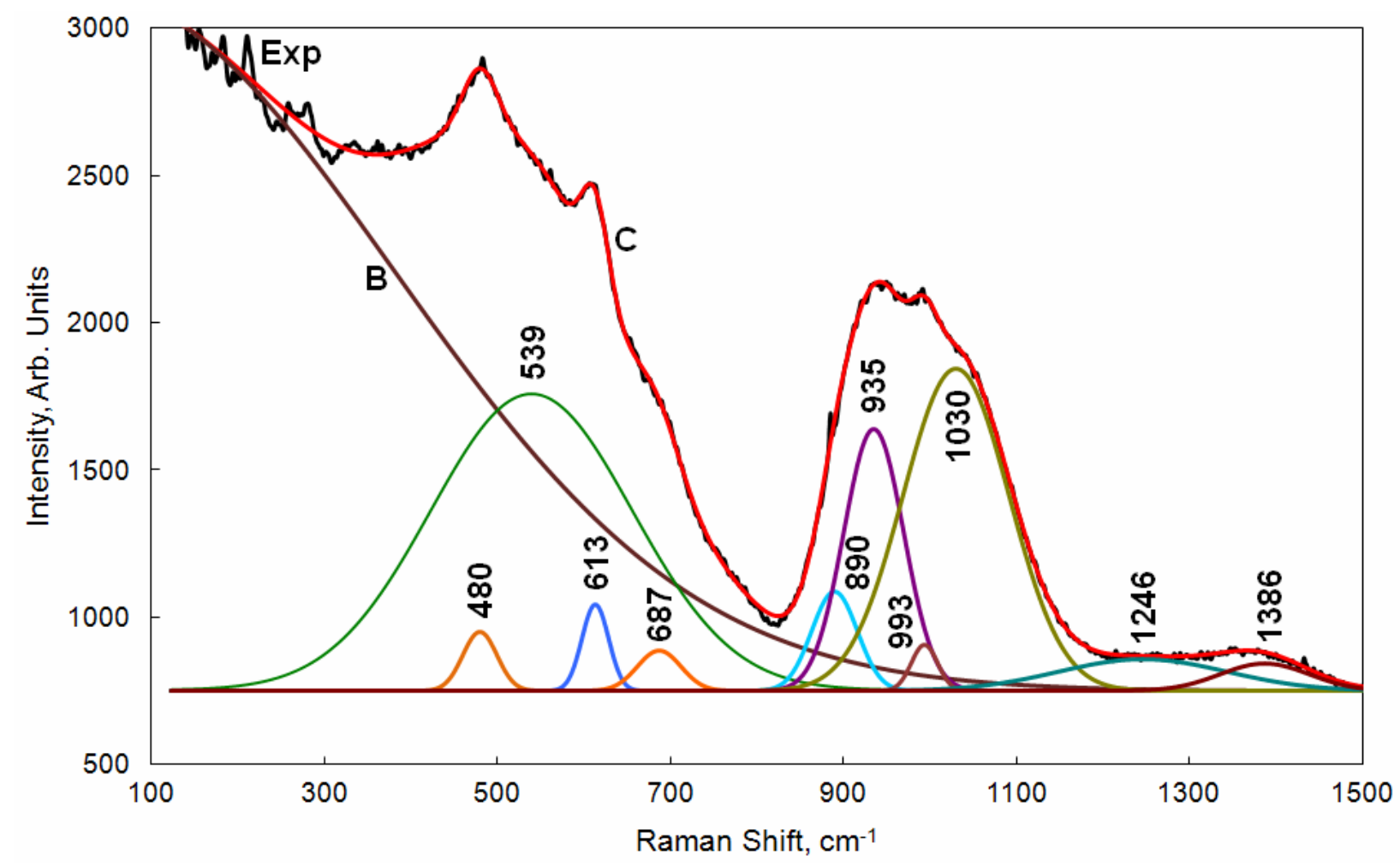

Figure 22. Computer fitting of the Raman spectra of the sample \#39.

Raman spectrum of the glass \#40 consists of numerous bands: strong broad with maxima at $327 \mathrm{~cm}^{-1}, 570$ $\mathrm{cm}^{-1}, 751 \mathrm{~cm}^{-1}, 924 \mathrm{~cm}^{-1}, 1045 \mathrm{~cm}^{-1}$, moderate narrow with maxima at $479 \mathrm{~cm}^{-1}, 629 \mathrm{~cm}^{-1}, 687 \mathrm{~cm}^{-1}$, weak narrow with a maximum at $991 \mathrm{~cm}^{-1}$, and weak broad with maxima at $1202 \mathrm{~cm}^{-1}$ and $1378 \mathrm{~cm}^{-1}$ (Figure 23).

Similarly to the previous spectra the bands with maxima at $570 \mathrm{~cm}^{-1}, 751 \mathrm{~cm}^{-1}, 924 \mathrm{~cm}^{-1}$, and $1045 \mathrm{~cm}^{-1}$ are due to bending and stretching modes in $\mathrm{SiO}_{4}$ tetrahedra and bridging bonds $\mathrm{Si}-\mathrm{O}-\mathrm{Si}, \mathrm{Si}-\mathrm{O}-\mathrm{Al}$ and $\mathrm{Si}-\mathrm{O}-\mathrm{Fe}$; the bands with maxima at $479 \mathrm{~cm}^{-1}, 629 \mathrm{~cm}^{-1}$ and $687 \mathrm{~cm}^{-1}$ are due to vibrations in $\mathrm{AlO}_{6}$, $\mathrm{AlO}_{5}$ and $\mathrm{AlO}_{4}$ polyhedra, and bands with maxima at $991 \mathrm{~cm}^{-1}$, and weak bands with maxima at $991 \mathrm{~cm}^{-1}$, $1202 \mathrm{~cm}^{-1}$ and $1378 \mathrm{~cm}^{-1}$ are due to vibrations in boron-oxygen constituent of glass network.

The spectrum of the glass \#41(Figure 24) within the range of $850-1200 \mathrm{~cm}^{-1}$ is similar to that of glass \#39 (Figure 22). Therefore attribution of the bands may be same. The range lower $850 \mathrm{~cm}^{-1}$ may be interpreted as superposition of strong band due to bending vibrations in $\mathrm{SiO}_{4}$ tetrahedra and bridging bonds $\mathrm{Si}-\mathrm{O}-\mathrm{Si}(\mathrm{Al}, \mathrm{Fe})$ and weak bands due to vibrations in $\mathrm{MeO}_{\mathrm{x}}$ polyhedra. 


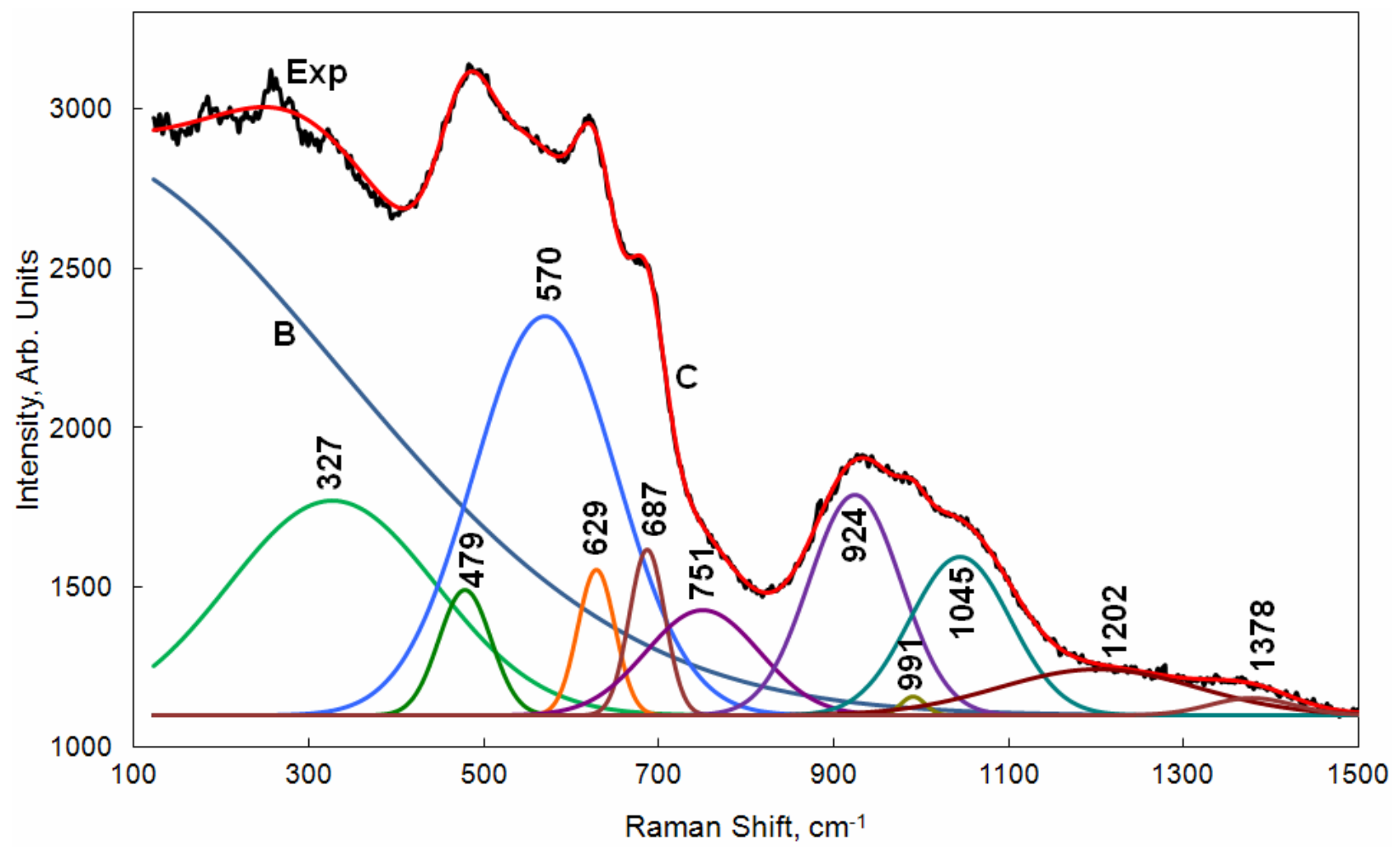

Figure 23. Computer fitting of the Raman spectra of the sample \#40.

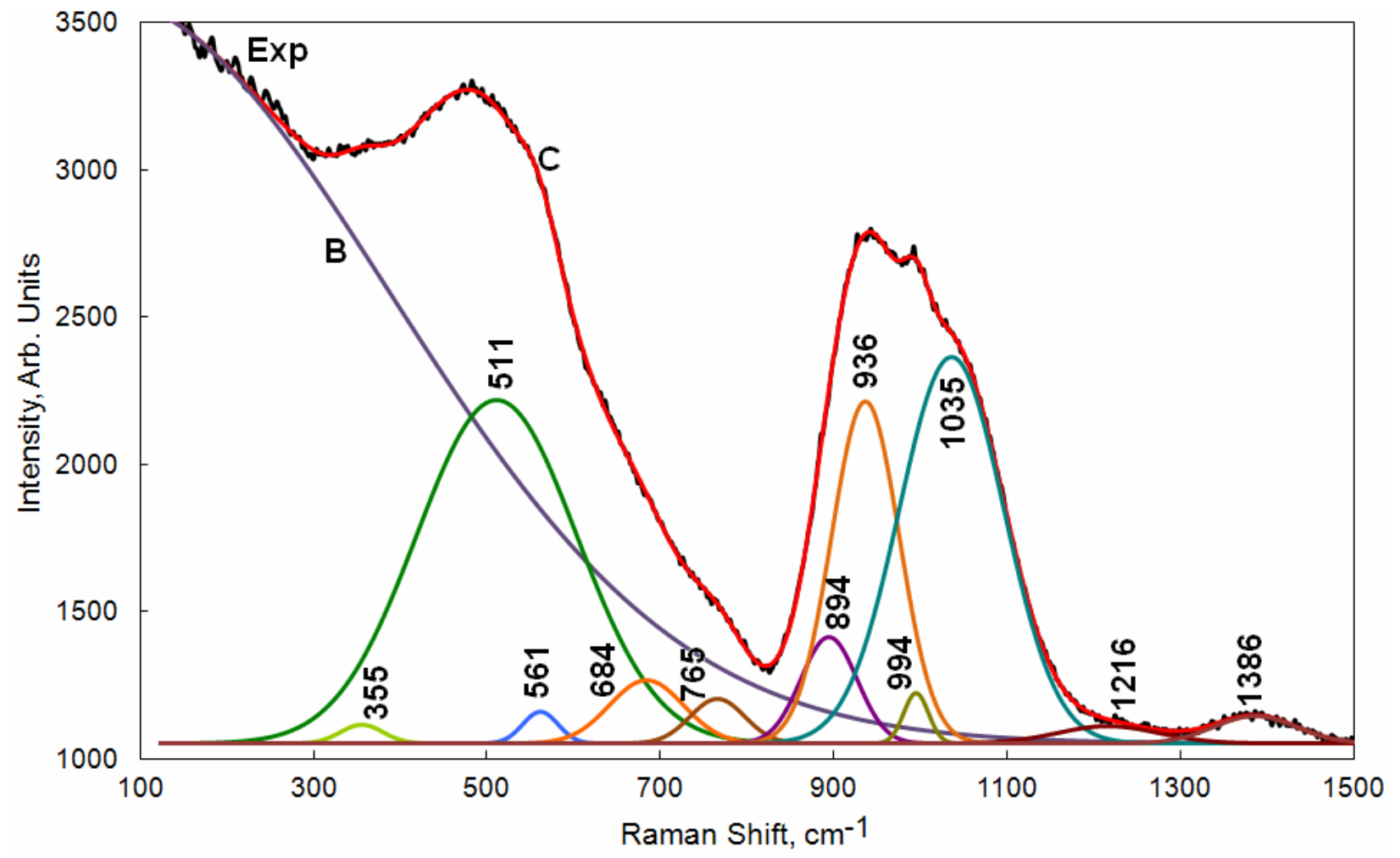

Figure 24. Computer fitting of the Raman spectra of the sample \#41. 
The spectrum of the glasses \#42 (Figure 25), \#43 (Figure 26) and \#48 (Figure 29) like the spectra of other glasses in the same group may be decomposed into the bands due to stretching and bending vibration in silica-oxygen, aluminum-oxygen, iron-oxygen, and boron-oxygen polyhedra.

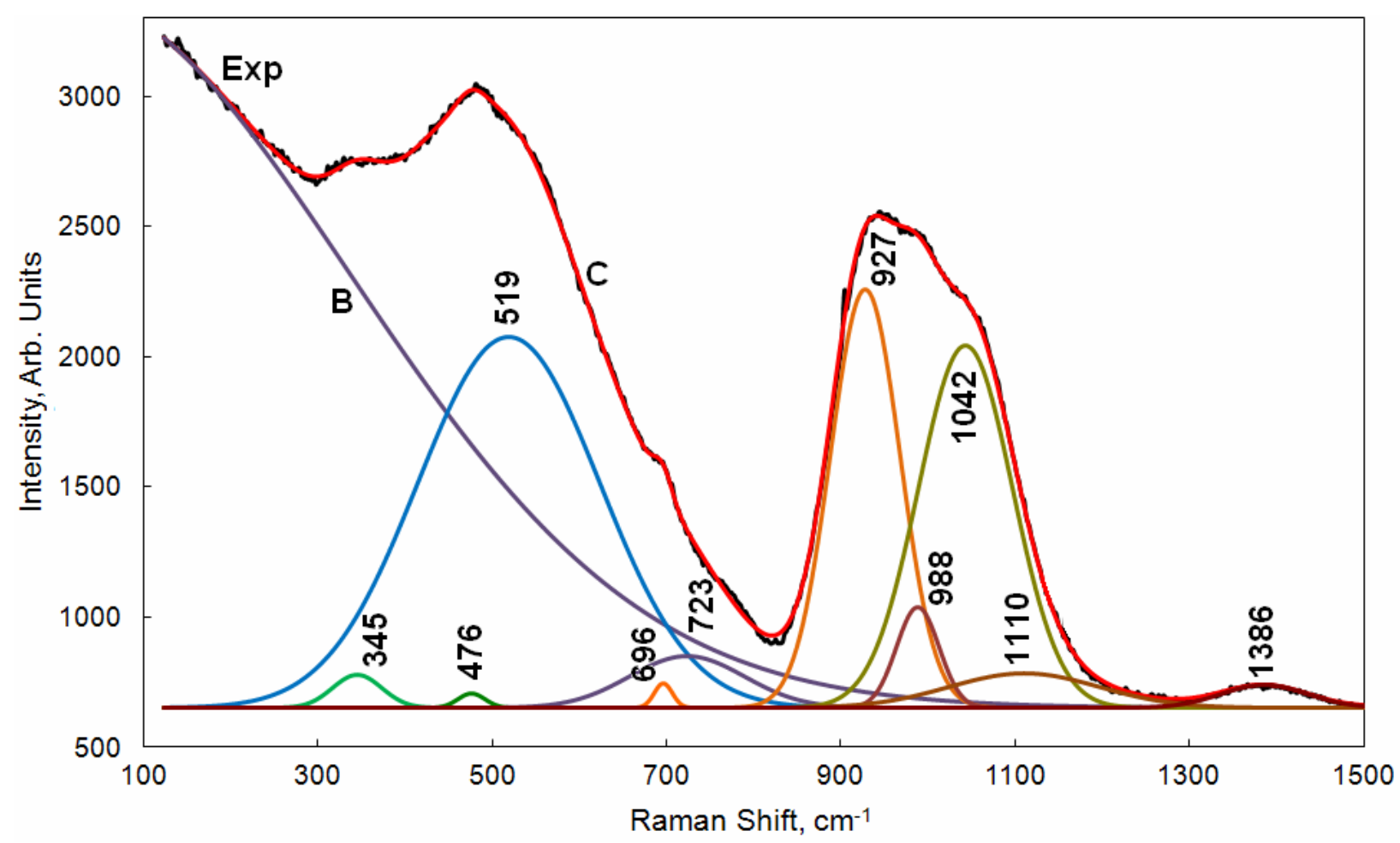

Figure 25. Computer fitting of the Raman spectra of the sample \#42.

A set of the bands obtained by resolving the spectra of the glasses \#39 (Figure 22), \#40 (Figure 23), \#44 (Figure 27), and \#45 (Figure 28) within th rang of $850-1200 \mathrm{~cm}^{-1}$ into components is similar to those obtained from the spectra of glasses belonging to different group. The difference is within the range of $300-850 \mathrm{~cm}^{-1}$ where numerous bands are required to achieve good alignment between experimental and fitted spectra.

In the whole, for the spectra of all the glasses within the range of $850-1200 \mathrm{~cm}^{-1}$ the best fit is achieved in suggestion of overlapping of three major components with maxima at 911-936 $\mathrm{cm}^{-1}, 988-996 \mathrm{~cm}^{-1}$ and $1020-1045 \mathrm{~cm}^{-1}$. For the best fit of spectra of the glasses \#39 and \#41 additional line with a maximum at 890-894 was required. So, it can be concluded that the structure of glasses is composed of metasilicate chains and rings containing incorporated $\mathrm{AlO}_{4}$ and $\mathrm{FeO}_{4}$ as well as minor $\mathrm{BO}_{4}$ tetrahedra. Major $\mathrm{BO}_{4}$ tetrahedra and $\mathrm{BO}_{3}$ triangles form complex borate units and are present as separate constituent.

Computer fitting of the range of $300-850 \mathrm{~cm}^{-1}$ is much more complicated. This range consists of numerous bands due to bending vibrations in silicon-oxygen network with incorporated $\mathrm{MeO}_{4}$ tetrahedra, symmetric stretching vibrations in silicon-oxygen network and stretching vibrations 


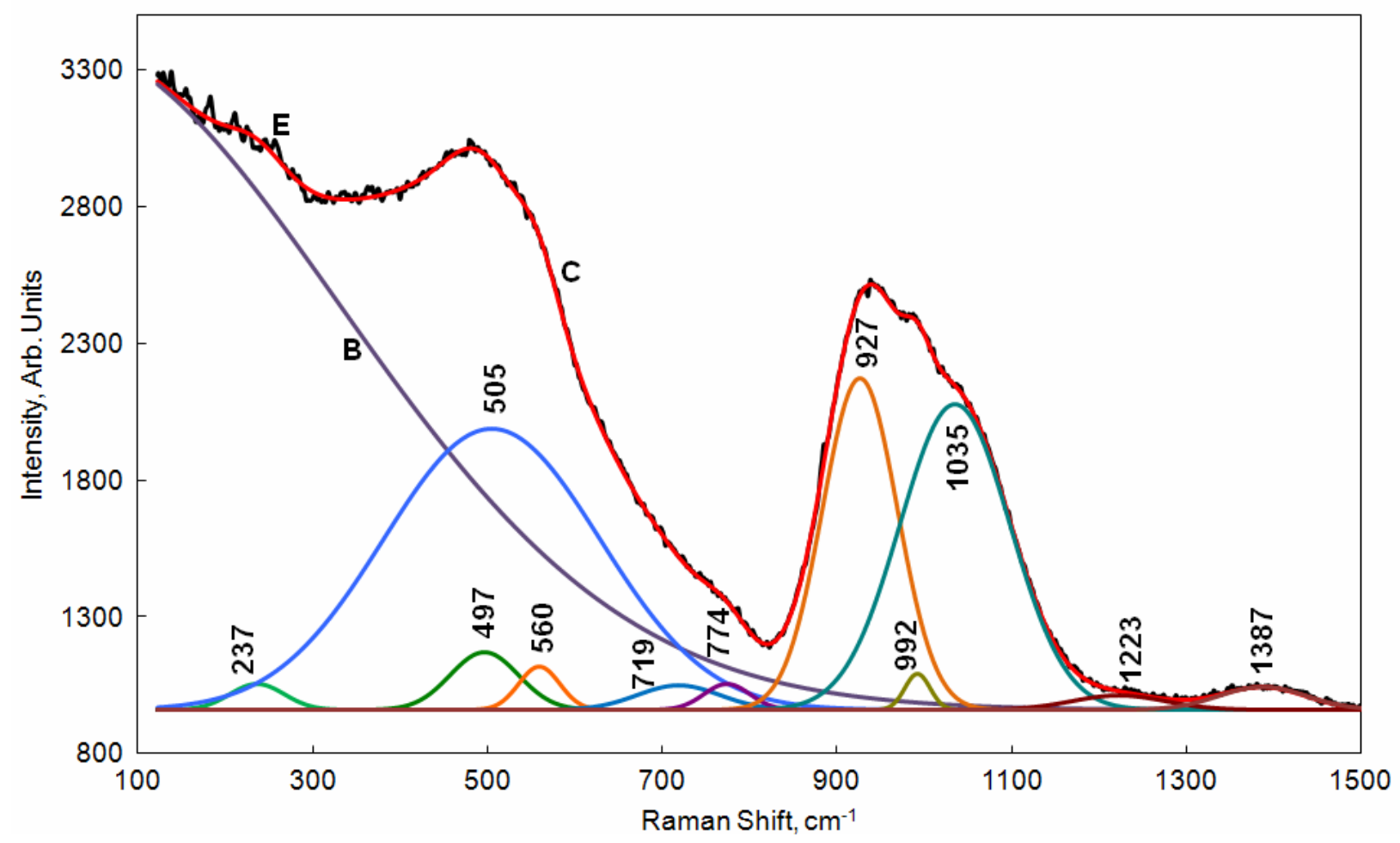

Figure 26. Computer fitting of the Raman spectra of the sample \#43.

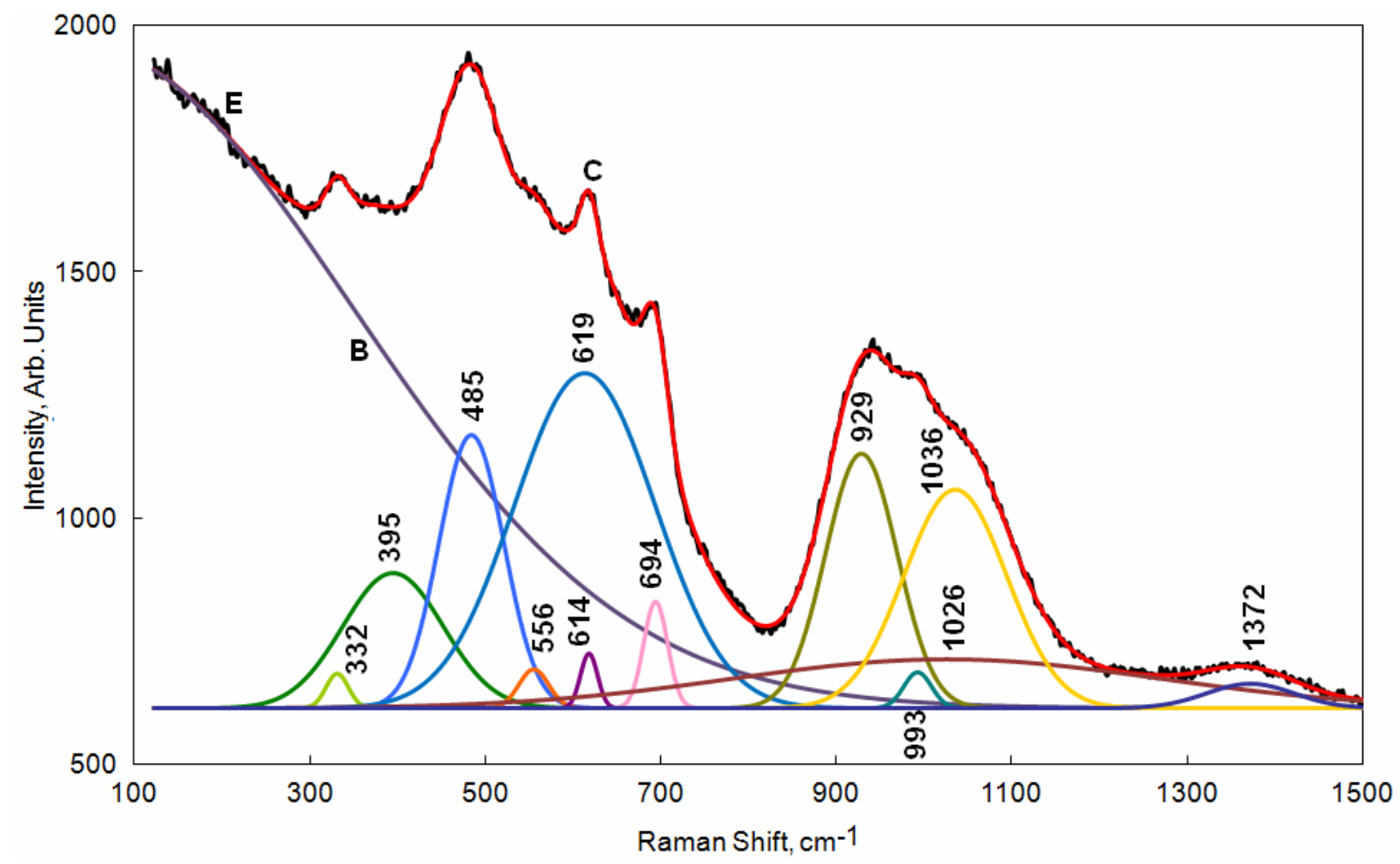

Figure 27. Computer fitting of the Raman spectra of the sample \#44. 


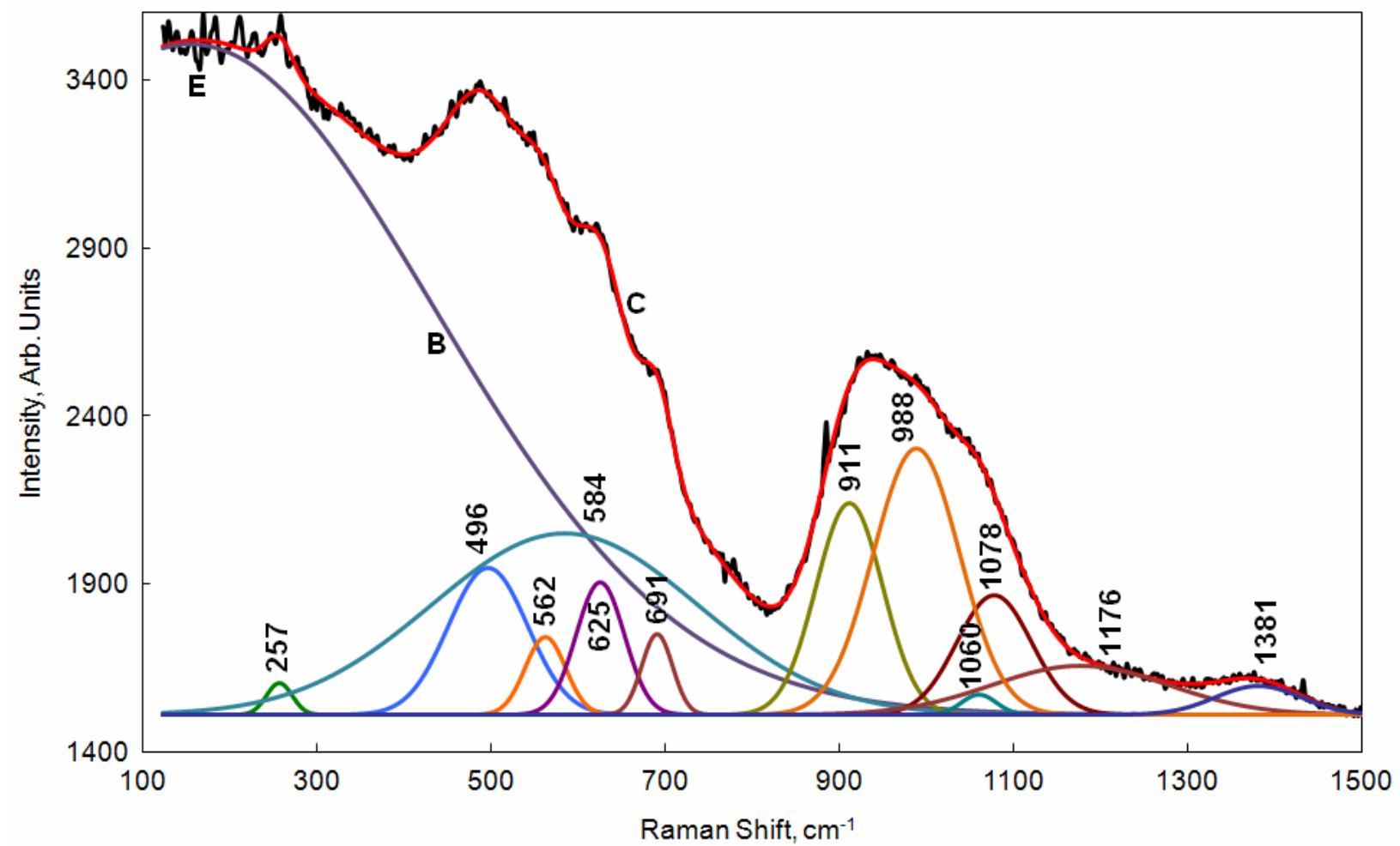

Figure 28. Computer fitting of the Raman spectra of the sample \#45.

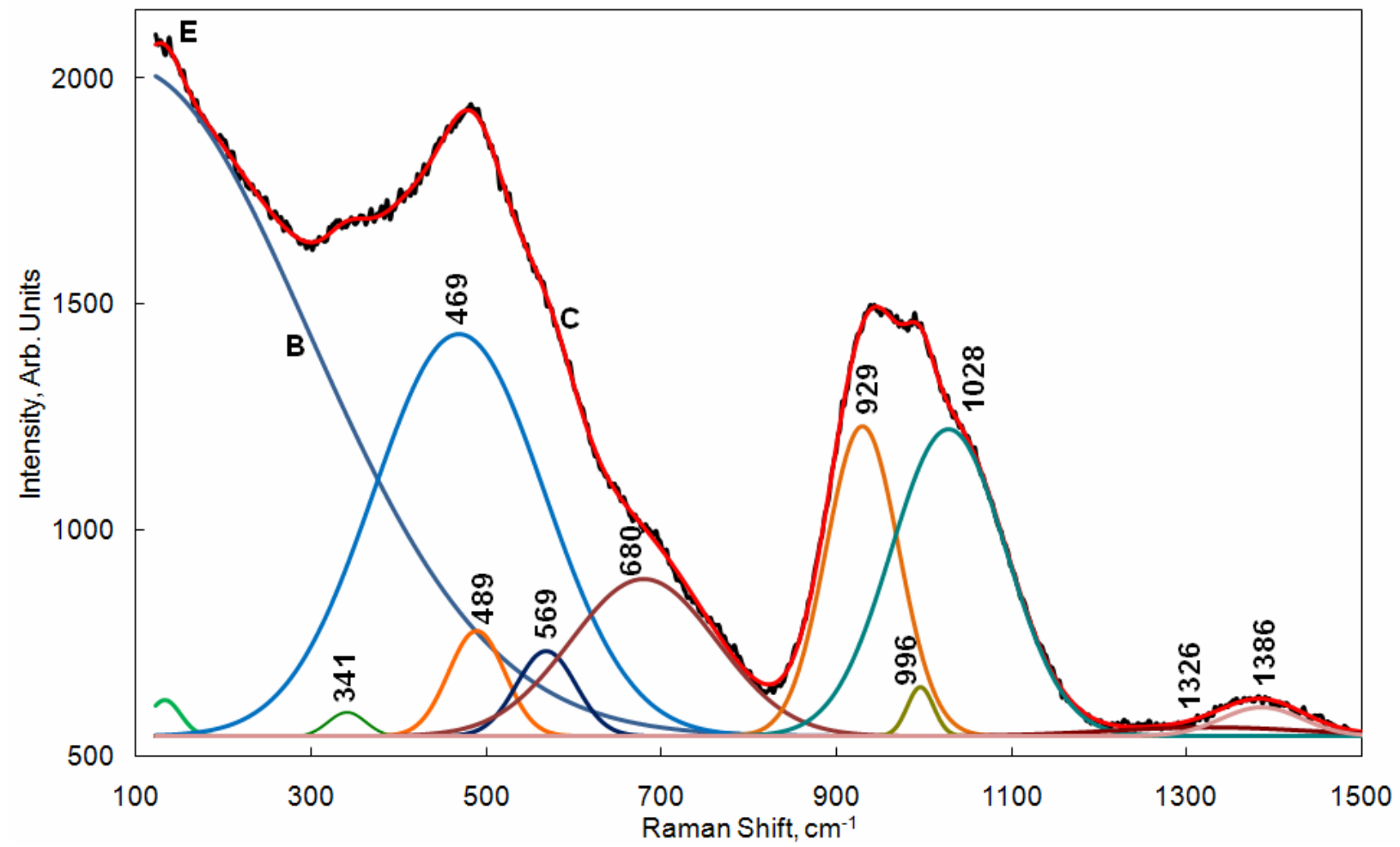

Figure 29. Computer fitting of the Raman spectra of the sample \#46. 
of $\mathrm{Me}-\mathrm{O}$ bonds in $\mathrm{MeO}_{n}$ polyhedra as well the bands due to stretching and bending vibrations of $\mathrm{Me}-\mathrm{O}$ bonds in spinel. This makes attribution of the bands in this range rather difficult and ambiguous.

Nevertheless some general suggestions concerning attribution of the bands within this range may be done. If to compare Raman spectra of the glasses \#45 (Figure 28) and \#46 (Figure 29) related to two different groups, then we can see some similarity in behavior of the bands: i) occurrence of strong broad band due to bending vibrations of the bonds in silica-oxygen network and bridging bands $\mathrm{Si}-\mathrm{O}-\mathrm{Me}$ bonding $\mathrm{SiO}_{4}$ and $\mathrm{MeO}_{4}$ tetrahedra; ii) occurrence of the bands with maxima at $496 \mathrm{~cm}^{-1}$ or $489 \mathrm{~cm}^{-1}$ and $562 \mathrm{~cm}^{-1}$ or $569 \mathrm{~cm}^{-1}$ (for the glasses \#45 and \#46, respectively). At the same time the spectrum of the glass \#46 contains broad band centered at $680 \mathrm{~cm}^{-1}$ whereas in the spectrum of the glass \#45 weak narrow band centered at $691 \mathrm{~cm}^{-1}$ is present. Moreover the spectrum of the glass \#45 contains an additional narrow band centered at $625 \mathrm{~cm}^{-1}$. If broad bands are due mainly to vibrations in low-symmetry structural units in random glass network, then narrow band are due probably to vibrations in high-symmetry structural units of the spinel structure phase.

Chemical composition of spinel may be represented by general formula (Mg, Mn, Ni,Cu $)^{2+}(\mathrm{Fe}, \mathrm{Al})^{3+} \mathrm{O}_{4}$. Taking into account low $\mathrm{MgO}, \mathrm{NiO}$ and $\mathrm{CuO}$ contents, major contribution to these bands make vibration of $\mathrm{Fe}-\mathrm{O}$ and $\mathrm{Al}-\mathrm{O}$ bonds in $\mathrm{FeO}_{4}$ and $\mathrm{AlO}_{4}$ tetrahedra, and in much less extent, $\mathrm{Mn}-\mathrm{O}$ and $\mathrm{Fe}-\mathrm{O}$ bonds in $\mathrm{MnO}_{6}$ and $\mathrm{FeO}_{6}$ octahedra. Thus, the bands within the range of 300-500 $\mathrm{cm}^{-1}$ may be associated with vibrations of $\mathrm{Mn}-\mathrm{O}$ and $\mathrm{Fe}-\mathrm{O}$ bonds in $\mathrm{MnO}_{6}$ and $\mathrm{FeO}_{6}$ octahedra in the spinel structure. The bands at 550-650 are due mainly to vibrations of $\mathrm{Fe}-\mathrm{O}$ bonds in $\mathrm{FeO}_{4}$ tetrahedra in both spinel and glass structures and, in some extent in $\mathrm{FeO}_{6}$ octahedra. Vibrations of $\mathrm{Al}-\mathrm{O}$ bonds in $\mathrm{AlO}_{4}$ tetrahedra in both spinel and glass are positioned at $650-750 \mathrm{~cm}^{-1}$. For more precise simulation of the spectra within the range of $300-850 \mathrm{~cm}^{-1}$ special studies with the use of model compounds (surrogates) with the known structure are required.

\section{XAS study}

XAS spectrum of Fe K-edge was found to be the same in all the glasses studied (Figure 30). This spectrum corresponds to $\mathrm{Fe}^{3+}$ ions in mixed octahedral and tetrahedral surrounding [12]. EXAFS (Figure 31) and Fourier transform of EXAFS spectrum demonstrate that only first coordination shell is appeared whereas contributions from the second and subsequent shells are negligible. This shows the $\mathrm{Fe}^{3+}$ ions are rather homogeneously distributed in glass and fraction of spinel is minor.

Nevertheless the peak due to the first coordination shell is markedly asymmetric (Figure 32). Results of computer fitting of major peak are given in Table III.

Table III. Fitting of the Fe K Edge EXAFS Spectra of Glasses.

\begin{tabular}{|c|c|c|c|}
\hline Bond & Distance, $\AA$ & Coordination Number & Debye-Waller Factor \\
\hline $\mathrm{Fe}-\mathrm{O}_{1}$ & $1.74 \pm 0.02$ & $1.6 \pm 0.2$ & 0.003 \\
\hline $\mathrm{Fe}-\mathrm{O}_{2}$ & $1.94 \pm 0.02$ & $2.4 \pm 0.2$ & 0.003 \\
\hline $\mathrm{Fe}-\mathrm{O}_{3}$ & $2.07 \pm 0.02$ & $5.9 \pm 0.3$ & 0.004 \\
\hline
\end{tabular}




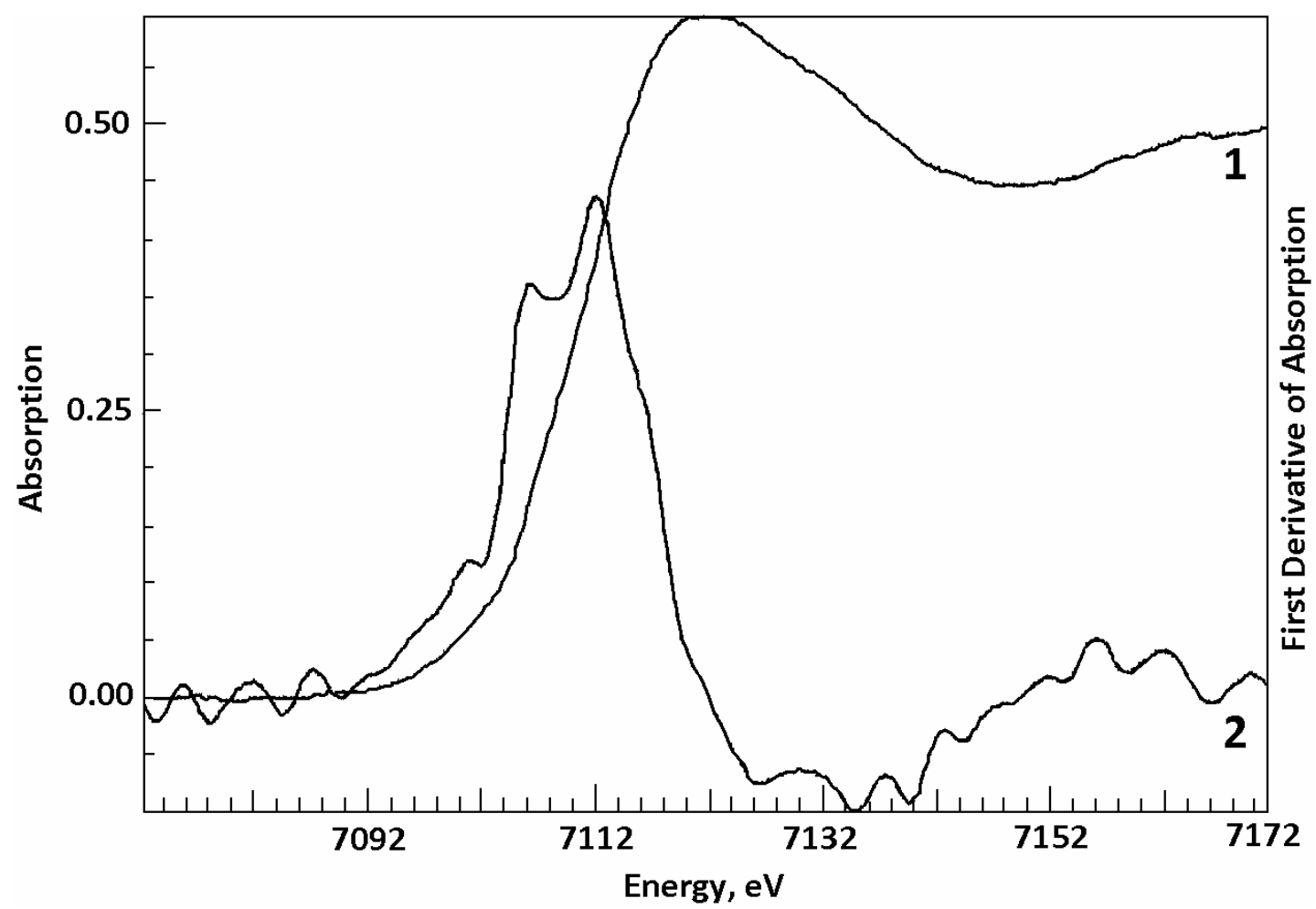

Figure 30. XAS (1) spectra of Fe K-edge and its XANES range (2) of the glasses.

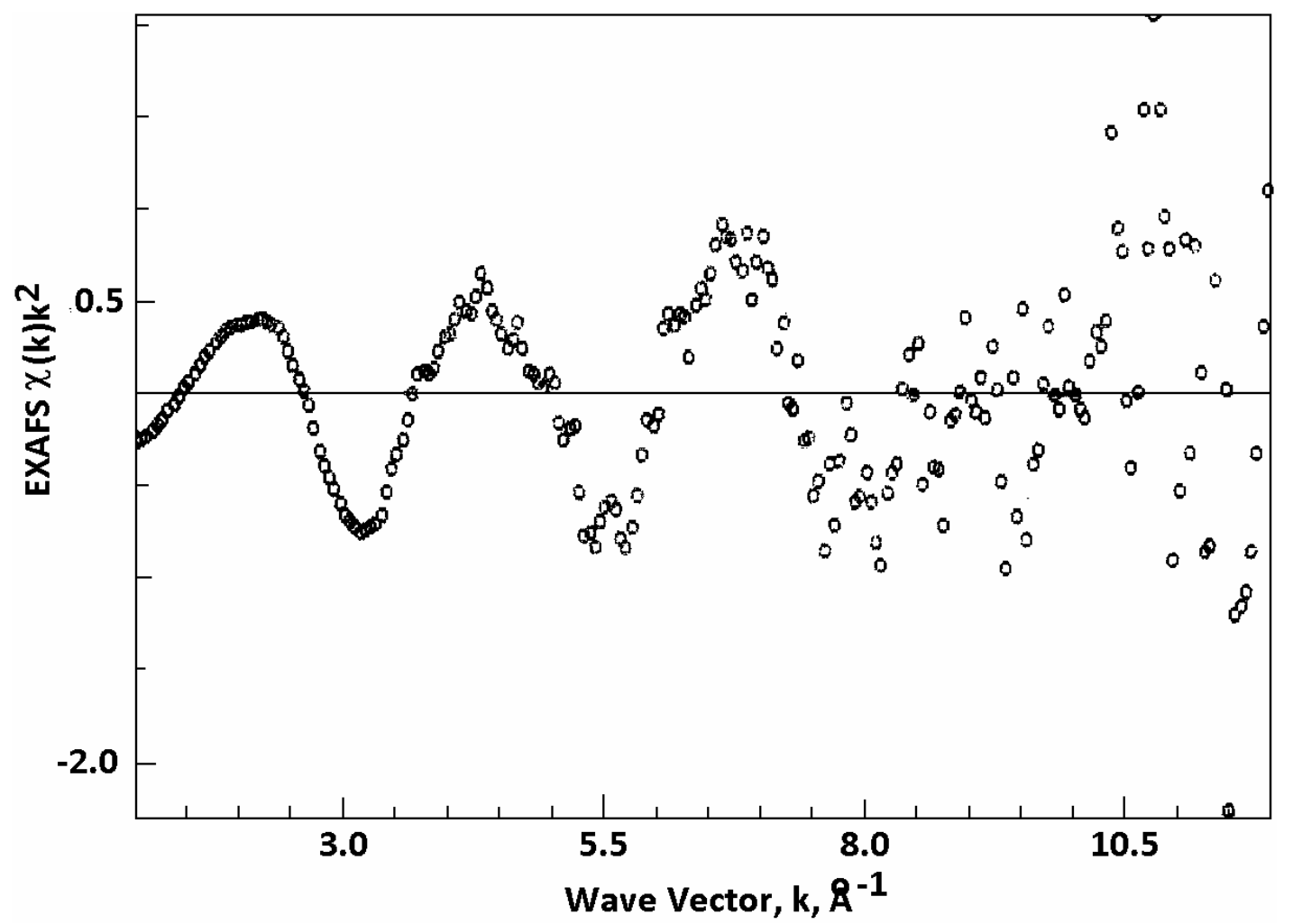

Figure 31. EXAFS of Fe K-edge of glasses. 


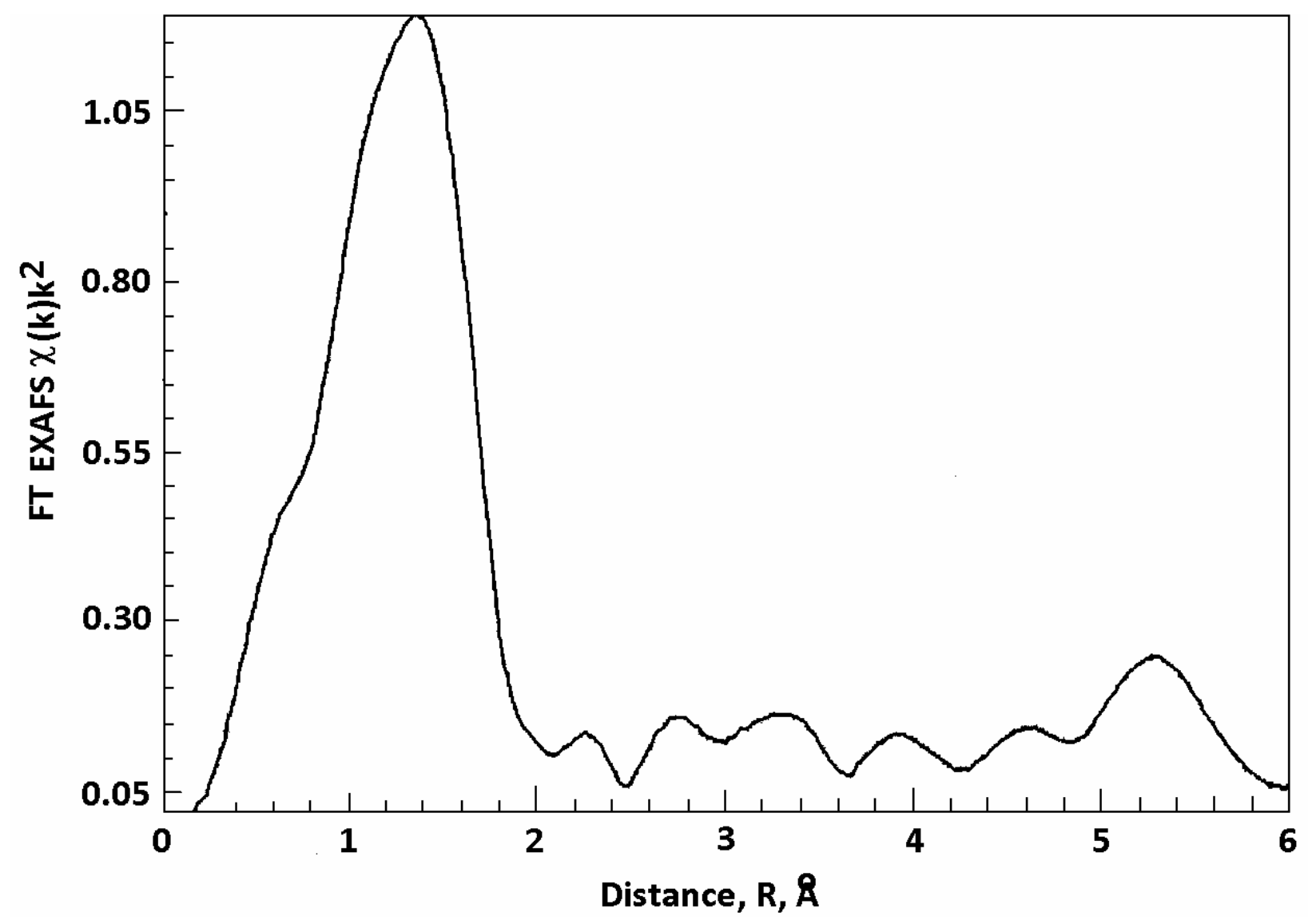

Figure 32. Fourier Transform of EXAFS Fe K-edge spectrum of glasses.

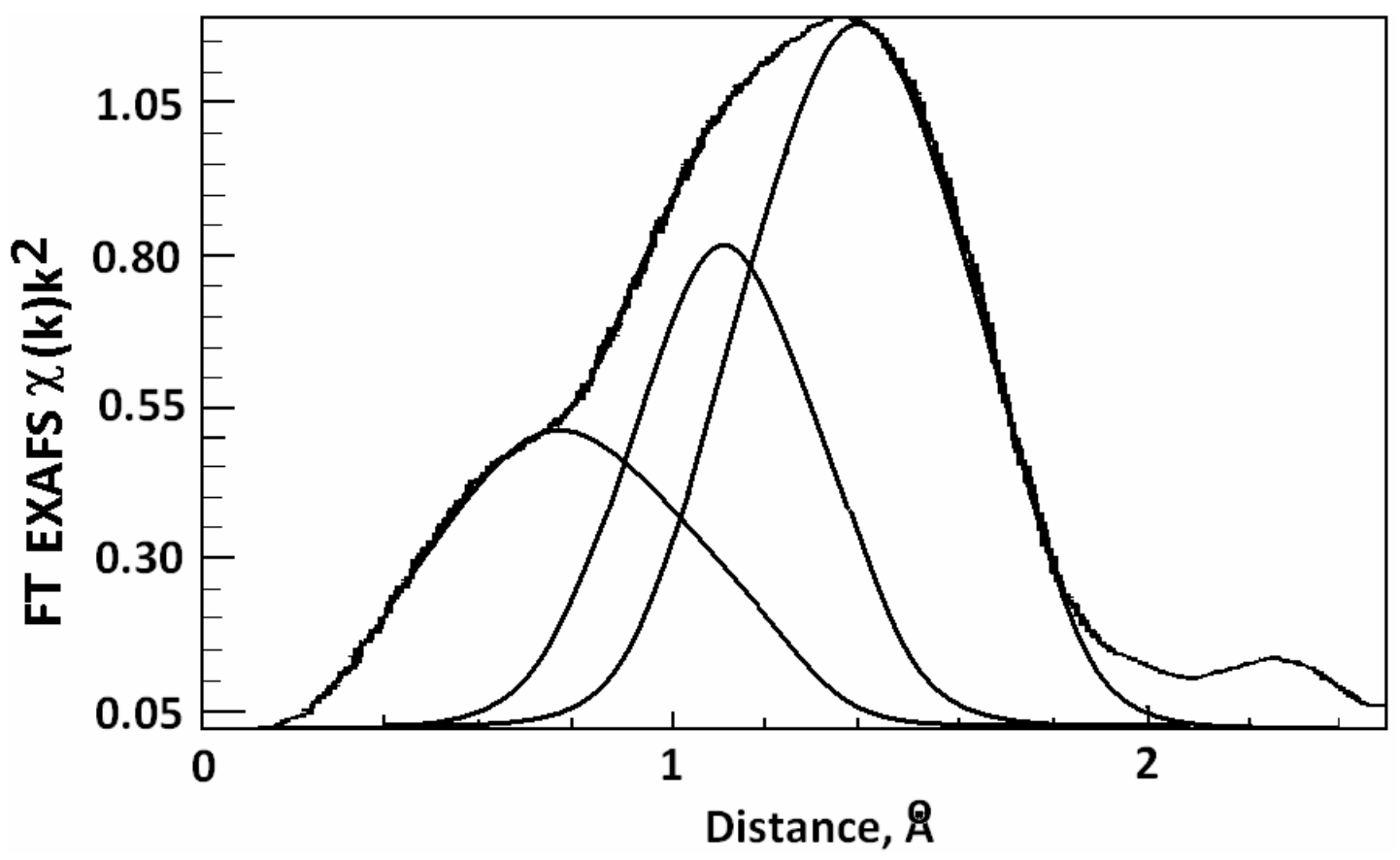

Figure 33. Computer fit of major peak in EXAFS spectrum of Fe K-edge in glasses. 
The first two distances are due to $\mathrm{Fe}-\mathrm{O}$ bonds in distorted tetrahedron. The third $\mathrm{Fe}-\mathrm{O}$ distance is close to that in $\mathrm{FeO}_{6}$ octahedra [13]. Contribution due to $\mathrm{Fe}-\mathrm{O}$ distances in spinel is very low.

\section{CONCLUSIONS}

All the glasses studied are composed of predominant vitreous phase and minor spinel structure phase. Spinel forms both isometric grains and cubic microcrystals $(\sim 1 \mu \mathrm{m})$. Microcrystals are aggregated in bands with variable glass and spinel contents. IR and Raman spectroscopic study the structure of all the glasses are similar and is composed of metasilicate chains and rings containing incorporated $\mathrm{AlO}_{4}$ and $\mathrm{FeO}_{4}$ as well as minor $\mathrm{BO}_{4}$ tetrahedra. $\mathrm{FeO}_{6}$ octahedral units may be also present. In the structure of all the glasses trigonally-coordinated boron dominats over tetragonally-coordinated. At that, major $\mathrm{BO}_{4}$ tetrahedra and $\mathrm{BO}_{3}$ triangles form complex borate units and are present as separate constituent.

As follows from XAS data, iron is predominantly present as $\mathrm{Fe}^{3+}$ ions. Major $\mathrm{Fe}^{3+}$ ions are tetrahedrallycoordimated and built in silicon-oxygen network. Minor $\mathrm{Fe}^{3+}$ ions are octahedrally-coordinated and may be considered as network-modifiers. Contribution due to spinel is negligible.

\section{REFERENCES}

1. A.A. Appen, Chemistry of Glass (Russ.), Khimiya, Leningrad (1974).

2. B. Ravel and M. Newville, J. Synchrotron Radiat. 12 537-541 (2005).

3. A.L. Ankudinov and J.J. Rehr, Phys. Rev. B 56 1712-1716 (1997).

4. H. Funke, A.C. Scheinost and M. Chukalina, Phys. Rev. B, 71, 094110 (2005).

5. H. Funke, M. Chukalina and A.C. Scheinost, J. Synchrotron Radiat. 14, 426-432 (2007).

6. www.esrf.fr/exp_facilities/BM20/Software/Wavelets.html.

7. V.A. Kolesova, Glass Phys. Chem. (Russ.) 12 [10] 4-13 (1986).

8. V.N. Anfilogov, V.N. Bykov, and A.A. Osipov, Silicate Melts (Russ.), Nauka, Moscow (2005).

9. I.I. Plyusnina, Infrared Spectra of Minerals (Russ.), MGU, Moscow (1977).

10. K. Nakamoto, Infrared Spectra of Inorganic and Coordination Compounds, John Wiley \& Sons, Inc. New York - London (2009).

11.

12. G.E. Brown, Jr., G.A. Waychunas, C.W. Ponader, W.E. Jackson, and D.A. McKeown, EXAFS and Near Edge Structure IV - J. de Physique. 47 C8, suppl. Au n²12, C8-661 - C8-668 (1986).

13. G. Licheri, G. Paschina, G. Piccaluga, G. Pinna, M. Magini, and G. Cocco, J. Non-Cryst. Solids, 72, 211-220 (1985). 


\section{Distribution:}

J. W. Amoroso, 999-W

A. B. Barnes, 999-W

A. L. Billings, 999-W

A. S. Choi, 773-42A

Y. T. Collazo, DOE-EM

C. L. Crawford, 773-42A

D. A. Crowley, 773-43A

S. D. Fink, 773-A

B. J. Giddings, 786-5A

A. M. Han, DOE-EM

C. C. Herman, 999-W

C. M. Jantzen, 773-A

F. C. Johnson, 999-W

J. C. Marra, 773-42A

S. L. Marra, 773-A

D. H. Miller, 999-W

D. K. Peeler, 999-W

F. M. Pennebaker, 773-42A

S. P. Schneider, DOE-EM

G. L. Smith, DOE-EM

J. D. Vienna, PNNL 